University of Louisville ThinkIR: The University of Louisville's Institutional Repository

Electronic Theses and Dissertations

$8-2019$

\title{
Comparative spending of medicaid dollars on child participants of Kentucky's sobriety treatment and recovery teams program versus a matched comparison group.
}

Matthew Thomas Walton

University of Louisville

Follow this and additional works at: https://ir.library.louisville.edu/etd

Part of the Emergency Medicine Commons, Health Economics Commons, Health Policy Commons, Pediatrics Commons, Social Statistics Commons, Social Welfare Commons, and the Social Work Commons

\section{Recommended Citation}

Walton, Matthew Thomas, "Comparative spending of medicaid dollars on child participants of Kentucky's sobriety treatment and recovery teams program versus a matched comparison group." (2019). Electronic Theses and Dissertations. Paper 3276.

https://doi.org/10.18297/etd/3276

This Doctoral Dissertation is brought to you for free and open access by ThinkIR: The University of Louisville's Institutional Repository. It has been accepted for inclusion in Electronic Theses and Dissertations by an authorized administrator of ThinkIR: The University of Louisville's Institutional Repository. This title appears here courtesy of the author, who has retained all other copyrights. For more information, please contact thinkir@louisville.edu. 
COMPARATIVE SPENDING OF MEDICAID DOLLARS ON CHILD PARTICIPANTS

OF KENTUCKY'S SOBRIETY TREATMENT AND RECOVERY TEAMS PROGRAM

VERSUS A MATCHED COMPARISON GROUP

by

Matthew Thomas Walton

B.S., University of Kentucky, 2009

M.S.S.W., University of Louisville, 2012

A Dissertation

Submitted to the Faculty of the Raymond A. Kent School of Social Work in Partial Fulfillment of the Requirements for the Degree of

Doctor of Philosophy in Social Work

Raymond A. Kent School of Social Work

University of Louisville

Louisville, Kentucky

And

College of Social Work

University of Kentucky

Lexington, Kentucky

August 2019 
Copyright 2019 by Matthew T. Walton

All rights reserved 

COMPARATIVE SPENDING OF MEDICAID DOLLARS ON CHILD PARTICIPANTS

OF KENTUCKY'S SOBRIETY TREATMENT AND RECOVERY TEAMS PROGRAM

VERSUS A MATCHED COMPARISON GROUP

by

Matthew Thomas Walton

B.S., University of Kentucky, 2009

M.S.S.W., University of Louisville, 2012

A Dissertation Approved on:

June 13, 2019

By the following dissertation committee:

Martin T. Hall, Ph.D., MSSW chair

Anita Barbee, Ph.D., MSSW

Jose Fernandez, Ph.D.

Seana Golder, Ph.D., MSW

Glen Mays, Ph.D., MPH 


\section{DEDICATION}

To Anna Marie, Caroline Swift, and Lincoln Bosworth 


\section{ACKNOWLEDGEMENTS}

This document is the fruition of a years-long labor of love; both for myself and for those who have supported me through the process. This has been a team effort, and I would like to acknowledge and thank those team members without whom this would have been impossible.

First, I would like to thank my devoted wife Anna. Her willingness to have her husband resign from his job in order to go back to school in order to fulfill a dream was an uncommon display of support and sacrifice. She has been a constant source of encouragement to me during times of discouragement, patience during times of restiveness, and confidence during times of self-doubt. She has endured many hours of discussion of child abuse research, data analysis, and study design for my sake. She has worked diligently over the last four years to make this goal a reality for me, and for that, I will be forever grateful to her.

Anna also gave birth to our beautiful little twins during this process. So she has navigated the twists and turns of learning to become a mother while braving the travails of the wife of a student. I want to thank my two year olds Caroline and Lincoln for the many ways that their presence in my life has enriched my perspective and taught me how to be a father. It was never lost on me that the children that I have written about here are wonderful little souls like them. Because of those two, the work of the START teams became that much more cherished to me as I meditated on how precious the relationship between a child and 
their parent is. The CPS workers who serve these families and protect these children from harm are storing up treasure in Heaven.

I would also like to thank the members of my dissertation committee - Martin Hall, Seana Golder, Anita Barbee, José Fernandez, and Glen Mays. I knew after the first sessions in Martin's MSSW practice class that he and I shared a common perspective, but I never imagined that I would eventually have the chance to publish academic papers with Professor Hall. Martin has been so incredibly generous to me with his time and attention during these last few years, and has taught me a great deal about program evaluation, working with large datasets, and how to conduct oneself as a scholar. I have been incredibly fortunate to have had the opportunity to study under and learn from Martin, and have truly enjoyed our collaboration.

I am also indebted to the other members of my committee for their time and their input on the many drafts they have read along the way to this final copy. Each has been a collegial and supportive guide to me as I completed this project. Dr. Golder provided crucial insights from her expertise in substance use disorders, especially considering the unique ways it affects women and mothers. Dr. Barbee shared her knowledge as a respected authority in the field of child welfare (a field that I was only tangentially familiar with prior to entering the doctoral program) to ensure that my thoughts were consistent with the scholarship. As a health economist, Dr. Fernandez offered an invaluable economic and methodological perspective on how to approach design and analyses. Finally, my thanks to Dr. Mays for his insights on how to approach the process of securing Medicaid claims data and for his counsel on the proper way to incorporate health services research design elements 
into this project. It has been an honor for me to have the involvement of these esteemed faculty on this dissertation.

I am blessed to have had the involvement of my family during this process of research and writing. For my parents, Tom and Carol Walton, who have made it their mission over the last 32 years to do everything they could for me to help me thrive and be successful. They taught me to love the process of learning, and modeled for me what it looks like when people apply their gifts towards the service of others. Since June 5, 2017, their love has taken the form of providing countless hours of care to their grandchildren and reminding their son and daughter in law that hard work eventually does get rewarded. They have been stalwarts of steady support for me as I set about completing this degree.

My brother and sister-in-law, Reese and Leah Walton have also been constant sources of fellowship and comradery during the process of writing this dissertation. Our Friday night dinners were a welcome reward for a week full of sitting in front of a computer by myself, and our weekend trips to the Louisville Zoo were always a rejuvenating source of joy.

I wish to thank the many other members of the University of Louisville who supported this research project. To Eric Schneider, who spent hours upon hours helping to prepare the dataset. To Dr. George Higgins, who advised me, made methodological recommendations, and helped to execute the propensity score matching process. My thanks to Dr. Gilbert Liu, who supported this project from his role at the Kentucky Department of Medicaid Services, and to Dr. David Lohr, who entertained several meetings with me from his role as the DCBS Medical Director. 
I also wish to thank the many people from the Kentucky Cabinet for Health and Family Services. In no particular order, I am grateful to Mr. Maik Schutze, Ms. Angela Taylor, Ms. Pamela Wright, Mr. Michael Jourdan, Mr. Jason Reed, Mr. Chris Cordell, and Ms. Jessica Brown. Thank you for your openness to this project and for your daily service to the Commonwealth of Kentucky.

Lastly, I wish to acknowledge the START teams and the clients that they serve. Without their work and the many hours they have spent recording data I would have had nothing to work with, and this dissertation would have been impossible. Thank you for the work that you do, and for involving me in it. You will likely never know the full extent of the benefits you've brought to the world. Hopefully our research helps some. 


\section{ABSTRACT \\ COMPARATIVE SPENDING OF MEDICAID DOLLARS ON CHILD PARTICIPANTS \\ OF KENTUCKY'S SOBRIETY TREATMENT AND RECOVERY TEAMS PROGRAM \\ VERSUS A MATCHED COMPARISON GROUP}

Matthew T. Walton

June 13, 2019

Child protective services agencies have long observed the complicating role that parental substance use and addiction plays in cases of child maltreatment. Families who struggle with these problems present unique challenges for child welfare professionals. These families are typically more difficult to engage, more likely to have children removed from the home, and have poorer outcomes when compared to other families.

These poorer outcomes often include health problems. Addiction has well-known effects on health, and the specific manifestations of these problems for parents have been documented for years in child protection casework. However, what has been less investigated are the ways that these issues correspond to the health of the children involved in these cases. In many instances, children in these homes are severely injured and require acute medical care. These harms commonly result in significant increases in public spending; especially for state Medicaid programs.

In Kentucky, the Cabinet for Health and Family Services created special child welfare units called Sobriety Treatment and Recovery Teams (START) to serve families where children have been harmed as a result of their parent's substance use. Previous research efforts suggest that families who participate in START have more favorable outcomes than 
comparable families who received standard services. These past efforts have even documented cost savings attributable to the work of START in the form of fewer days spent in out of home care for children. This study aimed to expand on that past research by investigating whether similar costs savings are also being generated in the form of reduced Medicaid spending on the children whose parents received START services. 


\section{TABLE OF CONTENTS}

DEDICATION

PAGE

ACKNOWLEDGEMENTS .....

ABSTRACT iv

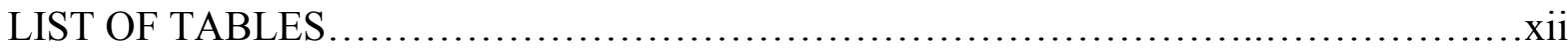

LIST OF FIGURES .................................................................

\section{CHAPTER}

I. PROBLEM STATEMENT AND STUDY OVERVIEW ............................

Interventions to Address Co-Occurring Substance Use and Child Maltreatment...5

Economic Evaluations of Child Welfare Programming ......................... 8

The Health Services Case for Providing the START Program.....................10

Purpose and Methodology ...................................................11

Significance of the Study .................................................. 16

II. CO-OCCURRING SUBSTANCE USE AND CHILD MALTREATMENT ...........18

Prevalence of Co-Occurring Substance Use and Child Maltreatment...............38

Consequences and Contributors.........................................49

Approaches to the Problem.................................................

Summary, Research Questions, and Hypotheses...............................93

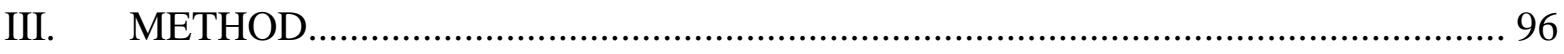

Participants and Sampling ..................................................

Measures and Variable Selection.........................................108

Preparation of the Dataset...............................................114

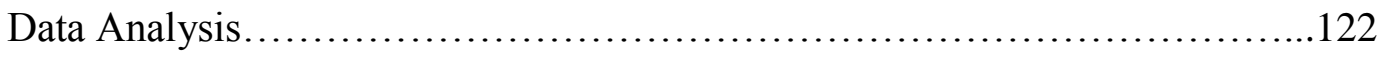

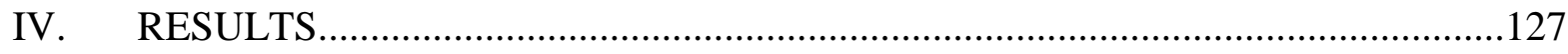


Further Breakdown of Utilization and Costs............................136

Regression Model of Medicaid Spending..................................139

Health Services Utilization......................................... 142

Outpatient Visits...................................................144

Emergency Room Visits............................................. 148

Hospital Visits.................................................. 152

V. DISCUSSION AND CONCLUSIONS ...................................... 156

Research Question 1 - Between Group Differences in Medicaid Spending......158

Research Question 2 - Between Group Differences in Utilization Rates........163

Research Question 3 - Regional Differences in Utilization...................167

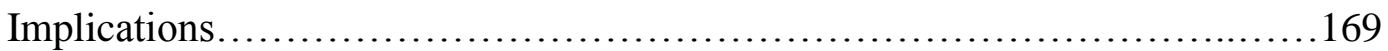

Limitations................................................... 173

Directions for Future Research.................................... 178

Summary and Conclusions.......................................... 182

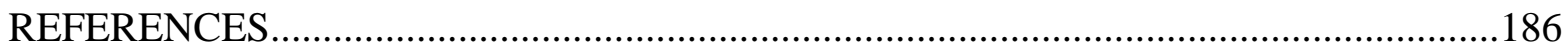

APPENDIX A: CHFS Institutional Review Board Approval Letter........................210

APPENDIX B: The Assessment and Documentation Tool (ADT) ......................211

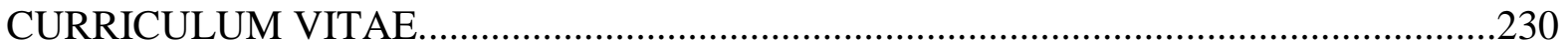




\section{LIST OF TABLES}

\section{TABLE}

1. Prevalence Studies of Co-Occurring Parental Substance Use and Child Maltreatment....40

2. Adverse Childhood Experiences Categories...................................52

3. Outcomes Studies of Family Treatment Drug Courts.............................83

4. County Clusters for the Propensity Score Matching Procedure....................... 103

5. Propensity Score Matching Variables........................................... 109

6. Sources of Data and their Use in the Present Study............................ 115

7. Results of Propensity Score Matching....................................... 130

8. Description of the Sample Before and After Medicaid Claims Data Matching..........131

9. Medicaid Spending by Study Period and Treatment Group $(\mathrm{n}=852) \ldots \ldots \ldots \ldots \ldots \ldots 137$

10. Medicaid Spending Over Two Year Period After Index CPS Case...................140

11. Healthcare Visits by Treatment Group, Service Category, and Study Period $(n=852) \ldots 142$

12. Poisson Regression Model of Outpatient Visits................................ 146

13. Zero-Inflated Poisson Regression Model of Outpatient Visits......................147

14. Poisson Regression Model of Emergency Room Visits..........................150

15. Zero-Inflated Poisson Regression Model of Emergency Room Visits.................151

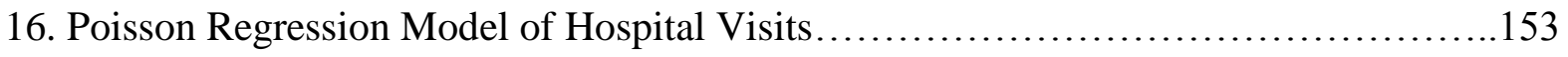

17. Zero-Inflated Poisson Regression Model of Hospital Visits........................ 155 


\section{LIST OF FIGURES}

\section{FIGURE}

1. Total Spend by Group.................................................. 138

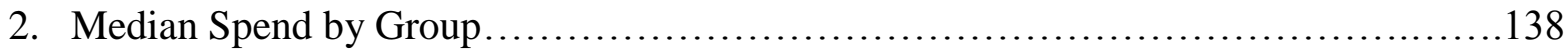

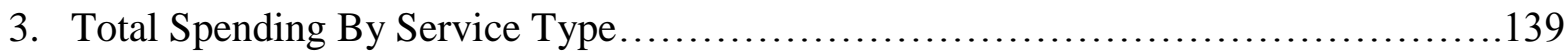

4. Mean Spend Per Child by Age Groups...................................... 141

5. Histogram of Outpatient Visit Counts by Individual Child..........................144

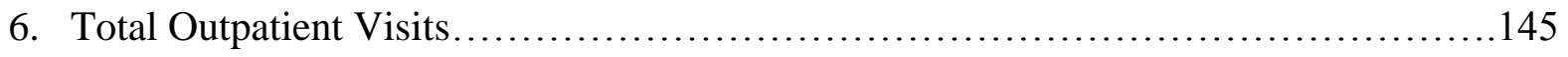

7. Histogram of Emergency Room Visit Counts by Individual Child...................148

8. Emergency Room Visits................................................ 149

9. Histogram of Hospital Visit Counts by Individual Child..........................152

10. Hospital Visits ............................................................ 153 


\section{CHAPTER I \\ PROBLEM STATEMENT AND STUDY OVERVIEW}

\section{Substance Use and Child Maltreatment}

When parents engage in high-risk drinking and drug use, their children often suffer as a result. The associated harms often occur in two distinct ways: (1) the medical and developmental effects borne by infants exposed to in utero substance use, and (2) abuse and neglect experienced by children whose parents have lost control of their behavior as a result of their substance use. Because substance use often results in unpredictable or aggressive behavior, it often interferes with healthy parenting.

As a result, it is common for children living in such households to struggle with forming secure parental attachment as well as being exposed to a greater risk of being physically abused, sexually abused, or severely neglected (Barnard \& McKeganey, 2004; Magura \& Laudet, 1996; Young, Boles, \& Otero, 2007). Consequent to this maltreatment, reviews of the literature suggest that these children are more likely to experience adverse health and social consequences later in their lives. These include: attention/hyperactivity problems, substance use disorders, cardiac disease, and poor academic achievement (Anda et al., 2006; Johnson \& Leff, 1999; Lander, Howsare, \& Byrne, 2013). When public Child Protective Service agencies (hereafter abbreviated as CPS) identify these cases, they often struggle in their efforts to resolve problems and prevent further maltreatment. Notably, when compared to non-substance-using parents, CPS agencies remove children from the home more frequently, report greater difficulty engaging parents in services, and are less likely to 
reunite children placed in out of home care with their parents (Wolock \& Magura, 1996; Gregoire \& Schultz, 2001; Magura \& Laudet, 1996).

Among this population, a significant proportion are young single mothers with low incomes, lower educational attainment, and who also lack a robust network of social support (Magura \& Laudet, 1996; Grella, Hser, \& Huang, 2006; Carlson, Matto, Smith, \& Eversman, 2006; Semidei, Radel, \& Nolan, 2001). The literature teaches two important lessons about such individuals: their dearth of resources contributes to significant challenges once they become involved with CPS, and it also renders them at a significantly higher risk for the development of chronic health conditions and an abridged lifespan (Marmot et al., 2008; Slack, Holl, McDaniel, Yoo, \& Bolger, 2004; Berger, 2004). The combined stressors associated with substance use, precarious family conditions, and the other so-called social determinants of health lead many such individuals to have significant contact with the healthcare and social services systems (Marmot, 2005). These problems are associated with substantial costs; both in terms of human suffering and strains on public financial resources. While such costs have been thoroughly observed in terms of the adults with addiction - both out of treatment (French, McGeary, Chitwood, \& McCoy, 2000) as well as in treatment; Parthasaruthy \& Weisner (2005) - less is known about how their children's health responds to intervention. This being the case, the present study was concerned with the nature of consumption of acute medical care in a sample of children from Kentucky families that exhibited co-occurring substance use and child maltreatment.

This significant association between parental substance use and harm to children is born out in prevalence data. Researchers have demonstrated relationships between epidemiologic trends in drug use and the realities on the ground for child welfare 
professionals, especially as it pertains to foster care (Brook, McDonald, Gregoire, Press, \& Hindman, 2010; Brook \& McDonald, 2009). As a case in point, the United States is currently in the midst of a well-documented opioid crisis, with a host of negative societal effects being reported (Kolodny et al. 2015). One of the most troubling characteristics of this trend involves a marked increase in overdose deaths associated with use of narcotic pain medications, heroin, and other illicit opioids - in many instances leaving young children without a parent. A report compiled by the Centers for Disease Control and Prevention (CDC) found that nearly 500,000 Americans died between 2000-2014 from drug overdoses (Rudd, Aleshire, Zibbell, \& Gladden, 2016). Concurrent with this upward trend, child welfare officials in the state of Kentucky have reported a significant increase in the number of children being removed from the home due to maltreatment. Since the summer of 2012, the number of children in foster care in Kentucky has swelled from approximately 6,000 children to over 10,000 at the time of this writing; many of whom were removed as a direct result of their parents' drug use (Simoneaux, 2017).

While these relationships are well known amongst professionals in both the child welfare and the addiction treatment fields, many parents with open CPS cases do not receive adequate treatment services when they need them. This occurs for a variety of reasons; most of which are beyond the influence or the scope of practice for the frontline CPS professionals that are charged with working these cases. These reasons include: a fragmented healthcare and social services system (Stange, 2009), a scarcity of appropriate treatment providers (especially those that are tailored for women with children; Finkelstein, 1994; Saloner \& Karthikeyan, 2015), problems related to payment for treatment (Friedmann, Lemon, Stein, \& D'aunno, 2003), and ideological orientations held by courts that are inconsistent with best 
practices in addiction treatment (Boldt, 1999; Hall, Wilfong, Huebner, Posze, \& Willauer, 2016).

It is within this ecosystem that CPS agencies oftentimes find themselves scrambling to track down open beds or other available treatment options that can meet the unique needs of their clients - all while being mindful of the permanency timeframes outlined in the Adoption and Safe Families Act (ASFA) (Hannett, 2007; Rockhill, Green, \& Furrer, 2007). These barriers are substantial, but it also bears mentioning here that successful recovery from a severe substance use disorder (hereafter abbreviated as SUD) is extraordinarily difficult, even under the best of circumstances. With these realities in mind, it is therefore unsurprising that cases involving parents with SUD's tend to be less successful, both in terms health and child welfare outcomes.

In spite of the inertia that holds a parent's patterns of drug use in place, the fear of losing custody over one's children can serve as a powerful motivator for behavior change. While it is typical for their substance use to result in feelings of alarm for family members and adverse health consequences for themselves, the involvement of CPS is often the critical impetus for parents to make their initial contact with an addiction treatment provider. Indeed, when a sample of 356 individuals at various stages of recovery (a range of $<6$ months to $<3$ years) was asked about their treatment-related priorities, many of them reported that reunification with their children was an especially important treatment goal (Laudet \& White, 2010).

This is particularly true for young, low-income mothers, who, compared to fathers, often bear a disproportionate share of child-rearing responsibilities. Several published studies confirm the reality that women constitute the overwhelming majority of CPS-involved 
parents served by addiction treatment agencies (Grella, Hser, \& Huang, 2006; Carlson, Matto, Smith, \& Eversman, 2006). For optimal family outcomes, the literature recommends that these parents be offered access to affordable, high-quality treatment that is provided in concert with the work of child protection agencies and the courts (Magura \& Laudet, 1996; Semidei, Radel, \& Nolan, 2001; Huebner, Young, Hall, Posze, \& Willauer, 2017).

\section{Interventions to Address Co-Occurring Substance Use and Child Maltreatment}

To provide such services, practitioners have created innovative partnerships between addiction treatment providers and CPS agencies. In many cases, these partnerships have spawned new intervention models that unite the efforts of both parties to offer more coordinated services and improve outcomes for families (for a review of these interventions, refer to Osterling \& Austin, 2008; Marsh, Smith, \& Bruni, 2011; Oliveros \& Kaufman, 2011). In an attempt to empirically test their efficacy, there have been multiple outcome evaluation studies of the most prominent of these interventions. These include the Recovery Coaches program in Illinois (Ryan, Marsh, Testa, \& Louderman, 2006), Family Treatment Drug Courts (Green, Furrer, Worcel, Burrus, \& Finigan, 2007), and the Strengthening Families program (Brook, McDonald, \& Yan, 2012).

In a review paper that investigated the relative efficacy of some of the most promising of these interventions, Oliveros \& Kaufman (2011) identified those with the strongest supporting evidence. The interventions summarized therein roughly fell into two categories: family treatment drug courts (FTDC's) and in-home treatment services. By far, the FTDC intervention has been the most rigorously studied of the two categories, and although individual counties may differ in terms of certain components of their implementation, there is a strong evidence base that supports the use of FTDC's to address co-occurring substance 
use and child maltreatment (Gifford, Eldred, Vernerey, \& Sloan, 2014; Lloyd, 2015). This evidence base for FTDC's is reviewed in more depth in the following chapter.

\section{The START Program}

In Kentucky, the Cabinet for Health and Family Services (CHFS) responded to this issue by incorporating the components of promising interventions into the creation of a special unit within its CPS division and charging it with the implementation of the Sobriety Treatment and Recovery Teams (START) intervention (Huebner, Willauer, \& Posze, 2012). The START program was launched in Kentucky in 2007, and was tasked with intervening in cases where a parent's high-risk substance use played a primary role in the abuse or neglect of their child. While START is not an FTDC or an explicitly in-home treatment program, it involves elements of both. For example, the Kentucky START teams do engage in contact with the family court systems in the counties in which they operate, and they do conduct visits with clients in their homes. Essentially, START provides a platform whereby the state CPS apparatus can marry its efforts to protect children with the mission of local addiction treatment providers to promote recovery for parents.

One essential and unique component of the START program is its use of family mentors. These are individuals (most often women) who are in long-term recovery from SUD that are paired with specially trained CPS workers as a means of helping clients navigate the parallel processes of recovering from their SUD while resolving child maltreatment cases. This often involves helping parents comply with court mandates in order to maintain or regain custody of their children. In many instances, these family mentors are also parents who have a history of involvement with CPS themselves, and their role is to use their experience to help foster a constructive relationship between substance using parents and 
CPS (Huebner, Posze, Willauer, \& Hall, 2015). The CPS worker and family mentor work cases together, and their partnership is called a dyad within the START intervention approach.

START also shares several elements of the interventions described above. Namely, START makes use of reduced caseloads (no more than 15 clients per CPS worker/family mentor dyad), specialized training germane to addiction issues, close partnerships between addiction treatment providers and child welfare agencies, and an emphasis on the use of evidence-based treatment practices (Huebner, Posze, Willauer, \& Hall, 2015; Oliveros \& Kaufman, 2011; Osterling \& Austin, 2008).

In an analysis of the same program evaluation data used for this study, Huebner and colleagues (2012) found that families that participated in START had their children removed from the home at approximately half the rate as families that received standard CPS services (hereafter abbreviated as SAU for "services as usual"). The same article reported that mothers who participated in START achieved sobriety at 1.8 times the rate of typical treatment. There was also an economic evaluation conducted, which found that every $\$ 1$ spent to provide START was associated with a cost offset of $\$ 1.07$ in the form of averted out of home care costs (e.g., per diem payments to foster families). When the authors included participants who were referred to START but not admitted to the program in the analysis, this averted cost rose to $\$ 2.22$ of savings for every $\$ 1$ spent providing START. These results suggest that receiving START contributes to a number of benefits for families. This study sought to determine whether such a beneficial relationship would also be found in terms of the reduction in preventable emergency room visits and inpatient hospitalizations for children whose parents participated in START. 


\section{Economic Evaluations of Child Welfare Programming}

Including such economic analyses to existing program evaluations can add considerable value to efforts to better understand the impact that such interventions have on the families that receive them. This is especially true in the case of interventions that address co-occurring parental substance use and child maltreatment, as each of these problems is associated with enormous financial costs to society (see Fang, Brown, Florence, \& Mercy, 2012; Barth, Lee, Wildfire, \& Guo, 2006). These costs can appear in the form of lost productivity, crime, preventable consumption of healthcare services, and other social services utilization. While some of these costs are borne directly by the parents and children themselves, most are borne by their fellow citizens in the form of taxes, insurance premiums, and unrealized economic activity.

Given these high financial costs associated with both child maltreatment and highrisk substance use, a number of researchers and program evaluators have identified the need to test whether improving treatment outcomes may also be associated with reduced cost to the agencies and organizations that provide services to families (Swenson et al., 2009; Corso \& Lutzker, 2006; Goldhaber-Fiebert, Snowden, Wulczyn, Landsverk, \& Horwitz, 2011; Chamberlain et al., 2011). In policy and practice environments that increasingly call for decision making to be informed by evidence, incorporating economic measures and analyses into existing program evaluations of child welfare interventions tailored to serve substance using parents is a promising strategy to generate the kind of knowledge needed to improve the way communities respond to families with these unique needs. Similarly to the methods employed when health insurance organizations decide which treatments and services to cover, it benefits the funders of child welfare programs to know whether a given intervention 
is both: (a) efficacious and, (b) capable of generating some secondary economic or social benefit.

Because they are the health-insurer of many CPS-involved families, state Medicaid programs are important stakeholders in these matters. These Medicaid programs are expensive to administer, and are under constant pressure to improve population health while reducing cost (Billings \& Mijanovich, 2007). Given the reality that high-cost medical conditions such as traumatic injuries and chronic diseases often occur as a result of child abuse or substance use, these are appropriate venues for investigation of treatment effects (Florence, Brown, Fang, \& Thompson, 2013). This is especially true in light of results of previous interventions that have shown sizeable reductions in cost for similar populations (Estee, Wickizer, He, Shah, \& Mancuso, 2010; Olds, Henderson, Chamberlin, \& Tatelbaum, 1986).

Even in light of the established relationships between the work of healthcare providers and the CPS-related treatment efforts for these families, there are few published studies of how participating in specialized CPS interventions affects health services utilization or Medicaid spending. The results of such studies would allow service providers to better understand the impact of their work, for researchers to more deeply investigate relationships between addiction treatment and other variables of interest, and for policy makers to make more informed decisions about the broader impact of allocating public dollars to such initiatives. For example, better information could help policy makers determine whether to continue funding a given program, determine whether the program is generating economic benefits to the broader community, and perhaps even make recommendations to scale up and implement the program in additional communities that face 
similar problems. Considering the devastating and multi-faceted effects of the state's current opioid crisis on children and families, such information would be timely.

\section{The Health Services Case for Providing the START Program}

The START program was not designed for the purposes of saving money, but evidence from studies of similar interventions suggests that it may be achieving that result anyway. While most of the emphasis devoted to addressing these co-occurring problems is rightfully rooted in the humanitarian desire to ameliorate human suffering for its own sake, there is also an economic case for intervention with these families. This case is laid out accordingly:

\section{Premise \#1 - Addiction and Child Maltreatment are Prevalent and Serious Problems}

Both high-risk substance use and child maltreatment are prevalent problems nationally, and are especially problematic in Kentucky. Moreover, when parents engage in risky substance use, these often present as co-occurring problems that bring families into contact with CPS.

\section{Premise \#2 - The Suffering They Cause Is Associated with Increased Cost to Medicaid} Whether through physical violence, leaving children in dangerous circumstances, or other means, these co-occurring problems are associated with an increase in ER visits and hospital stays for mistreated children. As many of these families are insured by Medicaid, this increased healthcare utilization drives costs higher for Kentucky's Medicaid program.

\section{Premise \#3 - There is Evidence that START Makes Life Better for Children and}

\section{Families}

Both addiction and child maltreatment are treatable and preventable problems, and the START intervention was created to address them both simultaneously. Previous evaluation research of START suggests that it can effectively reduce parents' substance use while concurrently reducing their likelihood of abusing or neglecting their children again. 


\section{Conclusion - START May be Reducing Medicaid Spending on Children's Health}

\section{Services}

Therefore, it is likely that such benefits may also include a reduction in high-cost medical care for children in families that participated in START compared to a group of children who were also maltreated (but were not involved with START).

The following chapter will provide a review of the literature to establish the strength of the case outlined above and then proceed to outline the methodology of a study that was conducted to test the hypothesis outlined in the conclusion above. By testing whether participation in Kentucky’s START program predicts a reduction in ER visits and inpatient hospital stays for child victims, this study aimed to determine whether there is, in fact, an additional economic component to the START program's work with families. Because highvolume ER visits and inpatient hospital days have been identified as a common driver of costs for state Medicaid programs, they were selected as the outcome variables of interest for this study.

\section{Purpose and Methodology}

This being the case, the purpose of this study was to evaluate whether participation in the START program was associated with a reduction in high-cost medical care (specifically ER visits and inpatient hospital stays) for children whose parents participated in START. To test this hypothesis, the Medicaid claims data of START children were compared to claims data from a group of children involved in similar CPS cases who received SAU. Additionally, if such reductions were found to be present, this study aimed to identify whether there were significant differences between service types (ER, hospital stays) or START sites (i.e., did some county-based teams perform better than others in terms of preventing high-cost healthcare utilization). 
To achieve these goals, an analysis was conducted using a dataset that included program evaluation data that was merged with Medicaid claims data from 852 children. The original data from these children were collected between January 1, 2010 and May 31, 2016. This dataset included a non-random sample of child victims selected from five clusters of Kentucky counties for inclusion in the analyses. Each of these clusters was oriented around a county where START operated (Boyd, Daviess, Jefferson, Kenton, \& Martin counties). Participants who received the START intervention were included in this study after satisfying a number of inclusion criteria. The most important of these were: (1) an act of abuse or neglect was committed against the child (or an investigation determined there was sufficient risk of future harm), (2) a CPS investigation identified parental substance use as the primary risk factor, (3) the family was eligible for Medicaid, and (4) a child younger than five years old resided in the home.

Given that the START program admits families that possess characteristics that are not shared by all CPS-involved families in Kentucky (e.g., engaging in high-risk substance use and its associated characteristics), a comparison group was generated using a propensity score matching procedure (hereafter abbreviated PSM). Once the intervention group and comparison group were identified, healthcare claims data was acquired from the Kentucky Department of Medicaid Services (DMS). Once these data were merged, a series of regression analyses were conducted to determine whether there were between-group differences in health services utilization and costs to Medicaid in terms of ER visits, inpatient hospital stays, and outpatient services.

\section{Clarification of the Scope of the Study}


To summarize the scope of this study, the following section will provide an operationalized definition of the problem, describe study parameters, offer a clarification of terminology used, and outline the study's significance.

\section{Problem Definition}

This study was concerned with the intersection of two problems in the Commonwealth of Kentucky: (1) the problem of child maltreatment that occurs as a result of a parent's substance use, and (2) the high costs to Kentucky's Medicaid program associated with providing medical treatment to these families. For the purposes of this study, child maltreatment included any commission or omission of behavior that results in serious harm or risk of harm to a child as outlined in Kentucky Revised Statutes (KRS) 600.020 (Kentucky State Legislature, 2012). In terms of substance use, this study involved the children of parents whose use of addictive substances was sufficiently high-risk such that it hindered their ability to effectively care for their children. For many (though not necessarily all) parents, this problem involved a diagnosed SUD (see diagnosis outlined in American Psychiatric Association, 2013). Given the increased propensity for high-risk substance users to engage in high rates of preventable consumption of health and social services compared to the broader population, this study was concerned with determining whether receiving START services was associated with a lower level of consumption of a select group of health services compared to those who did not receive START.

\section{Study Parameters}

The present study focused on young children (between the ages of birth to five years old). All participants were residents of the Commonwealth of Kentucky during the study period and resided in households with incomes that qualified them to receive Medicaid. 
Moreover, the families included in this study had CPS involvement during the study period where an incidence of child maltreatment was substantiated and parental substance use was indicated as a risk factor. Though significant efforts were taken to standardize the START intervention across implementation sites, the addiction treatment provider partners were regional - therefore START participants received treatment services that may have differed in modality from one county to another. The study data included information generated by CPS cases that were opened over a seven year period (2010-2017). As mentioned earlier, the data (i.e., the child victims identified by CPS) for this study was secondary administrative data gathered as part of a program evaluation of the START intervention in Kentucky.

\section{A Brief Word on Terminology}

This dissertation concerns topics that are broad in their definitions, and oftentimes those definitions are obscured by disagreement on specific grounds. Those who work in the child welfare field sometimes include different terms to describe the breadth of the phenomena of child abuse. A similar (and even more obfuscating) terminology dynamic exists in the addiction field, as terms such as "substance abuse", "chemical dependency", or "addiction" have been used interchangeably in the past.

In the interest of economy of language, as well as respecting the current convention in the literature, this document will use the term "child maltreatment" to describe the multidimensional construct of harm associated with acts of commission and omission by a child's primary caregiver. Practically, this term encompasses behaviors that CPS investigators in Kentucky seek to identify: physical abuse, sexual abuse, emotional/psychological abuse, and the most severe manifestations of neglect (e.g., medical neglect, exposing children to dangerous circumstances). 
Additionally, child welfare professionals often serve families with varied relations to one another. For example, while it is common for children to reside with their biological parent (at least the mother), some CPS-involved children are raised by their grandparents or other relatives. In other instances they are raised by adults who are not biologically related to them. This can create some confusion about the proper word to use to discuss the people involved in CPS cases. In many cases, this phenomenon is addressed in the literature by using the term "parent/caregiver" to be more inclusive of the various family structures. This being the case, for the sake of simplicity as well as respect for the reality that parenting can assume many forms, this report will use the terms "adult", or "parent" to describe the person whose act of maltreatment caused the initiation of the CPS case. Some flexibility is required depending on context, and for this reason, these terms all refer to the same individual.

This report will also use the term "high-risk substance use" to describe the mere act of using drugs in such a way that exposes the user to a significant threat of harm to themselves or others. When describing the clinical (and more specific) definition of pathological substance use, this report will use the term "Substance Use Disorder" (abbreviated SUD). This term describes the current diagnostic conventions outlined by the American Psychiatric Association (APA) in the Diagnostic and Statistical Manual of Mental Disorders $-5^{\text {th }}$ edition (DSM-V, 2013). These terms are consistent with the efforts currently underway within the addiction field to standardize terminology and to disabuse the field of stigmatizing language (e.g., referring to an individual who is using drugs as "dirty" vs. one who is abstaining from them as "clean"; see Wakeman 2013; Botticelli \& Koh, 2016; Kelly, Saitz, \& Wakeman, 2016). 


\section{Significance of the Study}

Social workers understand the scope of their practice as existing on a spectrum that ranges from micro to macro. When social workers engage in macro practice, their advocacy, lobbying, and policy crafting initiatives are most successful when they are bolstered by data; especially financial data. One constant that runs throughout all such efforts is the reality that the provision of services occurs within an ecosystem of simultaneous high demand for services, finite supply of helping professionals, and limited financial resources. In order to contribute to policy making efforts germane to co-occurring substance use disorders and child maltreatment, this study presents an analysis that estimates some of the economic effects of providing the START intervention in Kentucky.

Such an investigation is timely, as one particular macro-level trend currently threatens the well-being of large segments of the population of the Commonwealth, and places inordinate strains on its public resources. The surge in use of opioid drugs is creating disastrous effects that are radiating out into sectors of society that were unprepared for the magnitude of suffering that it would bring to their doorstep. This trend has forced interdisciplinary collaborations that, according to previous work, seem to offer a promising means of stemming the tide of SUD's tragic impact on children and families. This study aimed to view the effects of this collaboration through a new lens, and in doing so hopefully demonstrate the alignment of interests between two large state government agencies.

Implications of this study include applications for the field of social work in terms of education, research, and policy making efforts. The field of social work's stated mission involves promoting both social and economic justice. In that vein, further development of the field's capacity to consume and produce research that incorporates economic measures 
would significantly strengthen the field's ability to be effective. Specifically, continuing to strengthen the case that successful social work interventions not only directly benefit the clients that receive them, but can also produce indirect economic benefits to the broader society provide additional support for advocacy initiatives to expand services for vulnerable families.

Establishing such a case can mean more than the mere publication of an exciting academic paper. If interventions can reliably demonstrate their ability to reduce financial strains associated with a costly social problem, they provide yet another justification for their continued existence. Sometimes this could mean more funding in the traditional sense, but it could also demonstrate a case that a given intervention be considered by investment models such as "Pay for Success" grants or Social Impact Bonds. These newer models enable the influx of capital to scale up interventions to meet the needs of more communities (Trupin, Weiss, \& Kerns, 2014). Such information, when it is generated by sound empirical studies, may also be an especially effective means of cutting through partisan political rhetoric and directing debates about how to allocate public monies towards win/win arrangements. 


\section{CHAPTER II}

\section{CO-OCCURRING SUBSTANCE USE AND CHILD MALTREATMENT}

To begin, it is important to frame this issue within its proper context. Specifically, efforts to address co-occurring cases of parental substance use and child maltreatment require the convergence of two fields that have traditionally viewed themselves as being distinct from one another. As is often the case when two fields join forces to address a large and meaningful problem, this can be fertile ground for innovation as well as friction.

When these parties join forces, the decisions they make frame the nature of their collaborations - including how their work should be financed, what roles should be assumed by respective team members, and determining which outcomes are most important to measure. Like the Biblical story of the Tower of Babel, when these teams are unable to speak the same language, their projects suffer as a result. This dynamic must also be addressed in program evaluation. For this reason, evaluators who are knowledgeable about the scholarship of both fields are especially useful to efforts to determine which interventions "work". This being the case, this chapter will summarize the relevant professional literatures of both the child welfare field as well as the addiction field. Moreover, a special emphasis will be placed on the work that has been published regarding their points of intersection, and how that intersection is related to the provision of healthcare for families.

\section{Problem Definition and History}

Both of the professional bodies that have expertise in these fields have formalized methods to identify and respond to problems. This section will now outline the way that both 
SUD and child maltreatment are conceptualized, assessed, and diagnosed in practice settings. In so doing, it will also give a brief historical account of how these social and public health problems came to be viewed the way they are now, as well as describe how these views have been integrated into theoretical and practice models.

\section{Substance Use Disorders}

First, it is important to note that not all substance use is pathological and, moreover, that most parents who use substances do so in low-risk ways (e.g., an occasional beer after work). Furthermore, these parents typically do not harm their children as a result of their innocuous substance use. In fact, epidemiological data suggests that a significant amount of the substances consumed on any given day in the U.S. are not being consumed by individuals with an SUD (Merikangas \& McClair, 2012). In other words, many people who use substances do not go on to develop a pathological pattern of use (this includes illegal and other illicit "hard" drugs such as cocaine; see Substance Abuse and Mental Health Services Administration, 2017). Even amongst individuals who engage in episodes of risky or harmful substance use, not all meet the formal diagnostic criteria for severe SUD. For example, many students on college and university campuses engage in episodic binge drinking and other high-risk substance use during their course of study but do not suffer serious long term health or social consequences or go on to develop severe SUD (National Center on Addiction and Substance Abuse, 2007).

However, this does not mean that there are not serious risks associated with using addictive substances, especially during times when an individual is responsible for providing care for young children. Although many parents can safely manage their substance use without any deleterious effects on their capacity to look after their children, there is a well- 
known subset that cannot. CPS officials have long observed the array of physical, cognitive, and emotional impairments brought about by parents' substance use and how they significantly hinder their ability to execute the activities of daily living for themselves and their dependent children (Magura \& Laudet, 1996). When these impairments progress to chronic and significant problems that interfere with social relationships, occupational functioning, and health an individual is considered to have an SUD.

\section{Clinical Definition of Substance Use Disorder}

The clinical term Substance Use Disorder was coined to describe the health condition associated with habitual and compulsive high-risk use of euphoria-inducing substances. When mental health professionals assess cases of SUD, they typically issue substancespecific diagnoses (e.g., Alcohol Use Disorder, Cocaine Use Disorder, etc.). However, in spite of these substance-specific diagnoses, the list below comprises a common set of diagnostic screening items used by the DSM-V for the most common SUD diagnoses (APA, 2013):

1. A patient/client takes a substance in larger amounts or for longer than their intended period of use.

2. A patient/client expresses a desire to cut down or stop using a substance but is unsuccessful.

3. A patient/client spends a significant amount of time getting, using, or recovering from use of a substance.

4. A patient/client experiences recurrent cravings and urges to use the substance.

5. A patient/client fails to manage responsibilities of work, home, or school because of substance use.

6. A patient/client continues their use, even when it causes problems in relationships.

7. A patient/client gives up important social, occupational, or recreational activities because of substance use.

8. A patient/client engages in consistent use of a substance, even when it places them in danger.

9. A patient/client continues their use, even when they know they have a medical or psychological problem that could have been caused or exacerbated by their substance use. 
10. A patient/client reports needing more of the substance to get the desired effect (i.e., tolerance).

11. A patient/client developments withdrawal symptoms, which can only be relieved by consuming more of the substance (i.e., dependence).

These responses are coded as dichotomous “yes/no" scores during screening

examinations, and clients are asked to endorse an item if it was true for them within the past year. In clinical practice, if a client endorses 2-3 of these criteria, a mild SUD diagnosis is given, while 4-5 constitutes a moderate SUD, and endorsing 6-7 warrants a severe SUD diagnosis (APA, 2013). For a more comprehensive discussion of diagnostic matters in addiction treatment and the development of the DSM-V items, please refer to Hasin and colleagues (2013) and Goldstein and colleagues (2015).

Notice that five of these items (\#3, \#5, \#6, \#7, \& \#8) are particularly germane to the functioning of a parent responsible for the care of young children. For example, spending a significant amount of time obtaining and using drugs (see \#3) increases the likelihood that parents will neglect their children or leave them in unsafe environments. Similarly, it is hard to meet the material needs of young children if a parent cannot successfully keep a job because of the interferences of drug use (see \#5). This is even more so the case if their drug use results in a serious injury or illness (see \#8). While not an inevitability, a parent with a severe SUD diagnosis is likely to struggle with the daily responsibilities of parenting. For this reason, children living in homes with such parents are at greater risk of harm.

\section{Theories of Substance Use and Addiction and Their Application}

These diagnostic criteria emerge out of an overarching biomedical theory of addiction that is currently endorsed by the field of psychiatry. This theory was famously summarized by Dr. Alan Leshner (1997) and could broadly be called the chronic, relapsing brain disease model of addiction. Led by the direction of the U.S. National Institute on Drug Abuse 
(NIDA) and the National Institute on Alcohol Abuse and Alcoholism (NIAAA), recent decades have seen the emergence of research programs which have generated results that support this model and have ushered in a greater understanding of addictive behavior, especially as it relates to brain functioning.

Essentially, this theory is rooted in the assertion that drugs of abuse exert their power through the brain's dopamine reward system - a system which serves as a survival mechanism for human beings by promoting behaviors that are evolutionarily advantageous (e.g., eating high-calorie foods, sexual intercourse, etc.; see Panksepp, Knutson, \& Burgdorf, 2002). In particular, numerous studies have detected elevated levels of dopamine in the nucleus accumbens (a region associated with subjective experiences of pleasure) in the brains of individuals that have been administered addictive substances in laboratory settings (this evidence is reviewed in Volkow, Fowler, \& Wang, 2003). The theory further postulates that, as individuals continue to use these substances, a dynamic interaction between genetic, biochemical, environmental, and social factors leads to a dysfunction of the prefrontal cortex; the region associated with higher-order cognitive functions such as planning for the future, inhibiting inappropriate behaviors, or delaying gratification (Goldstein \& Volkow, 2011).

Notice that, in spite of the influential neuroscientific discoveries made in the field (and the subsequent theoretical framework that they have generated), the DSM-V diagnostic criteria do not involve any biomedical testing or analyses. Although the items that comprise the SUD diagnoses show a high level of validity and reliability (Hasin et al., 2013), the diagnosis is limited by its reliance on symptom clusters and descriptions of behavior patterns. Contrary to other diagnostic norms of American medical practice, which rely on more objective biologic measures (e.g., laboratory tests of blood or urine, medical imaging tests, 
biopsies, etc.), the taxonomy of this psychiatric disorder is forced to rely on these subjective measures until better methods are devised. Any honest discussion of the true nature and etiology of the condition must acknowledge this point, because it constitutes the ground on which serious scholars can debate.

This reality is acknowledged by the field, and researchers are currently investigating methods to improve the empirical validity of future SUD diagnostic testing. For example, some proposed future directions include brain scanning methods, identifying genetic markers, and investigating the unique ways an individual metabolizes drugs (Hasin et al., 2013). There are justice implications for this matter, especially in child welfare practice with substance using parents. If the presence of a diagnosis is going to be used in such cases, then it is incumbent on practitioners to only give SUD diagnoses when the condition is present and to definitively rule it out when it is not. Doing so effectively prevents individuals from receiving treatment they do not need, as well as avoiding attaching a "label" to them that could follow them into a number of other avenues in their lives. For instance, family court judges often issue rulings based on the testimony of mental health professionals, meaning a spurious diagnosis can have serious implications for families. Moreover, in the present health insurance regime, SUD diagnoses are often deemed "pre-existing conditions", which can affect insurers' decision making, which could in turn price a family out of affordable coverage (Beronio, Glied, \& Frank, 2014). Similarly, divorce hearings and hiring practices are all routinely influenced by an individual's addiction history.

Because psychiatric diagnoses are forced to rely on symptom clusters and the observations of professionals, they are notably subject to cultural interpretation. Indeed, some have noted that the mere act of discussing one's emotional states in an individuated and 
detached way (the bedrock of psychiatric assessment and treatment in this country) is a particularly Euro-American way of interacting with reality (Room, Janca, Bennett, Schmidt, \& Sartorius, 1996). While there are certainly cultural, religious, and socioeconomic features of the diagnosis and treatment of all health conditions (e.g., blood transfusions for Jehova's witnesses, supernatural explanations for seizure disorders, etc.), SUD presents a special case. In Amazonian tribal cultures, inducing powerful hallucinations by drinking Ayahuasca tea has been practiced for generations as a means for personal transformation and enlightenment. Should this be understood as "disordered" substance use? Ayahuasca has even been taken to overcome SUD (Loizaga-Velder \& Verres, 2014). However, in Western cultures, the use of so-called psychedelic drugs is legally prohibited and viewed as subversive behavior associated with the counter-culture. Western cultures especially stigmatize drug use amongst parents (and even more so for mothers), often viewing it as childish behavior that interferes with adult responsibilities.

As the problem can be viewed through cultural lenses, so too can its cure. In the United States, the dominant treatment paradigm is the 12-step approach; a non-medical program rooted in a particularly American version of Christian spirituality. 12-step methods are the bedrock of many of the treatment facilities that have partnered with the START program, and thus the way many clients in the program approach their process of recovery. There is considerable (and often vitriolic) debate within the field about whether these methods are effective and how readily they should be endorsed by professionals in the medical and allied health fields. The reality that individuals have successfully recovered (as well as failed to recover) in a variety of ways continues to frustrate efforts to precisely "nail down" the true nature of SUD and how to best treat it. 
The phenomenon of so-called "natural recovery" is perhaps the most confounding challenge to modern theories of addiction (Vaillant, 1982; Granfield \& Cloud, 2001). Although it is important to note that it is difficult to study natural recovery empirically and that some methodological problems have been identified in past publications (Sobell, Ellingstad, \& Sobell, 2000), people who recover without formal help may offer valuable insights into the true etiology of SUD. One classic case that has been discussed in the literature was the widespread use of heroin by American soldiers in Vietnam. High rates of heroin use and addiction on the front lines of the war led to serious fears amongst health officials in the military of waves of addicted G.I.'s returning home from combat. However, these fears never materialized on the scale at which they were anticipated. Though many veterans did return home with serious drug and alcohol problems, many former heavy users simply stopped without any formal treatment upon discharge from active duty (Robins, 1993).

This current understanding of compulsive substance use constitutes a sea change from past descriptions of the condition. Though there are recorded cases dating back to the Roman Empire where municipalities attempted to address addictive behavior through regulations of wine and other substances (Escohotado, 1999), it has not been until much more recently that societies have tapped the resources of their healthcare systems for this problem. One of the most important promulgators of the idea that addiction was best conceived as a disease were the Alcoholics Anonymous groups that began to form in the 1930's (Kurtz, 2010).

In the American context, the "disease concept" emerged against the backdrop of temperance movements, Prohibition, and religious injunctions against drunkenness and intoxication. It has been sources such as these that undergird initiatives such as the War on 
Drugs and efforts to criminalize drug use which have left lasting effects on American society (especially communities of color). These policies have inevitably affected the nuclear family beyond cases of maltreatment. As they drove drug use underground, the potency of illegally obtained drugs increased, which accounted for overdose deaths and orphaned children. Harsh drug possession penalties have also accounted for large prison populations, which have oftentimes left children to be raised without one or both of their parents. For more on this history, please refer to Lynch (2012), Valentine (2004), and Moore and Elkavich (2008).

While the steady movement away from explanations that rely on condemnations of character has been a positive societal development, there are still matters to adjudicate in the literature before a conclusive and philosophically rigorous definition of addiction can be arrived at. This is also an important point to mention because the parent participants involved in this study were not required to have a diagnosed case of SUD to meet inclusion criteria. In other words, in child welfare settings, it is often the case that high-risk parental substance use (with or without a clinical diagnosis), as long as it endangers children, is sufficient for intervention. For further reading on this matter, see Levy (2013), Hall, Carter, \& Forlini (2015), and Hammer and colleagues (2013).

\section{Child Maltreatment}

American society owes its current understanding of child maltreatment to past advocacy movements that have sought to safeguard the health and wellness of children. In fact, before the turn of the $20^{\text {th }}$ century, terms such as "child abuse" or "child neglect" would fail to convey the meaning attached to them in today's vernacular. Since those days, definitions have progressed from a description of the evident harms associated with physical violence inflicted on children (e.g., broken bones, burns, bruises, etc.) towards one that 
includes failure to provide adequate parental care. In other words, in addition to committing acts of harm, omitting acts that support the healthy development of children (such as medical care, basic necessities, and loving attention) now constitute maltreatment in the conventional understanding (Thomas, 1971).

This being the case, the maltreatment experienced by these children is a multidimensional construct, and one that warrants a thorough definition here. While at first glance the concept may seem obvious, there are many practical ways in which the definition can become uncertain or contentious. For example, is allowing a 5 year old child to walk to the neighborhood park by themselves an act of neglect? Would it matter if the child walked to the park during the day vs. in the middle of the night? What if the park is well known to the family, and is an objectively safe place? What if the child is 10 years old instead of 5 ? These very questions were addressed in a recent piece of state legislation in Utah known as the “Free-Range Parenting” law (De La Cruz, 2018). Such questions are why CPS agencies typically employ experienced intake supervisors to screen reports using established standards of practice to determine which reports merit investigation and decide whether maltreatment has actually occurred.

\section{A Brief History and Overview of Child Welfare Practice in the United States}

The adoption of child welfare laws such as those outlined in this section reflect attitudes about the proper treatment of children. Current policies such as providing large scale health insurance programs for children (e.g.., State Children's Health Insurance Program) or administering sophisticated foster care and adoption programs are a marked departure from the past. In the country's earlier days, beliefs about the role of children in society and family life were largely shaped by inherited English attitudes and norms 
(especially English Common Law). Under these early laws, parents (especially fathers) had near absolute authority over the lives of their children. Children were also typically expected to contribute to the family economically, especially in poorer households. Throughout the nation's progression from an agrarian economy to an industrial one, this often meant difficult and hazardous labor in fields, mines, factories, and other venues not deemed suitable for children in the modern ethos (Thomas, 1971).

In a lecture given in 1827, Chancellor James Kent (a prominent jurist and legal scholar of his day) articulated the prevailing legal conventions of the time:

"The father (and on his death, the mother) is generally entitled to the custody of the infant children, inasmuch as they are their natural protectors, for maintenance and education. But the courts of justice may, in their sound discretion, and when the morals, or safety, or interests of the children strongly require it, withdraw the infants from the custody of the father or mother, and place the care and custody of them elsewhere ..."

(Thomas, 1971, p. 300).

While modern institutions are much better equipped to serve families, each case still brings with it an underlying set of ethical challenges. In practice, granting state agencies the authority to effectively dissolve families and seize custody of children from their parents places them in a position of enormous responsibility. While the courts and CPS agencies are legally mandated to only resort to these measures once all other measures have been tried and failed, there are still many parents who have their parental rights terminated each year.

Empowering the government with this authority often invokes a particular manifestation of the long-standing debate about the proper role of government in the private lives of American citizens. The relationship between parents and their children is an element of private life that is especially sacred in American culture and jurisprudence. An overly 
muscular approach risks infringing on the rights of parents to raise their children as they see fit, thus depriving children of the opportunity to grow up in their family of origin. On the other hand, an overly lax approach risks leaving children in unsafe environments that can deprive them of their rights to liberty, the pursuit of happiness, and (potentially) their lives.

In a law review article pertinent to this matter, Adler (2001) illustrates how current child welfare policy is forced to exist in a state of genuine tension between these competing values. Briefly, Adler (2001) argues that this tension is derived from two competing sets of values that force courts into "terrifying dilemmas" (p. 2). On the one hand is a set of moral goods associated with liberty and justice - such as an appreciation of the free expression of cultural diversity (especially as it pertains to disciplinary tactics for children), family autonomy, and the right to be left alone by the government. On the other hand is a set of moral goods associated with group cohesion and preserving a stable national and cultural identity - such as a high regard for traditional civic virtues, preserving the safety of children, and personal responsibility and accountability for problems like poverty. While there are many cases where these two sets of values are not in conflict, there are times where CPS workers, judges, and law enforcement agencies must weigh them against each other.

\section{Kentucky Revised Statutes 600.020}

To clarify these matters, states have written laws to codify what constitutes child maltreatment. In practice, these federal and state laws provide the orienting definitions of child maltreatment that child welfare agencies are beholden to. Each of the 50 United States and the District of Columbia have laws against abusing or neglecting a child over whom one has custody (Levine, 1973). Such laws proliferated in the U.S. around the 1960's, but were reified with the passage of the Child Abuse Prevention and Treatment Act of 1974 (CAPTA) 
and the requirements it placed on states. Because public child protection agencies are predominantly administered by state governments, it is especially important how a given state's laws define what behaviors constitute abuse and neglect of a child. Kentucky's legislature drafted the state's first definition of its current understanding of child abuse and neglect in 1986, and today that definition is used in the court system to guide CPS practice as well as trying civil and criminal cases that involve the maltreatment of children. Kentucky Revised Statutes (KRS) Chapter 600, Section 020 outlines the phenomenon as follows:

(1) "Abused or neglected child" means a child whose health or welfare is harmed or threatened with harm when:

(a) His or her parent, guardian, person in a position of authority or special trust, as defined in KRS 532.045, or other person exercising custodial control or supervision of the child:

1. Inflicts or allows to be inflicted upon the child physical or emotional injury as defined in this section by other than accidental means

2. Creates or allows to be created a risk of physical or emotional injury as defined in this section to the child by other than accidental means

3. Engages in a pattern of conduct that renders the parent incapable of caring for the immediate and ongoing needs of the child including, but not limited to, parental incapacity due to alcohol and other drug abuse as defined in KRS 222.005

4. Continuously or repeatedly fails or refuses to provide essential parental care and protection for the child, considering the age of the child

5. Commits or allows to be committed an act of sexual abuse, sexual exploitation, or prostitution upon the child

6. Creates or allows to be created a risk that an act of sexual abuse, sexual exploitation, or prostitution will be committed upon the child

7. Abandons or exploits the child

8. Does not provide the child with adequate care, supervision, food, clothing, shelter, and education or medical care necessary for the child's well-being. A parent or other person exercising custodial control or supervision of the child legitimately practicing the person's religious beliefs shall not be considered a negligent parent solely because of failure to provide specified medical treatment for a child for that reason alone. This exception shall not preclude a court from ordering necessary medical services for a child

9. Fails to make sufficient progress toward identified goals as set forth in the court-approved case plan to allow for the safe return of the child to the parent that results in the child 
remaining committed to the cabinet and remaining in foster care for fifteen (15) of the most recent twenty two (22) months; or

(b) A person twenty-one (21) years of age or older commits or allows to be committed an act of sexual abuse, sexual exploitation, or prostitution upon a child less than sixteen (16) years of age

When CPS workers in Kentucky receive reports of alleged child maltreatment, it is on these grounds that they investigate the case. If, after collecting sufficient evidence, one or more of the above conditions are deemed to have occurred, the maltreatment is deemed "substantiated", and then an ongoing case is often subsequently opened. In the current study, nearly all of the participants included in the analysis met this criteria as a condition of participation in the START program or in terms of their inclusion in the comparison group. For those who did not, their family was determined that CPS services were needed to ensure the safety of the child.

\section{Adoption and Safe Families Act of 1997}

Laws such as KRS 600.020 are written to protect children from harm, but also to promote their placement in safe and permanent places to live. The present legal environment exists as a result of conclusions made on the codification of a particular definition of permanence in child welfare practice. Adler's (2001) paper uses the particular understanding of the concept of permanence as an orienting point for how laws understand this idea. Specifically, the foundation of much of today's CPS practice is the Adoption and Safe Families Act of 1997 (ASFA), a federal law passed during the Clinton administration. The aims of ASFA are simple and three-pronged: to promote children's safety, permanency, and wellbeing. In an attempt to promote these aims and more rightly prioritize them, ASFA made a series of substantial reforms to the preexisting federal child welfare policy established by 
the Child Abuse Prevention and Treatment Act of 1974 and the Adoption Assistance and Child Welfare Act of 1980.

The impetus to pass ASFA arose out of mounting concerns that, in attempt to preserve families, children were too often left in either unsafe or impermanent environments (Barth, Wulczyn, \& Crea, 2004). The concern at the time was that CPS agencies were giving parents too long of a time window to address the problems that led to the maltreatment (e.g., substance use), and during this time their children were missing critical developmental milestones (especially in terms of attachment and social skills development; see Moye \& Rinker, 2002 and O'Flynn, 1999). If past policies erred on the side of preserving families, many have argued that ASFA errs on the side of dissolving them prematurely. Indeed, there were concerns from the very beginning about how the law's passage would affect families dealing with SUD’s (Barth, Wulczyn, \& Crea, 2004).

This being said, in an effort to speed up the process between removing a child from their parents and placing that child in a permanent home setting, ASFA mandated that permanency hearings be held no longer than 12 months after a child had been removed from the home. Furthermore, it required states to terminate parental rights (TPR) once a child had been in out of home care for 15 of the last 22 months. Provisions were written into the law to award states that successfully complied with these timeframes with predetermined incentive payments. Finally, ASFA clarified earlier legal language describing "reasonable efforts" that CPS should take to preserve and reunify families. These particular changes had the ultimate effect of lowering the standards used by courts to terminate parental rights; effectively making it easier for judges and state agencies to complete that process and place children in the custody of the state or place them up for adoption (Hannett, 2007). For example, ASFA 
waived the "reasonable efforts" requirement in cases where a child in the home had been the victim of homicide perpetrated by the parent or guardian.

These policy changes have had notable and lasting implications for families dealing with substance use. For parents dealing with the characteristic cycles of relapse and recovery inherent to SUD, it is often difficult to achieve sustained wellness within the abridged timeframes outlined in ASFA. This is especially true in light of the problems mentioned earlier related to the insufficient number of appropriate treatment venues, complicated insurance regimes, and fragmented coordination of care. As a result, when CPS agencies work with these families, they are faced with the challenge of: (1) getting their client's problem properly diagnosed, (2) helping them find appropriate treatment and gain admission, (3) supporting the client in their recovery as they comply with other court orders and, (4) ensuring the child's safety and wellbeing are attended to throughout. On top of this, all of these conditions must be met within roughly one to two years' time.

\section{Attachment Theory}

Advocates for ASFA were motivated to stop "foster care drift" - the term used to describe the tendency for a temporary fix to become a long-term reality for children in care. At the time of ASFA's passage, reports of children moving between multiple foster care placements over extended periods of time were very concerning to policy makers. This animated the desire for permanency to be a focal point of the reform. Several psychologists advocated for this on the basis of insights from attachment theory (Barth et al., 2004). This theory describes a scientific framework that explains child development as a function of the quality of children's early relationships with their caregivers (especially their mother). 
Attachment theory developed from the early observations of John Bowlby, an English psychiatrist and psychoanalyst who lived from 1907-1990 (Bretherton, 1992). Put briefly, attachment theory posits that children who experience emotional warmth, material security, and consistent care from their parents and caregivers in their early years form secure attachments with them. As a result, this secure attachment allows those children to explore their world confidently - which ultimately translates to sound mental health and healthy social relationships in adulthood (Bretherton, 1992; Bowlby, 2008). Since Bowlby’s earliest observations of children's behavior, a number of research programs have yielded a considerable body of empirical evidence that supports the central claims of attachment theory (Hazan \& Shaver, 1994; Berlin, Appleyard, \& Dodge, 2011; Dixon, Browne, \& HamiltonGiachritsis, 2005).

Amongst this body of evidence are findings that children with insecure attachment styles often exhibit behavior problems that persist into adulthood; especially the development of certain psychopathologies and difficulties in romantic relationships. As a result of intense research interest in attachment, at least 29 different psychometric instruments have been developed to measure the different attachment styles (Ravitz, Maunder, Hunter, Sthankiya, \& Lancee, 2010). The range of categories used to represent them are generally concerned with how readily people engage in close relationships with others and how comfortable they feel when doing so. They are largely delineated between types of secure attachments (e.g., secure-autonomous) and types of insecure attachments (e.g., insecure-avoidant, insecuredisorganized; see Ravitz et al., 2010).

In spite of the variety of measures used to qualify the nature of relationships between children and their parents, consistent findings emerge when researchers study the effects of 
poor attachment and attachment-based trauma on wellness in adolescence and adulthood. For example, in a review of this literature, Dozier, Stovall-McClough, and Albus (2008) describe strong relationships between attachment-related traumas (e.g., death of a parent, a child's removal from the home due to maltreatment, etc.) and mood disorders, anxiety disorders, dissociative disorders, personality disorders, eating disorders, and schizophrenia. In a study conducted in Israel, Ponizovsky, Nechamkin, \& Rosca, (2007) found that insecure attachment styles were associated with symptomatology and the course of illness in adult male patients diagnosed with schizophrenia. The study administered clinical surveys of adult attachment and the positive and negative symptoms of schizophrenia to 30 male inpatients admitted to a psychiatric hospital and 30 age-matched male control participants without a schizophrenia diagnosis. Their results suggested that the insecure-avoidant attachment style was especially strongly associated with the positive symptoms of schizophrenia (e.g., delusions, hallucinations, racing thoughts).

In another study that tested the hypothesis that the nature of the attachment relationship is related to later psychological functioning, Kostelecky (2005) found that parental attachment was associated with adolescent substance use. Dr. Kostelecky's study regressed substance use against three predictor variables (parental attachment, positive and negative life events, and academic achievement) in a sample of 133 Midwestern high school seniors and found that parental attachment explained a significant amount of the variance in substance use. The study operationalized substance use in three ways: (1) alcohol use, (2) marijuana use, and (3) other illicit drug use, and found that parental attachment was a significant predictor of all three types in the sample. 
This work suggests that the decisions made by CPS workers can have life-long implications. These insights have forced child welfare authorities to view a child's entire episode of contact with CPS as a series of attachment-based traumas. For example, when a child is physically abused by a parent the child has learned that there are instances where a trusted caregiver cannot be relied upon for safety and comfort. Once CPS becomes involved, they may remove the child from the home and place them in foster care; an experience that in and of itself can be confusing and upsetting for children (even those old enough to understand that it is to protect their safety). Throughout this process, young children are moved around between adults as they are navigating the crucial psychological process of identifying a caregiver to help them meet their basic needs, regulate their emotional states, and provide them with a sense of security. In environments where caseloads are high, parents have serious problems, and too few high-quality foster homes are available, CPS agencies are often limited in their ability to mitigate the threats to their clients' ability to form secure attachments (Miller, 2011).

\section{Lack of Addiction Training in CPS Workforce}

Such environments create circumstances where child welfare practitioners are faced with a staggeringly complex series of decisions. Beyond the structural limitations listed above, authorities have also noted that many CPS workers are entering the field with inadequate preparation to make those complicated decisions. Researchers have long documented the problems associated with under-preparation, insufficient training, and job turnover in child welfare workforces around the nation (Barbee et al., 2009; Auerbach, McGowan, \& Laporte, 2008). Moreover, despite the known prevalence of addiction and high-risk substance use in child welfare populations, there is evidence that many of the frontline workers do not have adequate time, training, or resources to properly screen for and 
address issues that arise as a result of the substance use problems in the families they serve (Schroeder, Lemieux, \& Pogue, 2008; Dore, Doris, \& Wright, 1995; Chuang, Wells, Bellettiere, \& Cross, 2013; Gregoire, 1994). While it is (usually) beyond the scope of their practice to provide the treatment themselves, when CPS workers lack the skills to identify or refer families for appropriate services, they miss opportunities to intervene.

Furthermore, this lack of education has the capacity to influence the decision-making process when fieldwork is informed by schemas and negative biases of substance users and their capacity to make positive behavior change or care for their children. For example, in a study of 86 CPS intake supervisors, Howell (2008) found that an individual supervisor's values related to drugs and substance use were significantly predictive of their decision to investigate allegations of maltreatment; more so than their training, education, or professional experience.

In the study, participants were administered a test including 10 scenarios that involved parental substance use and were asked to rate how likely they were to recommend the cases for investigation. Remarkably, these 10 vignettes were based on previous CPS cases that had been determined to not meet the established standard of practice criteria for investigation in actual previous reports. The average length of experience for these supervisors was 5.45 years. Howell's discussion of his results suggested that their participants' values related to parental substance use were more predictive of their decision to investigate a case than their knowledge and training of their agency's policy (2008). Unfortunately, this study also found that intake supervisors were more likely to recommend a case for investigation if the alleged perpetrator in the vignette was Black or Latino than if they were White (Howell, 2008). It also found that whether an intake supervisor possessed a 
social work degree made no significant difference in their decision-making when compared to supervisors who pursued other courses of study. Results such as these suggest that closer collaboration between CPS workers and addiction treatment professionals is warranted whether that be in the form of additional training, greater utilization of consultation and referrals, or full-integration within specialized teams.

\section{Prevalence of Co-Occurring Substance Use and Child Maltreatment}

Prevalence and Results of Epidemiologic Studies

How pervasive is this problem? A reading of the available literature yields a range of prevalence estimates of co-occurring high-risk substance use and child maltreatment - a range that is largely affected by study methodology. Several authorities have concluded that substance use is reported as a risk factor in approximately half of all CPS cases (Hanson, Saul, Vanderploeg, Painter, \& Adnopoz, 2015; Jones, 2004; Young, Boles, \& Otero, 2007). Capturing a true prevalence of this phenomenon is difficult for researchers for a number of reasons; some conceptual and some practical. Among the conceptual difficulties are questions related to operational definitions. Is drug use by a pregnant woman child abuse? State laws differ on this matter. Should researchers only concern themselves with formally diagnosed incidences of SUD, or should they represent the data more broadly and count all cases of child maltreatment related to any substance use? These are research decisions that have very serious analogues in the child welfare policy and practice realm. This section will present studies that have used both criteria in their reporting of results.

The more practical or methodological questions involve how to gather such sensitive information. In an attempt to study larger and more representative sample sizes, some studies have used federal child welfare reporting databases and surveys. What these studies gain in 
scope, they sacrifice in sensitivity to the details of individual cases. However, many studies that can gather a more refined level of detail must rely on self-report measures, which have the potential to be unreliable in child welfare contexts where issues like child custody or criminal prosecution are at stake (Negriff, Schneiderman, \& Trickett, 2017). Finally, as many affected individuals never disclose that they were the victim of child abuse or that they have a problem with substance use, there is a known phenomenon of under-reporting in epidemiological studies of both issues (Gilbert et al., 2009; Johnson, 2014). This, in addition to practical problems related to difficulty reaching or contacting affected individuals, leads researchers to believe that estimates advanced in the published literature are likely conservative and underestimate the true prevalence (Grant et al., 2004).

The literature table in Table 2.1 demonstrates some of the ways that studies have addressed these conceptual and methodological decisions in an attempt to understand how many CPS cases are generated as a result of a parent's substance use. It is important to state that not all of the studies are nationally representative, and therefore may represent the effects of important regional differences (e.g., the availability and price of illegal drugs, statutory differences between drug policies, cultural practices related to family and community life, etc.). This being said, in the research catalogued below, estimates of cooccurring substance use and child maltreatment range from as low as $15.1 \%$ during a oneyear prospective study period (Chaffin, Kelleher, \& Hollenberg, 1996) to as high as 79\% during an approximately 1.5 year retrospective study period (Besinger, Garland, Litrownik, \& Landsverk, 1999).

While this range of prevalence estimates exists in the literature, there is virtually no debate about the prominence of parental substance use in child welfare settings in the United 
States (Barnard \& McKeganey, 2004). The literature summarized below also presents some consistent elements of the profiles of families that exhibit co-occurring substance use and child maltreatment. These features broadly conform to what is known in the broader child welfare and addiction fields, and seems to suggest that these families represent particularly acute presentations of the overlapping problems. Specifically, these families are more often households headed by single mothers (Besinger, Garland, Litrownik, \& Landsverk 1999), have experienced unstable housing (Jones, 2004), and involve younger children (Besinger et al., 1999). They also seem to be particularly vulnerable to substantiated cases of omission of parental duties (e.g., general neglect, medical neglect, etc.) compared to other forms of maltreatment such as sexual or physical abuse (Kelleher, Chaffin, Hollenberg, \& Fischer, 1994; Chaffin, Kelleher, \& Hollenberg, 1996). Additionally, there appear to be proportionate increases in a parent's likelihood of committing acts of child maltreatment as the acuity of their use increases (i.e., increased frequency of use, increased dosages, dual use of drugs and alcohol; Young, Boles, \& Otero, 2007; Jones, 2004). These results are summarized in Table 2.1 .

\section{Table 2.1}

\begin{tabular}{|c|c|c|c|c|}
\hline \# & Publication & $\begin{array}{c}\text { Location of } \\
\text { Study }\end{array}$ & Study Participants & Main Findings \\
\hline 1. & $\begin{array}{l}\text { Besinger, } \\
\text { Garland, } \\
\text { Litrownik, \& } \\
\text { Landsverk } \\
\text { (1999) }\end{array}$ & $\begin{array}{l}\text { San Diego, } \\
\text { CA }\end{array}$ & 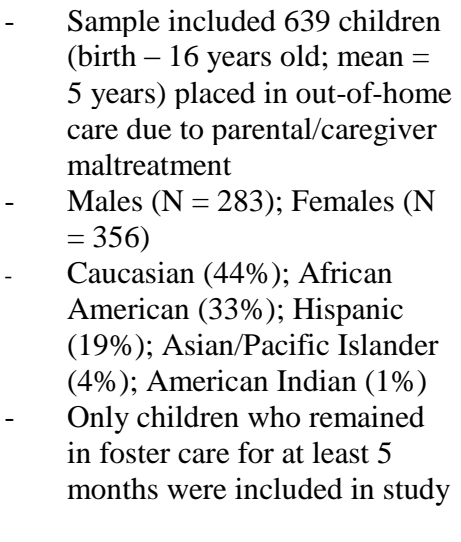 & $\begin{array}{l}\text { Of the total sample, } 79 \% \text { of cases } \\
\text { contained evidence of caregiver } \\
\text { substance abuse } \\
\text { Children whose caregivers used } \\
\text { substances tended to be younger at time } \\
\text { of removal ( } 4.46 \text { years v. } 7 \text { years), were } \\
\text { more often removed due to neglect } \\
\text { (63.7\% v. } 48.5 \%) \text {, and were less often } \\
\text { removed for physical or sexual abuse } \\
\text { than children from homes without } \\
\text { substance use. } \\
\text { Children removed from homes due to } \\
\text { maltreatment associated with caregiver } \\
\text { substance use were more often from a } \\
\text { single-parent home (59\% v. } 47 \%)\end{array}$ \\
\hline
\end{tabular}


Table 2.1 (continued).

\begin{tabular}{|c|c|c|c|c|c|}
\hline \# & Publication & $\begin{array}{c}\text { Location of } \\
\text { Study }\end{array}$ & & Study Participants & Main Findings \\
\hline 3. & $\begin{array}{l}\text { Walsh, } \\
\text { MacMillan, \& } \\
\text { Jamieson } \\
(2003)\end{array}$ & $\begin{array}{l}\text { Ontario, } \\
\text { Canada }\end{array}$ & - & $\begin{array}{l}\text { Sample included } 8,472 \\
\text { respondents to the Ontario } \\
\text { Mental Health Supplement } \\
\text { survey instrument from year } \\
1990-1991 \\
\text { Survey respondents were at } \\
\text { least } 15 \text { years of age }\end{array}$ & $\begin{array}{l}\text { - Parental/caregiver substance use was } \\
\text { associated with a more than twofold } \\
\text { increase in the risk of either physical or } \\
\text { sexual abuse victimization (OR }=2.4) \text {. } \\
\text { Respondents were asked to report which } \\
\text { parent engaged in substance use (only } \\
\text { father, only mother, or both). For all } \\
\text { abuse categories, risk of victimization } \\
\text { was higher for respondents who reported } \\
\text { "maternal substance abuse only" vs. } \\
\text { "paternal substance abuse only". } \\
\text { This risk profile was amplified if both } \\
\text { parents engaged in substance use. There } \\
\text { was a more than threefold increase in risk } \\
\text { of physical or sexual abuse victimization } \\
\text { for respondents who reported substance } \\
\text { use in both parents (OR = 3.7). The risk } \\
\text { profiles were even higher for the severe } \\
\text { abuse categories (severe physical: OR = } \\
\text { 5.9; severe sexual: OR =6.4). }\end{array}$ \\
\hline 4. & $\begin{array}{l}\text { Kelleher, } \\
\text { Chaffin, } \\
\text { Hollenberg, } \\
\text { \& Fischer } \\
\text { (1994) }\end{array}$ & $\begin{array}{l}\text { Five Sites: } \\
\text {-New } \\
\text { Haven, CT } \\
\text {-Baltimore, } \\
\text { MD } \\
\text {-St. Louis, } \\
\text { MO } \\
\text {-Durham, } \\
\text { NC } \\
\text {-Los } \\
\text { Angeles, CA }\end{array}$ & - & $\begin{array}{l}\text { Participants were taken from } \\
\text { The National Institute of } \\
\text { Mental Health } \\
\text { Epidemiological Catchment } \\
\text { Area Study of } 18,000 \text { non- } \\
\text { institutionalized adults living } \\
\text { in American communities } \\
\text { Experimental Group (+ child } \\
\text { maltreatment): } \\
\mathrm{N}=378 \\
\text { Matched Comparison Group (- } \\
\text { child maltreatment): } \\
\mathrm{N}=378\end{array}$ & $\begin{array}{l}\text { Comparison group participants were } \\
\text { parents matched with other parents on the } \\
\text { basis of: gender, age ( } \pm 5 \text { years), race, } \\
\text { socioeconomic status quartile, and study } \\
\text { site. Among parents who reported } \\
\text { committing child abuse, } 40 \% \text { also } \\
\text { reported a lifetime incidence of a drug or } \\
\text { alcohol disorder. Among parents who } \\
\text { reported child neglect, } 56 \% \text { reported also } \\
\text { having a drug or alcohol disorder. } \\
\text { Parents who reported a lifetime incidence } \\
\text { of a diagnosed drug or alcohol disorder } \\
\text { were } 2.7 \text { times more likely to have } \\
\text { physically abused their children and } 4.2 \\
\text { times more likely to have neglected their } \\
\text { children than the comparison parents. } \\
\text { These relationships remained significant } \\
\text { after controlling for: household size, } \\
\text { social support, depression diagnosis, and } \\
\text { antisocial personality disorder diagnosis. }\end{array}$ \\
\hline 5. & $\begin{array}{l}\text { Chaffin, } \\
\text { Kelleher, \& } \\
\text { Hollenberg } \\
\text { (1996) }\end{array}$ & $\begin{array}{l}\text { Five Sites: } \\
\text {-New } \\
\text { Haven, CT } \\
\text {-Baltimore, } \\
\text { MD } \\
\text {-St. Louis, } \\
\text { MO } \\
\text {-Durham, } \\
\text { NC } \\
\text {-Los } \\
\text { Angeles, CA }\end{array}$ & - & $\begin{array}{l}\text { Participants were taken from } \\
\text { The National Institute of } \\
\text { Mental Health } \\
\text { Epidemiological Catchment } \\
\text { Area Study of non- } \\
\text { institutionalized adults living } \\
\text { in American communities } \\
7,103 \text { parents with no } \\
\text { maltreatment reports at Wave } \\
\text { I were included in the study }\end{array}$ & $\begin{array}{l}\text { - } 15.1 \% \text { of parents who committed a new } \\
\text { act of child physical abuse had a } \\
\text { substance use disorder compared to } 5.7 \% \\
\text { of control parents } \\
21 \% \text { of parents who committed a new act } \\
\text { of child neglect had a substance use } \\
\text { disorder compared to } 5.7 \% \text { of control } \\
\text { parents } \\
\text { Parents with diagnosed substance use } \\
\text { disorders were } 2.9 \text { times more likely to } \\
\text { physically abuse their children and } 3.2 \\
\text { times more likely to neglect their } \\
\text { children. }\end{array}$ \\
\hline
\end{tabular}


Table 2.1 (continued).

\begin{tabular}{|c|c|c|c|c|}
\hline \# & Publication & $\begin{array}{c}\text { Location of } \\
\text { Study }\end{array}$ & Study Participants & Main Findings \\
\hline 7. & $\begin{array}{l}\text { Young, Boles, } \\
\text { \& Otero } \\
(2007)\end{array}$ & $\begin{array}{l}\text { Nationwide } \\
\text { Review of } \\
\text { the } \\
\text { Literature }\end{array}$ & $\begin{array}{ll}\text { Review of studies involving: } \\
-\quad \text { Pregnant women } \\
-\quad \text { Infants born with prenatal } \\
\text { substance exposure } \\
\text { - } \quad \text { Parents of minor children } \\
\text { admitted to treatment facilities } \\
\text { - } \quad \text { CPS-involved parents } \\
\text { receiving in-home services } \\
\text { CPS-involved parents with child in } \\
\text { out of home care }\end{array}$ & $\begin{array}{l}\text { - An estimated } 1,082,947 \text { parents of minor } \\
\text { children were admitted to publicly } \\
\text { funded addiction treatment facilities in } \\
2004 \text { ( } 408,460 \text { mothers; } 674,487 \text { fathers). } \\
\text { It is estimated that } 22,440 \text { child victims } \\
\text { who received in home services had } \\
\text { parents who meet criteria for SUDs. For } \\
\text { child victims in out of home care (i.e., } \\
\text { foster care, residential facilities) the } \\
\text { estimate is between } 128,640 \text { to } 211,720 \\
\text { parents. } \\
\text { Epidemiological studies estimate that } 8 \% \\
\text { to } 11 \% \text { of babies born each year in the } \\
\text { U.S. are born exposed to alcohol or } \\
\text { illegal drugs. This results in } ~ 328,000 \text { to } \\
\sim 451,000 \text { babies with prenatal substance } \\
\text { exposure out of the total } 4 \text { million annual } \\
\text { live births. }\end{array}$ \\
\hline
\end{tabular}

Notably, most of the studies conducted report results that explicitly pertain to CPSinvolved mothers. In spite of the fact that males are estimated to be as much a five times more likely than females to develop SUD’s (Brady, Grice, \& Dustan, 1999), this feature of the literature reflects the reality that the majority of CPS cases pertain to the child's mother. In spite of the known benefits to having an engaged paternal presence in cases, a number of reasons for the absence of fathers in CPS casework have been proposed in the literature. These include views of fathers as problematic for achieving desired case outcomes (Brown, Callahan, Strega, Walmsley, \& Dominelli, 2009) and relational discord between parents (Perry, Rollins, Sabree, \& Grooms, 2016).

In addition to sex differences in prevalence rates of SUD, important distinctions have also been made between the unique treatment needs of women and men and how providers can tailor their services accordingly (Grella, 2008; Covington, 2002). This being the case, future solutions to these co-occurring problems will inevitably need to find ways to both encourage the participation of fathers as well as draw from the broader knowledge base of 
fields concerned with women's health (Golder, 2007; Hall, Golder, Conley, \& Sawning, 2013; Berlyn, Wise, \& Soriano, 2008).

\section{Data from Kentucky}

Prevalence statistics in Kentucky are consistent with the findings presented in Table 2.1, and fall within the range outlined there. According to the 2016 annual report issued by Prevent Child Abuse Kentucky (PCAK), there were 54,263 CPS reports in the state (involving 75,710 unique children) that met necessary criteria for investigation. Of these reports, 15,612 cases (involving 22,090 unique children) were determined to be substantiated or in need of services (Prevent Child Abuse Kentucky, 2016). These figures indicate an average of between one and two children involved in each substantiated report

$\left(\frac{22,090 \text { children }}{15,612 \text { cases }}=1.4\right.$ children per case $)$. Of particular relevance to this study, PCAK (2016) found that substance abuse was documented as a risk factor in $61 \%$ of the substantiated or "services needed" maltreatment reports.

Tragically, $47 \%$ of children in those reports were 5 years old or younger; meaning that the incident of maltreatment occurred in the midst of that critical development period in the earliest years of life. This finding is also consistent with existing literature that demonstrates that the youngest children in a given population are the most at risk for maltreatment (Berger, 2004). Furthermore, consistent with Hussey, Chang, \& Kotch (2006), neglect was also the most common form of maltreatment, with 21,407 children involved in incidents of neglect $(75.1 \%$ of the sample). It is on these grounds that this study elected to choose the youngest child in a given case for inclusion in the analyses. Race, Poverty, \& the Child Welfare System 
As researchers have conducted this work at the level of populations, they have detected demographic anomalies that appear to be the result of past and present racial and economic injustices. Specifically, several studies have identified associations between a family's membership in racial and socioeconomic groups and their experiences with the child welfare system. Broadly, investigators have noted that Black children's presence in the child welfare system is disproportionate to their representation in the broader U.S. population (Shaw, Putnam-Hornstein, Magruder, \& Needell, 2008; Boyd, 2014).

More specifically, in a study of young children who entered out-of-home care in California in 1988, Barth (1997) found that Black children were significantly less likely to be reunified with their parents (41\% of Black children vs. $58 \%$ of White children) and were also significantly less likely to be adopted when compared with White children (11\% of Black children vs. $24 \%$ of White children). Other authors have written about these associations, and have pointed to the presence of institutional biases and the role of residing in communities of concentrated poverty in manifesting these racial differences (Hines, Lemon, Wyatt, \& Merdinger, 2004). When substance use is factored into this picture, it contributes its own influence to investigations but cannot alone account for racial differences. For example, if Black parents were using substances in high-risk ways at a higher rate than their White counterparts, this could explain some of the observed differences in their experiences with CPS. However, evidence suggests that this is not the case, and that no significant differences in high-risk substance use exists between racial groups (some studies even show Whites to have higher rates of use; Petry, 2003; Rote \& Taylor, 2014).

This being said, there are essentially two hypotheses offered in the literature to explain observations of disproportionate representation of Black families in CPS. Either the 
rates of maltreatment truly differ significantly by racial groups and CPS agencies are responding appropriately (the so-called "risk hypothesis"; see Drake et al., 2011), or they do not and the difference lies in the way that CPS agencies are choosing to direct their efforts (the so-called "bias hypothesis"; see Drake et al., 2011). The conclusions that the field comes to with regard to interpretations of this phenomena bear on subsequent policy and practice decisions. Reforms based on the former hypothesis would aim to address the disparity by addressing underlying causes (e.g., poverty, unsafe communities), while reforms based on the latter would aim to address it using education, training, and punishment initiatives with the human services workforce. While supporting evidence exists in support of both hypotheses, incorrect interpretations risk allowing racial bigotry to remain unchecked on the one hand, and leaving genuinely endangered children in unsafe homes on the other.

Scholars in the "risk" camp argue that the disproportionality is best explained by past and present social policies that have disadvantaged minority groups in terms of access to quality housing, education, and employment, and that these have resulted in a genuine increased risk for child maltreatment against children in these groups (Bartholet, 2009). Using data collected by four waves of the National Incidence Study of Child Abuse and Neglect (NIS-1 - NIS-4), Drake and colleagues (2011) tested these two hypothesis by comparing ratios of reported cases of maltreatment to public health data that was less subject to potential racial biases (e.g., infant death by homicide confirmed by an autopsy).

Results of the analysis found that the data supported the risk hypothesis more strongly than the systemic bias hypothesis. A White/Black disproportionality ratio of 1:1.84 was found in maltreatment reporting, yet White/Black disproportionality ratios for the measures that were less susceptible to bias were comparably higher than expected if racial profiling 
alone could explain differences in CPS reporting (e.g., infant accidents: 1:2.97; SIDS cases: 1:1.79; low birth weight: $1: 1.92$; premature birth: $1: 2.56)$. In their discussion of these results, although not precluding the presence of racially biased reporting, the authors recommended that the best way to reduce disparities in CPS populations would be to address the underlying issues that predispose Black children to maltreatment (namely poverty and other broader ecological risk factors).

Scholars in the "bias" camp posit that disproportionate representation of Black children is due to direct and purposeful systemic racial bias and profiling mechanisms in the child welfare field. There are a number of features of the child welfare workforce as well as historical cases where supporting evidence can be found. First of all, the demographic composition of the child welfare workforce creates an environment whereby most decisions to investigate reports, substantiate investigations, or remove children from Black families will be made by White female professionals (Barth, Lloyd, Christ, Chapman, \& Dickinson, 2008).

While this in and of itself may not have arisen out of malevolence, it should be cause for careful consideration of the role that race and historical injustices often play in CPS work. This is especially true in light of episodes in the past where transracial adoption policies were implemented in harmful ways. Examples of this involve historical cases of broad policies where Black children were placed with White adoptive parents against the desires of Black communities (Carter-Black, 2002) and cases where Native American children were placed with White adoptive parents to "cleanse" them of their cultural heritage (Palmiste, 2011).

In an empirical test of this hypothesis, Dettlaff and colleagues (2011) investigated 186,182 alleged cases of child maltreatment from the Texas Department of Family and 
Protective Services. The authors then tested the results of two multivariate logistic regression models: one that tested whether race was a significant predictor of substantiation when all things were held equal, and a second that added CPS worker risk assessment scores. In the first model, there were no significant differences between racial groups aside from Latino families being significantly less likely than White families to receive substantiations. Household income was a much stronger predictor of substantiation in the first model, with lower income families being almost twice as likely as higher income families to have their case substantiated. However, in the second model, Detlaff and colleagues (2011) found that adding the risk assessment variable resulted in the race variable emerging as a significant predictor of substantiation. In their interpretation of these results, the authors suggested that their results may indicate the presence of the fundamental attribution error in CPS worker decision-making. In other words, poor White families were deemed to be at higher risk for harming their children because they were poor, and poor Black families were deemed to be at higher risk because they were poor and Black (Dettlaff et al., 2011).

The history of race-based slavery in the U.S. (as well as the subsequent prejudicial social policies established after the abolition of slavery) has left a legacy that is evidenced by present-day realities. Specifically, Black and other racial minority children have entered the child welfare system at higher rates than their peers of other races. These studies illustrate the dynamic ways that families interact with child welfare organizations and, therefore, how many decision points exist where bias can enter individual case encounters (e.g., reporting, investigating, substantiating, removing, and referring to services).

Child welfare scholars have long known that these racial dynamics are present in CPS casework. The explanation for this phenomenon is complex, and the aforementioned 
hypotheses are not entirely mutually exclusive. It is undeniable that many families are reported to CPS because the reporter holds racially bigoted views. It is also true that other families are appropriately referred to CPS by reporters who are genuinely concerned for the wellbeing of a child. Those cases can then be conducted by competent professionals who justifiably deem the home to be unsafe for that child to remain in. This is often how biased and prejudicial thinking becomes entrenched: once it has achieved sufficient cultural power, it can create the means for its own self-perpetuation. In other words, once a group becomes relegated to second-class citizenship, the strain of that status will often beget further social problems, which then serve to reinforce the original idea in the minds of the dominant group that the people they have disadvantaged are inherently inferior to them (i.e., are inept parents, are incapable of managing a family and household, etc.). The presence of substance use (yet another marker of stigmatization) can exacerbate this dynamic in society.

The nature of this process, in addition to the multiple variables present in each individual case, create difficulties for researchers to pinpoint the precise reasons for the observed racial disparities. Despite some differences of opinion, the existing literature suggests three macro-level efforts to address this problem:

(1) Encourage the hiring and retention of child welfare professionals that belong to racial minority groups.

(2) Create initiatives to educate professionals about the harmful effects of bias in their practice.

(3) Participate in broader efforts to reduce the ecological risks for maltreatment, such as poverty, teenage pregnancies, and the dissolution of supportive families (e.g., mass incarceration).

Kentucky is a predominantly White state - especially in the areas outside urban communities such as Louisville. However, there are several families that have been served by START that belong to racial minority groups, and for the reasons outlined above, a child's 
race was included as a matching variable in the construction of the comparison group. A more comprehensive discussion of the effects of race and poverty on child welfare decision making, along with future directions for research is presented in Boyd (2014).

\section{Consequences and Contributors of Substance Use Disorder and Child Maltreatment}

\section{Health Consequences}

There are real health consequences for these families and their children. Responsive, caring bonds between children and their parents are essential for healthy child development. While cases of sexual abuse or child homicides are extraordinarily upsetting and make newspaper headlines, cases of extreme neglect (especially of newborns and infants) are far more prevalent and are especially damaging to neurological development. Parents of very young children bear the enormous responsibilities of teaching them (among many other things): which settings are safe and which are dangerous, which people are trustworthy and which are not, and that they can rely on their caregivers to meet their basic needs for survival. These duties are especially difficult to perform under the chronic influence of drugs or alcohol.

Neuroscientists have been able to describe the neural mechanisms behind this teaching process. When infants cry out for their parents, their sympathetic nervous system activates, which signals two primary stress response regions in their brains (the sympathetic adrenal medullary and the hypothalamic pituitary axis) to elevate adrenaline and cortisol levels in their bodies (Center on the Developing Child at Harvard University, 2012). This reaction gives rise to an elevated heart rate, rapid and shallow breathing, and feelings of distress. When parents lovingly respond to their infants, their children's brains engage their parasympathetic nervous systems, which brings their heart rate back down, slows their 
respirations, and soothes them. If their cries are chronically not responded to and they are routinely neglected, serious damage can result in critical brain regions associated with coping with stress, attention, memory, and behavioral regulation (Eluvathingal et al., 2006). Notably, these are some of the very regions that have been implicated in SUD. Brain imaging studies have also found evidence of cortical atrophy and other abnormalities in children who were severely neglected as infants, especially in the prefrontal cortex region (Center on the Developing Child at Harvard University, 2012).

These results are exemplified by the Bucharest Early Intervention Project (BEIP), which investigated the experiences of children who grew up in brutal orphanages set up by Romanian dictator Nicolae Ceausescu (Zeanah et al., 2003). In 1966, Romania's communist regime passed decree 770 , which aimed to drastically increase the country's population by, among other means, outlawing abortion and contraception for Romanian women. Decree 770 resulted in a generation of children who were sent to draconian orphanages that were so understaffed that children were left alone for long periods. In 1989, Ceausescu's regime fell and the countries of Western Europe and North America began to discover the horrors that had been endured by the children housed in these institutions. Researchers that toured these facilities commented on how eerily quiet they were - the children had learned that there was no use in crying out for someone to come attend to them. The families that adopted these children noted that many of them had serious problems in terms of social interactions with others, executing cognitive tasks, and interpreting the emotions of their peers (Zeanah et al., 2003). What has been learned from that episode in history is illustrative of how devastating it can be when children's need for human interaction and responsive care from their parents and caregivers go unmet. 


\section{Adverse Childhood Experiences}

A similarly impactful study was conducted to investigate the effects of some of the more common adverse childhood experiences in this country (hereafter abbreviated ACE's). Those studies demonstrated a number of remarkable and previously undocumented relationships between some of the most commonly experienced ACE's (e.g., physical abuse, a parent's mental illness, divorce, etc.) and a set of adult health outcomes.

In the original ACE study, Vincent Felitti and his colleagues (1998) demonstrated these associations using a large sample of predominantly White, middle-income adult patients $(n=9,508)$. When compared to those without any childhood trauma, patients who reported experiencing 4 or more of the ten most common ACE's had a strikingly increased risk for high-risk substance use, depression, and attempting suicide (ranging from a 4-fold increase to a 12-fold increase). They were also significantly more likely to engage in a set of unhealthy behaviors (e.g., cigarette smoking, high-risk sexual behavior, poor diet, etc.; Felitti et al., 1998).

The series of studies that have followed after their example have consistently demonstrated that the association between ACE's and adult health measures is not linear, but multiplicative. For example, Dube, Felitti, Dong, Giles, and Anda, (2003) found that individuals with $1 \mathrm{ACE}$ were 1.5 times more likely to attempt suicide than their peers with none - but the odds increased to 10.9 times for those with 4 or more ACE's. This is especially concerning for child welfare officials working cases of substance-related maltreatment, because parental substance use can substantially increase children's risk of exposure to all ten of the identified ACE categories (parental substance abuse is itself one of the categories). 
Notably, the most commonly used categories of child maltreatment (refer to table below), were categorized as ACE's in the studies. Additionally, there exists empirical evidence of associations between substance use and increased incidence of divorce (Leonard, Smith, \& Homish, 2014), domestic violence (Stuart et al., 2008), mental illness (Kessler, 2004), and incarceration (Bush-Baskette, 2000; Dube et al., 2001) (i.e., all of the other ACE categories).

\section{Table 2.2}

\begin{tabular}{|c|c|c|}
\hline Child Abuse & Child Neglect & Household Dysfunction \\
\hline Sexual Abuse & Physical Neglect & Mental Illness in Home \\
\hline Physical Abuse & Emotional Neglect & Substance Abuse in Home \\
\hline Emotional Abuse & & Divorce of Parents \\
\hline
\end{tabular}

*Felitti et al., 1998; Centers for Disease Control and Prevention

Beyond the effects this kind of maltreatment can have on adult health problems later in life, there are very real consequences for these children while they are still young. These effects are so prevalent that child victims regularly come into contact with the healthcare system. For example, Keshavarz, Kawashima, \& Low (2002) found that parental substance use was associated with confirmed cases of child abuse diagnosed in a New York City pediatric emergency department. Among the most common diagnoses in that study were: bruises (24\%), lacerations or abrasions (20\%), and burns (10\%) (Keshavarz et al., 2002).

There is also noteworthy evidence that child maltreatment accounts for a large percentage of inpatient days admitted to pediatric hospitals (Wright \& Litaker, 1996; Rovi, Chen, \& Johnson, 2004). Among these admissions, a notable proportion of children are covered by Medicaid plans compared to other forms of health insurance (Leventhal, Martin, \& Gaither, 2012). Sadly, the full national burden of injury and illness associated with child 
maltreatment amounts to the fourth leading cause of childhood deaths; most heavily affecting the youngest and most vulnerable children (Guenther et al., 2009). Perhaps even more tragically, an investigation by King, Kiesel, \& Simon (2006) found that $19 \%$ of children who died from abuse were seen by a healthcare professional within a month prior to their death. Consequences to Social Life, Educational Performance, and Generational Cycles of Abuse

These health and developmental consequences often translate to a series of difficulties for affected children. Exposure to childhood trauma has been linked to a number of challenges in terms of social functioning. In a study of 87 physically abused 8-12 year olds in a New York City school setting, Salzinger, Feldman, Hammer, \& Rosario (1993) noted that abused children had a lower peer status and less positive reciprocity with their friends. Additionally, they were rated by their peers to be more aggressive and less cooperative. Parent and teacher participants deemed the abused children as less socially competent than the 87 comparison children who had not experienced abuse.

Other authors have noted that these social problems can persist into adult relationships. In a prospective study of 1,196 children born between 1967 and 1971, Colman and Widom (2004) found that men and women who had been victims of child maltreatment were more likely to divorce their spouse or walk out on their romantic partner. Males and females appeared to respond to maltreatment in unique ways, as some outcome variables in the analyses differed by sex. Female victims of childhood maltreatment were more likely than non-victims to be unfaithful sexually, but this result did not hold true for males. Perhaps counterintuitively, male victims of physical abuse were more likely than non-victims to endorse high marital satisfaction, but this was not true for females (Colman \& Widom, 2004). 
In a review of the international literature on the burden of child maltreatment to rich countries, Gilbert and her colleagues (2009) found that experiencing childhood abuse or neglect was also associated with a number of educational variables. Among these were: greater likelihood of enrolling in special education classes, decreased likelihood of graduating from high school, and lower educational attainment over the lifespan. These educational deficits appear to transfer to occupational outcomes; a prospective study by Widom (1998) found that adult workers who had been abused as children were significantly less likely to be working in managerial or professional jobs when compared to a control group. The Widom (1998) study also found that the cohort of adults who had experienced abuse as children were significantly more likely to be underemployed than the control group.

An extensive literature in the medical and social sciences has described the relationship between an individual's experience of maltreatment as a child and their subsequent maltreatment against their own children. A discussion of such relationships can be found in Zuravin, McMillen, DePanfilis, and Risley-Curtiss (1996), Dixon and colleagues (2005), and Brown, Cohen, Johnson, and Salzinger (1998). Maltreatment occurs in environments that often contain other known risk factors, and for this reason it is difficult to isolate the unique contribution of victimization on an individual's propensity to go on to harm their child. In spite of this reality, a number of studies have attempted to control for confounding variables and still found evidence that an adult's commission of child maltreatment can be a consequence of their own experience of maltreatment as a child.

One example involved a study of 499 mothers and their infants in the Southeastern U.S. In this research Berlin, Appleyard, and Dodge, (2011) investigated the extent that a mother's experience of abuse in her childhood was associated with her infant child being 
abused in the home within the first 26 months after birth. The study design compared survey results to state child abuse records and was thus limited to only being able to report whether a child had been a victim of abuse, and not whether the mother herself had been the alleged culprit (i.e., a boyfriend or relative in the home may have been the named adult on the case). Their analysis found that mothers who experienced physical abuse themselves were 19\% more likely to have children who were victimized by the age of 26 months than mothers who did not experience abuse as children.

However, they also pointed out that $83 \%$ of the mothers who experienced physical abuse did not have victimized children by 26 months - meaning that abuse did increase the likelihood of contact with CPS in the study sample, but by no means guaranteed it. Similar results were found by Pears \& Capaldi (2001), who found that, even when risk factors such as socioeconomic status were controlled for, experiencing childhood abuse was associated with a $23 \%$ increased likelihood of intergenerational transmission of abuse.

These results must be interpreted in light of the retrospective study design used in many tests of the intergenerational transmission hypothesis. There is disagreement within the field about the strength of these associations, and some have pointed to problems related to other methodological decisions and detection bias as a cause for inflated estimates (Widom, Czaja, \& DuMont, 2015). Beyond this, there is still no clear consensus about the mechanism by which intergenerational cycles of abuse happen. Likely candidates involve social learning of harsh disciplinary practices, development of mental health and substance use problems as a result of abuse, and the disruption of healthy parent-child attachment (Belsky, Conger, \& Capaldi, 2009). 
While this effect is real, additional study is required to more properly understand it. Moreover, results of such analyses should be communicated with competence and sensitivity to the audiences that hear them. Real harm can be done to victims of child abuse when authorities intending to educate the public inadvertently tell people that they are doomed to repeat what happened to them. In their strident rebuke of such narratives, Kaufman and Zigler (1987) called this phenomenon the "intergenerational myth." One line from their work is particularly instructive here: "The time has come for the intergenerational myth to be put aside and for researchers to cease asking, 'Do abused children become abusive parents?' and ask, instead, 'Under what conditions is the transmission of abuse most likely to occur?'” (Kaufman \& Zigler, 1987, p. 191).

Consequences to the Foster Care System

The extent of this maltreatment is also felt by foster care systems. While the current surge in opioid overdoses and other opioid-related problems is harrowing, it is important to note that this is not the first time the U.S. has faced a drug epidemic. Before the present prescription opioid and heroin crisis, there was an earlier heroin crisis in the late 70's, a cocaine crisis in the 1980's, and a methamphetamine crisis in the 1990's - which lasted into the early 2000's (Courtwright, 2009). Amongst the ER visits, the arrests, and the surges in gang violence that accompanied these historical episodes, another theme was present: enormous swells in the number of children entering foster care systems (Kohomban, Rodriguez, \& Haskins, 2018; Cunningham \& Finlay, 2013; Smith, Johnson, Pears, Fisher, \& DeGarmo, 2007; Mowbray, Victor, Ryan, Moore, \& Perron, 2017).

Such cases were reported by media outlets across the nation. These cases often began in the ways outlined earlier in this report. For example, substance-exposed births are often 
removed from their mothers after delivery, children are removed from homes after their parents have been incarcerated as a result of drug offenses, and, in extreme cases, children are also brought into foster care when their parents die of overdoses. Despite these established relationships, many states get caught unprepared when drug epidemics begin to manifest themselves within their borders.

When these problems start to harm their electorates, policy makers tout initiatives to increase funding for treatment or train new police officers and EMT's. However, similar initiatives to shore up foster care systems for the influx of new children get less attention. Children cannot vote or pay taxes, so campaign promises to protect the interests of the children of substance-using parents seldom generate the same cachet as other policy proposals. These circumstances effectively create conditions where the supply of foster homes and residential facilities get overwhelmed by increased demand.

Moreover, successful placement of children with substance-using parents (especially those who were prenatally exposed) require foster parents to possess special skills and resources (Marcellus, 2010). Whether it be out of a lack of confidence in their ability to meet those children's needs or out of stigmatized beliefs about substance use, many foster parents avoid taking such children into their homes. All of this leaves CPS workers in challenging circumstances.

\section{Economic Consequences}

Economic estimates have found that both the experience of maltreatment as a child and the behaviors associated with SUD are related to a number of adverse economic consequences to society. These consequences are most often grouped into categories that include (in order of their relative costs): (1) lost workforce productivity and taxable income 
(e.g., fewer days worked, less tax paid, etc.), (2) preventable healthcare consumption (e.g., emergency room visits for drug-related health problems, transmission of infectious diseases, premature deaths, etc.), (3) crime (e.g., days spent in jails and prisons, costs to court systems, etc.) and, (4) consumption of government social welfare programs (e.g., SNAP, Social Security Disability, TANF, etc.). Though there is little published literature that estimates the unique costs associated with cases of co-occurring parental substance use and child maltreatment, there is a significant body of knowledge that establishes the financial costs associated with these two problems independently.

\section{The Societal Costs of Child Maltreatment}

In an analysis of the total annual economic burden of child maltreatment in the U.S., Fang and colleagues (2012) estimated a lifetime cost of all cases of child maltreatment during a 1 year period to be approximately $\$ 124$ billion (combined nonfatal and fatal cases). These analyses were based on child maltreatment incidence data provided to the U.S. Department of Health and Human Services for the year 2008. Acknowledging the conventional understanding that CPS data significantly underestimates the true prevalence of child maltreatment, Fang and colleagues (2012) tested their results under a series of assumptions. In the highest cost scenario, when the authors conducted a sensitivity analysis assuming that each case that CPS agencies investigated was a true substantiated incidence of maltreatment, their lifetime cost estimate soared to $\$ 585$ billion.

Their analyses of non-fatal child maltreatment cases estimated a lifetime per-case cost of $\$ 210,012$ (in 2010 dollars). This included $\$ 144,360$ in lost economic productivity, $\$ 32,648$ in pediatric health care costs, $\$ 10,530$ in adult medical costs, $\$ 7,999$ in special education costs, $\$ 7,728$ in costs associated with child welfare services, and $\$ 6,747$ in criminal justice 
costs. In cases of maltreatment that resulted in the death of the child, the estimated average lifetime cost per case in 2008 was $\$ 1,272,900$. This included $\$ 14,100$ in medical costs and $\$ 1,258,800$ in productivity losses.

In a separate report written for Prevent Child Abuse America, Gelles and Perlman (2012) presented economic estimates using a different method. Rather than describing lifetime estimates broken down into non-fatal and fatal cases, they took data from 2005-2006 and divided costs into annual direct costs (e.g., acute medical treatment of children, costs of administering child welfare systems, etc.) and indirect costs (e.g., special education, emergency housing and shelters for homeless youth, later commission of crime, etc.). Adjusted to reflect the value of a U.S. dollar in 2012, their analyses generated annual direct cost estimates of $\$ 33.33$ billion and annual indirect costs estimates of $\$ 46.93$ billion, for a sum of $\$ 80.26$ billion per year attributable to child maltreatment in the United States.

More specifically, a study conducted by a CDC-funded research group that is particularly relevant to this effort estimated that child maltreatment accounts for approximately $9 \%$ of all annual Medicaid claims for children (Florence, Brown, Fang, \& Thompson, 2013). The study authors used nationally representative data from the National Survey of Child and Adolescent Well-Being and then utilized PSM to match children who had experienced maltreatment with those who had not. They then obtained Medicaid claims data for the sample and matched those datasets.

What they found was striking: children with an allegation of maltreatment that had been investigated by a local CPS agency were associated with an average annual spend that was greater than $\$ 2,600$ higher than children without any CPS contact (Florence et al., 2013). The observed differences in costs between the matched groups were especially significant for 
psychiatric services, inpatient hospitalizations, and outpatient physician visits. In their discussion of their results, Florence and colleagues asserted that their analyses suggest that the child maltreatment-related healthcare costs account for approximately $\$ 5.9$ billion dollars annually for the Medicaid program. As a consequence, they suggest that child maltreatment prevention efforts could drive a significant cost reduction to state Medicaid programs.

\section{The Societal Costs of Substance Use and Substance Use Disorder}

It is difficult to generate a broad estimate of the true societal costs of substance use for a number of reasons. First among these is the reality that many studies separate their cost estimates by category of substance use (e.g., cocaine, heroin, alcohol). This is an artificial representation of reality, because it is well known that many substance users are polysubstance users. Therefore, while many individuals might have a "drug of choice", forcing them into study groups such as "cocaine users" or "heroin users", is likely to distort conclusions regarding which substance to attribute their economic behavior to (Conway et al., 2006; Ogbu, Lotfipour, \& Chakravarthy, 2015). This issue notwithstanding, associations between substance use and the economic consequences listed above are well-established in the literature (French \& Drummond, 2005).

It is often lost in the present media coverage, but even in light of increased opioid overdose deaths, alcohol and tobacco still account for considerably more harm to the public health of the U.S. They are the most widely consumed addictive substances in the United States, and are related to significant national disease burden. According to data collected by the National Center for Health Statistics, those two substances account for a large proportion of the top five causes of death in this country (\#1 - heart disease, \#2 - cancer, \#3 - 
unintentional injuries, \#4 - chronic lower respiratory diseases, and \#5 - stroke; see Kochanek, Murphy, Xu, \& Arias, 2017).

In an analysis of the national economic burden of excessive drinking conducted by Bouchery, Harwood, Sacks, Simon, and Brewer (2011), the authors estimated a \$223.5 billion cost in 2006 (approximately $\$ 1.90$ per alcoholic drink consumed that year). This estimate broke down into $\sim \$ 161.4$ billion from lost productivity (72.2\% of total), $\sim \$ 24.6$ billion from healthcare costs (11.0\% of total), $\$ 21$ billion from criminal justice costs $(9.4 \%$ of total), and $\sim \$ 16.8$ billion ( $7.5 \%$ of total) from other costs.

In a similar analysis conducted using data collected from illicit prescription opioid users, Birnbaum and colleagues (2006) estimated an annual cost of \$8.6 billion in 2001 dollars ( $\$ 12.3$ in 2018 dollars). Broken down by cost variable, illicit prescription opioid use accounted for $\$ 2.6$ billion in healthcare costs, $\$ 1.4$ billion in criminal justice costs, and $\$ 4.6$ billion in workplace costs and lost productivity. Lastly, a study conducted by Mark, Woody, Juday, \& Kleber (2001) estimated that heroin addiction accounted for a $\$ 21.9$ billion cost to society in 1996. Of these total costs, lost productivity accounted for 53\% (\$11.5 billion), crime accounted for $24 \%$ ( $\$ 5.2$ billion), medical care accounted for $23 \%$ ( $\$ 5.0$ billion), and social welfare expenditures accounted for $0.5 \%$ (\$109 million).

While not an exhaustive list, the above section has outlined some of the most detrimental consequences of co-occurring high-risk substance use and child maltreatment. While many of the interventions for this problem are focused on ensuring the safety of children and promoting the wellness of their parents, the reality is that many other parties have a stake in their success. As discussed above, these families often require additional services from the educational system, the healthcare system, and public agencies such as CPS 
and the courts. Just as the consequences can be found at the micro and macro level, so too can the contributors. This section will now move on to a review of some of the most wellestablished of those contributors.

\section{Contributors: Risk and Protective Factors}

As stated above, there is a complex intergenerational dynamic for these families. Therefore, the conclusions that a given researcher draws from their data are necessarily contingent on which generation they choose to investigate. Though it is clear that high-risk substance use is prevalent in CPS populations, it is not yet clear which unique factors contribute to this problem. In other words, much is known about the factors that uniquely increase a person's risk for developing an SUD or harming their children (many of which are shared). However, what it is less clear is how the risk profile of a substance using CPS parent differs from that of a non-substance using CPS parent. Whether these two problems are the result of independent causal structures that ultimately intersect or twin manifestations of some single underlying mechanism is unknown. More work is required to understand the moderating and mediating effects of the known risk factors and how they interact with protective factors and other experiences to predispose families to co-occurring substance use and child maltreatment (Briere \& Jordan, 2009).

No single variable is determinative of whether a parent will harm their child as a result of their substance use. As has been described for other health conditions, this risk profile is really the result of dynamic interactions between variables that increase risk (i.e., risk factors) and those that decrease it (i.e., protective factors). These factors exist both within individuals as well as the environments they live in. Taken together, a collection of existing studies have described profiles where a high count of risk factors and a low count of 
protective factors reliably increases the likelihood that a parent will harm their child as a result of substance use.

This section will outline contributors to substance use-related child maltreatment by reviewing the literature on some of the most prominent risk and protective factors associated with high-risk substance use and with child maltreatment. While it is important to remember that statistical outcomes from large samples are of limited use in explaining individual circumstances, a robust knowledge of these factors affords practitioners and policy makers with valuable targets for intervention.

\section{Risk Factor: Genetic Profiles}

Using epigenetic research methods, medical researchers have modeled some of the complex gene/environment interactions explaining the prevalence of SUD in certain groups (Wong, Mill, \& Fernandes, 2011). Primarily, these discoveries have made it clear that SUD is a non-Mendelian condition (i.e., no single gene accounts for whether or not it is passed from parent to child or whether an individual develops it). This reality is easy for clinicians to accept, as there are numerous cases in practice where clients do not have an SUD in spite of an extensive family history. The research suggests a much more dynamic causal mechanism that consists of an individual's genotype, environment, and personal choices. Specifically, in terms of these gene/environment relationships, one especially salient finding that consistently emerges in the research is that prolonged periods of extreme stress interact with genetic material to substantially increase the likelihood that individuals will develop SUD. For another example, Maze and Neslter (2012) demonstrate that the act of repeatedly consuming cocaine alters the genetic behavior of cells in the nucleus accumbens, and report an estimate that approximately $50 \%$ of the risk for SUD can be explained by genetics. 
In a review of adoption, family, and twins studies of addiction, Agrawal and Lynskey (2008) reviewed results that found first-degree relatives of individuals with SUD's to be eight times more likely to have an SUD diagnosis themselves when compared to a control group. The review also outlined the results of an adoption study where 55 male children of alcoholics were adopted into non-alcoholic homes. Compared to adopted children of nonalcoholic biological parents, children of alcoholics were more likely to have received treatment for alcoholism (9\% vs. $1 \%)$ and meet criteria for alcoholism (18\% vs. $5 \%)$ than controls (Agrawal \& Lynskey, 2008).

Such genetic associations are not quite the same for risk for child maltreatment. However, a recent study suggests there may exist some genetic component to the commission of sexual crimes (sexual abuse of children being one of them; Långström, Babchishin, Fazel, Lichtenstein, \& Frisell, 2015). Their study compared the male relatives of 21,566 Swedish men convicted of a sexual crime over a nearly 37 year period (1973-2009) to the male relatives of control individuals who were not convicted of sexual crimes. In their analyses, brothers of men convicted of child molestation were 5.9 more likely to also be convicted of child molestation than control brothers. Fathers of those same men were 4.3 times more likely to have committed such a crime. Their results also found that $46 \%$ of the variance in child molestation was accounted for by heritability. There is evidence that certain genetic profiles may be associated with aggression more broadly (Anholt \& Mackay, 2012), but further study is warranted to determine how this translates to individual predisposition to harm children. Furthermore, although there is evidence that the biologic correlates of experiencing child maltreatment (e.g., extreme chronic stress, sensitization of the sympathetic nervous system) can alter genetic processes and lead to later psychopathology, 
there is little evidence that there is such a thing as a "child abuse gene" (McCrory, De Brito, \& Viding, 2012).

\section{Risk Factor: Poverty}

Another important factor to consider in terms of individual risk is poverty and its associated stressors. While associations between poverty and SUD have been found, it is one of the most extensively studied risk factors associated with child maltreatment (Coulton, Crampton, Irwin, Spilsbury, \& Korbin, 2007; Drake \& Pandey, 1996; Schneider, Waldfogel, \& Brooks-Gunn, 2017). Associations between child maltreatment and the many manifestations of poverty (unstable housing, unemployment, food insecurity) are among the most consistent findings in the child welfare literature. For example, in a report delivered to the U.S. Congress, Sedlak and his colleagues (2010) found that families of low socioeconomic status in the Fourth National Incidence Study of Child Abuse and Neglect (NIS-4) were five times more likely to commit acts of child maltreatment than families of higher socioeconomic status.

Much of the research that connects poverty with increased likelihood of child maltreatment measures the degree of association between certain neighborhood factors and incidence of abuse and neglect (e.g., Drake \& Pandey, 1996; Coulton et al., 2007). Examining associations this way allows researchers to condense these variables into a single unit. While there is variation within neighborhoods, they are often predictive of a number of important factors. These often include:

○ Household income (paychecks, stock dividends, interest payments on bonds, etc.)

O Other assets (real estate, tangible assets, savings, etc.) 
- Social support and robustness of social networks (family connections, close friends, crime rates, etc.)

○ Prospects for the future (employment opportunities, projected inheritance, level of indebtedness, likelihood of going to prison, etc.)

○ Acquired knowledge, skills, and aptitudes (university degrees, socialization into professional cultures, etc.)

There have been multiple explanations offered to explain why poorer families are more prominently represented in CPS-involved populations. For maltreatment characterized by acts of omission (e.g., emotional neglect, medical neglect), many argue that poor parents are investigated by CPS simply because they are stretched too thin, and therefore statutory definitions of neglect essentially make involvement with CPS inevitable (i.e., "making it illegal to be a poor single mother"; see Pelton, 1997). For example, low wage work means many hours are required to earn sufficient income to support a family, and this can leave parents with too little time left over to look after their children's needs. In other cases, something such as postponing trips to the pediatrician's office out of aversion to paying a copay could look like medical neglect.

For maltreatment characterized by acts of commission (e.g., physical abuse), the prevailing explanation is that the stressors of poverty overwhelm parents' restraint. This hypothesis draws some credence from the psychological concept of willpower depletion (also known as ego depletion), which states that self-control is a finite resource that can be exhausted by prolonged episodes of stress or repeated tasks that require restraint. These explanations are more comprehensively summarized by Berger and Waldfogel (2011). Whatever the true underlying cause, repeated analyses have found that less income means more risk for children. In a few particularly striking examples of this, relationships have been observed between rates of child maltreatment and the financial strain on households 
associated with increases in cigarette taxes, gas prices, and sales taxes (McLaughlin, 2018;

McLaughlin, 2017).

\section{Protective Factors: Income}

As the oft-quoted statement goes, "Money cannot buy happiness, but it can prevent a lot of pain." In terms of child maltreatment, there is some evidence of the truth of this statement. While low incomes and financial hardship tend to predict involvement with CPS, alternately, financial security and material assistance tend to predict the opposite.

To test the effects of additional household income on the incidence of child maltreatment, a research team at the University of Wisconsin designed a study around a unique state child support policy (Cancian, Yang, \& Slack, 2013). At the time of the study, the state of Wisconsin allowed a subset of their TANF-receiving population to collect the full monthly amount of awarded child-support payments (a policy referred to as "full pass through and disregard"). The study used random assignment to either the "full pass through and disregard" group or a control group that was only allowed to keep $41 \%$ of the full monthly child support payment ("partial pass through and disregard"). In their regression model, the experimental group was estimated to be two percentage points less likely than the control group to have a screened-in case of child maltreatment (i.e., a case deemed worthy of investigation; Cancian et al., 2013). Notably, this result arose from a very modest annual between-group difference in family income (an average absolute amount of about $\$ 100$ per year).

These results do not represent isolated cases of the protective factors of improved financial security. Similar results have been found by Fein and Lee (2003) in Delaware; Slack, Lee, and Berger (2007) in Illinois; and Raissian and Bullinger (2017) in a 14-state 
sample. Notably, when compared to other forms of maltreatment, each of these studies found the most significant association between increased income and reduced reports of neglect. Such outcomes lend credence to the "stretched thin" hypothesis of poverty and neglect.

Results reported by Raissian and Bullinger (2017) are particularly striking in terms of this relationship. Their analyses sought to investigate whether an increase in the minimum wage at the state level was associated with decreased rates of child maltreatment. The authors analyzed minimum wage data from the National Conference of State Legislatures (NCSL) against child maltreatment data from the National Child Abuse and Neglect Data System (NCANDS) and reported results from 14 states (Alabama, Alaska, Connecticut, Idaho, Indiana, Kentucky, Maryland, Michigan, North Carolina, Ohio, Oklahoma, Tennessee, Vermont, and Virginia). Their results found that every $\$ 1$ increase in a state's minimum wage was associated with a $9.6 \%$ reduction in reports of neglect to CPS agencies (Raissian \& Bullinger, 2017).

While these studies do not explicitly report on substance use related maltreatment, it is reasonable to assume that decreased financial stress may also reduce the incidence of high risk substance use, as it is often used as a means of coping (Peirce, Frone, Russell, \& Cooper, 1994). Future studies would be wise to consider the effects of greater financial security on this subset of the broader CPS client population.

\section{Protective Factor: Social Support}

While increased financial security can be beneficial in and of itself, it is important to understand how it operates in tandem with other protective factors. For example, there is evidence that social support is beneficial for well-resourced families, but is especially protective against child maltreatment in low-income parents (Hashima, \& Amato, 1994; Li, 
Godinet, \& Arnsberger, 2011). Social support, conventionally described as the presence of caring individuals in one's life that provide material and emotional assistance with life's challenges, is a phenomenon that has received considerable attention by researchers in recent years. In the child welfare literature, studies have found that factors such as access to quality child care resources, help from friends and family members with daily family responsibilities, and the presence of caring relationships have all been shown to buffer against the risk that a child will be harmed in the home (Counts, Buffington, Chang-Rios, Rasmussen, \& Preacher, 2010; Li et al., 2011).

One such study was conducted by a team of researchers at the University of Hawaii. Using data from a consortium of studies called the Longitudinal Studies of Child Abuse and Neglect (LONGSCAN), Li and colleagues (2011) found a number of factors that decreased the risk of victimization among children aged 4-8 years. These factors included marriage (married mothers where 0.19 times as likely to mistreat their children as unmarried mothers); educational attainment (mothers who had attained 12 or more years of education were 0.09 as likely as less educated mothers to mistreat their children); and social support (mothers with a high level of support were 0.29 as likely as mothers with low levels of support to mistreat their children). Presumably, the protective nature of marriage is related to support from children's fathers, which can be manifested in a number of beneficial ways. This result is consistent with a body of knowledge that has documented a number of significant benefits that an active and engaged father has on young children (e.g., Perry, Rollins, Sabree, \& Grooms, 2016; Sarkadi, Kristiansson, Oberklaid, \& Bremberg, 2008).

Interestingly, $\mathrm{Li}$ and her colleagues (2011) found that the effect of social support was most robust for mothers with low educational achievement. One other notable protective 
factor that significantly reduced reported cases of maltreatment included regular church attendance; perhaps as a result of church congregations serving as an additional source of social support. These results are consistent with other studies that suggest that higher measures of family wellness, such as educational achievement and social support, reduce the likelihood that children will be abused or neglected by a caregiver (Martin, Gardner, \& Brooks-Gunn, 2012; Dubowitz et al., 2011; Counts et al., 2010; Hashima, \& Amato, 1994). Risk Factors: Child Age, Health Status, and Behavior

Beyond neighborhood factors and other measures of poverty, a number of studies have also documented that certain traits of individual children are associated with increased risk of maltreatment. While no child ever deserves to be mistreated by their parents, a number of analyses have found evidence that children with characteristics that make them more difficult to care for (e.g., premature birth, colic, severe disability, etc.) may be more liable to experience maltreatment than children without such characteristics (Sullivan \& Knutson, 2000; Hunter, Kilstrom, Kraybill, \& Loda, 1978; Brewster et al., 1998). While these associations consistently appear, discussions of such results typically acknowledge that other variables such as income and parental stress moderate the effects of child-level characteristics (i.e., wealthier parents may be more able to weather the challenges of caring for a severely sick or disabled child than lower-income parents).

One of the most frequently cited analyses of these risk factors is a study conducted by Brown, Cohen, Johnson, \& Salzinger (1998). In their 17-year long prospective study of 644 families in two counties in upstate New York, Brown and colleagues found a number of risk factors associated with the adult, the child victims, and the circumstances surrounding the maltreatment. In terms of child-level risk factors, the presence of pregnancy or birth 
complications where significantly associated with cases of physical abuse $(\mathrm{OR}=2.45)$. For cases of neglect, two child-level risk factors were associated with substantiated reports: low verbal IQ $(\mathrm{OR}=2.70)$ and anxious/withdrawn affect (2.02). Two additional child-level risk factors were associated with sexual abuse: female gender $(\mathrm{OR}=2.44)$ and the presence of a disability $(\mathrm{OR}=11.79)$. Risk factor profiles were highly predictive of cases of maltreatment in their analyses. For children with no risk factors, $0 \%$ were physically abused, $2 \%$ were neglected, $1 \%$ were sexually abused, and $3 \%$ were victims of any type of maltreatment. By comparison, children with four or more risk factors had prevalence rates that increased to $16 \%$ for physical abuse, $15 \%$ for neglect, $33 \%$ for sexual abuse, and $24 \%$ for any abuse or neglect (Brown et al., 1998).

\section{Intersection with the Health Care System}

Many of these problems ultimately result in increased demands placed on the U.S. healthcare system. Moreover, when compared to the systems in place in peer countries, the U.S. is uniquely challenged in responding to the needs of parents who become involved with CPS as a result of their substance use. While the U.S. trains high-quality practitioners, develops cutting edge therapies, and operates several world class treatment and research facilities, it does so at an inordinate cost. While the exact causes for such high costs are subject to debate, there is broad agreement that they at least include: (1) accelerating pharmaceutical and medical device prices, (2) innovations that have extended the lives of patients with serious chronic diseases and, (3) redundancies and other inefficiencies associated with poor coordination of care (Anderson, Reinhardt, Hussey, \& Petrosyan, 2003).

Furthermore, where many peer nations guarantee universal health coverage to their citizens through government policy frameworks, the U.S. has a comparably large portion of its population that is uninsured. The American model is also heavily reliant on the provision 
of health insurance coverage offered as a benefit of employment with a firm that provides it. While employers participate in covering some of the premium payments for their employees in some peer nations (e.g., Germany), the level of reliance on employer-based coverage is a particularly American feature, and one that is especially problematic for those struggling with substance use.

The Medicaid program was created to plug one of the holes in the broader system and provide health coverage to poor Americans. As will be discussed, this has meant that it has gradually assumed a preeminent role in the financing of behavioral healthcare broadly, and of addiction treatment specifically. This section will go on to outline some of the ways that cooccurring substance use and child maltreatment affect patterns of health services utilization and, therefore, why it is reasonable to assume that treatment interventions such as START could simultaneously improve health and decrease costs for Kentucky's Medicaid program.

\section{Health Service Utilization and Associated Medicaid Spending}

Given its associated problems, it is unsurprising that severe SUD often drives up costs for insurers broadly, and state Medicaid systems in particular. First of all, whether it be because of past felony charges, absenteeism, or disagreeable behavior on the job, patterns of chronic drug use commonly lead to problems securing or maintaining steady employment (Walton \& Hall, 2016). Without the reliable income or health insurance benefits of a job, many high-risk substance users are forced to turn to Medicaid plans to pay for their healthcare needs. Indeed, this is borne out in the results of health services research. In two analyses of trends in U.S. national health spending Mark, Levit, Vandivort-Warren, Buck, \& Coffey, (2011) and Mark, Levit, Vandivort-Warren, Coffey, \& Buck (2007) both determined 
that the two largest funders of addiction treatment were (in order of total dollars spent): (1) state and local governments and, (2) Medicaid programs.

Not only can the characteristics of SUD result in the need for Medicaid coverage, but it also often renders people sicker once they get there. This general process of decompensation often coincides with the exacerbation of existing health conditions or the development of new ones. For example, using stimulant drugs at high doses can result in a range of devastating cardiac and cerebrovascular diseases, including myocardial infarctions and strokes (Westover, McBride, \& Haley, 2007). Similarly, using drugs via injection is associated with an increased risk for contracting blood-borne pathogens and other infectious diseases such as HIV, Hepatitis C, and endocarditis (Nelson et al., 2011). These problems are often compounded by traumatic injuries sustained while intoxicated and pulmonary issues related to cigarette smoking, which are also common amongst substance using populations (Soderstrom et al., 1997; Restrepo et al., 2007).

State Medicaid plans know that there are certain cost centers that disproportionately affect their per-member per-month spend. Two of the most important of these are emergency room care and admissions to inpatient hospitals, which can be especially costly for those diagnosed with an SUD (Rockett, Putnam, Jia, Chang, \& Smith, 2005; Tang, Stein, Hsia, Maselli, \& Gonzales, 2010; Friedmann, Hendrickson, Gerstein, Zhang, \& Stein, 2006). For example, McGeary \& French (2000) note that substance use is a significant predictor of emergency room presentations for both men and women. In a cost-benefit study of a Screening, Brief Intervention, and Referral to Treatment (SBIRT) intervention delivered in ER's in Washington State, Estee, Wickizer, He, Shah, and Mancuso (2010) found that providing SBIRT was associated with a net savings of $\$ 366$ per member per month. 
Similar associations have been documented in other analyses of health insurance claims data. Beyond the more obvious use of addiction treatment services, a number of studies have demonstrated relationships between the diagnosis of SUD and consumption of health services for medical care more broadly. In a study of Medicaid spending in six states (Arkansas, Colorado, Georgia, Indiana, New Jersey, \& Washington), Clark, Samnaliev, \& McGovern, (2009) found that an SUD diagnosis was a significant predictor of medical expenditures for each state except Arkansas. The authors analyzed claims data from a one year period (1999). Their results also suggested that Medicaid beneficiaries with SUD diagnoses used acute care settings for conditions that could be more effectively managed in ambulatory care settings (e.g., seeking routine care for diabetes-related issues at a hospital emergency department vs. a primary care clinic). Effectively, states paid \$104 million more for medical care and $\$ 105.5$ million more for behavioral health care for beneficiaries with SUD's than for care given to beneficiaries with other behavioral health disorders but no SUD diagnosis (Clark et al., 2009).

Similar results were found by Ford, Trestman, Steinberg, Tennen, \& Allen (2004). Their prospective case-control study compared high utilizers of the University of Connecticut Health Center to mid-range utilizers. The study defined high utilizers as patients that presented to the primary care clinic for a number of visits that represented two standard deviations beyond the mean ( $>8$ visits per year for women; $>7$ visits per year for men). The comparison group of mid-range utilizers were patients with 2 annual visits. Their analyses found that high utilizers were 4.3 times more likely than mid-range utilizers to have an SUD diagnosis. They also found that high utilizers were significantly more likely to visit the ER and carry a number of specialty care diagnoses (including many of those discussed above, 
such as cardiovascular and pulmonary disease). These results were found even after controlling for a number of demographic variables, type of insurance coverage, and medical morbidity (Ford et al., 2004).

Hearteningly, in spite of this cost relationship, there is evidence that treatment can bring costs down and shift utilization to more appropriate avenues of care. In a five-year study of healthcare utilization trends after admission to Kaiser Permanente addiction treatment programs, Parthasaruthy and Weisner (2005) found that: (1) treatment was associated with a general downward trend in healthcare costs, (2) within this trend, healthcare consumption shifted from acute services (e.g., inpatient admissions, ER visits) to primary care services, and (3) average medical costs peaked at 6 months post treatment intake and steadily declined after that point. In terms of total average per-member per-month spend (including psychiatric and addiction treatment services), Parthasaruthy and Weisner (2005) found an average per-member per-month spend of $\$ 389.81$ at baseline, then a peak of $\$ 707.13$ at 6 months post intake, down to an ultimate decline to $\$ 234.61$ at five years postintake ( $\sim 40 \%$ unadjusted cost reduction from baseline). These results seem to support claims that, amongst individuals that respond favorably to addiction treatment, many begin to manage their health more diligently as they simultaneously avoid crisis-oriented medical care.

In the case of START families, these established relationships can help describe what is happening with the substance using parents. The relationships can be fairly straightforward - substance use raises the risk of receiving acute medical services, and subsequent treatment can then reduce that risk. What is less well-known is how the family members (especially the 
affected children) respond to the benefits of their parents' treatment. It is unclear whether, or how, those benefits would translate to the child victims in the home.

Evidence collected from the Kaiser Permanente health system suggests that such benefits can manifest themselves as a result of successful addiction treatment. On an especially hopeful note, there is evidence that this effect can even extend to the family members of those who receive addiction treatment. First, there is reason to believe that these family members experience elevated stress and other associated health problems (with consequent increases in health care utilization), even compared to the family members of individuals with other chronic health conditions (Svenson, Forster, Woodhead, \& Platt, 1995; Ray, Mertens, \& Weisner, 2007). With this in mind, Weisner, Parthasarathy, Moore, and Mertens (2010) tested whether receipt of addiction treatment was associated with utilization and cost reductions in the whole family unit of the recipient.

To do this, Weisner and her colleagues (2010) examined the health care costs of three groups of participants insured by Kaiser Permanente of Northern California: (1) families where one member received addiction treatment and was abstinent at a 1 year follow up (i.e., successful treatment), (2) families where one member received addiction treatment and was not abstinent at a 1 year follow up (i.e., unsuccessful treatment) and, (3) control families where no member had ever received addiction treatment (i.e., no SUD present). Over a five year study period, costs for family members of non-abstinent participants trended upward every year, while costs for family members of abstinent participants trended downward until they were not significantly different from control families at year five (Weisner et al., 2010). The study found a significantly higher prevalence of some of the highest cost diagnoses in family members of SUD patients compared to controls (specifically, congestive heart failure, 
ischemic heart disease, diabetes, asthma, lower back pain, injuries, poisoning, and hepatitis C). The authors noted that their findings suggest at least two things. First, that providing quality addiction treatment may have ancillary benefits for the health and quality of life for family members and, second, that their results may provide further justification for incorporating family wellness services into treatment programming (Weisner et al., 2010). The Role of Cost Studies in Healthcare Policy

The benefits outlined in the studies above represent a positive externality incurred by providing successful addiction treatment. To economists, the term externalities refers to the indirect consequences that a given economic activity has on uninvolved third parties. For example, in the study conducted by Weisner and colleagues (2010), the provision of treatment directly involved the treatment provider (i.e., the seller), the insurance company (i.e., the buyer), and the client (i.e., the consumer). In this case, the economic activity between these parties produced indirect benefits for the other policy holders of Kaiser Permanente, whose premium payments were put to efficient use by paying for treatment that potentially reduced the likelihood they would need to pay more to participate in the health plan in the future.

The findings presented in this section are only a part of a large body of knowledge that demonstrates the ways addiction treatment produces positive externalities for families and communities (McGeary and French, 2000; Rockett et al., 2005). In another example, Rockett and colleagues (2005) estimated that unmet substance abuse treatment needs accounted for an additional $\$ 777.2$ million in preventable hospital care in Tennessee during a six month study period (June 1996 - January 1997). In that case, when addiction treatment can help clients shift their medical care-seeking behavior from costly acute services to more 
appropriate and cost-effective services (e.g., outpatient offices, preventive care, etc.), two beneficial results can happen. First, clients begin to consume healthcare in a way that prioritizes their sustained wellness over a patchwork of episodic, crisis-oriented acute care.

Second, system-wide cost containment can result when clients receive the right care in the right place at the right time. For health insurance organizations, tax payers, and patients, these benefits can take the form of lower per-member per-month spend, lower taxes (or at least less need to raise taxes), and shorter wait times to receive care, respectively.

\section{Summary}

When the Commonwealth of Kentucky participated in the Medicaid expansion policies outlined in the Patient Protection and Affordable Care Act (ACA), it solved a host of problems for its uninsured population. However, the solution for these problems came with a price tag. Should this price tag rise too high, it would risk taking state resources away from other important programs or even, in the worst case scenario, threaten the solvency of the program itself.

In its crucial role of stewarding the health and wellbeing of Kentuckians, the Department of Medicaid Services must use a combination of approaches to pay for the healthcare needs of a large portion of the state population while keeping its costs contained to a sustainable rate. As the evidence presented in this section suggests, the START program may be delivering quantifiable cost-savings to the Medicaid program in the form of reduced acute healthcare utilization. The present study was conducted to determine whether this is, in fact, the case. As mentioned above, the START program is one of many similar interventions, and as such, it incorporates several features found in its peer treatment models. 
In the next section, this report will discuss in greater depth the variety of approaches to the problem of co-occurring substance use and child maltreatment.

\section{Approaches to the Problem}

Once child welfare agencies moved from mere recognition of this problem to actively seeking out means to address it, they began to develop intervention models. Such efforts have brought about innovation and creative thinking, which has generated some promising programs that have been implemented across the country. In this case, the innovation is driven by one central question: "How can the most successful elements of addiction treatment be fused with the most successful elements of child protection?"

Several challenges arise in these efforts. When interventions are implemented across multiple sites or in multiple counties, as is the case with START, administrators and program evaluators must take into consideration the unique characteristics of each team. Even when teams are providing the same intervention, there can be cases when they adapt it to their geographic, social, or cultural context. Factors such as team dynamics, the average level of experience, the level of training and preparation of individual workers, and the quality of supervision have all been demonstrated to affect outcomes in child welfare work (Barbee et al., 2009; Antle, Barbee, Sullivan, \& Christensen, 2009). It can be difficult to ensure a coordinated service delivery across sites, and that each site maintains a level of fidelity to the intervention model.

In light of this, solutions to this problem are capable of creating a synergy that benefits the child, the family, and the community. Nevertheless, finding parsimonious ways to do this within budgetary constraints and regulatory frameworks is a challenge. This section will outline the ways in which this question has been answered around the country and 
conclude with a description of how the knowledge generated as a result of testing those interventions informs the work of the START teams in Kentucky. In keeping with this aim, the section begins with a description of three of the most commonly used and most rigorously studied of these interventions: the Family Treatment Drug Court, the Strengthening Families Program, and the Family Based Recovery Program.

\section{Family Treatment Drug Courts}

Some of the earliest intervention models were born in family court rooms, and are now called Family treatment drug courts (FTDC's). Because so much of child welfare practice revolves around the provisions of state law and judicial decision-making, the court system became a logical platform to initiate and monitor such family preservation interventions. These models evolved within the therapeutic jurisprudence framework and employ methods that are similar to the criminal drug courts that predated them. In other words, where traditional drug courts use avoiding prison sentences as leverage to motivate substance users to comply with treatment and avoid further criminal behavior, FTDC's use child custody to achieve the same ends.

Successful recovery from an SUD requires intense resolve and sustained effort over long periods of time. Through their use of legal leverage, FTDC's effectively create potent external pressures on individuals to augment their internal drive to change their behavior, make healthier choices, and be better parents to their children. Though certain FTDC components may differ from state to state in terms of approach or particular array of services offered, they share a common set of features. Oliveros \& Kaufman (2011) outline five such features that are present in most FTDC's. These include: (1) providing SUD evaluation either within the courthouse or in an affiliated location, (2) linking parents to addiction treatment 
services, (3) regular court hearings to monitor treatment compliance, (4) frequent (and often random) urine drug screens, and (5) providing conditional rewards and sanctions to parents in proportion to their efforts and progress (especially graduation ceremonies for clients that successfully complete treatment and abide by court mandates; Oliveros \& Kaufman, 2011).

While "drug courts" have been in existence for decades now, these courts were novel in that they were the first to incorporate a child protection component. The first operational FTDC was created by the Washoe County court system in Reno, NV in 1994. This court found that it needed a response to the high degree of substance use present on their protection and permanency court docket, and adopted earlier models for use with this population (CEBC, 2008; Oliveros \& Kaufman, 2011). Since that first FTDC was established, many more have been added to court systems around the U.S. In terms of procedure, FTDC's tend to follow a common progression.

Before a case comes before a judge, an incidence of child maltreatment must be reported, investigated by child protection professionals, and substantiated based on the results of the investigation. If the investigation discovers that the maltreatment was related to the parent's substance use, the case will be referred to specialist teams who conduct evaluations to verify that a true SUD diagnosis is present and then coordinate the treatment components of the FTDC intervention. If a case proceeds to this point, the parent comes before a protection and permanency court judge who presides over the intervention process. Officials will discern whether it is safe for the child to remain in the home or if they must be removed and placed in out of home care (typically with family member, foster parents, or residential facilities). 
If the assessment screens positive for SUD, and other conditions of participation are met (e.g., no other severe and persistent mental illnesses are diagnosed, client is a Medicaid beneficiary, etc.,), the parent is admitted to the full degree of FTDC programming. Once admitted, they will begin to participate in the array of services included in the specific intervention program (e.g., addiction treatment, case management, parenting skills training). It is then typical for FTDC judges and child protection professionals to monitor progress and make determinations about whether to reunite a child with their parent or, in severe cases, terminate parental rights and put the child up for adoption. As discussed earlier, many of these families also struggle with various features of poverty, and therefore it is also common for these interventions to help families gain access government social programs such as TANF, SNAP, or Section 8 benefits. Excepting the elements related to judicial decisions, these steps are very similar to those employed by the START teams.

\section{Evidence in Support of Family Treatment Drug Courts}

There is a significant body of knowledge that suggests that FTDC's promote favorable outcomes for families. Outcome studies have specifically found that FTDC participation is associated with: (1) quicker initiation of addiction treatment, (2) longer duration of treatment, and (3) improved likelihood of completing treatment. While these outcomes are relatively simple to measure, in and of themselves they say very little about whether FTDC's “work” (i.e., mere completion of a program is an insufficient measure if the treatment itself is bad).

More meaningfully, evidence suggests that FTDC's promote favorable child welfare outcomes. The table below summarizes a group of 14 studies of FTDC outcomes (published 2004-2016) with families where co-occurring substance use and child maltreatment were 
present. A survey of this literature returns several notable results. First, the published research is clustered around the coasts of the U.S; only one study of an FTDC in the central U.S. was identified by this search (conducted in Oklahoma). For studies that explicitly reported the location of the courts, only 8 states are represented in this sample, many of which are among the largest and most populous (California, New York, and Florida are featured prominently).

Table 2.3

Outcomes Studies of Family Treatment Drug Courts

\begin{tabular}{|c|c|c|c|c|}
\hline$\#$ & Publication & Location & Participants & Main Findings \\
\hline 1. & $\begin{array}{l}\text { Ashford } \\
\text { (2004) }\end{array}$ & $\begin{array}{l}\text { Pima } \\
\text { County, } \\
\text { Arizona }\end{array}$ & $\begin{array}{l}\text { Treatment Group: } \mathrm{N}=33 \\
\text { Control Group A (refused } \\
\text { treatment): } \mathrm{N}=42 \\
\text { Control B (treatment as usual): } \mathrm{N} \\
=45\end{array}$ & $\begin{array}{ll}\text { FTDC participation resulted in: } \\
-\quad \text { Higher successful } \\
\text { engagement in treatment } \\
\text { relative to control groups } \\
\text { (97\% vs. } 69 \% \text { \& } 67 \%) \\
\text { - Higher placement with } \\
\text { parents relative to control } \\
\text { groups } \\
\text { (52\% vs. } 39 \% \text { \& } 36 \%)\end{array}$ \\
\hline 2. & $\begin{array}{l}\text { Boles et al. } \\
\text { (2007) }\end{array}$ & $\begin{array}{l}\text { Sacramento } \\
\text { County, } \\
\text { California }\end{array}$ & $\begin{array}{l}\text { Treatment Group: } \mathrm{N}=573 \\
\text { (parents); } \mathrm{N}=861 \text { (children) } \\
\text { Control: } \mathrm{N}=111 \text { (parents); } \\
\mathrm{N}=173 \text { (children) }\end{array}$ & $\begin{array}{l}\text { FTDC participation resulted in: } \\
\text { - } \\
\text { Significantly more treatment } \\
\text { admissions }(\mathrm{M}=2.6, \mathrm{SD}= \\
2.4) \text { than the comparison } \\
\text { group }(\mathrm{M}=1.3, \mathrm{SD}=1.7) \\
\text { - } \\
\text { Higher rate of reunification } \\
\text { with family at } 24 \text { months } \\
(42.0 \% \text { vs. } 27.2 \%) \\
\text { - } \quad \text { Parents whose primary drug } \\
\text { was heroin were } \\
\text { significantly less likely to } \\
\text { successfully complete } \\
\text { treatment }\end{array}$ \\
\hline 3. & $\begin{array}{l}\text { Brook et } \\
\text { al. }(2015)\end{array}$ & $\begin{array}{l}\text { Tulsa } \\
\text { County, } \\
\text { Oklahoma }\end{array}$ & $\begin{array}{l}\text { Treatment Group: } \mathrm{N}=214 \\
\text { children } \\
\text { Control Group: } \mathrm{N}=418 \text { children }\end{array}$ & $\begin{array}{l}\text { FTDC participation resulted in: } \\
\text { - } \\
\text { Higher incidence of } \\
\text { reunification with family, } \\
\text { and at a faster rate }\end{array}$ \\
\hline
\end{tabular}


Table 2.3 (continued).

\begin{tabular}{|c|c|c|c|c|}
\hline \# & Publication & Location & Participants & Main Findings \\
\hline 4. & $\begin{array}{l}\text { Bruns et } \\
\text { al. }(2012)\end{array}$ & $\begin{array}{l}\text { King } \\
\text { County, } \\
\text { Washington }\end{array}$ & $\begin{array}{l}\text { Treatment Group: } \mathrm{N}=76 \text { parents } \\
\text { Control Group: } \mathrm{N}=76 \text { parents }\end{array}$ & $\begin{array}{l}\text { FTDC participation resulted in: } \\
\text { - } \\
\text { A } 1.5 \text { times increased } \\
\text { likelihood of admission to } \\
\text { addiction treatment vs. } \\
\text { control group } \\
\text { Higher number of days spent } \\
\text { in treatment, and a } 1.3 \text { times } \\
\text { increased likelihood of } \\
\text { successfully completing } \\
\text { treatment vs. control group } \\
\text { Children of parents who } \\
\text { participated in FTDC spent } \\
\text { fewer days under child } \\
\text { welfare supervision (median } \\
=718 \text { days) than the control } \\
\text { group (median = 813 days) }\end{array}$ \\
\hline 5. & $\begin{array}{l}\text { Burrus et } \\
\text { al. (2011) }\end{array}$ & $\begin{array}{l}\text { Baltimore } \\
\text { County, } \\
\text { Maryland }\end{array}$ & $\begin{array}{l}\text { Treatment Group: } \mathrm{N}=200 \\
\text { Control Group: } \mathrm{N}=200\end{array}$ & 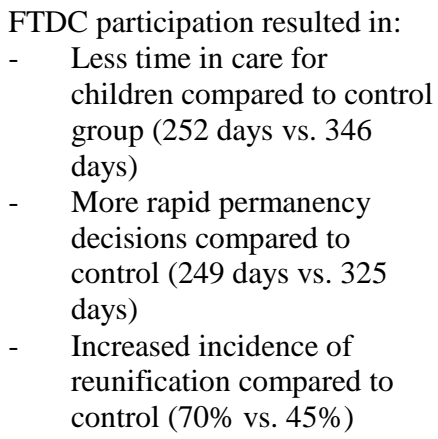 \\
\hline 6. & $\begin{array}{l}\text { Chuang et } \\
\text { al. (2012) }\end{array}$ & $\begin{array}{l}\text { Hillsborough } \\
\text { County, } \\
\text { Florida \& } \\
\text { Pinellas } \\
\text { County, } \\
\text { Florida }\end{array}$ & $\begin{array}{l}\text { Treatment Group: } \mathrm{N}=95 \text { FDTC } \\
\text { participants } \\
\text { Control Group A (Counties } \\
\text { without FTDC): } \mathrm{N}=424 \text { families } \\
\text { Comparison B (matched } \\
\text { comparison): } \mathrm{N}=95 \text { families }\end{array}$ & 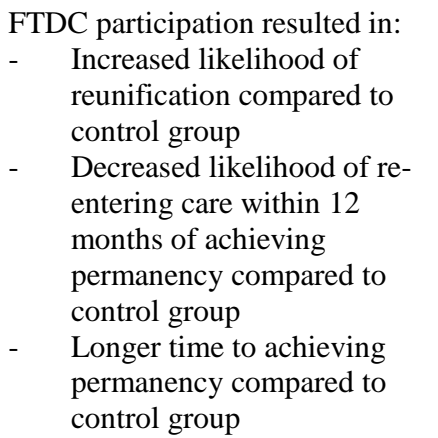 \\
\hline 7. & $\begin{array}{l}\text { Dakof et } \\
\text { al. (2009) }\end{array}$ & $\begin{array}{l}\text { Dade } \\
\text { County, } \\
\text { Florida }\end{array}$ & $\begin{array}{l}\text { Treatment Group: } \mathrm{N}=43 \\
\text { Control Group: } \mathrm{N}=37\end{array}$ & $\begin{array}{l}\text { FTDC participation resulted in: } \\
\text { - Increased rate of graduation } \\
\text { from court based services } \\
\text { compared to control group } \\
\text { ( } 72 \% \text { vs. } 38 \%) \\
\text { Increased rate of } \\
\text { reunification compared to } \\
\text { control group } \\
\text { ( } 70 \% \text { vs. } 40 \%\end{array}$ \\
\hline
\end{tabular}


Table 2.3 (continued).

\begin{tabular}{|c|c|c|c|c|}
\hline \# & Publication & Location & Participants & Main Findings \\
\hline 8. & $\begin{array}{l}\text { Gifford et } \\
\text { al. (2014) }\end{array}$ & $\begin{array}{l}11 \text { Counties } \\
\text { in North } \\
\text { Carolina }\end{array}$ & $\begin{array}{l}\text { Treatment Group: } \mathrm{N}=194 \text { parents } \\
\text { Control Group A (referred to } \\
\text { FTDC, but did not enroll): } \mathrm{N}= \\
157 \\
\text { Control Group B (enrolled in } \\
\text { FTDC, but did not complete): } \mathrm{N}= \\
215\end{array}$ & $\begin{array}{l}\text { FTDC participation (and } \\
\text { completion) resulted in: } \\
\text { - } \\
\text { Improved rate of exiting } \\
\text { foster care. Children whose } \\
\text { parents were referred to } \\
\text { FDTC but who did not } \\
\text { enroll exited foster care } 36 \% \\
\text { slower than treatment group. } \\
\text { Children of enrolled parents } \\
\text { also had statistically } \\
\text { significant longer stays than } \\
\text { children whose parents } \\
\text { completed-they exited } 27 \% \\
\text { slower than children of } \\
\text { parents in treatment group. } \\
\text { Increased likelihood of } \\
\text { reunification. Children of } \\
\text { parents who were referred } \\
\text { but did not enroll were } 14 \\
\text { times more likely to exit } \\
\text { foster care to adoption than } \\
\text { children from treatment } \\
\text { group. Children of parents } \\
\text { who enrolled but did not } \\
\text { complete were } 32 \text { times } \\
\text { more likely to exit to } \\
\text { adoption than children from } \\
\text { treatment group. }\end{array}$ \\
\hline 9. & $\begin{array}{l}\text { Green et } \\
\text { al. }(2007)\end{array}$ & $\begin{array}{l}3 \text { Western } \\
\text { U.S. Metro } \\
\text { Areas } \\
1 \text { Eastern } \\
\text { U.S. Metro } \\
\text { Area }\end{array}$ & $\begin{array}{l}\text { Treatment Group: } \mathrm{N}=250 \\
\text { Control Group: } \mathrm{N}=200\end{array}$ & $\begin{array}{l}\text { FTDC participation (and } \\
\text { completion) resulted in: } \\
\text { - } \\
\text { treare favorable addiction } \\
\text { in the treatment group } \\
\text { entered addiction treatment } \\
\text { more rapidly than controls } \\
\text { (73 vs. } 182 \text { days), spent } \\
\text { more time in treatment (303 } \\
\text { vs. } 185 \text { days), and had a } \\
\text { higher rate of successful } \\
\text { treatment completion ( } 45 \% \\
\text { vs. } 34 \% \text { ) } \\
\text { More favorable child welfare } \\
\text { outcomes. Children of } \\
\text { parents in the treatment } \\
\text { group were placed more } \\
\text { quickly in permanent living } \\
\text { situations ( } 360 \text { vs. } 435 \text { days) } \\
\text { and were more likely to be } \\
\text { reunified ( } 57 \% \text { vs. } 44 \% \text { of } \\
\text { children reunified). } \\
\text { No significant differences in } \\
\text { likelihood of having at least } \\
\text { one subsequent substantiated } \\
\text { CPS report ( } 23 \% \text { and } 15 \%, \\
\text { respectively). }\end{array}$ \\
\hline
\end{tabular}


Table 2.3 (continued).

\begin{tabular}{|c|c|c|c|c|}
\hline$\#$ & Publication & Location & Participants & Main Findings \\
\hline 11. & $\begin{array}{l}\text { Rodi et al. } \\
\text { (2015) }\end{array}$ & $\begin{array}{l}12 \text { FTDC's } \\
\text { located in } 6 \\
\text { states }\end{array}$ & $\begin{array}{l}\text { Treatment Group: } \\
-\quad \mathrm{N}=2,596 \text { adults } \\
-\quad \mathrm{N}=4,054 \\
\text { Control Group: Outcomes were } \\
\text { compared with county averages }\end{array}$ & $\begin{array}{l}\text { FTDC participation resulted in: } \\
-\quad \text { More favorable family } \\
\text { functioning outcomes as } \\
\text { measured by the North } \\
\text { Carolina Family Assessment } \\
\text { Scale (especially in courts } \\
\text { that incorporated } \\
\text { programming for children) } \\
\text { - Reduced incidence of } \\
\text { maltreatment and shorter out } \\
\text { of home care stays }\end{array}$ \\
\hline 12. & $\begin{array}{l}\text { Worcel et } \\
\text { al. (2008) }\end{array}$ & $\begin{array}{l}1 \text { East Coast } \\
\text { FTDC } \\
2 \text { West } \\
\text { Coast } \\
\text { FTDC's }\end{array}$ & $\begin{array}{l}\text { Treatment Group: } \mathrm{N}=183 \\
\text { families } \\
\text { Control Group (treatment as } \\
\text { usual): } \mathrm{N}=736 \text { families }\end{array}$ & $\begin{array}{l}\text { FTDC participation resulted in: } \\
-\quad \text { Higher likelihood of } \\
\text { entering treatment than } \\
\text { control group and } \\
\text { significantly faster treatment } \\
\text { entry } \\
\text { - Staying in treatment twice as } \\
\text { long and twice the likelihood } \\
\text { of completing treatment. } \\
\text { Child welfare outcomes } \\
\text { were more mixed (e.g. no } \\
\text { differences in time spent in } \\
\text { out of home placements) }\end{array}$ \\
\hline 13. & $\begin{array}{l}\text { Wormer \& } \\
\text { Hsieh } \\
(2016)\end{array}$ & $\begin{array}{l}\text { Snohomish } \\
\text { County, } \\
\text { Washington }\end{array}$ & $\begin{array}{l}\text { Treatment Group: } \\
-\quad \mathrm{N}=82 \text { parents } \\
\text { Control Group: } \\
-\quad \mathrm{N}=386 \text { parents }\end{array}$ & $\begin{array}{l}\text { FTDC participation resulted in: } \\
-\quad \text { Significantly faster time to } \\
\text { permanency than the control } \\
\text { group (393 vs. } 848) \\
\text { - } \\
\text { Significantly higher } \\
\text { likelihood of reunification } \\
\text { than the control group }\end{array}$ \\
\hline 14. & $\begin{array}{l}\text { Zeller et } \\
\text { al. (2007) }\end{array}$ & $\begin{array}{l}\text { Six courts in } \\
\text { Maine }\end{array}$ & $\begin{array}{l}\text { Treatment Group: } \\
-\quad \mathrm{N}=49 \text { parents } \\
\text { Control Group: } \\
-\quad \mathrm{N}=93 \text { parents }\end{array}$ & $\begin{array}{ll}\text { FTDC participation resulted in: } \\
\text { - } & \text { Children of FTDC parents } \\
\text { - } & \text { Hent less time in foster care } \\
\text { Higher likelihood of } \\
\text { entering into and completing } \\
\text { treatment } \\
\text { - } \quad \begin{array}{l}\text { Decreased recurrence of } \\
\text { child maltreatment after } \\
\text { child returned home }\end{array} \\
\end{array}$ \\
\hline
\end{tabular}

* This table was inspired by one that appears in Gifford et al. (2014). It is a modified and updated version including more recently published work. This table also appears in Matthew Walton's comprehensive examination report (2017).

As evidenced by Table 2.3, the FTDC is the intervention model of choice for several communities. It is understandable that this approach is widely implemented - in nearly every reported domain, participants that received treatment from an FTDC had better outcomes than those who did not. These studies are unique from the broader literature in their use of concurrent reporting of addiction treatment and child welfare outcomes. As opposed to 
reporting these outcomes as disparate and isolated from one another, many of them operationalize these outcomes as twin manifestations of the same domain. Conceptualizing a given family's response to treatment in this way is perhaps one of the most valuable contributions of this vein of research. In this, they are likely the bellwethers of the emerging collaborations between researchers with expertise in addiction treatment, those concerned with child welfare and prevention of child maltreatment, and those with expertise in pediatrics and public health.

In addition to the summary in Table 2.3, there is also some evidence that FTDC's provide cost-beneficial results. In an evaluation of three FTDC's in Maine, Zeller, Hornby, and Ferguson (2007) compared a sample of 76 children whose parents received FTDC services with a comparison sample of 76 children whose parents received standard court services. Their results indicated that providing FTDC services produced a net savings of approximately $\$ 10,000$ per child in terms of foster care and CPS services over a period of one year following the closure of the CPS case. Notably, there were 7 FTDC participants that delivered healthy (i.e., non-drug exposed) babies during the evaluation period, likely providing substantial savings in neonatal intensive care and other medical services.

\section{The Strengthening Families Program}

Another way of responding to substance use in child welfare populations is the Strengthening Families Program (SFP). SFP was developed by Dr. Karol Kumpfer in the early 1980's in collaboration with NIDA, and was created with a goal of preventing the intergenerational development of SUD's in victimized children. The program is described in depth in Brook, McDonald, and Yan (2012) and Kumpfer, Whiteside, Greene, and Allen (2010). 
Briefly, SFP is conventionally provided as a collection of 14 educational sessions (1 per week over a 14-week period), with four leaders and a site coordinator involved in each session. Sessions are conducted in a public location with a maximum capacity of approximately 10-12 families at time. The sessions begin with a family meal, and devote a portion of the weekly programming to dividing the sessions into child-only groups and parent-only groups and delivering the instruction for parents and children separately. After the instruction, sessions involve opportunities for parents and children to convene and practice utilizing the course content with one another. The curriculum content is designed to focus on three core areas: parenting skills training, child skills training, and general family training. Within these three areas, the curriculum content includes instruction on: "Child development, behavior management techniques, child skills training, family skills enhancement and attachment/bonding, parental supervision, and psycho-educational material targeted at improving the parent child relationship" (Brook et al., 2012, p.692). While the program is tailored for families with parental substance use, there is less direct content related to addiction recovery compared to family functioning material.

\section{Evidence in Support of the Strengthening Families Program}

There are a number of peer-reviewed studies, book chapters, and pilot projects that have demonstrated positive outcomes in families that received the SFP intervention (Kumpfer et al., 2010). Studies of the SFP also display the aforementioned dynamic of reporting outcomes in terms of the family system and functioning (e.g., recurrence of maltreatment, reduction in substance use, prevention of children's future substance use etc.) as opposed to isolated results (i.e., only those of interest to child welfare agencies). In a broad review of the program, Kumpfer and colleagues (2010) discuss results collected from several 
adaptations of the program version administered in multiple states (culturally-appropriate and age-appropriate versions have been developed for various groups). In particular, the results of a 5-year NIH Phase 5 outcomes study of 1,600 families in New Jersey found marked reductions in parental alcohol and drug use and significant improvements family functioning (Kumpfer et al., 2010). Based on the reviewed studies, the analyses also produced a costbenefit estimate of $\$ 36$ saved for every $\$ 1$ spent to provide SFP to families.

As robust as that cost-benefit ratio is, it did not include savings generated in the form of prevented days in foster care. Fortunately, a team of researchers from the University of Kansas have conducted a cost-benefit study to provide this information. In an analysis of child welfare data from 262 SFP participants and 519 propensity score matched nonparticipants who were tracked from February 2008 through March 2011, Johnson-Motoyama, Brook, Yan, and McDonald (2013) found that every \$1 spent on providing SFP yielded an average benefit of $\$ 9.83$ in terms of averted days in foster care. Based on sensitivity analyses of the range of out of home care costs and staffing models, these benefit estimates ranged from a low of $\$ 9.15$ to a high of $\$ 25.35$. These results were based on an event history analysis, which found that children whose families participated in SFP typically spent 190 fewer days in out of home care than comparison group children. This amounted to a net savings of $\$ 16,340$ per child that received SFP (calculation based on an average per diem payment of $\$ 86)$.

In another similar test of the efficacy of the program in Kansas, Jody Brook and her colleagues at the University of Kansas (2012) analyzed data from 214 SFP participants and 423 propensity score matched non-SFP participants to determine whether receipt of SFP was associated with shorter stays in foster care. Families included in the study were those whose 
children had already been removed from the home and placed in foster care as a result of parental substance use. An event history analysis of their data revealed that, at one year posttreatment, $45 \%$ of children whose families received SFP were reunified with their parents versus only $27 \%$ of children in the comparison group. At two years post-treatment, these results rose to $69 \%$ of SFP children and 32\% of comparison children (Brook et al., 2012).

\section{Family Based Recovery}

Where FTDC's are coordinated in courthouses and SFP is provided in community centers, the Family Based Recovery program (FBR) is administered in the family's home. The program is administered by the Yale Child Study Center in collaboration with the Connecticut Department of Children and Families, and was launched in 2007 (Hanson et al., 2015). The following description provides an overview of the program as outlined in Hanson and colleagues (2015).

The FBR program provides addiction treatment, individual psychotherapy, group therapy sessions, parent-child relational skill-building, and comprehensive case management. Like START, FBR is designed to target families with young children (0-36 months), and parents are eligible for participation if they have both an open CPS case and have used substances in the last 30 days. Contrary to other models, FBR clinicians are trained to provide all aspects of the intervention, which is intended to reduce the challenges often associated with referring to and coordinating with multiple service providers (e.g., transportation issues, health insurance coverage, waitlists, etc.). FBR is designed to be provided in teams of three professionals: two master's-prepared clinicians and one bachelor's-prepared family support specialist. The program also makes a psychiatrist available to clients for additional diagnosis and treatment of other mental health conditions. Similarly to START, FBR caseloads are restricted (only 12 families at a time per team), 
meaning that services are much more intensive and available to clients versus treatment as usual CPS services.

FBR is the newest at least evidence-supported of the interventions outlined in this section, but is included here because of its observed efficacy as well as the unique nature of its implementation that is especially pertinent to this study. Specifically, FBR is being evaluated under a "Pay for Success" contract (also called a Social Impact Bond; see Lantz, Rosenbaum, Ku, \& Iovan, 2016). Pay for Success contracts will be described in greater detail in the Discussion section.

Briefly, the terms of this particular contract involve a collaboration between the Connecticut Department of Children and Families, the Yale Child Study Center, the University of Connecticut Health Center, and a funder called Social Finance, LLC. Under the terms of this contract, Social Finance, LLC provided $\$ 11.2$ million to finance the implementation of the program in 2016, and will be repaid a maximum payout of $\$ 14.8$ million if the project achieves predetermined outcome goals (5\% interest rate on senior notes and 3\% rate on junior notes; Nonprofit Finance Fund, 2017). These outcome goals include four targets: (1) Reduction in out-of-home placements, (2) reduction in subsequent referrals to DCF, (3) reduction in parental substance use and, (4) successful enrollment of families into the FBR program. The contract is predicated on the premise that a significant improvement in these outcome domains would result in such a considerable reduction in spending for the Connecticut DCF that they would have enough money in their budget to repay the initial loan with a high enough interest rate to make it worth the risk to funders. Evidence in Favor of the Family Based Recovery Program 
Unlike the other models, FBR has not been studied in multiple states or with multiple providers, and thus has the smallest evidence base currently. However, one published study indicated that parents who received FBR showed improvement on both the Edinburgh Depression Scale and Postpartum Bonding Questionnaire between intake and discharge (Hanson et al., 2015). Additionally, families seemed to respond well in terms of protection and permanency outcomes (as measured by subsequent maltreatment reports) and substance use (as measured by negative urine drug screens; see Hanson et al., 2015).

\section{Summary}

The interventions discussed in this section share some elements in common with the START program, and diverge from it in other ways. All of the models understand the necessity of collaborations between treatment providers and CPS agencies. Each of them make efforts to restrict caseloads or class sizes to intensify the service provision and keep family to worker ratios as small as possible. Each of them place an emphasis on objectively measuring response to treatment - often making use of urine drug screens, validated psychometric tests, and measures of family wellbeing.

The differences demonstrate how programming decisions affect the client experience, and potentially the ultimate outcomes. While most START clients do have open cases in family court, court involvement is not a necessary condition of participation the way it is for FTDC's. Similarly, START does incorporate educational components, but these are not provided in the structured way that the SFP provides them, and there is less emphasis on rehearsing parenting skills in START services. Unlike FBR, workers in the START model utilize partnerships with addiction treatment agencies; they do not provide it themselves. Though there is some variation in the other models, it is not explicitly required that there be a 
family mentor (i.e., a person in recovery themselves who uses their shared experience to build rapport), this is an essential component of START. In terms of funding, where START derives a large portion of its funding from Title IV-E of the Social Security Act, FBR is currently being funded by a Pay for Success contract with a private funder, and FTDC's rely on a constellation of funders for their operating expenses.

While not by any means an exhaustive discussion of the many programs that have been implemented to address the issue of co-occurring substance use and child maltreatment, this section captures some of the pertinent matters that stakeholders must consider when planning their strategy. Factors such as which service providers will offer treatment, what treatment modality they will use, where clients will receive it, who will pay for it, and how success will be measured all affect whether a given model can be deemed successful. For a more comprehensive coverage of these services, interested readers may refer to Oliveros and Kaufman (2011), Choi and Ryan (2006), and Marsh, Smith, \& Bruni, (2011).

\section{Summary, Research Questions, and Hypotheses}

High-risk substance use and child maltreatment are both problems that are prevalent and costly in American society. The available information from Kentucky seems to support claims that these broad findings are also true in the Bluegrass State. These problems are presently manifesting themselves in an environment where overdose rates have increased substantially, War on Drugs policies bring a criminal component to most drug use, and rates of divorce and single-parent households are at notably high levels. Authorities in the child welfare field have long known that these problems often exist in tandem when parents' drug use endangers the safety and well-being of their children. This subset of CPS-involved families are especially difficult to serve, and often do not respond well to standard CPS 
interventions that do not incorporate addiction treatment into the case plan. Such cases often result in substance-exposed newborns, removing children from their homes, and even child fatalities. As a result, multiple initiatives have been launched to address a parent's disordered substance use as a central part of the effort to prevent future maltreatment and help them become well enough to parent their children effectively. Amongst the menu of interventions developed by these initiatives, the Kentucky Cabinet for Health and Family Services selected the START program to respond to the high rates of substance-related child maltreatment.

The administration of this program comes at an increased cost compared to typical child welfare services. Recipients of the START program benefit from more contact with their CPS worker and access to a family mentor (both of which have their caseloads restricted to 15 clients), as well as enhanced addiction treatment services. START was not designed to serve as a public health initiative or a cost-cutting measure, but past evidence suggests that it may be achieving those ends as a secondary effect of its primary aims. These past investigations have demonstrated that START generates cost-savings as a result of decreased foster care expenses, but none have yet measured its effects on Medicaid spending (Huebner, Robertson, Roberts, Brock, \& Geremia, 2012).

While the costs associated with removing children from their homes can be considerable (e.g., per diem foster care payments, adoptions and legal fees, etc.), they likely pale in comparison to the summed costs that the consequences of substance related CPS cases generate to the Medicaid system. If results from past studies of the START program still hold true, and families that receive these services are healthier, safer, and better off than their peer families, then it is reasonable to assume that material benefits to Medicaid will be found. 
This chapter sought to expound upon the premises contained within the argument outlined at the end of Chapter I. An extensive review of the literature reveals that Premise \#1, which asserted that child maltreatment that results from parental substance use is prevalent in families served by CPS, is borne out by the evidence. A review of the parallel literature on the costs of this maltreatment reveals that Premise \#2, which asserted that the problem is not only prevalent but also expensive to society, is also supported by research results. A review of intervention studies demonstrated that Premise \#3, which claimed that effective interventions have been developed to reduce the costly consequences of the problem, is also accurate. Finally, the argument's conclusion, which stated that these interventions will be associated with favorable cost-benefit outcomes proved true for interventions similar to the START program. In an attempt to test these hypotheses, this study will be oriented around the following three research questions:

Research Question \#1:"Is participation in the START program associated with reduced Medicaid costs compared to a matched comparison group that received conventional CPS services?"

○ Hypothesis \#1: There will be a significant difference between START participants and comparison participants in terms of overall Medicaid spending.

Research Question \#2: "If such a cost reduction result is found, in which health service category are the benefits the most pronounced (e.g., ER visits, inpatient hospital days)?"

$\circ$ Hypothesis \#2: There will be a significant difference between reductions in healthcare utilization by service domain.

Research Question \#3: "Are there differences in cost savings between START sites (e.g., Jefferson County, Kenton County, etc.)?"

- Hypothesis \#3: There will be a significant difference in costs savings according to the county in which a participant received START. 


\section{CHAPTER III}

\section{METHOD}

This chapter is divided into five sections: (1) an overview of the research design, (2) a description of the inclusion and exclusion criteria for study participants, (3) a description of the selected measures, (4) an explanation of the preparation of the dataset and, (5) an outline of the data analyses. Because this study involved analyses of secondary data collected from several sources, special attention will be devoted to describing the process of collating data and formatting it into an appropriate format for the analyses.

\section{Overview of Research Design}

This study was an economic evaluation that extended the scope of an existing multisite program evaluation of the START intervention in Kentucky that began in 2007. To accomplish this, secondary administrative data was collected and reformatted for the purposes of a between-groups analysis of health services utilization and associated Medicaid spending (one intervention group that received START, and one matched comparison group that did not). More specifically, the final dataset was comprised of a compilation of existing datasets collected by three entities: the START program evaluation (which used a data collection portal called the START Information Network [START-IN]), the DCBS office of Information and Quality Improvement (DCBS referred to this dataset by the name "272”), and the Kentucky Cabinet for Health and Family Services - Office of Health Data and Analytics.

This investigation was designed to test whether a family's receipt of the START intervention was associated with a reduction in their utilization of certain health services. 
More specifically, this was a retrospective, quasi-experimental test of the effects of receiving START on some of the costs to Medicaid associated with these health services. The source of information was administrative, observational data (both CPS report data from The Worker Information System [abbreviated TWIST] and Medicaid claims data). In order to test this hypothesis, two groups were constructed: an intervention group of children from families who received START between January 1, 2010 and May 31, 2016, and a comparison group of similar children from families with substance-related child maltreatment who did not receive START but received standard CPS interventions. This comparison group was constructed using propensity score matching (PSM).

In terms of the study period, when possible, three years of data for each child were collected: one year prior to the index CPS contact, and then two years post index contact with CPS. In other words, for the experimental group, this study first collected claims information from the year preceding the CPS report that prompted participation in START, a one year active intervention period (cases vary in length, but one year is a common approximate length of time for the average START case), and then one year after discharge from treatment. For the comparison group, this time frame allowed for the provision of conventional CPS services, which often involve referrals to addiction treatment when a parent could benefit from it. Like START, such cases also often vary in length depending on the unique features of the case. Many of the children included in this study were newborns or infants whose CPS case was initiated at their birth; in which case a one year baseline period of claims data was non-existent. In these cases, any available baseline Medicaid claims data was collected (in most cases, this was just the claim generated to pay for the delivery of the child). 
The purpose of collecting available baseline claims data from the year prior to a child's index event was to serve as a means of ensuring the presence of between-group balance prior to the initiation of services. In other words, significant differences in spending prior to entering CPS would be suggestive of systematic differences in healthcare consumption between the START and comparison groups (and likely the baseline health status of the children). Such a result would risk biasing the analyses. In light of this, analyses of baseline spending were conducted prior to running the final generalized linear models.

\section{Participants and Sampling}

\section{The START Team Sites}

At the time of this writing, the START program was administered in five counties in the Commonwealth of Kentucky. These counties included Jefferson County, Kenton County, Boyd County, Daviess County, and Fayette County. In addition to these, one START team operated in Martin County from 2007-2012. While the Martin County site no longer accepts new referrals, data from that START team was included in the final analyses for this project. Data from Fayette Co. was excluded from the final analyses due to a lack of sufficient sample size (the Fayette Co. START team only began operating in January of 2017). Beyond concerns related to statistical power, this small sample size also posed an increased the risk of confidentiality breaches in the process of merging and de-identifying data. In other words, the fewer the participants, the easier it would have been for the evaluation team to identify which claims data belonged to which participant; thus invalidating the de-identification process. This was observed both to respect the privacy of participants' protected health information (PHI) as well as to abide by a CHFS policy. Participation in START: Inclusion and Exclusion Criteria 
Five primary criteria were necessary in order to be considered for admission to the START program. First, all families that received the intervention were required to have been investigated by CPS for child abuse or neglect. Only cases of maltreatment that had been substantiated or deemed in need of services by a CPS investigation were eligible to participate in START (i.e., a family may have been without a substantiated case of abuse, yet the CPS team determined that offering services would be helpful to keep the child safe). Any type of maltreatment (e.g., medical neglect, physical abuse, etc.), as long as it satisfied those criteria, was eligible to qualify a family to participate in START.

Second, only cases where parental or caregiver substance use was identified as a primary contributing factor to the maltreatment were considered for participation. Typically, the discovery of such patterns of substance use was made during the investigation phase of the CPS cases. Notably, as discussed above, the CPS workers were not credentialed to issue psychiatric diagnoses, so a clinical SUD diagnosis was not a necessary component of the inclusion criteria. Although many START participants were likely diagnosed with SUD's upon later psychiatric assessment, oftentimes these diagnoses were not made until after they were accepted to the program.

Third, only families who met both of the above criteria and also had a child under six years of age in the home were considered eligible to receive START services. This range did include newborns - indeed, post-partum mothers constitute a significant population of the START clientele. This being the case, a substantial proportion of START cases were initiated by hospital maternity units after a newborn tested positive for in utero exposure to drugs or alcohol. In cases with multiple children in the home, the child under six years of age needn't be the victim of the maltreatment in order to satisfy this criteria - though in most 
instances this was the case. Fourth, a family needed to be Medicaid eligible in order to receive START. Fifth and finally, a family could not have an existing open and ongoing CPS case and receive START. In other words, a START team can serve a family with past cases that have been closed, but they cannot take over a case that is actively being worked by a non-START CPS team.

Beyond these primary inclusion criteria, families needed to reside in one of the aforementioned counties in order to receive START services. Because the START teams do not operate beyond the borders of their county, substance using parents in any of Kentucky's other 115 counties were ineligible for START. Note that this does not mean that families outside of the START counties did not get referred to addiction treatment - many do, as referral to treatment is a best practice in such cases. Additionally, while not a formal inclusion criteria, caseload availability has served as a limiting factor for participation in START since its inception. Families are denied START services when START teams are operating at capacity, at which time the families are referred back to regular ongoing CPS services.

In terms of exclusion criteria, participants were excluded from receiving START primarily based on the determination of team supervisors. Typically, such determinations to not accept a family were made on a case-by-case basis while taking into account a family's particular circumstances. For example, while START is capable of serving adults with cooccurring addiction and psychiatric disorders (so-called "dual diagnosis" clients), families that otherwise met all of the inclusion criteria are sometimes excluded due to the severity of the adult's mental illness. In such cases, adults with severe and persistent mental illnesses were excluded if the START teams determined that the severity of their condition precluded 
them from participating in treatment, and thus benefiting from the intervention. While far less common, in other cases, participants were excluded from participation if they were incarcerated or under some other form of legal supervision that prevented them from complying with crucial START activities (such as attending family team meetings or addiction treatment programming).

\section{The Intervention \& Comparison Groups}

To make more valid conclusions regarding whether receiving START services was associated with decreased Medicaid costs, it was necessary to compare START participants to similar CPS families who received standard CPS services. As stated above, sampling for the START program evaluation was conducted non-probabilistically. It was beyond the scope of the original evaluation to randomly assign families into a control group, so this study generated a comparison group using data collected from families with similar problems and comparable case characteristics, but who did not receive START. Data from a large pool of eligible children was then submitted to a PSM procedure to "match" them to intervention group participants along theoretically determined variables. There were 522 identified START children who met each of the inclusion criteria and were thus included in the PSM process. After restricting the larger 272 dataset in accordance with the aforementioned inclusion criteria (e.g., only families where substance use was a risk factor, only families with a child under the age of 6 , etc.), the remaining pool of eligible non-START children were submitted to the PSM procedure.

Several considerations were made in order to construct this comparison group appropriately. As noted earlier, while it is common for CPS-involved families to engage in high-risk substance use, it is likely that START families share a constellation of 
characteristics that increase the risk for selection bias when comparing their outcomes to other CPS-involved families.

For example, as mentioned previously, the literature describes a number of these characteristics: families who come to CPS as a result of substance use tend to stay in services longer, they tend to have more serious health and social problems, and their children are more susceptible to developmental delays and other medical problems (Leslie et al., 2005; Magura \& Laudet, 1996; Semidei, Radel, \& Nolan, 2001). It is virtually certain that other important characteristics were unmeasured or unreported by CPS, and thus unavailable to be accounted for when determining which families constitute the ideal comparison group. For this reason, while this matching method is a generally accepted means of reducing selection bias, it cannot claim to control for it entirely. What follows is an outline of the measures taken to further mitigate selection bias as much as possible given the limitations of the available data.

\section{Isolating Participants by County Clusters}

The first step taken to mitigate selection bias and account for the effects of unobserved variables was to restrict the comparison group to only predetermined geographic regions of Kentucky. In other words, for the purposes of this study, only non-START families from proximate counties to their corresponding START sites were eligible for inclusion in the comparison group. In nearly all cases, these candidate counties were contiguous to the START counties. Some exceptions to this were made to include higherpopulation counties for the purposes of increasing sample size for the PSM. Specifically, this included more dense urban areas that are close to smaller metro areas (e.g., Daviess County and Boyd County). A very large sample size has been noted as a particularly important 
component of successful PSM procedures, as it increases the likelihood of identifying participants that suitably match along observed covariates (Ye \& Kaskutas, 2009). These collections of counties were referred to as county clusters, which included the START County itself as well as the comparison counties. The PSM procedure allowed for START children to match to non-START children within their same county.

This step was intended to account for regional variations in important variables that are relevant to this study, such as poverty rates, local culture, population health status, and access to healthcare resources (proximity to a hospital with an ER being especially pertinent). Indeed, comparing responses to government social programs between individuals who reside within close geographical proximity to one another has been demonstrated to notably reduce selection bias in past economic studies (especially in analyses of propensity score matched samples; Michalopoulos, Bloom, \& Hill, 2004; Heckman, Ichimura, \& Todd, 1997). The clusters created for this study very closely mirror the existing Kentucky Area Development Districts organized by the Kentucky Association for Economic Development. A list of these county clusters, along with relevant U.S. Census data is provided in Table 3.1.

\section{Table 3.1}

County Clusters for the Propensity Score Matching Procedure

\begin{tabular}{lllll}
\hline $\begin{array}{c}\text { Cluster } \\
\#\end{array}$ & $\begin{array}{c}\text { START } \\
\text { County }\end{array}$ & $\begin{array}{l}\text { Comparison Group } \\
\text { Counties }\end{array}$ & $\begin{array}{c}\text { Approximate } \\
\text { Population Density* }\end{array}$ & $\begin{array}{c}\text { \% of Population } \\
\text { Living in Poverty }\end{array}$ \\
\hline 1 & Boyd & Boyd (non-START & 309.9 & $19.1 \%$ \\
& & clients) & 107.2 & $17.4 \%$ \\
& & Greenup & 67.7 & $22.6 \%$ \\
& & Carter & $27.1 \%$ \\
& & Lawrence & $25.4 \%$ \\
\hline 2 & Rowan & 83.4 & $16.2 \%$ \\
& Daviess & Daviess (non- & 210.9 & $12.6 \%$ \\
& & & $17.1 \%$ \\
& START clients) & 45.6 & $17.3 \%$
\end{tabular}


Table 3.1 (continued).

\begin{tabular}{|c|c|c|c|c|}
\hline $\begin{array}{c}\text { Cluster } \\
\#\end{array}$ & $\begin{array}{l}\text { START } \\
\text { County }\end{array}$ & $\begin{array}{c}\text { Comparison Group } \\
\text { Counties }\end{array}$ & $\begin{array}{c}\text { Approximate } \\
\text { Population Density* }\end{array}$ & $\begin{array}{l}\% \text { of Population } \\
\text { Living in Poverty }\end{array}$ \\
\hline \multirow{8}{*}{3} & \multirow{8}{*}{ Jefferson } & Union & 43.8 & $18.6 \%$ \\
\hline & & Webster & 41.0 & $17.9 \%$ \\
\hline & & Warren & 210.1 & $18.5 \%$ \\
\hline & & $\begin{array}{l}\text { Jefferson (non- } \\
\text { START clients) }\end{array}$ & $1,948.1$ & $17.3 \%$ \\
\hline & & Oldham & 322.2 & $5.9 \%$ \\
\hline & & Shelby & 110.8 & $11.5 \%$ \\
\hline & & Spencer & 91.4 & $8.8 \%$ \\
\hline & & Bullitt & 250.2 & $10.4 \%$ \\
\hline \multirow[t]{6}{*}{4} & \multirow[t]{6}{*}{ Kenton } & $\begin{array}{l}\text { Kenton (non- } \\
\text { START clients) }\end{array}$ & 996.7 & $13.3 \%$ \\
\hline & & Gallatin & 84.8 & $14.5 \%$ \\
\hline & & Boone & 482.3 & $7.6 \%$ \\
\hline & & Grant & 95.6 & $15.6 \%$ \\
\hline & & Pendleton & 53.7 & $14.4 \%$ \\
\hline & & Campbell & 597.0 & $12.5 \%$ \\
\hline \multirow[t]{5}{*}{5} & \multirow[t]{5}{*}{ Martin } & $\begin{array}{l}\text { Martin (non- } \\
\text { START clients) }\end{array}$ & 56.3 & $36.6 \%$ \\
\hline & & Knott & 46.5 & $38.2 \%$ \\
\hline & & Johnson & 89.2 & $25.9 \%$ \\
\hline & & Floyd & 100.3 & $30.4 \%$ \\
\hline & & Pike & 82.6 & $31.4 \%$ \\
\hline
\end{tabular}

* As reported by the U.S. Census Bureau (2010). Describes the amount of people per square mile who reside in the experimental (i.e., START) county.

** As reported by the U.S. Census Bureau (2010). Describes the percentage of the population of the experimental group (i.e., START children) county whose household income falls below the federal poverty line.

\section{Boyd County Cluster (FIVCO Area Development District)}

Boyd County is located in the northeastern region of Kentucky and resides within a tristate area where the borders of Ohio, Kentucky, and West Virginia meet. It has a population of approximately 49,500 people, and is considered a part of the Appalachian region of Kentucky. Ashland, the largest city in the county, is where the START team is headquartered in Boyd County. The candidate counties in this cluster (Greenup, Carter, Lawrence, \& Rowan) are all similar to Boyd in terms of economics, culture, and population size. For example, this region bears a significant economic and cultural heritage that arose as 
a result of coal mining. Boyd, Greenup, Carter, \& Lawrence counties are all members of the FIVCO development district region of Kentucky. While not part of the FIVCO district, Rowan County is close to the others and was added to increase the raw sample size for the PSM procedure (Rowan County contains Morehead, a city with a mid-sized public university). The primary community mental health center that serves these counties is called Pathways. Pathways is the partner organization that provides addiction and mental health treatment services to START clients in Boyd County.

\section{Daviess County Cluster (Green River Area Development District)}

Daviess County is located in the western half of Kentucky and sits on the banks of the Ohio River, along the northern border with Indiana. Its population is approximately 99,500, and its county seat of Owensboro is the $4^{\text {th }}$ largest metropolitan area in Kentucky by population size. Daviess County is a member of the Green River Area development district, which also includes Hancock, Henderson, McLean, Ohio, Union and Webster counties. These counties all share common economic, cultural, and economic traits. For example, many individuals in this region are employed in manufacturing and agricultural jobs. Warren County was included in this cluster to include the city of Bowling Green, KY as a candidate for comparison families. Bowling Green is the third largest metropolitan area in Kentucky, is near Owensboro, and is in many ways similar to Daviess County. The primary community mental health centers that serve these counties are River Valley Behavioral Health and Mountain Comprehensive Care Center ("Mountain Comp"), both of which have partnered with START to provide addiction and mental health treatment services in Daviess County. Jefferson County Cluster (KIPDA Area Development District)

The Jefferson County cluster is unique amongst the five clusters. Principally, this is 
because Jefferson County is home to the city of Louisville, which has the largest and most heterogeneous population out of any single community in Kentucky. Approximately 763,500 people reside within Jefferson County, with the Louisville metropolitan statistical area including a sum total of over 1,000,000 people (this number includes some of southern Indiana). Louisville is located along the Ohio River in the western half of Kentucky. In Kentucky's cluster are Oldham, Shelby, Spencer, and Bullitt counties; each of which are also part of the KIPDA development district in Kentucky. There are cultural and economic similarities within this cluster of counties, as many residents are employed by healthcare organizations (e.g., Humana, Kindred Healthcare, Norton Healthcare), food and beverage businesses (e.g., Papa John's, YUM! Brands, Brown-Forman), or manufacturing (Ford, GE). This cluster is largest by population as well as total CPS cases generated within the study period. The primary community mental health center that serves these counties is Centerstone of Kentucky; Centerstone is the partner organization that provides addiction and mental health treatment services to START clients in Jefferson County.

\section{Kenton County Cluster (Northern Kentucky Area Development Distrcit)}

Kenton County sits on Kentucky's northern border with Ohio, directly across the Ohio River from Cincinnati. The county has a total population of approximately 165,000 , and its county seat of Covington is the fifth largest city in Kentucky. Kenton, along with the other counties included in this cluster (Gallatin, Boone, Grant, Pendleton, and Campbell) all belong to the Northern Kentucky Area development district. Due in large part to its proximity to Cincinnati, poverty rates are lower in this cluster and residents tend to be more urban in terms of culture. The primary community mental health center that serves these counties is called NorthKey Community Care; NorthKey is the partner organization that provides 
addiction and mental health treatment services to START clients in Kenton County.

\section{Martin County Cluster (Big Sandy Area Development District)}

Martin County is located in the Appalachian Mountain region of Kentucky, and is home to approximately 12,000 people. As such, it is bordered by West Virginia to the west and is very close to Kentucky's border with Virginia to the southeast. The Martin County cluster is most similar in terms of economics, culture, and history to the Boyd County cluster (i.e., coal mining has historically played a central role in community life). In terms of poverty rates, Martin County is the poorest START site investigated in this study. It is also the smallest in terms of population, as well as the smallest volume of CPS cases. Four counties in this cluster belong to the Big Sandy development district (Martin, Johnson, Floyd, \& Pike), while Knott belongs to the KAED development district. The Martin County START program ended in 2015, and are thus no longer actively providing the intervention. The primary community mental health center that serves these counties is also Mountain Comprehensive Care Center; Mountain Comp is the partner organization that provided addiction and mental health treatment services to START clients in Martin County.

To summarize, all participants met the following criteria: (1) they were served by CPS between 2010 and 2016 for a verified case of child maltreatment (or indicated to be in need of services), (2) the parents involved in the cases had problems related to substance use that significantly contributed to the maltreatment, (3) a child aged 5 years old or younger resided in the home at the time the CPS case was initiated and, (4) the CPS case was originated within one of the five identified county clusters. These criteria were inclusive of any form of maltreatment identified in KRS 600.020 (e.g., sexual abuse, medical neglect, physical abuse, etc.). They were also inclusive of cases with any of form of resolution, 
regardless of the length of time it took to close the case (e.g., termination of parental rights, reunification with family of origin, etc.).

\section{Measures and Variable Selection}

\section{Measures Used for Study Sample Creation}

In order to match START clients with non-START comparison clients, data collected from the CPS assessment instruments were used as PSM matching variables. During the period within which data was recorded (2010-2016), two CPS assessment tools were used. The Comprehensive Quality Assessment (CQA) was used until January 1, 2014, at which point CPS switched to the Assessment and Documentation Tool (ADT). The ADT is still to the present day the assessment tool used by CPS workers in Kentucky. These instruments are used to collect and record information about families that have been referred to CPS for alleged child maltreatment, including information related to demographics, criminal justice issues, health status, and other variables that are germane to CPS investigations. These measures are completed and recorded by CPS workers and the data is stored in the TWIST system and warehoused by the Information and Quality Improvement division of DCBS.

For this study, the primary use for the data collected by the CQA and ADT was to ensure that only non-START participants that met the aforementioned inclusion criteria were eligible for entry into the PSM procedure. Additionally, once eligible participants were isolated, CQA and ADT data were also used as matching variables for PSM.

The PSM procedure used those observed variables that were common across the source data sets (i.e., data from both START-IN and non-START participants in the 272; both CQA [pre-2014] and ADT [post-2014]). These include demographic variables such as the race and gender of the child, as well as variables that describe some specifics of the case 
and the home environment. Table 3.2 below outlines the proposed matching variables as well as a brief description and rationale for its inclusion.

\section{Table 3.2}

Propensity Score Matching Variables

\begin{tabular}{lc}
\hline \multicolumn{1}{c}{ Variable } & Description \\
\hline Demographic Variables & \\
County & A given family's county of \\
Cluster & residence. County clusters \\
& include the START site \\
& county plus the selected \\
& comparison counties which \\
& were eligible for \\
& comparison
\end{tabular}

Child's Age Only the youngest child in a family was considered for inclusion, and only families with a child younger than 6 in the home

Sampling from the same geographic region helps reduce selection bias in non-experimental studies (see Michalopoulos et al., 2004) was included

Child's Race

Coded as White, or other (there were few non-White participants)

This is a START inclusion criteria. Additionally, it is known that younger children are most at risk of maltreatment (Besinger et al., 1999)

There are meaningful differences between the experiences that White families and racial minority families have with CPS (see Drake et al., 2011; Boyd, R. (2014)

Child's Coded as either male or female Gender

Boys and girls have different risk profiles for certain types of abuse (e.g., sexual abuse reports more typically involve girls compared to boys; see Brown et al., 1998)

\section{$\underline{\text { Case Characteristics Variables }}$}

Investigation Only cases that were deemed Finding "Substantiated" or "Services needed" were included for matching

Index Year of

Contact with CPS
Only cases that initiated between 2010 and 2016 were considered for matching
START families can only be appropriately compared to families with similar investigation findings

These dates allow for implementation of the intervention and for a suitable amount of time after receiving START to track outcomes 
Table 3.2 (continued).

\begin{tabular}{|c|c|c|}
\hline Variable & Description & Justification for Inclusion \\
\hline \multicolumn{3}{|c|}{ Family Risk Factor Variables } \\
\hline $\begin{array}{l}\text { Parental } \\
\text { Mental Illness }\end{array}$ & $\begin{array}{l}\text { CPS investigator deemed an } \\
\text { adult's mental health to be a } \\
\text { contributing factor to the } \\
\text { maltreatment } \\
\text { (coded as a dichotomous } \\
\text { yes/no variable) }\end{array}$ & $\begin{array}{l}\text { Parents with mental health problems } \\
\text { have poorer CPS outcomes than parents } \\
\text { that do not (see Park, Solomon, \& } \\
\text { Mandell, 2006) }\end{array}$ \\
\hline $\begin{array}{l}\text { Domestic } \\
\text { Violence in } \\
\text { the Home }\end{array}$ & $\begin{array}{l}\text { CPS investigator deemed a } \\
\text { history of domestic violence in } \\
\text { the home to be a contributing } \\
\text { factor to the maltreatment } \\
\text { (coded as a dichotomous } \\
\text { yes/no variable) }\end{array}$ & $\begin{array}{l}\text { The presence of domestic violence in } \\
\text { the home can significantly complicate } \\
\text { CPS cases (see Holt, Buckley, \& } \\
\text { Whelan, 2008) }\end{array}$ \\
\hline Poverty & $\begin{array}{l}\text { CPS investigator deemed } \\
\text { issues with income or meeting } \\
\text { a child's basic needs to be a } \\
\text { contributing factor to the } \\
\text { maltreatment } \\
\text { (coded as a dichotomous } \\
\text { yes/no variable) }\end{array}$ & $\begin{array}{l}\text { There are strong associations between } \\
\text { a family's socioeconomic status and } \\
\text { their experience with CPS (see Coulton } \\
\text { et al., 2007) }\end{array}$ \\
\hline $\begin{array}{l}\text { Criminal } \\
\text { History }\end{array}$ & $\begin{array}{l}\text { An adult in the home has a } \\
\text { history of arrest or } \\
\text { incarceration } \\
\text { (coded as a dichotomous } \\
\text { yes/no variable) }\end{array}$ & $\begin{array}{l}\text { Criminal behavior is associated with } \\
\text { risk for child maltreatment (see Felitti } \\
\text { et al., 1998) }\end{array}$ \\
\hline $\begin{array}{l}\text { Substance Use } \\
\text { Risk Level }\end{array}$ & $\begin{array}{l}\text { CPS investigator deemed a } \\
\text { history of substance use in the } \\
\text { home to be a contributing } \\
\text { factor to the maltreatment } \\
\text { (coded as "was a risk factor", } \\
\text { "indirectly contributed", or } \\
\text { "directly contributed" }\end{array}$ & $\begin{array}{l}\text { The principal focus of the START } \\
\text { program is to reduce substance use and } \\
\text { thereby improve the safety, } \\
\text { permanency, and well-being of } \\
\text { children. The degree to which substance } \\
\text { use was related to the maltreatment is } \\
\text { material to way a case proceeds }\end{array}$ \\
\hline
\end{tabular}




\section{Independent Variables}

The above matching variables served as a means to make the most valid comparisons possible based on available baseline TWIST data. Once children were matched, a set of variables were selected to serve as independent variables to answer the research questions. Specifically, the final regression models incorporated five independent variables to examine their relationship to Medicaid spending and health services consumption. These include: treatment condition (START vs. Comparison), county cluster (i.e., where CPS services were provided), the child's age, the child's gender, and whether the child was identified in a subsequent case of maltreatment with CPS within 12 months of their index event. A description of these variables will now be provided.

Treatment Condition. The treatment condition variable was be a dichotomous variable that described whether the child participant's family received START services or received CPS services as usual. This is the primary independent variable of interest because it allowed for the treatment effect estimates related to participation in START.

County Cluster: The county cluster variable that described where a child's family received CPS services and was coded 1-5 in the analyses. The inclusion of this variable was intended to investigate whether differences existed between regions in terms of health services outcomes.

Child Age: The child's age was included as an indicator variable because of the aforementioned relationships between a child's age and their level of risk for harm that has been described in the literature. Because a given CPS case can last over a duration of several months, this variable described the child's age at the time their case was referred to CPS (i.e., "index event"). This was a seven-level variable that condensed a child's age in months into 
categories, divided into yearlong increments. These categories were: 1) birth - six months, 2) seven - 11 months, 3) $12-23$ months, 4) $24-35$ months, 5) $36-47$ months, 6) $48-59$ months, and 7) 60+ months.

Child Sex: The child's sex was included as an independent variable because male and female children often differ in their healthcare needs and their susceptibility to types of maltreatment, and therefore consume health services in ways that can meaningfully differ.

Subsequent Maltreatment: The larger program evaluation identified cases of subsequent maltreatment within twelve months of the child's index case. This was collected as a means of testing whether participation in START served as a means of tertiary prevention for further maltreatment. This variable was included to determine whether any subsequent maltreatment was associated with health services utilization (i.e., irrespective of when in that twelve-month period the maltreatment occurred).

\section{Dependent Variables/Outcome Measures}

The outcome measures for this study were divided into two domains: (1) The sum of Medicaid spending during each child's two year period after their index CPS event (i.e., total Medicaid spend on the child's outpatient visits, ER visits, and hospital stays) and, (2) The sum of each child's visits to the three service types during the same period (i.e., number of outpatient visits, number of ER visits, and number of inpatient hospital days). The outcome variables were chosen both because they are generally considered to be among the most costly services that Medicaid pays for as well as being particularly amenable to reduction through services that address addiction (Clark, Samnaliev, \& McGovern, 2009; McCollister \& French, 2003). Moreover, they are in accordance with conventional ways of operationalizing the construct (e.g., French et al., 2000; Florence et al., 2013). They are also 
of particular interest to Kentucky Medicaid officials because they are expensive services to pay for, and because there are precedents in the literature where a family's use of high-cost medical services are reduced when one member receives addiction treatment (Weisner et al., 2010). These outcome measures are described in greater detail below. Again, each of these measures describe the sum of the number of visits a child made to a healthcare provider during their first and second years after the initiation of their index CPS case.

Emergency Room Visits: This variable was operationalized as a discrete count variable that described how many times a child was treated at an emergency room during the two-year period following the index contact with CPS. In this study, an emergency room visit was identified by Medicaid's claims database, which included any emergency department in the state of Kentucky capable of billing Medicaid. This data, including the primary diagnosis codes associated with the visit was acquired from CHFS.

Inpatient Hospitalizations: This variable was operationalized in the same way as the emergency room variable. This was also a discrete count variable that described the number of inpatient hospital stays associated with each child that were paid by Medicaid during the two year (intervention and follow-up) study period. In this study, a hospital visit was also identified by Medicaid's claims database, which included any inpatient hospital facility in the state of Kentucky capable of billing Medicaid. This category most generally involved general inpatient medical facilities, but also included inpatient psychiatric hospitals. Admission for inpatient hospitalization is generally the most acute, most specialized, and most expensive type of medical service provided to children, and is thus typically reserved for only the most severe diagnoses. 
Outpatient Visits: This variable was also operationalized in terms of the number of visits over the two year period following the index contact with CPS. This variable was included because outpatient services constitute another large cost to Medicaid. Due to the way Medicaid warehouses claims data, this variable included visits to physician offices and clinics as well as other providers who bill Medicaid for pediatric health services (e.g., speech pathologists, clinical social workers, etc.). In this study, an outpatient visit was identified by the recorded claims paid for this array of office-based ambulatory care services; which also included providers such as dental offices, physical therapy offices, and primary care practices.

Total Spend: This variable was included to be a summary of the net effects of treatment on Medicaid spending. It was a simple sum of the total spend of the three service categories described above that a child consumed over the two year period following the index event. Because those three categories constitute a large portion of Medicaid's total annual spend, this variable allowed the analyses to estimate a general sense of START's effects on costs to Medicaid for this vulnerable population in Kentucky.

\section{Preparation of the Dataset}

\section{Source Datasets}

As described above, before this study could conduct its analyses, it required the generation of a single dataset by merging secondary administrative datasets collected from three sources. Again, these were: (1) a very large dataset (> 1.6 million cases) provided by the Information and Quality Improvement (IQI) division of the Protection and Permanency office at CFHS, (2) one program evaluation dataset collected from START-IN data, and (3) one Medicaid claims dataset provided by CHFS. This merging process was necessary 
because, although the data required to test the study's hypotheses had already been collected, they did not reside within a solitary repository for the purposes of analyses. Table 3.3 below provides more detailed descriptions of the data contained within these three sources, as well as their use in this study.

\section{Table 3.3}

\begin{tabular}{|c|c|c|}
\hline Data Source & Brief Description of the Data & Purnose in the Present Study \\
\hline $\begin{array}{l}\text { IQI Adult \& } \\
\text { Child Protective } \\
\text { Services Case- } \\
\text { Based Dataset }\end{array}$ & $\begin{array}{l}\text { Contained records of calls } \\
\text { placed to APS/CPS hotlines } \\
\text { in all } 120 \mathrm{KY} \text { counties } \\
\text { (regardless of findings) } \\
\text { - Master dataset contained over } \\
1.6 \text { million calls to APS/CPS } \\
\text { hotline } \\
\text { - These include important } \\
\text { dates, demographic } \\
\text { information, investigation } \\
\text { findings, case descriptions, } \\
\text { etc. }\end{array}$ & $\begin{array}{l}\text { Used to identify candidate } \\
\text { families for inclusion in the } \\
\text { PSM procedure to construct } \\
\text { comparison group of families } \\
\text { who did not receive START } \\
\text { - Only included data from } \\
\text { families served within the } \\
\text { defined study period (2010- } \\
\text { 2016) }\end{array}$ \\
\hline $\begin{array}{l}\text { START-IN } \\
\text { dataset }\end{array}$ & $\begin{array}{l}\text { Contained records of families } \\
\text { who have received the } \\
\text { START intervention } \\
\text { - This included administrative } \\
\text { data involving over 2,000 } \\
\text { individuals (parents and } \\
\text { children) who have been } \\
\text { served by START }\end{array}$ & $\begin{array}{l}\text { Used to construct the } \\
\text { experimental group } \\
\text { - Only included data from } \\
\text { families served within the } \\
\text { 2010-2016 period }\end{array}$ \\
\hline $\begin{array}{l}\text { CHFS Medicaid } \\
\text { claims dataset }\end{array}$ & $\begin{array}{l}\text { Contained insurance claims } \\
\text { information related to } \\
\text { participant's receipt of health } \\
\text { services } \\
\text { - This dataset is restricted to } \\
\text { only a subset of health service } \\
\text { categories selected by the } \\
\text { investigators }\end{array}$ & $\begin{array}{l}\text { Used to quantify health } \\
\text { services consumption over the } \\
\text { duration of the study period } \\
\text { (both number of service } \\
\text { contacts and associated costs) }\end{array}$ \\
\hline
\end{tabular}

Given that these sources contained administrative data, none of which were explicitly collected for the purposes of this study, a considerable amount of cleaning and reformatting 
was necessary in order to generate an appropriate dataset for the analyses. What follows is an outline of the process of obtaining these data and formatting them for the ultimate study dataset that was used for the Medicaid claims analyses.

Step 1: Merging START-IN Data with CPS data

First, the data from START-IN (i.e., that which only contains data from intervention group participants) was consolidated with the larger dataset provided by DCBS (i.e., that which contains data from all calls to CPS from 2010-2016 - including START participants). CPS generates an identification number for all families they come into contact with called a TWIST ID (TWIST is short for The Worker Identification System). These two datasets were first merged using TWIST case numbers. Because START families were already housed in the larger 272 dataset, this process' chief utility was to carry over data that was uniquely collected by the START teams (e.g., unique treatment outcomes) and merge it with the existing information on the families whose data already resided in that dataset.

\section{Step 2: Eliminate Inappropriate Cases According to Study Parameters}

The resultant dataset included information on a number of individuals who were not appropriate for inclusion in the final analyses. Specifically, APS (adult protective services) cases and domestic violence cases were eliminated from the large dataset, as they were not relevant to this study. Cases that were called in to the DCBS abuse hotlines before 1-1-2010 and after 12-31-16 were also eliminated, as they fell outside the study period. Parenthetically, this study range begins approximately three years after START was launched in its first site in Kentucky in order to account for the adoption and implementation phase of the intervention. While this criterion was primarily put in place because of the characteristics of the source dataset, this is also in consonance with the broader program evaluation literature. 
Specifically, insights from the field of implementation science suggest that organizations often require 2-4 years to successfully adopt a new intervention, train staff, and administer it with high fidelity (Fixsen, Blase, Naoom, \& Wallace, 2009). The study range ends when it does to allow for participants to have at least two years of time post-index CPS case before measuring Medicaid outcomes ( $~ 1$ year of intervention time; $~ 1$ year of follow up time).

Next, any maltreatment cases that were investigated by a CPS worker and given any designation other than "Substantiated" or "Services Needed" were eliminated. Because a case must have received one of these designations in order to be eligible for START, only nonSTART families who also received them were considered for the comparison group. In other words, START cases were only be compared with other CPS cases where a child was deemed to have been harmed or in need of CPS services to protect the child and assist the parent(s).

This step necessarily eliminated all cases where a CPS intake supervisor deemed an allegation of maltreatment to not even merit an investigation (the dataset designates this as "Did Not Meet Acceptance Criteria"). This effectively retained only those cases where: (1) abuse or neglect was confirmed to have occurred or, (2) cases where a CPS investigator found that the maltreatment did not occur as reported, but the family needed supportive services to ensure a child's safety. Furthermore, within this refined set of cases, all cases that did not involve substance use (i.e., substance use was not listed as a risk factor for the maltreatment) were also removed. This created a subsample that further conformed to the types of cases seen by the START teams.

Step 3: Identifying Focal Children 
CPS cases often involve more than one child. This could arise for multiple reasons. In some cases, it was the result of more than one child being victimized. In others, CPS also recorded the non-victim siblings who reside in the home. To account for this, the strategy was to match the youngest child in a START family with the youngest child in a candidate non-START family. The theoretical basis for this decision involved evidence from the broader child welfare literature that suggests that children are at the greatest risk for maltreatment in their first years of life (Besinger et al., 1999). This line of research suggests that the risk for the most severe forms of maltreatment tend to decrease as children get older and less vulnerable. Because of their role in the matching process, these children are referred to as the "focal children". For the purposes of the match, a variable was created that designated which child within a given case was the focal child. Once identified, the data from these focal children was isolated from their siblings (i.e., any other named children in their case), and they became matching candidates for the final study sample.

Furthermore, in order to receive START, a family must have had a child in the home that was five years old or younger at the time of the index CPS report. This being the case, non-START families with CPS cases not involving a child within this age range were not considered as candidates for the comparison group, and were thus removed from the dataset. These steps effectively retained non-START families within the county clusters whose cases met START inclusion criteria and shared another important characteristic of the intervention group families.

One further complicating factor to this process was the reality that some families enter and exit CPS multiple times over a given timeframe. In other words, a single family may be reported to CPS multiple times over a three year period. This was true of this dataset 
- several of the non-START families who met the inclusion criteria had more than one CPS case opened over the duration of the study period. In instances where this was true, the strategy was to randomly select one of the cases for inclusion in the comparison group. This decision was made in order to reduce any bias that may have resulted through systematically selecting a family's first or last CPS case. In other words, inadvertently filling the comparison group with families on their first case would risk biasing the group against START if it increased the potential they may have future recurrence. Past evidence also suggests that a previous report to CPS is associated with increased risk for future reports, and may suggest a higher level of underlying risk (Sledjeski, Dierker, Brigham, \& Breslin, 2008). This being the case, the randomization process was intended to avoid biasing the comparison group sample for or against the experimental group.

\section{Step 4: Obtaining Medicaid Claims Data}

The outcome data for the study relied on data obtained from the Kentucky Department for Medicaid Services. Because this study aimed to investigate the health services utilization of children, the nature of the request for claims data was especially sensitive. As such, this study was reviewed and approved by the CHFS Institutional Review Board (IRB) as a continuation of the existing authorization of the broader ongoing START program evaluation. Through a reciprocal institutional authorization agreement, the University of Louisville's Institutional Review Board also approved this study. Because this study involved the analysis of administrative data, the only risk to human subjects was the breach of their confidentiality. This risk was addressed through the use of a speciallydesignated, password-protected Microsoft SharePoint@ platform to warehouse data. The 
process of sharing sensitive information between the evaluation team and CHFS was facilitated using the MOVEit@ secure file transfer software.

Once the PSM process successfully generated a matched comparison group, identifying information for the 1,043 children was supplied to officials at CHFS and claims data for each child was returned in a de-identified format.

\section{Obtaining Medicaid Claims Data from CHFS}

After PSM was conducted, a 1:1 match was identified for each child in each cluster except for one child in the Martin County cluster for which no suitable match was identified. Bias reduction statistics standards were deemed to be met if the PSM process generated mean and median bias values below 10 for each county cluster. Once the final list of 1,043 unduplicated children was identified from the TWIST data system through this process, a meeting was scheduled at the Kentucky CHFS headquarters in Frankfort, KY to discuss matching these children with their corresponding Medicaid claims data. Upon consultation and review of data sharing agreements, the aims of the START program evaluation, and the terms outlined in the IRB approval, the request for de-identified Medicaid data was approved by CHFS.

Once the approval was granted from CHFS officials, the list of 1,043 child names and other identifying information taken from the TWIST system (date of birth, address, county of residence, etc.) was provided to a team of analysts in the Office of Health Data and Analytics at CHFS. This initial record-merging process returned a match for 675 of the original 1,043 identified children (341 START children and 334 Comparison Children). While this match rate was considered a preliminary success, it was determined that another attempt was warranted in order to determine whether the final sample size could retain a larger amount of 
the original sample of children. Because Medicaid eligibility is an inclusion criteria for START, as well as the reality that Medicaid is a significant provider of health insurance for the CPS-involved population, a $65 \%$ match rate seemed lower than expected.

In order to improve this match rate, officials at DCBS coordinated with the Office of Health Data and Analytics to share social security numbers for the identified children (which have not been data historically included in the broader START evaluation and thus not available to the evaluation team). With this additional identifying information, 177 more children who were not initially matched were able to be matched with their corresponding Medicaid claims data. After this process, a sum total of 852 children (81.7\% of propensity score matched sample) were identified for inclusion into the final analyses (435 START children; 417 comparison children). A description of the sample before and after the Medicaid match is provided in Table 4.2 in the following chapter.

\section{More on Ethical Concerns, Data Storage, and Confidentiality}

This study used sensitive information that was protected by confidentiality regulations such as HIPAA. All other pertinent laws were observed, and several measures were put in place to protect the confidentiality of participants. The process of sharing, storing, and analyzing information conformed to existing standards and norms established by the START program evaluation. To further mask the individual identities of a given child participant, CHFS removed identifiable variables (child's name, date of birth, address, date of index contact with CPS, TWIST ID's, and county of residence) from the dataset before returning it to the evaluation team for analyses. 


\section{Data Analysis}

\section{Propensity Score Matching}

There are two chief ways that the use of a PSM procedure adds value to program evaluation analyses: (1) it can reduce the presence of selection bias when constructing comparison groups from observational data and (2) it can therefore increase the validity of conclusions regarding between-group differences and treatment effects using observational data (Guo et al., 2006; Barth et al., 2008). The method originated from the work of statistician Donald Rubin, and first appeared in published form in Rosenbaum and Rubin (1983). The theoretical underpinning of PSM is known as the Rubin causal model, which describes a counterfactual framework in which participants have potential outcomes in each assignment condition (i.e., treatment vs. non-treatment).

For example, in this particular case, this counterfactual framework would assert that what the research questions are actually concerned with is whether a given child's outcomes would be better after receiving START than they would be if they could be compared to an alternate reality where that same child did not receive START. Because this is impossible, the process of matching intervention group participants with comparison group participants on the basis of a score that describes their propensity to receive treatment is effectively treating the comparison group as a proxy for that counterfactual reality. In their original work, Rosenbaum and Rubin (1983) describe this value as such: "The propensity score is the conditional probability of assignment to a particular treatment given a vector of observed covariates." (p. 41). This procedure has been used in multiple authoritative child welfare studies of the effect of addiction services on outcomes for substance using parents. Specifically, the approach used here was conducted based on the insights presented in Guo, 
Barth, and Gibbons (2006), Johnson-Motoyama, Brook, Yan, and McDonald (2013), and Brook, McDonald, \& Yan, (2012).

As described above, this process was conducted after erroneous cases had been removed from the dataset. At that point, five separate PSM procedures were conducted (one for each county cluster). This decision was made for two reasons: (1) it simplified the PSM procedure by restricting possible comparisons to a defined geography. The alternative would have been to treat the county as just another matching variable, which would in turn have created the opportunity for participants from different clusters to match with one another (an unacceptable selection bias risk). (2) It created a useful variable to allow for the program evaluation to draw conclusions about the differences in treatment effects from one site to another.

Using the convention outlined in Barth and colleagues (2008), the PSM parameters in this study used one to one, nearest-neighbor matching without replacement. A caliper size of 0.20 of the standard deviation of the propensity score was used. The PSM procedure was conducted using the psmatch2 command in the STATA ${ }^{\circledR}$ statistical software package (StataCorp, College Station, TX). Once matches were generated from the psmatch2 command, the results of the match were tested using the pstest command, which generated significance tests to determine whether the two groups differed significantly along the matching variables (i.e., observed covariates). The pstest command also checked the accuracy of the match by producing mean and median bias reduction statistics for the matched model. The pstest command produces bias reduction statistics both for individual covariates as well as for the full model. As reported in Pan and Bai (2015), "The selection bias associated with a covariate $\mathrm{Xk}(\mathrm{k}=1, \ldots, \mathrm{K})$ is defined as the mean difference in the 
covariate between the treatment conditions; that is, $\mathrm{B}=\mathrm{M} 1(\mathrm{Xk})-\mathrm{M} 0(\mathrm{Xk})$, where $\mathrm{M} 1(\mathrm{Xk})$ and $\mathrm{M} 0(\mathrm{Xk})$ are the means of the covariate for the units in the treatment and control groups, respectively.” (p. 8). Mean and median bias levels below 10 for the full PSM model were determined to indicate a sufficient match. This process of checking the quality of a PSMgenerated output is referred to as assessing the range of common support. The results of this process are presented in Chapter IV.

Analyses of Health Services Utilization and Costs

Once the dataset had been adequately prepared, the comparison group had been successfully created using PSM, and the cost data had been collected from CHFS and integrated into the study dataset, the final analyses were conducted. The analytic decisions relied on a diagnosis of the underlying distribution of the Medicaid claims data.

Broadly speaking, health services data does not typically meet the assumptions of parametric statistics. More specifically, the distributions are seldom normal, and are very commonly right skewed and leptokurtic, with a large mass of values at zero. Practically speaking, such characteristics describe scenarios where many members of health insurance programs consume little to no healthcare during a given period of time, and only a few members consume large amounts (Afifi, Kotlerman, Ettner, \& Cowan, 2007). This was the case for the outcome variables of interest in this study (e.g., many participants made 0 emergency room visits in the study window), which often indicates that the distribution will fail to meet the assumptions of traditional ordinary least squares regression techniques.

There are a collection of analytic strategies used to account for the characteristics of the data. Zero-inflated Poisson or negative binomial regression analyses are common methods for analyzing count data in health services research. Zero-inflated regression models 
are used for count data that include many zeros (Ridout, Hinde, \& DeméAtrio, 2001). Moreover, these statistical approaches must also often account for overdispersion; where the variance in a given distribution is larger than the mean (Afifi et al., 2007). This is another feature of the claims data that is likely to be present, and is a point of flexibility that negative binomial models have that Poisson models do not allow for. This approach was used in French and colleagues (2000) in their analysis of health services utilization of out of treatment substance users.

A final benefit of zero-weighted regression models are that they can accommodate zero counts that arise for different reasons. Theoretically, zero values may be produced by exogenous variables that are independent of the count process, or they may caused by the count process. For example, a given START participant may have 0 emergency room visits for a period of time for at least two reasons. (1) Their health is not significantly impacted by participation in START, and their lack of emergency room care is attributable to some other reason (e.g., lack of transportation), or (2) They have become healthier as a result of their participation in START and have thus been able to prevent emergency room care during a given observation period. While both cases would have a 0 on this count variable, the differences between the circumstances that resulted in that outcome are meaningful. The Vuong test is a statistical method that tests whether a given distribution is zero-weighted, and can be run on the claims data for the purposes of fitting the appropriate model (Desmarais \& Harden, 2013). An alternative to the zero-inflated approach is the hurdle model (also called the truncated model), which treats a given distribution that contains many zeros as two separate distributions: one distribution of zeros and one containing positive values greater than zero. Theoretically, this approach treats the underlying count process as differing 
between those with zero vs. positive count values (DeSantis, Lazaridis, Ji, \& Spinale, 2014). For example, in this case, a given family may have zero visits to the hospital because they are especially fearful or distrustful of doctors, and out of principle do not take their children to hospitals for care. This group would theoretically belong to a different distribution than those families who took their children to a hospital at least one time.

Another approach is the Poisson regression model with robust standard errors. Similarly to the approach described above, this method makes many of the same assumptions of the underlying distribution and attempts to account for them in its output. The inclusion of robust standard errors allows for researchers to account for heteroscedastic standard errors in count distributions. For example, in the present study, it is very likely that unobserved family characteristics were present that influenced whether a parent brought their child to the hospital (e.g., level of health literacy, access to transportation, etc.). Each of these count models was explored in this study, but the Poisson model and zero-inflated Poisson models were chosen and reported.

For the cost variable (which was measured as a continuous variable in dollars), a natural log transformation of the data could was used before conducting the generalized linear model. The results of these analyses are presented in the following chapter. 


\section{CHAPTER IV}

\section{RESULTS}

This chapter will describe the results of the analyses outlined in the previous chapter. In so doing, it will begin with a description of the winnowing process that led to the identification of the final study sample. Then, it will proceed to report on health services utilization and Medicaid spending broadly before describing the results of the count and cost regression models.

\section{Characteristics of the Sample}

\section{Prior to Propensity Score Matching}

As previously discussed, the experimental group was identified by using the STARTIN system of children whose families were START participants between 2010 and 2016. After screening participants using the inclusion and exclusion criteria described above, 522 START children were identified for inclusion in the analyses. In terms of county clusters, the Jefferson County cluster contributed the greatest number of children to the experimental group, and the Martin County contributed the fewest. The number of participants from each cluster, in order from largest to smallest, was as follows: Jefferson $(n=196)$, Kenton $(n=$ 128), Boyd $(n=110)$, Daviess $(n=55)$, and Martin $(n=33)$. These relative values are unsurprising given the number of teams operating in each county, the population size of each region, and the range of time during which the program was provided during the 2010-2016 period.

Once these children were identified, it was possible to begin the process of identifying appropriate children for the matched comparison group. After reducing the larger 
272 dataset from CHFS to meet the broad, pre-PSM criteria described above (e.g., child younger than 6 years of age, CPS case was related to parental substance use, case originated after 2010, etc.), large pools of eligible comparison children were identified for each of the five START sites. Again, as a means of reducing the potential for selection bias, these children were only considered eligible for the PSM procedure if their CPS case was originated in one of the aforementioned county clusters.

Upon further examination of the 272 dataset, this data cleaning process required a number of additional measures to ensure that only appropriate children from appropriate families were included in the final PSM procedure to create the comparison group. These measures included: (1) removing cases where a START child was involved in a prior or subsequent non-START case (which could result in inadvertently matching a START child to themselves), (2) identifying families with more than one child under the age of 6 and "flagging" the youngest one, and (3) tailoring the date range to the site. For example, the Daviess County START team began operation in 2013 - so as an additional precaution, this process involved removing non-START children who first contacted CPS in the 2010-2012 range to ensure a 2013 START child could not be matched to a 2010 comparison child.

While this process likely reduced the ultimate risk for selection bias, it also considerably reduced the universe of eligible children for PSM. Specifically, the total pools of match candidates for each cluster were as follows: Jefferson ( $n=6,263$ non-START children), Kenton ( $\mathrm{n}=3,925$ non-START children), Boyd ( $\mathrm{n}=1,888$ non-START children), Daviess ( $\mathrm{n}=1,077$ non-START children), and Martin ( $\mathrm{n}=1,749$ non-START children). When utilizing PSM, larger sample sizes of untreated candidates for comparison are better for achieving optimal matches. However, in light of this reduction from the considerably 
larger pre-conditioned universe of untreated children in the original 272 dataset, every county cluster retained a ratio of treated to untreated children that was deemed sufficient to meet the conventional requirements of PSM. According to Rubin and Thomas (1996), a ratio of 1:20 is appropriate. These ratios of treated to untreated children ranged from a low of 1:17 in the Boyd County Cluster to a high of 1:53 in the Martin County cluster. For the purposes of clarity, these children will hereafter be referred to as "comparison candidates" as opposed to "confirmed comparisons".

Results of the Propensity Score Matching Procedure by County Cluster

A series of bivariate analyses revealed that, before PSM, there were important and statistically significant differences between the study groups on a set of the matching variables. Even granted the restriction of the data to impose more stringent criteria, comparisons between the START group and the larger pool of comparison candidates showed differences that were consistent with the established nature of the START program's clientele base as well as the population demographics of Kentucky. Specifically, before matching, the average START child was significantly: (1) younger, (2) less likely to belong to a racial minority group (i.e., more likely to be White), (3) more likely to have their case directly related to parental substance use, and (4) more likely to have a parent with a criminal history than their peer children in the comparison pool.

As described in Chapter III, the PSM method required that the children be segregated by county cluster before matching to ensure that only children who lived near to a START child would be eligible to match to that START child. Each of the separate models achieved convergence, and propensity scores were estimated for each of the children in the county cluster samples. Table 4.1 provides a summary of the results from each of the five PSM 
models and demonstrates satisfactory reductions in mean and median bias for each of the county cluster samples. Table 4.1 indicates that mean and median bias were high prior to matching (i.e., there was significant imbalance along the observed covariates between treated and untreated children), but was sufficiently reduced after matching. Generally, consensus dictates that mean and median bias values below 10 are adequate to conclude that PSM has sufficiently reduced validity threats due to selection bias.

\section{Table 4.1}

Results of Propensity Score Matching

\begin{tabular}{|c|c|c|c|c|c|c|}
\hline $\begin{array}{l}\text { County } \\
\text { Cluster }\end{array}$ & $\begin{array}{l}\text { Matched vs. } \\
\text { Unmatched }\end{array}$ & Pseudo $\mathrm{R}^{2}$ & Likelihood Ratio $\chi^{2}$ & $\mathrm{p}>\chi^{2}$ & $\begin{array}{c}\text { Mean } \\
\text { Bias }\end{array}$ & $\begin{array}{c}\text { Median } \\
\text { Bias }\end{array}$ \\
\hline \multirow[b]{2}{*}{ Boyd } & $\begin{array}{l}\text { Unmatched } \\
(\mathrm{n}=1,994)\end{array}$ & 0.188 & 159.75 & 0.000 & 33.3 & 33.4 \\
\hline & $\begin{array}{l}\text { Matched } \\
(\mathrm{n}=220)\end{array}$ & 0.015 & 4.54 & 0.952 & 7.6 & 3.8 \\
\hline \multirow{2}{*}{ Daviess } & $\begin{array}{l}\text { Unmatched } \\
(\mathrm{n}=1,132)\end{array}$ & 0.275 & 120.91 & 0.000 & 38.4 & 29.5 \\
\hline & $\begin{array}{l}\text { Matched } \\
(\mathrm{n}=110)\end{array}$ & 0.022 & 3.41 & 0.970 & 6.6 & 4.5 \\
\hline \multirow{2}{*}{ Jefferson } & $\begin{array}{l}\text { Unmatched } \\
(\mathrm{n}=6,457)\end{array}$ & 0.376 & 660.04 & 0.000 & 46.6 & 28.3 \\
\hline & $\begin{array}{l}\text { Matched } \\
(\mathrm{n}=392)\end{array}$ & 0.007 & 3.72 & 0.977 & 4.6 & 2.4 \\
\hline \multirow{2}{*}{ Kenton } & $\begin{array}{l}\text { Unmatched } \\
(\mathrm{n}=4.048)\end{array}$ & 0.221 & 250.64 & 0.000 & 36.9 & 34.8 \\
\hline & $\begin{array}{l}\text { Matched } \\
(\mathrm{n}=256)\end{array}$ & 0.010 & 3.6 & 0.980 & 3.5 & 3.1 \\
\hline \multirow{2}{*}{ Martin } & $\begin{array}{l}\text { Unmatched } \\
(\mathrm{n}=1,782)\end{array}$ & 0.140 & 31.07 & 0.000 & 27.3 & 23.8 \\
\hline & $\begin{array}{l}\text { Matched } \\
(\mathrm{n}=65)^{*}\end{array}$ & 0.018 & 1.64 & 0.996 & 7.6 & 8.0 \\
\hline
\end{tabular}

*One START child did not match in the Martin County cluster 
The Final Study Sample

Table 4.2

Description of the Sample Before and After Propensity Score Matching

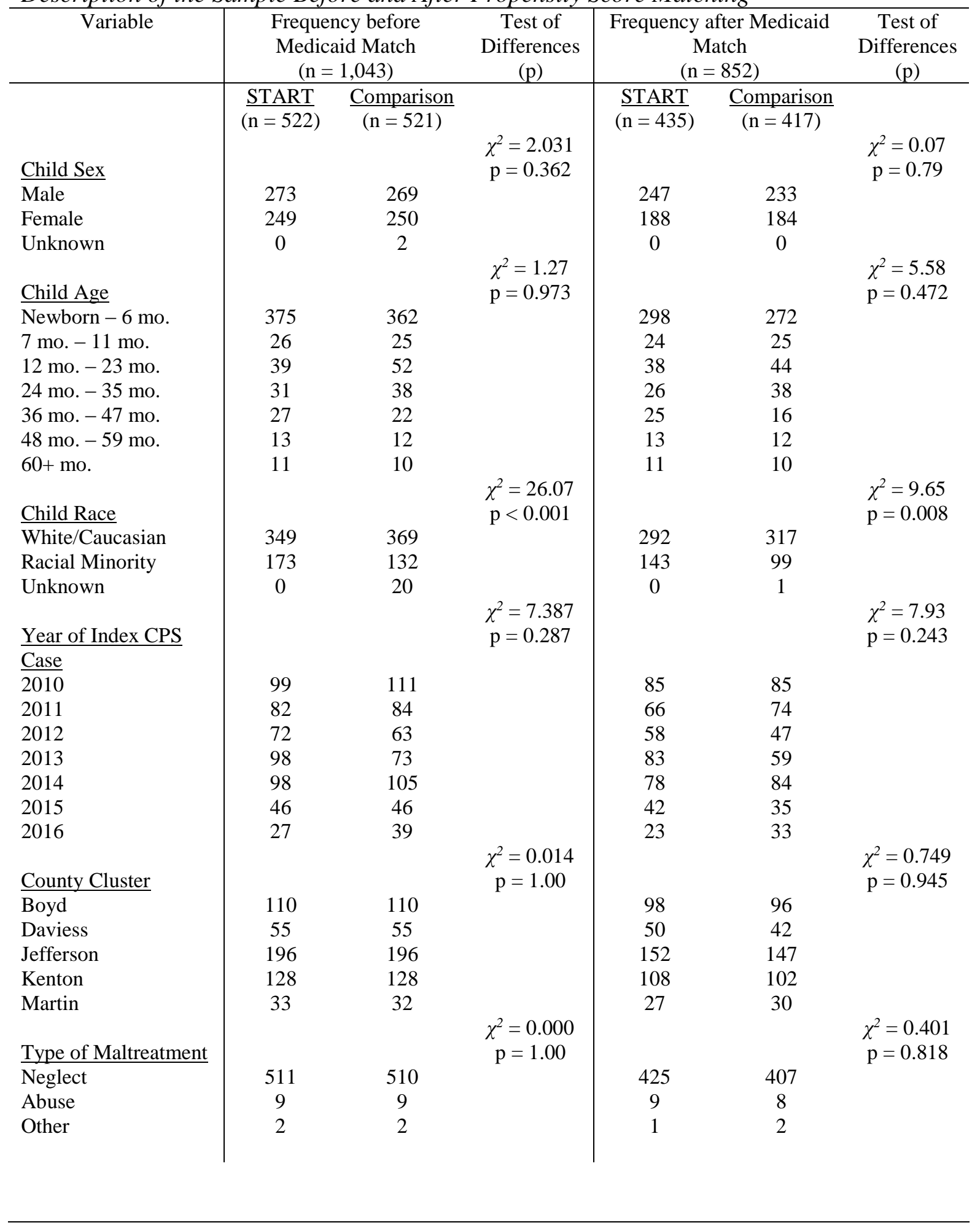


Table 4.2 (continued).

\begin{tabular}{|c|c|c|c|c|c|c|}
\hline \multirow[t]{2}{*}{ Variable } & \multicolumn{2}{|c|}{$\begin{array}{l}\text { Frequency before } \\
\text { Medicaid Match } \\
(\mathrm{n}=1,043)\end{array}$} & \multirow[t]{2}{*}{$\begin{array}{l}\text { Test of } \\
\text { Differences } \\
\text { (p) }\end{array}$} & \multicolumn{2}{|c|}{$\begin{array}{c}\text { Frequency after Medicaid } \\
\text { Match } \\
(\mathrm{n}=852) \\
\end{array}$} & \multirow[t]{2}{*}{$\begin{array}{c}\text { Test of } \\
\text { Difference } \\
(\mathrm{p})\end{array}$} \\
\hline & $\frac{\text { START }}{(\mathrm{n}=522)}$ & $\frac{\text { Comparison }}{(\mathrm{n}=521)}$ & & $\frac{\text { START }}{(\mathrm{n}=435)}$ & $\frac{\text { Comparison }}{(\mathrm{n}=417)}$ & \\
\hline $\begin{array}{l}\text { Investigation Finding } \\
\text { Substantiated }\end{array}$ & & & $\begin{aligned} \chi^{2} & =2.392 \\
p & =0.122\end{aligned}$ & & & $\begin{array}{l}\chi^{2}=* \\
\mathrm{p}=*\end{array}$ \\
\hline $\begin{array}{l}\text { Services Needed } \\
\text { Extent that Substance } \\
\text { Use Was Related to } \\
\text { the Case }\end{array}$ & 59 & 44 & $\begin{aligned} \chi^{2} & =2.665 \\
p & =0.446\end{aligned}$ & $*$ & $*$ & $\begin{array}{l}\chi^{2}=1.78 \\
p=0.619\end{array}$ \\
\hline $\begin{array}{l}\text { Was a Risk Factor } \\
\text { Indirectly Contributed } \\
\text { Directly Contributed } \\
\text { Other }\end{array}$ & $\begin{array}{c}353 \\
0 \\
126 \\
43\end{array}$ & $\begin{array}{c}328 \\
2 \\
140 \\
51\end{array}$ & & $\begin{array}{c}293 \\
0 \\
105 \\
29\end{array}$ & $\begin{array}{c}260 \\
2 \\
112 \\
29\end{array}$ & \\
\hline$\frac{\text { Parental Mental }}{\text { Health Problem }}$ & & & $\begin{aligned} \chi^{2} & =0.735 \\
p & =0.391\end{aligned}$ & & & $\begin{aligned} \chi^{2} & =1.746 \\
p & =0.186\end{aligned}$ \\
\hline $\begin{array}{l}\text { No } \\
\text { Yes }\end{array}$ & $\begin{array}{l}335 \\
187\end{array}$ & $\begin{array}{l}321 \\
200\end{array}$ & & $\begin{array}{l}286 \\
149\end{array}$ & $\begin{array}{l}256 \\
161\end{array}$ & \\
\hline Domestic Violence & & & $\begin{aligned} \chi^{2} & =0.735 \\
\mathrm{p} & =0.391\end{aligned}$ & & & $\begin{array}{l}\chi^{2}=8.86 \\
\mathrm{p}=0.114\end{array}$ \\
\hline$\overline{\text { Was a Risk Factor }}$ & 266 & 235 & & 220 & 194 & \\
\hline Indirectly Contributed & 0 & 2 & & 0 & 1 & \\
\hline Directly Contributed & 39 & 48 & & 33 & 40 & \\
\hline $\begin{array}{l}\text { Was Not a Risk } \\
\text { Factor }\end{array}$ & 217 & 236 & & 182 & 182 & \\
\hline Poverty Risk Factor & & & $\begin{array}{c}\chi^{2}= \\
126.036 \\
\mathrm{p}<0.001\end{array}$ & & & $\begin{aligned} \chi^{2} & =8.098 \\
p & =0.004\end{aligned}$ \\
\hline No & 139 & 139 & & 114 & 107 & \\
\hline Yes & 383 & 254 & & 321 & 208 & \\
\hline Missing Data & 0 & 128 & & 0 & 102 & \\
\hline $\begin{array}{l}\text { Parental Criminal } \\
\text { History }\end{array}$ & & & $\begin{aligned} \chi^{2} & =0.023 \\
p & =0.879\end{aligned}$ & & & $\begin{aligned} \chi^{2} & =0.003 \\
p & =0.958\end{aligned}$ \\
\hline No & 222 & 224 & & 187 & 180 & \\
\hline $\begin{array}{l}\text { Yes } \\
\text { Medicaid Member } \\
\text { Months }\end{array}$ & 300 & 297 & & 248 & 237 & $\begin{array}{l}t=1.247 \\
\mathrm{p}=0.21\end{array}$ \\
\hline$\overline{\text { Mean }}$ & N/A & N/A & & $\begin{array}{l}24.33 \\
(\mathrm{SD}= \\
7.52)\end{array}$ & $\begin{array}{c}24.98 \\
(\mathrm{SD}=7.68)\end{array}$ & \\
\hline Median & N/A & N/A & & 25 & 25 & \\
\hline
\end{tabular}




\section{Note on the Final Sample}

There are several important things to note regarding the characteristics of the final sample that matched to Medicaid data. First, as evidenced by a series of bivariate tests, the process achieved a level of balance that was ultimately deemed satisfactory to proceed with the analyses. The multiple rounds of paring down the sample, matching with untreated children, and finally conducting a blind match to Medicaid data left only two variables with between-group differences: race and the poverty risk factor. There were more racial minority children in the START group than the comparison group. It is possible that the PSM process identified families that were so similar along the other observed covariates (mental health risk, child's age, etc.) that the child's race was comparably less significant to their propensity to participate in START. The differences in the poverty risk factor were likely due to missing data from the 272 file where data on the comparison children was obtained. Similar rates of overall Medicaid enrollment between the groups, as evidenced by a match rate of $\sim 80 \%$ for each group support that rates of poverty were likely not significantly different.

\section{Equivalence of Medicaid Spending in One-Year Period Prior to Index CPS Case}

While bivariate balance on the observed covariates and the reduction of mean and median selection bias are important indicators of similarities between treatment groups, this study was also able to make use of baseline Medicaid spending as another means of verifying the validity of the match. In other words, a significant between-group difference in cost prior to entry to services would tend to suggest that there were, in fact, important unobserved covariates beyond mere group assignment affecting the observed outcomes (such as a child's baseline health status at birth, prevalence of chronic diseases, etc.). 
Of note on this matter, it is important to report that the study design called for examining baseline costs for up to one year prior to a child's index entry to CPS services. However, given that approximately two thirds of the children in the study sample were less than one year old at the time of their index CPS event, the data pulled by Medicaid necessarily reported much less information about these children. In the case of newborns, the claim generated for their delivery was the only data point included for their baseline period, and thus the event that began their particular study period (i.e., every subsequent claim for that year was considered to fall within the intervention year). For this reason, the entire duration of a given study period for a newborn was 24 months (12 month intervention period; 12 month follow-up period), and the full duration of a given study period for a child 1-year or older was 36 months $(12+12+12)$.

Moreover, to account for the fact that newborns could not have any identified spend prior to their birth, it was decided that a claim generated for a child's delivery and immediately subsequent hospital care (e.g., NICU stay) was to be considered to fall within the baseline period. This was ultimately decided upon because, although CPS often initiates services for newborns in the hospital before they have been discharged home, they cannot feasibly have any real impact on a child's utilization of healthcare services that early in the case.

In terms of total dollars spent during this baseline period, Medicaid reported spending $\$ 2,468,124.30$ on the 417 children in the comparison group and $\$ 3,135,106.37$ on the 435 children in the START group - for a sum total of $\$ 5,603,230.67$ spent in the one year period preceding a child's index CPS contact. These sums include the sum of each child's utilization of outpatient care, emergency room care, and hospital care. Most of this spend was 
attributable to the costs of hospital care for childbirth. Specifically, Medicaid spent a combined $\$ 4,669,564.03$ (54.6\% of total spending) on claims associated with deliveries and care for newborns. Of the 521 birth claims identified in the dataset, 40 had primary diagnoses coded 7795 (the ICD-9 code for newborn drug withdrawal syndrome). It is possible that this frequency underestimated the true prevalence of substance exposed births in the sample, because hospitals may have documented this information as a secondary diagnosis - in which case it was unavailable for analysis.

As is common with healthcare data, the distribution of the spend variable was highly right skewed and non-normal. Therefore, to test baseline differences in spend, a nonparametric Mann-Whitney U test was conducted, which found no statistically significant difference between the comparison and START groups prior to their entry to CPS services $(\mathrm{U}=92,312.5 ; \mathrm{p}=0.645)$. As a second measure, a generalized linear model was conducted which found that a typical START child was more expensive at baseline than their peers in the comparison group, but this difference in spend was nonetheless non-significant $(\mathrm{p}=$ $0.264)$.

It is well-established in the health services research literature that, for any given population, a small subset will generate a significant portion of total health spending. This was the case for this sample as well. As an example of the severity of the skewness of this data, there were five outlier children whose medical care during their baseline periods resulted in a summed spend of $\$ 709,834.19$ (12.7\% of total baseline period spending for the sample). Again, these outlier claims were predominantly due to expensive hospital care for newborns, such as treatment of congenital heart defects, premature/low birth weight deliveries, and respiratory diagnoses. 
Further Breakdown of Utilization and Costs During Two-Year Period After Index Case

The expense dedicated to caring for children in the first days of their lives is not unique to the children described in this study, but is a notable feature of this data. The data provided by Medicaid would not allow for a full assessment of the extent that neonatal exposure to substances contributed to this reality, as only primary diagnosis codes were provided by Medicaid (and often, the hospitals coded births with the blanket ICD code V3000 - single live birth in hospital w/o C-section). In other words, given the way that these children were identified (i.e., substantiated maltreatment at birth, parental substance use, high cost hospital delivery, etc.), it is possible that the available data underestimated the true prevalence of substance substance exposed births.

Table 4.4 below outlines medical spend by study period and by treatment group. In total, the 852 children generated a total of $\$ 8,558,110.03$ worth of medical spending on a combination of outpatient care, emergency room care, and hospital care over the entire study period. Over the full course of the study period, Medicaid spent $\$ 448,818.59$ less on comparison children than START children. However, this difference was entirely accounted for by baseline spending that occurred before children entered CPS services for their index case. Spend on the START children as a group was actually lower over the period of time that spanned two years after CPS became involved with the family.

By group, the total spend on comparison children was $\$ 4,054,645.72$ while the total spend on START children was $\$ 4,503,464.31$. Both groups displayed a general downward trend in Medicaid spending over time. 
Table 4.3

Medicaid Spending by Study Period and Treatment Group $(n=852)$

Baseline Intervention Follow-up

Total (By

Period

Year

Year

Treatment Group)

\begin{tabular}{lllll}
\hline $\begin{array}{l}\text { Comparison } \\
(\mathrm{n}=417)\end{array}$ & $\$ 2,468,124.30$ & $\$ 1,348,047.94$ & $\$ 238,473.48$ & $\$ 4,054,645.72$ \\
$\begin{array}{l}\text { START } \\
(\mathrm{n}=435)\end{array}$ & $\$ 3,135,106.37$ & $\$ 1,034,551.46$ & $\$ 333,806.48$ & $\$ 4,503,464.31$ \\
$\begin{array}{l}\text { Total (By Study } \\
\text { Period) }\end{array}$ & $\$ 5,603,230.67$ & $\$ 2,382,599.40$ & $\$ 572,279.96$ & $\$ 8,558,110.03$ \\
\hline
\end{tabular}

For the combined intervention and follow-up periods, the unadjusted per member per month spending on each group totaled $\$ 174.90$ for the comparison group and $\$ 145.17$ for the START group (a difference of $\$ 29.73$ per member month). This difference equated to $\$ 218,163.48$ less Medicaid spending on the START group than the comparison group over these two-year periods.

Per Member Per Month $($ Comparison $)=\frac{\$ 1,586,521.42(\text { Total Spend })}{9,071(\text { Total Member Months })}=\$ 174.90$

Per Member Per Month $($ START $)=\frac{\$ 1,368,357.94(\text { Total Spend })}{9,426(\text { Total Member Months })}=\$ 145.17$ 


\section{Figure 4.1 - Total Spend by Group}
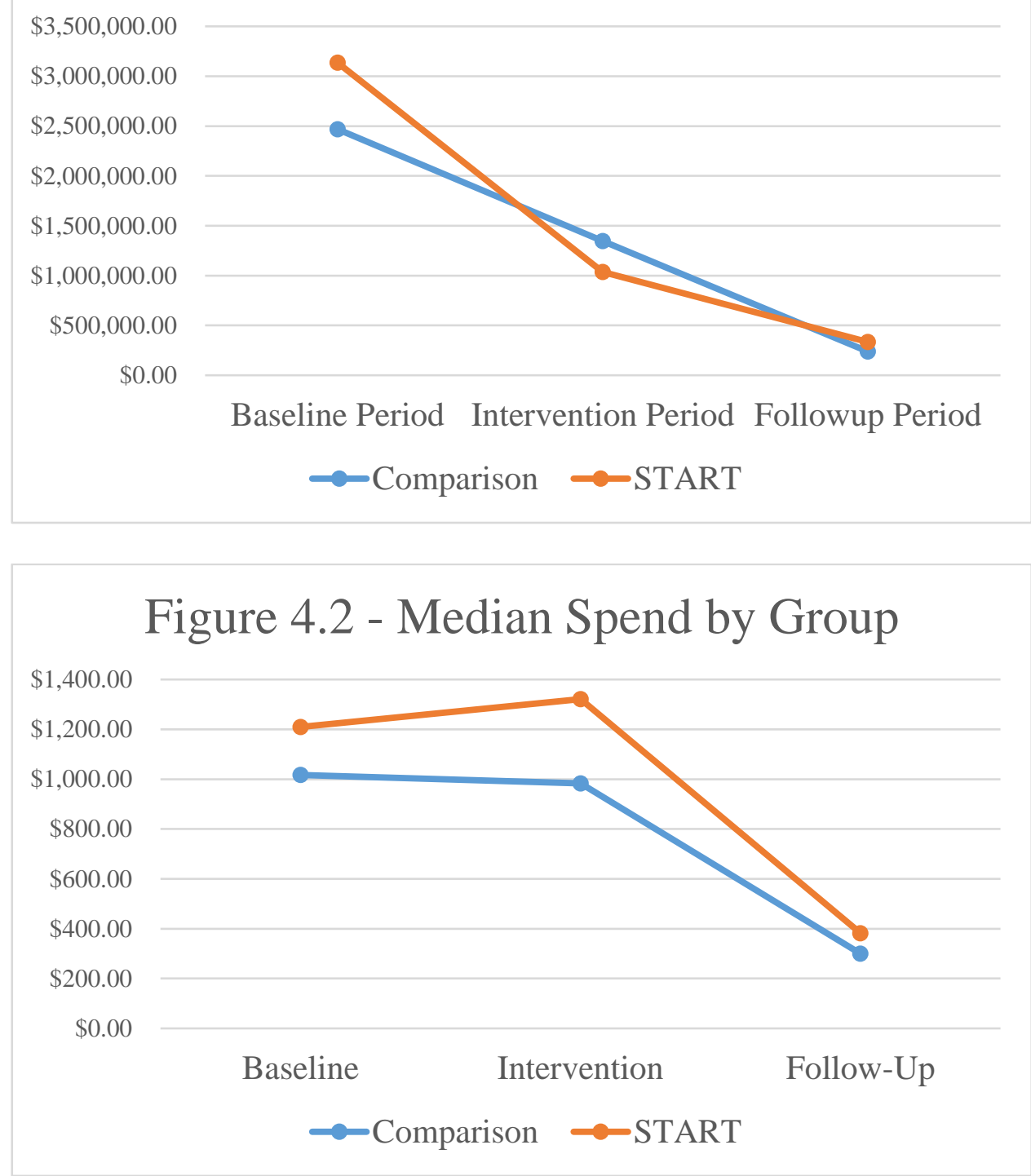


\section{Figure 4.3 - Total Spending By Service Type}

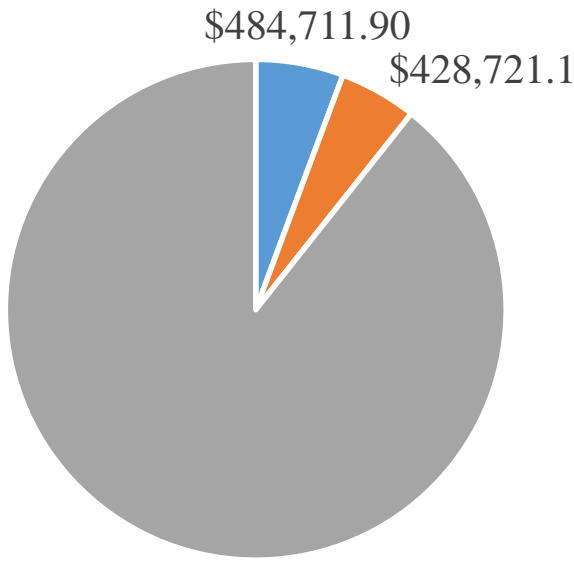

$\$ 7,644,677.02$

- Outpatient $(5.7 \%) \quad$ Emergency Room (5\%) $\quad$ Hospital $(89.3 \%)$

\section{Regression Model of Medicaid Spending}

To estimate treatment effects of START participation on Medicaid spending over the two year period beginning after their initiation of CPS services, a generalized linear model was conducted using the five independent variables described above: (1) treatment group, (2) county cluster, (3) child's sex, (4) child's age and, (5) whether the child endured recurrent maltreatment within 12 months after their index case. The natural log transformation of the variable that described each individual Medicaid spend over the two year period suitably addressed the distributional concerns, and resulted in a non-significant Kolmogorov-Smirnov normality diagnostic test. After a generalized linear model was conducted with the transformed dependent variable, another generalized linear model of the untransformed distribution was conducted using the gamma probability distribution (not shown). Neither of these models estimated a significant difference between the START and comparison groups. The results of this procedure are listed in Table 4.4 below: 


\section{Table 4.4}

Medicaid Spending Over Two Year Period After Index CPS Case ${ }^{a}$ Variable Coefficient $95 \% \mathrm{CI}$ $\mathrm{p}$

\begin{tabular}{|c|c|c|c|}
\hline Variable & Coefficient & $95 \% \mathrm{CI}$ & $\mathrm{p}$ \\
\hline Treatment Group $=$ & -.098 & $-.344-.148$ & .437 \\
\hline \multicolumn{4}{|l|}{ START(reference - comparison) } \\
\hline \multicolumn{4}{|l|}{ County Cluster (reference - Boyd) } \\
\hline Daviess & -.003 & $-.457-.451$ & .988 \\
\hline Jefferson & .172 & $-.189-.534$ & .349 \\
\hline Kenton & .214 & $-.141-.569$ & .237 \\
\hline Martin & .504 & $-.030-1.037$ & .064 \\
\hline $\begin{array}{l}\text { Child Sex = Male (reference - } \\
\text { female) }\end{array}$ & .067 & $-.181-.315$ & .596 \\
\hline \multicolumn{4}{|l|}{$\begin{array}{l}\text { Child Age (reference - newborn - } \\
6 \text { mo.) }\end{array}$} \\
\hline 7 mo. -11 mo. & -.212 & $-.743-.319$ & .434 \\
\hline 12 mo. -23 mo. & -.741 & $-1.184--.297$ & $.001 *$ \\
\hline 24 mo. -35 mo. & -.593 & $-1.108--.078$ & $.024 *$ \\
\hline 36 mo. -47 mo. & -.409 & $-1.046-.228$ & .208 \\
\hline 48 mo. -59 mo. & .273 & $-.485-1.031$ & .480 \\
\hline $5+$ years & -.908 & $-1.754--.062$ & $.035 *$ \\
\hline Recurrent Maltreatment at 12 & .390 & $-.026-.805$ & .066 \\
\hline Months $=$ Yes $($ reference - No $)$ & & & \\
\hline
\end{tabular}

Though this model did estimate that children in the START group had a lower perchild spend vs. comparison children, this difference did not achieve statistical significance. Beyond this, Medicaid spending was estimated to be non-significantly higher on male children vs. female children. In this model, the only significant indicator of Medicaid spending was the child's age, with newborns and infants tending to be the most expensive age group. This model further estimated that Medicaid had higher spending on the youngest and second oldest age groups, with spending being comparably less on older children. There were significant differences between the oldest age group (those who were at least 5 years old at entry to CPS services) and the youngest age group, as well as between the youngest age group (newborn -6 month olds) and the 1 year -23 months and 2 years -35 months age 
groups. Though not statistically significant, this model also estimated lower spending on children who were not the victim of substantiated maltreatment within 12 months after their index CPS case. In other words, the commission of a new substantiated case of maltreatment tended to estimate a moderately higher Medicaid spend.

A Note on the Relationship between a Child's Age at Entry to Services and Medicaid Spending

Figure 4.4 - Mean Spend Per Child by Age Groups

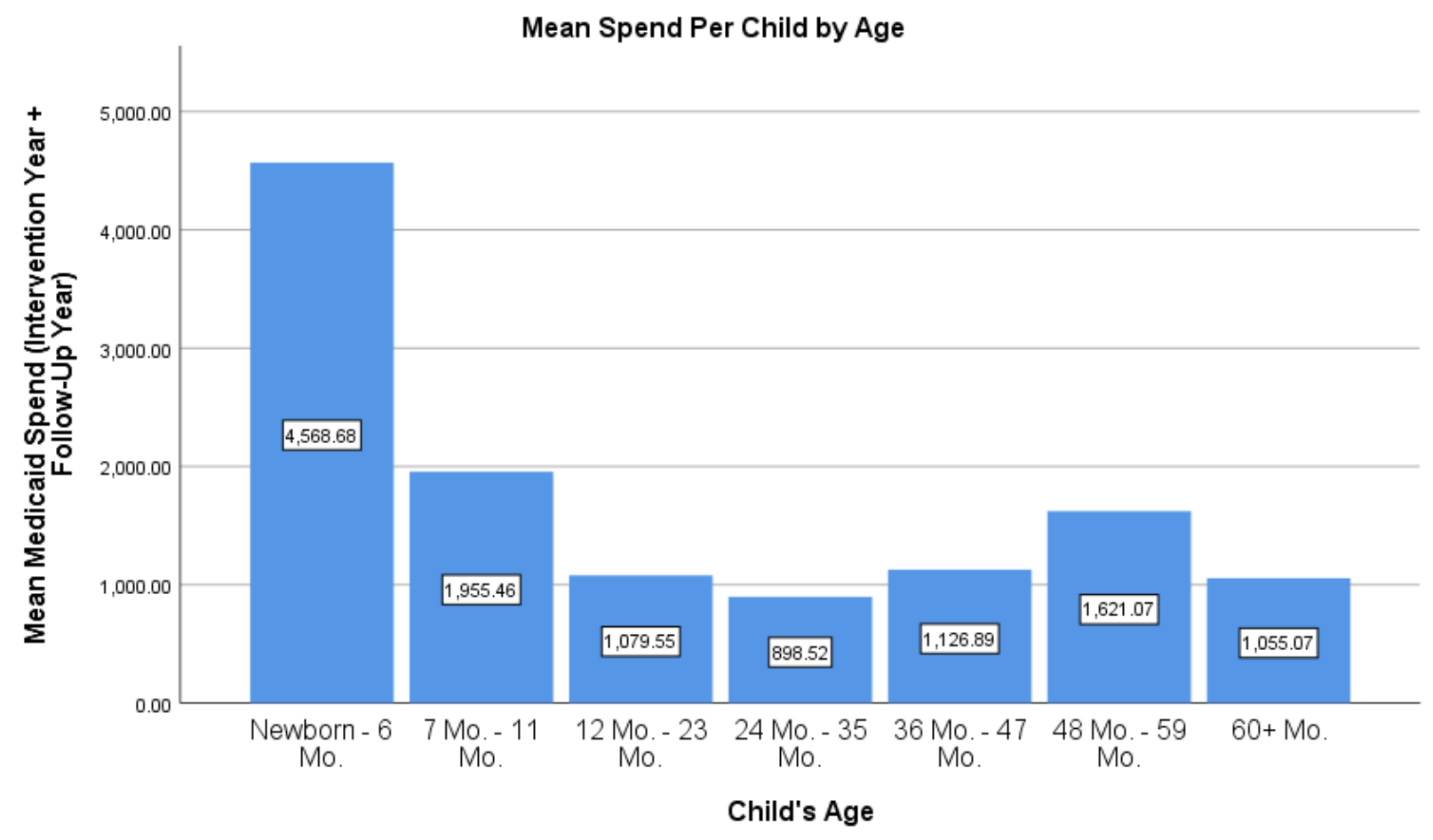

Figure 4.4 illustrates the mean differences in Medicaid spending over the duration of each child's two year post-index period. This figure provides another means of demonstrating that Medicaid spent the most on the youngest age group (newborns to sixmonth-olds). Specifically, the mean difference between the youngest age group and the oldest age group was $\$ 3,513.61$ over the two-year period. Additionally, this figure 
demonstrates that Medicaid tended to spend decreasingly less on children the older they were when they entered CPS services.

\section{Health Services Utilization}

First, the summed total of visits was calculated for each child by study period. These results are listed in Table 4.5. Tests of baseline utilization were conducted for each service type, and no statistically significant between-group differences were found in the year prior to entry to CPS. Utilization rates between groups tended to follow similar patterns. For example, hospitalizations in both groups were most frequent in the baseline period (a result of the high incidence of admissions for birth/labor \& delivery), and then trended sharply downward as children aged. For both study groups, outpatient visits and ER visits rose between the baseline period to the intervention period, and then dropped off in the follow-up period.

\section{Table 4.5}

Healthcare Visits by Treatment Group, Service Category, and Study Period ( $n=852)$ Baseline Period

\begin{tabular}{cccc}
\hline & Outpatient Visits & Emergency Room Visits & Hospital Visits \\
Comparison & 115 & 183 & 295 \\
START & 109 & 146 & 272
\end{tabular}

$\underline{\text { Intervention Period }}$

$\begin{array}{cccc} & \text { Outpatient Visits } & \text { Emergency Room Visits } & \text { Hospital Visits } \\ \text { Comparison } & 485 & 378 & 76 \\ \text { START } & 428 & 473 & 87\end{array}$

$\underline{\text { Follow-Up Period }}$

\begin{tabular}{cccc}
\hline & Outpatient Visits & Emergency Room Visits & Hospital Visits \\
Comparison & 394 & 342 & 15 \\
START & 370 & 394 & 31 \\
\hline
\end{tabular}

To estimate treatment effects of START participation on health services utilization over the two year period that began after their initiation of CPS services, a set of count 
regression models were conducted using the same independent variables as above. Because the distribution of these outcomes variables were discrete-level data that was right skewed, over-dispersed, and with large masses at zero (a common feature of health insurance claims data), it was determined to investigate these relationships using Poisson regression models and compare measures of model fit with negative binomial regression models. Although the negative binomial distribution does relax the Poisson's assumption that the variance $=$ the mean, Woolridge (1999) noted that Poisson models with robust standard errors often perform as well or better than negative binomial models. Zero-inflated Poisson and hurdle Poisson versions of these models were also conducted to determine whether accounting for the large number of zeros provided a better model fit for the data. The results of the standard (with and without robust standard errors) and zero-inflated Poisson models are presented below.

As a preliminary diagnostic check of a child's likelihood to have 0 visits for a given service, binary logistic regression models were conducted to determine whether treatment group membership was associated with whether a child had at least one visit. These each revealed no significant differences for outpatient visits, emergency room visits, or hospital visits. Though there were differences in model fit statistics between each of the models, the interpretations regarding estimates of health services utilization were broadly similar. These are presented in the following section. 


\section{Outpatient Visits}

Figure 4.5 - Histogram of Outpatient Visit Counts by Individual Child

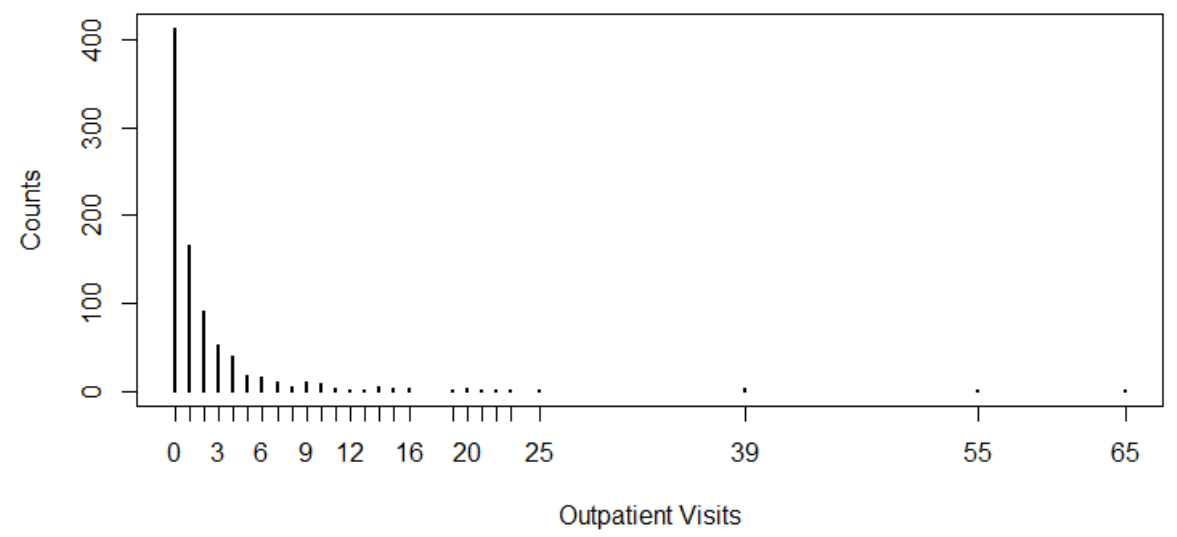

Among the most common reasons for presenting for an outpatient visit were:

speech/language pathology (4.5\% of total visits), cough (4.1\% of total visits), ear infections ( $3 \%$ of total visits), and routine child health examinations (2.9\% of total visits). Figure 4.5 below illustrates the raw sums of outpatient visits by study group and by study period. The median spend per outpatient visit during this study was $\$ 47.48($ mean $=\$ 254.98)$, although there were many cases where an outpatient visit was much more expensive (presumably at a specialist practice or for a complex procedure). For example, the most expensive outpatient claim paid was for $\$ 15,457.88$ for a child's dental care to address dental caries. 


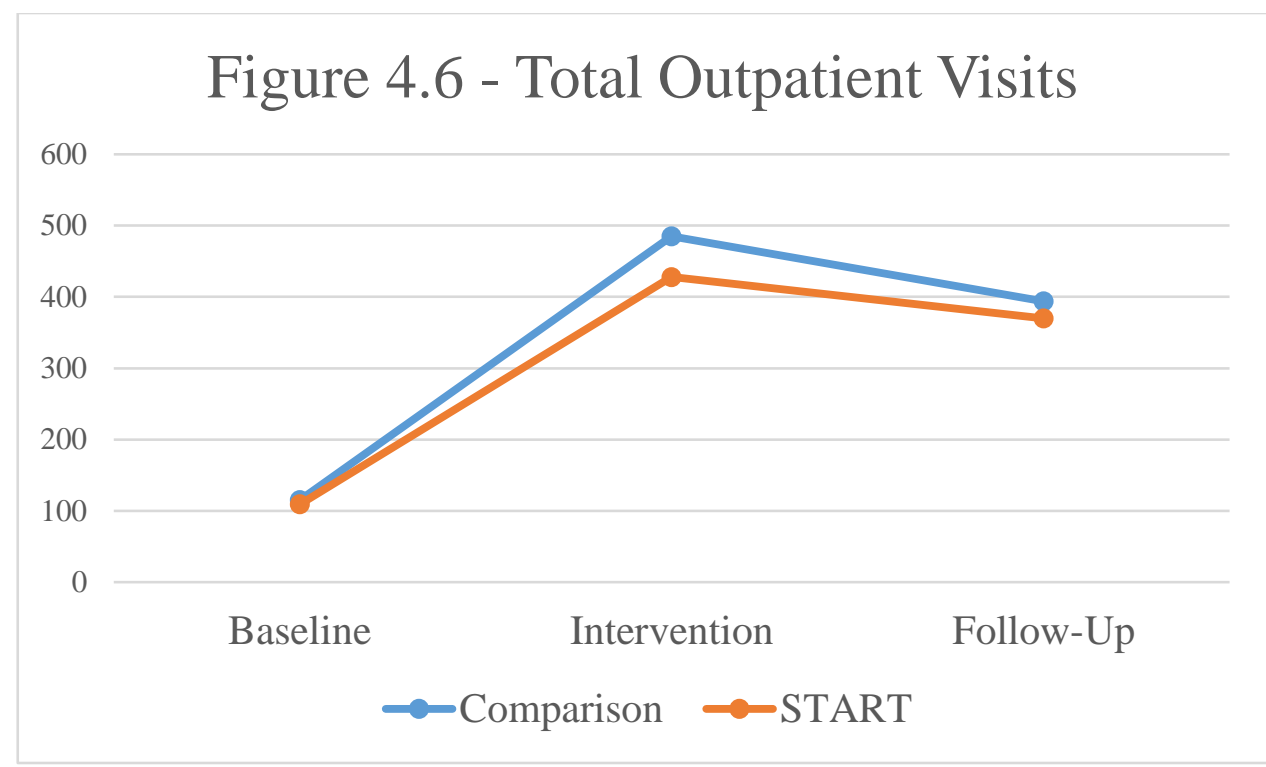

Figure 4.6 illustrates that the general trend in outpatient visits was comparable between groups. Each group began at a relatively low level of consumption of outpatient care, which then almost quintupled in terms of total visits for the comparison group and more than quadrupled for the START group during the year following the index CPS case. The prominent increase in consumption for this type of service was again a direct result of the fact that most of the children in this sample were not born yet in the year prior to their index CPS case; therefore, it was impossible for them to be treated at an outpatient provider's office. It is important to consider that the raw visit counts by group are sensitive to the reality that the START group contained 18 more children than the comparison group, and as a result, this information is helpful only in gauging the general patterns of consumption (not the effects of the independent variables on outcomes). The generalized linear models outlined below is more capable of estimating such effects. 
Table 4.6a

Poisson Regression Model of Outpatient Visits

\begin{tabular}{|c|c|c|c|c|}
\hline Variable & Coefficient & $95 \% \mathrm{CI}$ & IRR & $\mathrm{p}$ \\
\hline $\begin{array}{l}\text { Treatment Group = START } \\
\text { (reference }- \text { Comparison) }\end{array}$ & -.191 & $-.288-.093$ & .844 & $.001 *$ \\
\hline \multicolumn{5}{|l|}{ County Cluster (reference - Boyd) } \\
\hline Daviess & -.645 & $-.222-.167$ & .973 & $.000 * \mathrm{a}$ \\
\hline Jefferson & -1.376 & $-1.422--.995$ & .299 & $.000^{*}$ \\
\hline Kenton & -.195 & $-.719--.236$ & .620 & $.002 * \mathrm{a}$ \\
\hline Martin & -.167 & $-.027-.361$ & 1.182 & .092 \\
\hline Child Sex = Male $($ reference - female $)$ & -.077 & $.174-.020$ & .926 & .120 \\
\hline \multicolumn{5}{|l|}{ Child Age (reference - newborn -6 mo.) } \\
\hline $7 \mathrm{mo.}-11 \mathrm{mo}$ & -.266 & $-.456--.076$ & .767 & $.006 * \mathrm{a}$ \\
\hline 12 mo. - 23 mo. & -.791 & $-.977--.605$ & .454 & $.000^{*}$ \\
\hline 24 mo. -35 mo. & -1.233 & $-1.484--.982$ & .291 & $.000 *$ \\
\hline 36 mo. - 47 mo. & -.932 & $-1.204--.661$ & .394 & $.000 *$ \\
\hline 48 mo. - 59 mo. & -.844 & $-1.170--.517$ & .430 & $.000 *$ \\
\hline $5+$ years & -1.160 & $-1.585--.735$ & .314 & $.000 *$ \\
\hline $\begin{array}{l}\text { Recurrent Maltreatment at } 12 \text { Months }=\text { Yes } \\
\text { (Reference }- \text { None) }\end{array}$ & .214 & $.065-.363$ & 1.238 & $.005^{* \mathrm{a}}$ \\
\hline $\begin{array}{l}\mathrm{CI}=\text { Confidence Interval } \\
\mathrm{IRR}=\text { Incidence Rate Ratio } \\
*_{\mathrm{p}}<.05\end{array}$ & & & & \\
\hline
\end{tabular}

The standard Poisson model estimated each of the independent variables, except the child's sex, to be significantly associated with outpatient utilization. When the model was estimated using robust standard errors, the recurrence of maltreatment variable was no longer significant. Furthermore, this models estimated that children in the comparison group had significantly higher incidence rates of use of outpatient medical facilities when compared to START children. In terms of incidence rates, when holding other variables in the model constant, participation in START was associated with an incidence rate of outpatient visits that was .844 that of children in the comparison group. Additionally, the model estimated that children in the Boyd, Kenton, and Martin clusters had higher incidence rates of using 
outpatient medical services when compared to the other county clusters (Jefferson and Daviess).

\section{Table 4.6b}

Zero-Inflated Poisson Regression Model of Outpatient Visits

\begin{tabular}{|c|c|c|c|}
\hline Variable & Coefficient & IRR & $\mathrm{p}$ \\
\hline $\begin{array}{l}\text { Treatment Group }=\text { START } \\
\text { (reference }- \text { Comparison) }\end{array}$ & -.204 & .815 & $.001 *$ \\
\hline \multicolumn{4}{|l|}{ County Cluster (reference - Boyd) } \\
\hline Daviess & -.406 & .666 & $.000 *$ \\
\hline Jefferson & -.887 & .412 & $.000 *$ \\
\hline Kenton & .119 & 1.126 & .058 \\
\hline Martin & .041 & 1.041 & .635 \\
\hline Child Sex = Male (reference - female) & -.124 & .883 & $.019 *$ \\
\hline \multicolumn{4}{|l|}{ Child Age (reference - newborn -6 mo.) } \\
\hline 7 mo. -11 mo. & -.141 & .868 & .160 \\
\hline 12 mo. - 23 mo. & -.460 & .631 & $.000 *$ \\
\hline 24 mo. - 35 mo. & -1.041 & .353 & $.000 *$ \\
\hline 36 mo. - 47 mo. & -.748 & .473 & $.000 *$ \\
\hline 48 mo. -59 mo. & -.799 & .449 & $.000 *$ \\
\hline $5+$ years & -1.033 & .355 & $.000^{*}$ \\
\hline $\begin{array}{l}\text { Recurrent Maltreatment at } 12 \text { Months }=\text { Yes } \\
\text { (Reference }- \text { None) }\end{array}$ & .251 & 1.285 & $.001 *$ \\
\hline
\end{tabular}

The zero-inflated Poisson model estimated parameters that provided a similar interpretation of the relationships between the independent variables and outpatient utilization - with the exception of the sex variable. This model also estimated significantly higher incidence of outpatient visits for children who were the victim of substantiated maltreatment within 12 months subsequent to their index CPS case. Finally, both models estimated that older children tended to utilize outpatient medical services at lower rates than younger children, with significant differences detected between the older age groups (at least one year of age or older at entry to CPS) and the youngest age group. 


\section{Emergency Room Visits}

Figure 4.7 - Histogram of Emergency Room Visit Counts by Individual Child

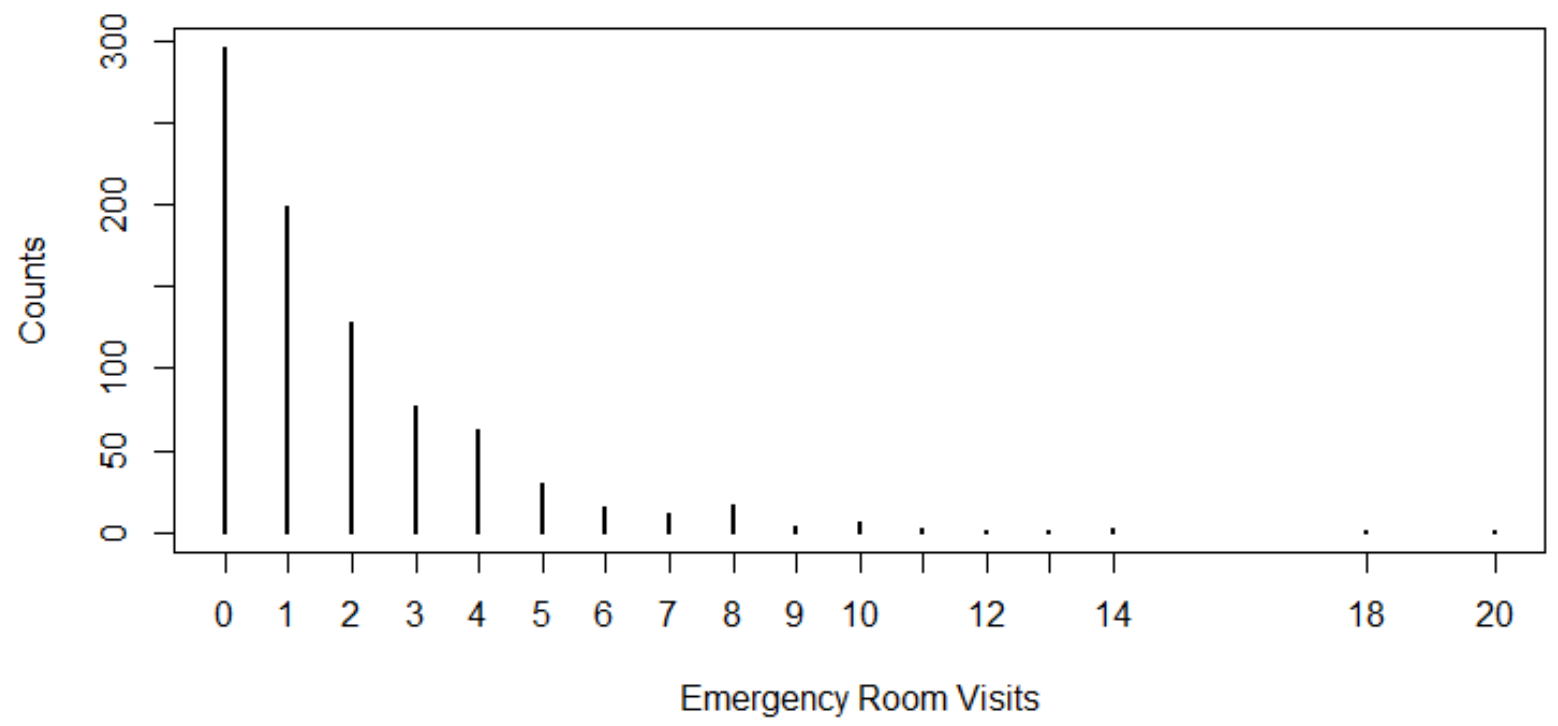

Among the most common reasons for presenting to an emergency room were upper and lower respiratory tract infections (12.8\% of total visits), ear infections (10.1\% of total visits), and fevers (5.8\% of total visits). Figure 4.8 below illustrates the raw sums of emergency room visits by study group and by study period. The median spend per emergency room visit for this study was $\$ 170$. 


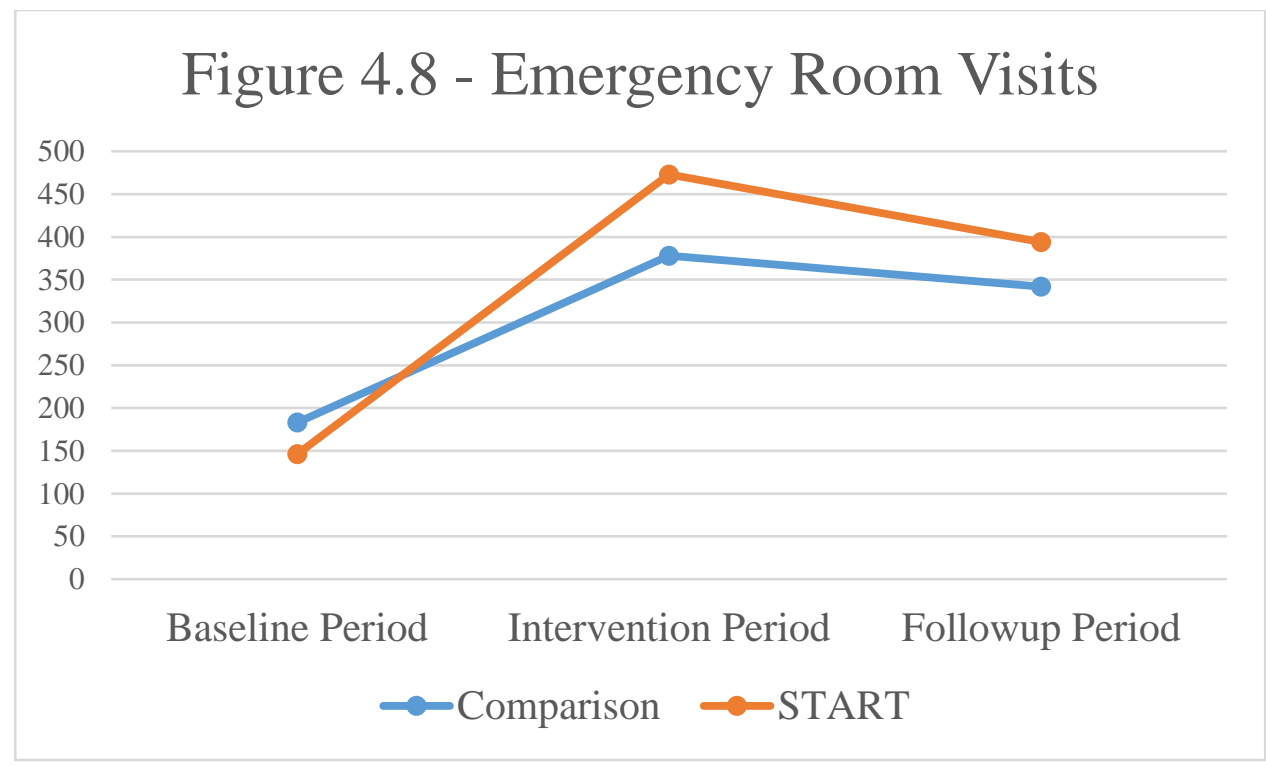

Figure 4.8 illustrates a general trend in emergency room visits that was similar to what was observed in outpatient visits. Specifically, each group began at a relatively low level of consumption of emergency care, which then rose precipitously for both groups in the first year after their index case, and then leveled off in the following year. The prominent increase in consumption for this type of service was also a direct result of the fact that most of the children in this sample were not born yet in the year prior to their index CPS case; therefore, it was also impossible for them to be treated in emergency rooms. The results from the generalized linear model for emergency room visits is outlined below in table 4.8a. 
Table 4.7a

Poisson Regression Model of Emergency Room Visits

\begin{tabular}{|c|c|c|c|c|}
\hline Variable & Coefficient & $95 \% \mathrm{CI}$ & IRR & $\mathrm{p}$ \\
\hline $\begin{array}{l}\text { Treatment Group }=\text { START } \\
\text { (reference }- \text { Comparison) }\end{array}$ & .125 & $.042-.240$ & 1.151 & $.015^{* \mathrm{a}}$ \\
\hline \multicolumn{5}{|l|}{ County Cluster (reference - Boyd) } \\
\hline Daviess & -.121 & $-.320-.078$ & .886 & .234 \\
\hline Jefferson & .038 & $-.110-.185$ & 1.038 & .616 \\
\hline Kenton & .022 & $-.129-.174$ & 1.023 & .771 \\
\hline Martin & .210 & $-.007-.426$ & 1.233 & .057 \\
\hline Child Sex = Male (reference - female) & .140 & $.038-.241$ & 1.150 & $.007 * \mathrm{a}$ \\
\hline \multicolumn{5}{|l|}{ Child Age (reference - newborn -6 mo.) } \\
\hline 7 mo. -11 mo. & .099 & $-.105-.303$ & 1.104 & .342 \\
\hline $12 \mathrm{mo} .-23 \mathrm{mo}$. & -.350 & $-.549--.152$ & .704 & $.001 *$ \\
\hline 24 mo. -35 mo. & -.429 & $-.659--.198$ & .651 & $.000 *$ \\
\hline 36 mo. -47 mo. & -.692 & $-1.007--.377$ & .501 & $.000 *$ \\
\hline 48 mo. -59 mo. & -.304 & $-.644-.036$ & .738 & .079 \\
\hline $5+$ years & -.736 & $-1.184--.288$ & .479 & $.001 *$ \\
\hline $\begin{array}{l}\text { Recurrent Maltreatment at } 12 \text { Months }=\text { Yes } \\
\text { (Reference }- \text { None) }\end{array}$ & .191 & $.034-.348$ & 1.210 & $.017 * \mathrm{a}$ \\
\hline $\begin{array}{l}\mathrm{CI}=\text { Confidence Interval } \\
\mathrm{IRR}=\text { Incidence Rate Ratio } \\
*_{\mathrm{p}}<.05\end{array}$ & & & & \\
\hline
\end{tabular}

The test of model effects revealed that each of the variables, except for a child's county cluster, were significantly associated with emergency room utilization in the Poisson model. The model for emergency room visits estimated higher incidence rates of emergency room utilization in the START group as compared to the comparison group. When holding other variables in the model constant, participation in START was associated with an incidence rate of emergency room visits that was 1.151 that of children in the comparison group. When the model was estimated with robust standard errors, the significant difference between treatment groups was eliminated. In terms of the other indicators, the model estimated lower incidence rates of utilization for residents of the Daviess County cluster compared to the other regions. There were additional significant differences found in the sex variable (male children had higher incidence rates than female children), and the age variable (younger children had 
significantly higher incidence rates than the oldest age group). These models also estimated significantly higher incidence of emergency room visits for children who were the victim of substantiated maltreatment within 12 months subsequent to their index CPS case.

Table 4.7b

Zero-Inflated Poisson Regression Model of Emergency Room Visits

\begin{tabular}{lccc}
\hline \multicolumn{1}{c}{ Variable } & Coefficient & IRR & $\mathrm{p}$ \\
\hline & & & \\
Treatment Group = START & .112 & 1.118 & .051 \\
(reference - Comparison) & & & \\
$\begin{array}{l}\text { County Cluster (reference - Boyd) } \\
\quad \text { Daviess }\end{array}$ & -.250 & .779 & $.016^{*}$ \\
$\quad$ Jefferson & -.020 & .980 & .814 \\
$\quad$ Kenton & -.118 & .889 & .170 \\
$\quad$ Martin & .041 & 1.04 & .739 \\
Child Sex = Male (reference - female) & .122 & 1.129 & $.033^{*}$ \\
Child Age (reference - newborn -6 mo.) & & & \\
$\quad$ 7 mo. - 11 mo. & .073 & 1.076 & .513 \\
$\quad$ 12 mo. - 23 mo. & -.288 & .749 & $.012^{*}$ \\
$\quad$ 24 mo. - 35 mo. & -.297 & .743 & $.031^{*}$ \\
$\quad 36$ mo. - 47 mo. & -.605 & .546 & $.001^{*}$ \\
$\quad$ 48 mo. - 59 mo. & -.309 & .734 & .144 \\
$\quad$ 5+ years & -.676 & .509 & $.011^{*}$ \\
Recurrent Maltreatment at 12 Months = Yes & .237 & 1.267 & $.006^{*}$ \\
(Reference - None) & & & \\
\hline IRR = Incidence Rate Ratio & & & \\
*p < .05 & & &
\end{tabular}

The zero-inflated model provided parameter estimates that offered a similar interpretation. Both models illustrate the particularly strong association between a child's age when they entered CPS services and their subsequent use of emergency care. Children that entered at older ages tended to have lower incidence rates of emergency room use. 


\section{Hospital Visits}

Figure 4.9 - Histogram of Hospital Visit Counts by Individual Child

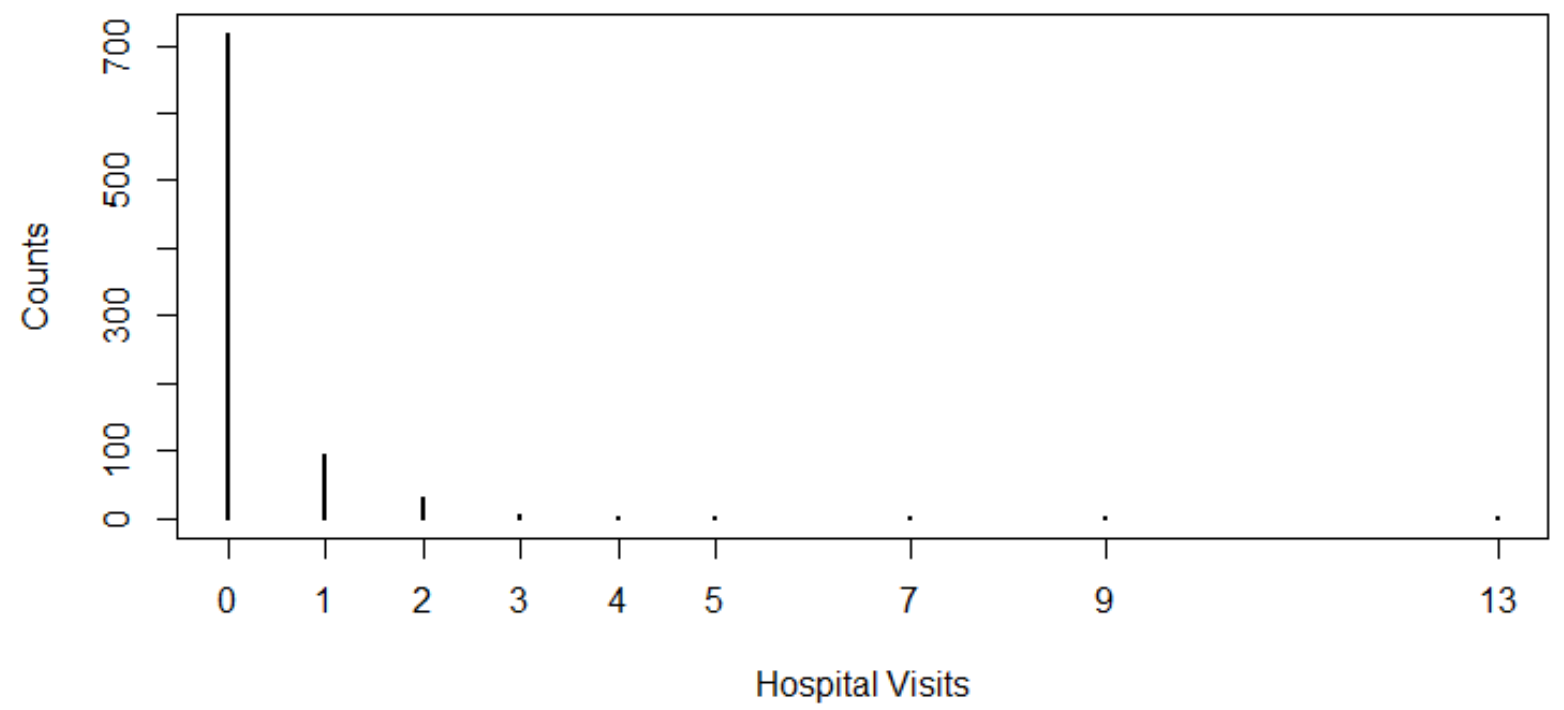

Children in this sample were admitted to hospitals at much lower rates than their utilization of outpatient clinics or emergency rooms. Moreover, they tended to be less frequent for older children, and were also far less frequent during the follow-up period than after their first year of CPS contact (i.e., intervention year). Among the most common reasons for presenting for hospitalization were: acute bronchiolitis (most commonly due to respiratory syncytial virus $[\mathrm{RSV}])$ (23\% of total visits), pneumonia (6.3\% of total visits), and respiratory distress $(2.4 \%$ of total visits), and fever (2.4\% of total visits). Figure 4.10 below illustrates the raw sums of hospital visits by study group and by study period. The median spend per hospital visit during this study was $\$ 2,469.84$. 


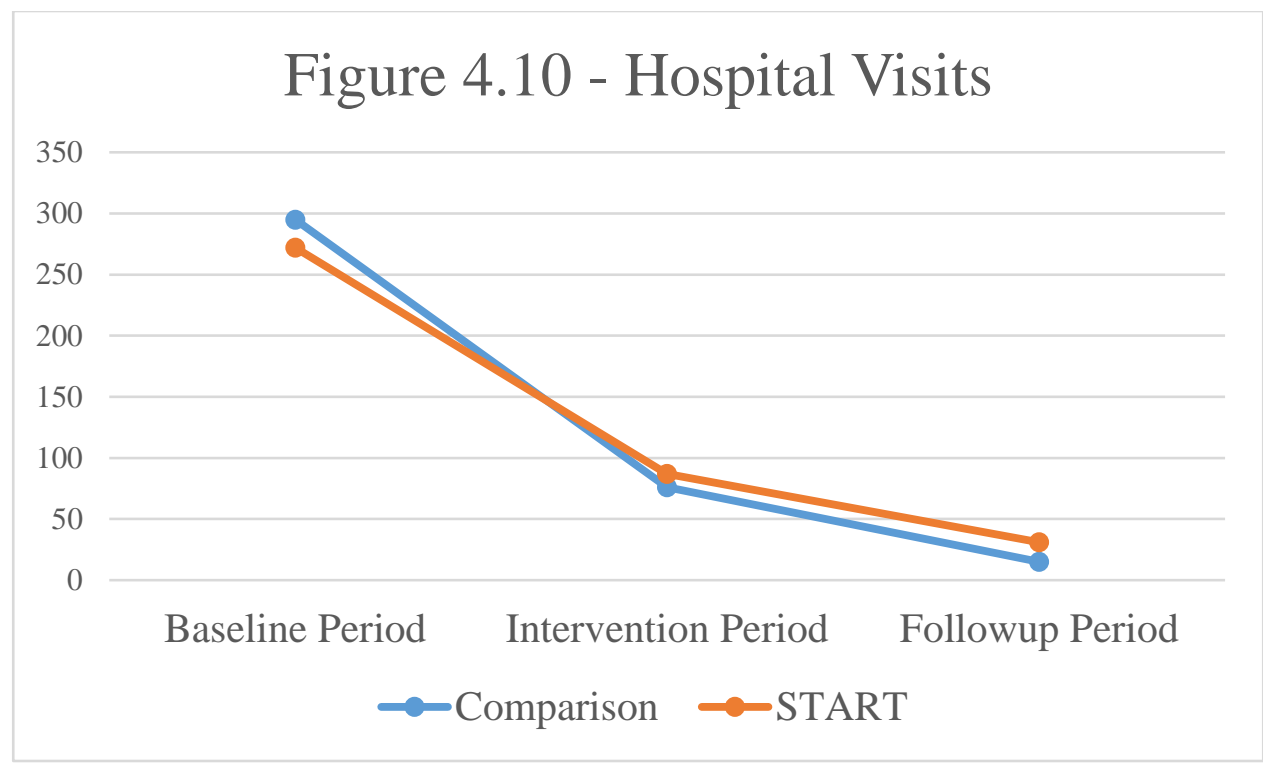

Trends in terms of rates of hospital utilization were distinct from the other two service types. This was again the result of child birth, however, instead of utilization increasing over time, they decreased. This is a direct result of child birth-associated hospital visits, this single most common diagnosis code for that service type in the data set. Hospital visits became especially rare and infrequent for children as time progressed after their index CPS event. This is not uncommon in health services research, and it is thus unsurprising that there were a very high number of 0's in the hospital visit count distribution.

\section{Table 4.8a}

Poisson Regression Model of Hospital Visits

\begin{tabular}{lcccc}
\multicolumn{1}{c}{ Variable } & Coefficient & $95 \%$ CI & IRR & $\mathrm{p}$ \\
\hline & & & & \\
Treatment Group = START & .084 & $-.197-.365$ & 1.087 & .559 \\
(reference - Comparison) & & & & \\
County Cluster (reference - Boyd) & & & & \\
$\quad$ Daviess & -.913 & $-1.594--.232$ & .401 & $.009 *$ \\
$\quad$ Jefferson & -.417 & $-.790--.045$ & .659 & $.028 *$ \\
$\quad$ Kenton & -.200 & $-.597-.197$ & .819 & .323 \\
$\quad$ Martin & .371 & $-.175-.918$ & 1.450 & .183 \\
Child Sex = Male (reference - female) & -.120 & $-.395-.155$ & .887 & .393 \\
Child Age (reference - newborn -6 mo.) & & & & \\
$\quad 7$ mo. -11 mo. & -.606 & $-1.261-.049$ & .545 & .070 \\
$\quad 12$ mo. -23 mo. & -1.584 & $-2.408--.759$ & .205 & $.000 *$
\end{tabular}


Table 4.8a (continued).

\begin{tabular}{|c|c|c|c|c|}
\hline Variable & Coefficient & $95 \% \mathrm{CI}$ & IRR & $\mathrm{p}$ \\
\hline 24 mo. -35 mo. & -1.553 & $-2.456--.650$ & .212 & $.001 *$ \\
\hline $36 \mathrm{mo}-47 \mathrm{mo}$. & -1.682 & $-2.835--.529$ & .186 & $.004 *$ \\
\hline 48 mo. -59 mo. & -.216 & $-.992-.560$ & .806 & .585 \\
\hline $5+$ years & -1.390 & $-2.795-.015$ & .249 & .052 \\
\hline $\begin{array}{l}\text { Recurrent Maltreatment at } 12 \text { Months }=\text { Yes } \\
\text { (Reference }- \text { None) }\end{array}$ & .941 & $.598-1.285$ & 2.563 & $.000 *$ \\
\hline
\end{tabular}

The test of model effects revealed that the county cluster, child age, and maltreatment recurrence variables were significantly associated with hospital utilization. Estimating the Poisson model with robust standard errors produced no meaningful differences in interpretation for the hospital visit outcome variable. Although the model estimated higher utilization in the START group, this difference was not significantly different from the comparison group. In terms of the other independent variables, the model estimated lower incidence rates of utilization for residents of the Daviess County, Jefferson County, and Kenton County clusters compared to the other regions. There were no significant differences found between males and females in terms of hospital utilization, although males were estimated to be moderately less likely to visit the hospital. In terms of age, again, the youngest children were estimated to be the highest utilizers of hospital services. These models also estimated significantly higher incidence of hospitalization for children who were the victim of substantiated maltreatment within 12 months subsequent to their index CPS case. 
Table 4.8b

Zero-Inflated Poisson Regression Model of Hospital Visits

\begin{tabular}{|c|c|c|c|}
\hline Variable & Coefficient & IRR & $\mathrm{p}$ \\
\hline $\begin{array}{l}\text { Treatment Group }=\text { START } \\
\text { (reference }- \text { Comparison) }\end{array}$ & .306 & 1.36 & .193 \\
\hline \multicolumn{4}{|l|}{ County Cluster (reference - Boyd) } \\
\hline Daviess & -.711 & .491 & .067 \\
\hline Jefferson & -.028 & .972 & .901 \\
\hline Kenton & -.245 & .783 & .317 \\
\hline Martin & .635 & 1.89 & .063 \\
\hline Child Sex = Male $($ reference - female $)$ & -.213 & .808 & .212 \\
\hline \multicolumn{4}{|l|}{ Child Age (reference - newborn -6 mo.) } \\
\hline 7 mo. $-11 \mathrm{mo}$ & -.716 & .489 & .066 \\
\hline $12 \mathrm{mo} .-23 \mathrm{mo}$. & -1.568 & .208 & $.001 *$ \\
\hline 24 mo. -35 mo. & -1.484 & .227 & $.004 *$ \\
\hline 36 mo. -47 mo. & -1.573 & .207 & $.015^{*}$ \\
\hline 48 mo. -59 mo. & -.016 & .984 & .973 \\
\hline $5+$ years & -1.347 & .260 & .086 \\
\hline $\begin{array}{l}\text { Recurrent Maltreatment at } 12 \text { Months }=\text { Yes } \\
\text { (Reference }- \text { None) }\end{array}$ & 1.131 & 3.099 & $.000^{*}$ \\
\hline
\end{tabular}

The zero-inflated model produced very similar results to the standard Poisson model.

The two models each estimated a particularly strong relationship between having a subsequent maltreatment report and the incidence rate of hospital visits. Holding all other variables in the model constant, the rate of hospital visits for children that were victims of subsequent maltreatment was 2.5 times higher than non-victim children in the Poisson model (the zero-inflated model estimated this incidence rate ratio to be 3 times higher). Summary and conclusions of these results are presented in the following chapter. 


\section{CHAPTER V}

\section{DISCUSSION AND CONCLUSIONS}

Cases of co-occurring substance use and child maltreatment cause considerable harm to American families and communities. Among the most commonly reported of these harms are the associated deaths of parents and their children, births of substance-exposed newborns, and additional burdens placed on child welfare agencies. This phenomenon is not new, and has been described numerous times in the academic literature, in professional resources for child protection agencies, and in the popular news media. While this problem is pervasive across the country, due to its unique profile of ecological risks, Kentucky has been particularly hard hit in recent years.

These harms are costly in terms of human suffering, but they also exact a financial toll on the institutions charged with stemming the tide of that suffering. Many interventions that aim to serve this unique population have been developed, implemented, and tested to determine whether they can successfully promote parental wellness while simultaneously reducing the future risk of harm to children. In Kentucky, the authorities that administer CPS have selected the START intervention as one of its most prominent tools to help families who have harmed their children because of their high-risk substance use. Past evaluation work has produced a body of knowledge that suggests that the Kentucky START teams do promote favorable child welfare outcomes and addiction recovery. In other words, these past results illustrate reductions in human suffering for children and their parents (e.g., Huebner, Willauer, \& Posze, 2012). 
However, less is known about how START's successful work with families affects children's health and the associated economic realities for Medicaid. While previous evaluation work estimated cost reductions resulting from less state spending on out of home care, the broader child welfare literature demonstrates several other ways that good outcomes can produce cost savings; none of which had previously been explored for START. The purpose of this study was to respond to this knowledge gap by specifically testing whether participation in START was associated with reductions in healthcare spending by the Kentucky Department of Medicaid services on acute healthcare services for children.

This outcome domain was selected for three reasons. First, there is a known relationship between child maltreatment and increases in preventable healthcare consumption. Therefore, it was reasonable to assume that an intervention that has demonstrated the capacity to reduce the harms associated with child maltreatment could also bring about reductions in the most expensive forms of health service utilization (Florence et al., 2013; Keshavarz, Kawashima, \& Low, 2002). Second, Medicaid is an expensive program for the state of Kentucky to administer (as well as the primary funder of health services for children in state custody through CPS), meaning that even a modest prevention of ER visits or hospital stays could result in the realization of important cost savings (Grossman, Rich, \& Johnson, 1998). Finally, and most importantly, observed reductions in acute health services for children involved with CPS are suggestive of households where children are safer - being cared for by adults who are no longer harming them, are seeking care for them in a more appropriate way, or both.

In this discussion, the findings from three research questions are summarized. These three questions each address the fundamental desire to gauge whether participation in 
START produces a demonstrable impact on children's health services utilization and associated spending for Medicaid. Question \#1 related to the broader concern of whether any between-group differences existed in terms of overall spend. Question \#2 sought to take the results of Question \#1 and determine if any significant between-group differences in utilization rates were present by service category. Finally, Question \#3 sought to determine whether the site where a family resided during their CPS case was associated with differences in utilization. Implications of these results, limitations of the study, and directions for future research are also addressed.

\section{Research Question 1 - Between Group Differences in Medicaid Spending}

As expected, the children in this study sample accounted for a high Medicaid spend relative to typical Medicaid spending on pediatric care in Kentucky. As a reference point, the Henry J. Kaiser Foundation estimated that Kentucky Medicaid spent $\$ 3,123$ per child in FY 2014. If spending on this sample of children (START + Comparison) were more in line with that annual average during their periods of observation, the estimated total spend for all 852 children for the entire observation period would have been closer to $\$ 5.32$ million; actual total spending was $\$ 8,558,110.03$. This suggests that, as a group, these children tended to be higher risk and more costly to care for than a more typical set of children enrolled in Medicaid.

To judge differences in cost, Medicaid claims data were collected from a two-year period that began at the index CPS case for children in both groups. The total spend included the sum of the costs of outpatient treatment (dental visits, primary care, physical therapy, etc.), emergency room care, and hospitalizations that were not associated with the child's birth. For the two year period that began at their respective index CPS cases, Medicaid spent 
$\$ 1,586,521.42$ on medical care for the 417 comparison group children. For the 435 START group children over that same two year period, Medicaid spent $\$ 1,368,357.94$ on the combined cost of outpatient, emergency, and hospital care (a difference of $\$ 218,163.48$ lower spending on the START group).

Though this was an apparently favorable outcome for START, when a generalized linear model was conducted for all children with $>\$ 1$ in spending during that period, results indicated that a child's treatment group assignment was not a significant indicator of Medicaid spend. While this model estimated spending to be moderately higher for comparison group children than for their peers who received START, this result was not statistically significant.

Medicaid tended to spend less on START children in the two year period subsequent to the initiation of their contact with CPS. While this result was not statistically significant in a generalized linear model of Medicaid spending, it is a notable finding. While the available data did not contain variables that might have been useful for a more precise matching strategy (e.g., gestational age of newborns at birth, presence of chronic conditions at baseline, etc.), the available information suggests that the comparison group was suitably balanced with the START group along observed covariates. This increases confidence in the validity of between-group comparisons of Medicaid spending, which suggest that START participation was associated with moderately lower healthcare spending for these children. Moreover, in terms of net dollars spent on this group, spending began moderately higher than the comparison group during their baseline period, and then dropped lower during the intervention period. 
These results suggest that, for this study sample, participation in the START program was not associated with any significantly lower costs to Medicaid when compared to healthcare spending for similar children who participated in typical CPS services. Therefore, the null hypothesis for this research question was retained. As was expected, outpatient care tended to be the least expensive per-visit of the three health services included in this study, with emergency medical care and hospital care being the more expensive, respectively. Of particular note, the Medicaid claims data revealed that this sample of children consumed the most expensive medical care during their baseline year. Unsurprisingly, this appears to have been the direct result of the age at which most of the children in the sample entered CPS services - at their birth. Because the START program is intended to serve younger children (ages birth to age 5), and because this study involved the youngest children in a given family, the sample described in this study was resultantly very young.

Therefore, the period of time for which health insurance claims data was collected for most of the children included the claims generated by hospitals for delivery and postnatal care. This finding is consistent with the literature which broadly outlines that pregnancies and deliveries account for a notable increase in healthcare costs among women of childbearing age in the U.S. (Lassman, Hartman, Washington, Andrews, \& Catlin, 2014). While healthy deliveries are often costly, exposure to substances during pregnancy appears to have contributed significant additional costs for this sample. These claims were often significantly more expensive than other types of care. For example, one outlier claim of $\$ 216,599.80$ was paid for a case of respiratory distress in a newborn related to drug withdrawal. This feature of the sample affected the utilization rates of the three categories of health services; notably, 
rates of hospital stays are considerably higher at baseline than during the intervention and follow-up periods.

Moreover, even considering the high-risk nature of this sample of children, it is wellknown that children tend to consume healthcare differently as they age. For instance, pediatric protocols and standards of care call for much more intensive medical monitoring of newborns and infants than for older children (Beauman, 2005). Routine outpatient office visits to check for appropriate weight gain, screen for developmental milestones or congenital conditions, and administer vaccines are all part of appropriate and responsible medical care for this age group. Moreover, the developing immune systems of infants leave them at greater risk for high fevers, ear infections, and other conditions that often require emergency medical care (fevers, ear infections, and respiratory tract infections were among the most common diagnoses for ER visits in this sample). For this reason, it is unsurprising that the cost model estimated the highest healthcare costs for the children in the youngest age groups. This finding is consistent with the other models that estimated utilization of the three service categories to be highest amongst the youngest children as well.

This reality highlights one important theme that presents itself in many important ways for this study. Namely, that judgements about a state's ideal levels of Medicaid spending on children's consumption of health services are difficult to make - particularly in CPS samples where concern over medical neglect can be present. On one hand, lower costs can be a win/win when they are indicative of strong primary care, prevention of serious illness and harm, and wise deployment of resources. On the other hand, lower costs can be suggestive of underinvestment in children's health and wellness and missing opportunities for appropriate medical intervention. Making such determinations - say, whether a given 
hospital admission is medically necessary or not - are frequently difficult at the point of care provision, even for well-trained physicians. While strategies for identifying non-medically necessary pediatric hospitalizations have been developed, (see Kemper, 1988), such judgements can be highly subjective, and an excess of caution in medical decision making concerning fragile newborns and infants is often warranted. This theme will be discussed in greater detail later in this chapter.

How the Between-Group Spending Differences Finding Compares to Past Work

This result in non-significant spending differences is contrary to similar work in this field, but potentially for important reasons. One study of health services utilization and spending for the family members of patients who received addiction treatment showed significant reductions in utilization and costs when the affected family member successfully responded to treatment (Weisner et al., 2010). A similar result was not found in this investigation. There are several important reasons why this might have been the case. Primarily, the populations under study were qualitatively distinct. In this study, $73 \%$ of the children in the sample were under the age of 1 year old when while their family initially entered child welfare services. While Weisner and her colleagues (2010) did not explicitly describe the ages of the family members included in their study sample, the context of that investigation (i.e., a large, private health insurance organization, non-child welfare clients, etc.) suggests the sample was primarily adult family members.

These differences in the ages of the samples may have contributed to a different health spending result from what was found by Weisner and colleagues (2010) because of the differences between how children and adults access the healthcare system. In this study, the children's treatment-seeking process relied on their parent's choices (or, in the case of 
children who were removed from the home, an alternative caregiver, such as a foster care provider). This is very different from the treatment-seeking decisions made by adult relatives, who direct their own process of scheduling visits and transporting themselves to medical facilities. Moreover, the adult stress process put forward by Weisner and colleagues (2010) to explain higher baseline healthcare costs for the loved ones of people in need of addiction treatment (i.e., worrying about a loved one's health to the point of illness) is not the same for children.

These data also appear to support the conclusions outlined in Florence and colleagues (2013), which found that child maltreatment accounted for a significant amount of the variance in Medicaid spending. In this case, the model estimated that children in families with recurrent child maltreatment at 12 months had higher Medicaid spend and were more likely to utilize outpatient, emergency, and hospital care - even more so than comparable children with a history of victimization but no 12-month recurrence. This relationship was especially strong in terms of hospital visits. This result seems to suggest that this recurrence reflects some underlying risk profile present in those families, which further strengthens the case that a relationship exists between child maltreatment and children's contact with the healthcare system (particularly those children insured by Medicaid).

\section{Research Question 2 - Between Group Differences in Utilization Rates}

While no significant differences were identified in terms of costs, there were important differences identified between START and comparison children in terms of their utilization of the three identified health services. Broadly, the models of visit counts estimated higher utilization of outpatient clinics for comparison children, higher utilization of 
emergency rooms for START children, and higher (yet not significant) utilization of hospital care for START children.

Just as was observed for the cost model, utilization rates fell between the intervention period and the follow-up period for each of the three services. This was most pronounced for hospital visits, which fell considerably between baseline periods and follow-up periods for the whole sample (again, a notable consequence of childbirth-associated hospitalizations). For outpatient care and emergency room care, these declines were much more modest, and each was preceded by increases in utilization - likely a reflection of the unique medical needs of newborns, infants, and toddlers that become less frequent as they become two and three year olds.

Generally, public health authorities and Medicaid programs prefer for children's health to be predominantly managed in primary care settings, where longer-term relationships with medical providers can develop and facilitate both a wellness and prevention-oriented approach to care (Gadomski, Jenkins, \& Nichols, 1998). The primary care setting is where problems can be caught early and addressed before they become more severe (and thus, oftentimes, more costly). This is considered to be a more patient-centered and cost-effective means of managing population health. This stands in contrast to a more crisis-oriented approach to healthcare consumption, where children are brought to emergency rooms for conditions that do not require such a high level of care.

Again, while it was beyond the scope or the capacity of this study to determine the extent that medically unnecessary or preventable visits to hospitals or emergency rooms affected outcomes, the simple reality that there were more net documented emergency room visits than outpatient visits in this sample suggests a degree of overutilization of emergency 
medical resources. Establishing and maintaining pediatric primary care for a child requires resources that are often not available for CPS involved families. Beyond the coverage provided by Medicaid (which is not universally accepted by pediatricians or family practitioners), families typically need to be able to speak fluent English, possess the means to schedule appointments, schedule those appointments around a work or school schedule, have access to reliable transportation, and live close enough to a pharmacy that can fill their child's medications. Given what is known about Medicaid populations and CPS-involved families, this relatively high use of emergency rooms is not surprising. For example, CPSinvolved families often deal with housing instability and are thus transient - which can result in difficulties with engaging children in consistent primary care (Freisthler, Merritt, \& LaScala, 2006). Moreover, issues related to lower levels of education and health literacy are often present in this population, which have been found to be predictors of higher rates of emergency room utilization (Herndon, Chaney, \& Carden, 2011).

It is unclear why START children tended to consume more acute medical services than children from the comparison group. One potential explanation for this result could be what has been called "surveillance bias" in the child welfare literature (see Chaffin \& Bard, 2006). In other words, the closer that child welfare workers monitor and engage with a given family, the more likely they are to detect and report further instances of maltreatment while the family is receiving services. This dynamic can often bias evaluations against tested interventions if the group they are being compared to was not monitored as closely. In these cases, any observed increases in the incidence of maltreatment are potentially independent of the efficacy of the intervention (it may even be better if it is indicative of more accurately identifying and responding to cases of abuse or neglect). This surveillance bias has been 
considered especially relevant to the work of START previously, because capped caseloads, higher intensity services, and greater collaboration with treatment providers all increase the number of eyes on START families.

While this hypothesis is most commonly used to explain recurrence rates of child maltreatment, it is possible that START families, knowing how closely they are being observed by their worker and mentor, feel compelled to be overcautious with their child's medical care. As a result, they may have directed their child's care towards more immediate means of treatment (e.g., an emergency room) vs. waiting to get appointments at outpatient offices. The narrowing of the margin between emergency room visits for START and comparison children between their intervention (95 more START than comparison visits) and follow-up periods (52 more START than comparison visits) would seem to support this explanation. Said another way, the total number of emergency room visits in the comparison group fell by $9.6 \%$ between intervention and follow-up - over the same period (when CPS surveillance ended for most START families), they fell $16.7 \%$ for START children. How the Between-Group Differences in Utilization Finding Compares to Past Work

These findings may also be placed in context alongside the work described in Raghavan, Brown, Allaire, Garfield, \& Ross (2014), which examined Medicaid expenditures on psychotropic medications for children who had been the victim of maltreatment. They found that children who had been the identified victim on a CPS case had twice the odds of receiving any psychotropic drug prescription, and \$190 higher mean annual expenditures on psychotropic drugs than PSM-matched children who were never victims. Because psychiatric care, especially the consumption of psychiatric medication, is a special concern many stakeholders have in terms of children in foster care, this is an outcome that is explored in 
several studies (e.g., Lohr et al., 2018; Davis et al., 2019). Taken together with the broader economic results from Fang and colleagues (2012), this study contributes to the body of knowledge which suggests that child maltreatment is strongly associated with children's utilization of healthcare resources.

This study is unique from much of the past work done in this area for two related reasons: (1) It makes comparisons between two groups where one received an experimental intervention, and as such, (2) It makes comparisons between groups of children in which both groups have been exposed to maltreatment. Many past studies have been designed to investigate the effects of victimization vs. non-victimization (e.g., Raghavan et al., 2014; Florence et al., 2013). For this reason, comparisons between the results of this study and past work that did not involve study groups where the entire sample was exposed to maltreatment are limited in their ability to draw broader conclusions. In light of this, the finding that children who were the victims of recurrent maltreatment does seem to resonate with the body of knowledge that demonstrates the strength of association between victimization and health and social service utilization (Fang et al., 2012).

\section{Research Question 3 - Regional Differences in Utilization}

Finally, this study sought to determine whether any meaningful differences could be identified between regions where the START intervention was provided. Broadly, the region of the state where a family received CPS services was not a significant indicator of Medicaid spending on children. The investigation estimated per-child spending and utilization to be highest in the Martin county cluster, with spending and health services utilization being comparably lower in the Daviess county cluster. Many such differences were not estimated to 
be statistically significant, and thus it is difficult to draw any meaningful and comprehensive conclusions regarding regional differences in the consumption of health services.

However, one notable finding from these models was the discrepancy between outpatient and emergency room utilization in the Jefferson County cluster. These results suggest that participants in this region were especially more likely to use the emergency room than an outpatient clinic for their child's care. It seems unlikely that children in the Jefferson County cluster suffered more acute and emergent medical problems during this study period than children from the other clusters. It is possible that this may be a result of the relatively high availability of emergency rooms in the Louisville area compared to the other regions. This is potentially concerning that children from the Jefferson cluster may be receiving less than optimal primary care, as their estimated marginal mean for any outpatient visits was the lowest of the five clusters (less than one visit per child over the two year periods). This result may suggest that the Jefferson START teams consider efforts to connect their clients with good primary care resources that can more adequately treat their children.

These models also estimated spending and utilization to be particularly high in the Martin County cluster. One possible explanation for the higher estimates of utilization and spend in the Martin County cluster is the high relative poverty present in that area compared to the other regions where START operates. According to the U.S. Census Bureau, Martin County has nearly twice the percentage of its population living below the federal poverty level as many of the other regions described in this study. As discussed in Chapter II, the literature has largely described the broader relationships between social determinants of health (poverty and economic hardship being among the most fundamental) and higher utilization of acute medical services (Marmot, 2005). It is notable that these estimates were 
high in spite of the relative scarcity of hospitals and clinics in that rural cluster as compared to the more urban clusters such as Jefferson or Kenton.

\section{Implications}

These results have several important implications for better understanding relationships between child welfare interventions and children's healthcare utilization and for understanding how families respond to the START program. First, this study provides further evidence in support of medical and social service interventions for pregnant women who struggle with substance use disorders. In this sample, $54.6 \%$ of all Medicaid spending was clustered within the first weeks of a child's life. Much of this spending was on expensive hospital-based care to treat the effects of in utero substance exposure, such as congenital cardiothoracic abnormalities, extreme prematurity, and respiratory diagnoses. While hospitalizations for delivery are understood to necessarily cost more than many other types of medical care, the margin between a claim for a healthy birth $(\$ 1,557.31-\$ 3,000)$ and a birth coded as substance-exposed $(\$ 80,000+)$ were considerable. Supporting the existing treatment infrastructure for these women and expanding its capacity to meet Kentucky's considerable unmet needs is therefore justified for both humanitarian as well as financial reasons.

Admittedly, prenatal intervention is beyond the scope of the START teams.

Historically, CPS cases in Kentucky have not been opened until after a baby is born, which means that child welfare professionals are often charged with protecting these high-needs newborns and infants during the stressful early postnatal days. However, the START teams do engage in partnerships and collaborative relationships with human service organizations in their region that provide services for pregnant and parenting women. The results from this 
study suggests that the START teams continue to make use of these referral sources and direct their pregnant clients there whenever appropriate.

In broad terms, the Medicaid claims data utilized for this study conformed to common features of health services research. Namely, most children consumed very little healthcare during their study period, and a small subset consumed a disproportionately large amount. Specifically, it is not uncommon in populations or large health plans for $5 \%$ of the insured population to consume $50 \%$ of the healthcare dollars within a given period of time (Berk \& Monheit, 2001). The U.S. Government Accountability Office has found this dynamic to be particularly true for the Medicaid program (2015). This finding may support the use of targeting the highest need START children using a technique called "hot-spotting", which is used in many parts of the US to coordinate healthcare services for those with especially complex medical circumstances (Cutts, Rafalski, Grant, \& Marinescu, 2014).

While the finding that Medicaid spent less on START children than their peers could be viewed favorably from a financial perspective, it should be interpreted with caution. As discussed above, a parent's treatment seeking behavior for their child can involve a multidimensional decision making process, and one that is informed by access to transportation, health literacy/ability to identify their child's health problems, a child's capacity to communicate their symptoms, and the availability of healthcare resources. Therefore, insofar as lower healthcare costs can be interpreted as a proxy for better health status, these results could indicate a comparably higher degree of wellness for START children than comparison children after their exposure to the intervention. However, any discussion about healthcare consumption for CPS-involved children should be nuanced with 
consideration for the unique needs of each child and an orientation towards wellness promotion.

For some instances, a visit to the emergency room is appropriate, and some children with higher needs are just going to be more expensive to insure. This being the case, these results could justify a recommendation for the START teams to partner with accountable care organizations (ACO's) for general medical care in similar ways that they have partnered with community mental health centers for addiction treatment. ACO's have grown in notoriety since the passage of the Patient Protection and Affordable Care Act, and aim to promote higher quality care while decreasing excessive costs through improved coordination of care and incentivizing outcomes vs. a fee-for-service approach (Hacker \& Walker 2013). Another similar recommendation and alternative approach would be to further support the implementation of integrated care models in the mental health settings that serve START families (i.e., the colocation of primary medical care with psychiatric services; see Raney, 2013).

Additionally, these care coordination efforts would be doubly prudent to consider children's dental health, and potentially establish relationships with pediatric dentists as referral sources. As a case in point, the claims data returned 24 cases of outpatient dental care provided for dental caries (a relatively simple condition to prevent with regular oral hygiene) that accounted for $\$ 67,997.23$ in Medicaid payments to dentists. Twelve of these cases were START children, and most were from Boyd $(n=6)$ or Kenton $(n=3)$, suggesting some referrals to pediatric dentists may be especially relevant for clients at those sites. Interestingly no children from the Jefferson County (neither comparison nor START) were treated for dental caries during this study, despite having the largest representation. This may suggest 
that there are some best practices being followed in Jefferson county that could be replicated in other regions of the state.

The relatively higher rates of emergency room utilization in the START group implies that the adoption of such approaches is warranted. Strong pediatric primary care involving effective parental education can help START families make wise choices for how to appropriately utilize the healthcare system for their children. While it is beyond the scope of practice of START staff members to provide medical advice, beginning new collaborations with partners who possess the skills and capacity to help manage the medical needs of START families could bring enormous value to their work. START has demonstrated its ability to form fruitful and established partnerships with addiction treatment providers, and could thus replicate that same process with medical providers. Referring families to the same physicians would allow them to learn the unique process of treating START families, and allow both parties to establish the kind of coordination of care that has been consistently shown to simultaneously improve health outcomes while decreasing net costs.

\section{Youngest Children Appear to be the Most Medically Fragile}

These results also suggest that these sorts of coordinated medical interventions may be most appropriate when they are provided to START children in their first months of life. Each of the models described in this study estimate utilization and its associated spending to be highest in the group of children aged birth to six months, which suggests this group may be the most appropriate for targeted intervention. Several evaluations of various home visitation programs for vulnerable pregnant and post-partum women have documented success in terms of promoting positive health outcomes for mothers and their newborns. In 
Kentucky, the Health Access Nurturing Development Services (HANDS) is one such program that has been operating in the state for several years. Specifically, a recent evaluation demonstrated the program's efficacy in terms of preventing pre-term births, reducing cases of child maltreatment, and lowering rates of maternal complications during delivery when compared to a comparison group that was referred to HANDS, but did not enroll (Williams et al., 2017). Another notable finding from that evaluation was that HANDS participants had higher rates of enrollment in the Women, Infants, and Children (WIC) supplemental nutrition program. This is notable because early access to nutrition in infants is important for neural, immunologic, and social development (Barness, 1993).

While not all START children will be appropriate for a referral to HANDS, the results outline in this study, coupled with the evaluation results outlined in Williams and colleagues (2017), support the practice of the START teams making continued use of HANDS as a referral source. Given that so many START referrals originate in hospital labor and delivery units, and that these children were found to be in the greatest need of outpatient visits, emergency room visits, and hospital stays, the START teams would be well served to develop working relationships with any available services for post-partum mothers. An increased utilization of the HANDS resource may be a powerful tool to help START mothers (especially first time mothers) manage the health of their babies.

\section{Limitations}

\section{Administrative Data, Propensity Score Matching, and Quasi-Experimental Design}

While this demonstration of the applicability of PSM is certainly valuable, it is also limited in what it can offer. Therefore, the most important limitation of this study to consider is its reliance on administrative data for the construction of a propensity score matched 
comparison group. Selection bias is always a threat to the validity of non-randomized study designs. Scholars have debated the merits and shortcomings of this approach when using observational data to estimate treatment effects, and have agreed that it cannot completely account for the effects of unobserved covariates on dependent variables (Rubin, 1997). While the lack of significant between-group differences in terms of the observed covariates improves confidence in these estimations of treatment effects, it is impossible to control for variables that were never measured in the first place.

As an example, this study was unable to account for the influence of parental capacity for behavior change (e.g., motivation, engagement in services, skill sets, etc.), which has been noted to be significantly related to child welfare outcomes (Platt \& Riches, 2016). It is likely that a parent's motivation to change is especially relevant when their involvement with CPS is related to their substance use. Given that START is a voluntary program, it is possible that parent participants that "opted in" differed in some significant way from their peers in the comparison group. This construct was simply not collected or recorded by CPS in a way that was deemed valid and reliable enough to be included in the analyses conducted in this study. Consequently, it is possible that the treatment groups differed along unobserved variables in ways that affected the observed outcomes.

Moreover, PSM is best understood as a theory-driven process. In addition to the limitations that arise as a result of the influence of unobserved covariates, it also matters which observed covariates are selected in the matching process. Thus, the choices that investigators make in terms of which variables to include in their matching model are guided by their particular understanding of the phenomenon under study; a process that introduces the opportunity for error or bias. While this PSM process did generate a parsimonious model 
of family functioning in CPS cases, it is possible that the eleven matching variables chosen for this PSM model could have neglected some other important covariates contained in the source data set that would have resulted in a more accurate between-group balance.

However, in spite of these concerns, several measures beyond the mere use of PSM were taken to limit the effects of such selection bias. These included the restriction of eligibility for inclusion in the comparison group to certain case characteristics (e.g., substance use was a risk factor), individual child characteristics (e.g., child was under the age of 6, the youngest in their family), and geographic characteristics (e.g., only children from the same region of Kentucky were matched) before the data was submitted to PSM. Notably, this study included known risk factors such as domestic violence, poverty, and parental mental illness in the PSM model - a notable improvement on similar investigations of treatment effects in child welfare settings (see Florence et al., 2013; Raghavan, Brown, Allaire, Garfield, \& Ross, 2014; Johnson-Motoyama et al., 2013). These decisions for this study were informed and supported by the methodological insights found in Barth, Guo, \& McCrae (2008) and Rubin (1997).

In spite of these measures to control for the risks posed by selection bias, this study does not make strong causal claims. The balance that random assignment produces in experimental designs is still a superior approach for causal inference; a claim that is even acknowledged by the creators of PSM. According to Rubin (1997), "In observational studies, confidence in causal conclusions must be built by seeing how consistent the obtained answers are with other evidence (such as results from related experiments) and how sensitive the conclusions are to reasonable deviations from assumptions..." (p. 762). Therefore, this study is best interpreted as a first attempt at determining whether a family's participation in 
START is associated with decreased health services utilization and costs to Medicaid for their children.

\section{Relatively Short Follow-up Period}

Although this study included data from a longer period of time than others who used a similar method with similar samples (e.g., Raghavan et al., 2014 - 1 year follow up), it is still possible that the window was too short to detect meaningful differences between the START and comparison groups. In the Weisner and colleagues (2010) study mentioned above, significant reductions in healthcare spending on family members of successfully treated addiction treatment clients were not detected until five years after their entry into treatment. It is possible that a similar dynamic may have been present for this sample, and that parents served by the START program may require longer than two years after their initiation of treatment to make the kinds of lifestyle changes that result in decreased Medicaid costs for their children. It is possible that the more immediate positive health effects of addiction treatment are realized by the adult clients themselves (e.g., reduced rates of overdose, infectious disease transmission, car accidents, etc.), and the spillover effects for START children take longer to manifest themselves. Future work in this vein would be well advised to involve longer follow-up periods if such data is available.

\section{Inferences from Medicaid Claims Data}

While this study collected data on two measures of acute medical care (emergency room visits and hospital visits) and one measure of chronic care (outpatient visits), attempts to infer a child's health status or changes in parental healthcare decision-making are limited without more information. This study did not make use of conventional measures of health status, such as the nine-item Patient Health Questionnaire (PHQ-9), and therefore this study 
cannot draw any conclusions about how START participation affected children's health beyond their mere utilization of health resources that were paid for by their Medicaid plan. Moreover, it is impossible to use the available data to make any reliable inferences in terms of relative rates of overutilization of a given health service (beyond the simple observation that many children appeared to use the emergency room as much or more than outpatient clinics). Such a result strongly suggests that those parents may have been using the emergency room for non-emergent concerns.

Additionally, in Kentucky, there were multiple Medicaid Managed Care Organizations (MCO’s) that operated in the state during the 2010-2016 period. Information related to which MCO provided Medicaid coverage to a given child was not information that was provided in the data request from Kentucky Medicaid. That being the case, it is very likely that the children in this sample were not all covered by the same MCO. While Medicaid policy regulates much of the behavior of these MCO's, they are granted some flexibility and discretion in how they fulfill their role of providing medical coverage to Kentuckians (e.g., which services to cover, which drugs are on their formulary, the duration of services that will be paid for a given service, etc.). Membership in a given MCO is often related to where a citizen lives in Kentucky, as it is common for one MCO to cover a large proportion of Medicaid enrollees in a given region. Therefore, it is possible that individual differences in the policies of the different MCO's may have affected the results observed in this study. However, there is no reason to believe that there were any systematic betweengroup differences in terms of MCO coverage, and it is therefore doubtful that knowledge of MCO coverage would have dramatically altered the conclusions described here. 


\section{Directions for Future Research}

These results also suggest that it is possible that this study sample contained at least two qualitatively distinct populations that each responded differently to their family's participation in START: (1) newborns and infants, (2) toddlers and young children. In this sample, the first group was substantially more represented than the second. As stated before, the healthcare needs of these two groups differ as a function of their developmental stage, such as immune system strengthening, changes in nutritional needs, and the ability to crawl and walk. In other words, it may be possible that a non-medical intervention like START has greater efficacy in terms of children's health promotion for older, and less medically fragile children than it does for newborns (especially those born substance-exposed). Future investigations with similar aims and methodologies would be wise to consider samples with more restricted age ranges, and only investigate newborns or older children in isolation of one another.

\section{Look for Medicaid Spending Differences Between START and Comparison Parents}

This investigation was solely focused on the children of families with cooccurring substance use and child maltreatment. They are, of course, an important stakeholder in the operation of the START program, but they are most properly understood as one participant in a family system. The very uniqueness of the START intervention is rooted in its more holistic approach to solving child welfare problems by partnering with parents more closely than conventional CPS services. Because the health behavior change of the substance-using adults in these cases is the chief target of the START intervention (as well as a variable that has been established to be one that is amenable to positive change through treatment; see Parthasarathy \& Weisner, 2005), future research would be well served 
to also examine START's effects on adult health services outcomes. Such research could replicate this methodology and focus solely on the adults involved in cases, or could expand it and analyze the combined outcomes of all family members (the child victim, siblings in the home, spouses/romantic partners, etc.).

\section{Therapeutic Foster Care}

One other notable opportunity for future work would be the inclusion of therapeutic foster care as an outcome variable. In Kentucky, this is a service provided for children in state custody with specialized medical needs that is paid for through the Medicaid program. While the three outcome variables included in this study's analysis likely captured a representative portion of Medicaid spending on the children in the sample, this study cannot comment on any savings that may have been generated by the START program as a result of the prevention of removing children from the home.

As demonstrated in Huebner and colleagues (2012), START has been demonstrated to reduce the rate of removing children from the home (an outcome that was also consistent with this study's sample). Investigating this outcome could effectively serve as an extension of the earlier finding in Huebner and colleagues (2012) that described cost savings attributable to reductions in per diem foster care payments. While not all children placed in out of home care require therapeutic foster care, it is likely that some degree of this sample utilized it during their study period. For this reason, estimates made by this study may underestimate the differences in Medicaid spending along these lines.

Investigate Other Outcome Variables of Interest

Investigating how parents respond to START services would also afford future research initiatives the opportunity to test whether the intervention positively affects other 
measures of healthy functioning in society. For example, this study involved linking CPS data with Medicaid data to ask questions related to healthcare spending - but there are other state agencies who warehouse information that could be relevant to future investigations and could be linked in a similar way. For example, Kentucky includes birth certificate data in its collection of vital statistics (e.g., Apgar scores, birth weight, etc.). There are examples in the literature that describe other positive economic externalities associated with successful addiction treatment beyond reductions in healthcare spending, such as crime reduction or improving rates of labor force participation (Gossop, Trakada, Stewart, \& Witton, 2005; Ginexi, Foss, \& Scott, 2003). Reaching out to the Kentucky State Police or the Kentucky Department of Labor to initiate a similar data sharing arrangement to the one arranged with the Department of Medicaid Services could be prudent towards the development of an even more extensive understanding of how families respond to the START intervention. Though it was beyond the scope of this investigation for test for such relationships, it is possible that they exist, and future study designs could use comparable methodology to the one employed here.

Beyond this, the longitudinal nature of the existing START program evaluation dataset could allow for parallel studies of how the children of families who respond well to START fare over longer periods of time and in a number of these functional dimensions. Initiatives to merge and link data between state agencies in Kentucky could create opportunities for the START evaluation team to investigate whether success in START is associated with later improvements in educational attainment, entry into the workforce, mental health status, or criminal behavior for the same children described in this study. 
Additionally, this study is the first known example of using TWIST data to generate a comparison group of CPS-involved children with PSM within the context of a program evaluation. While there are several recent examples in the literature of studies using similar methods with nationally representative datasets (including linkage with Medicaid claims data), TWIST data offers unique variables that provide important information about CPS cases in Kentucky. Specifically, the ADT assessment (Assessment and Documentation Tool) used by CPS collects data that were particularly useful in the PSM procedure used in this study. Items such as risks associated with parental mental health problems, parental criminal history, or domestic violence in the home are collected by the ADT, and were not used as PSM matching variables in the aforementioned studies (which used national datasets such as the National Survey of Child and Adolescent Well-Being; e.g., Florence et al., 2013).

The method employed by this study is one that could be replicated for several applications involving the evaluation of child welfare program outcomes in Kentucky. This is especially timely considering the advent of the Family First Prevention Services Act, which requires states to justify their choices of interventions to offer CPS-involved families on the basis of the strength of the evidence of their efficacy. Quasi-experimental studies with a comparison group, such as this one, are considered sufficient support for a state to justify such choices. Especially considering the reality that randomized controlled trials are not always feasible or appropriate with this population, the ability to utilize a tool that can approximate the function of randomization without needing to turn families away from services that are possibly very beneficial is a useful asset to researchers. 


\section{Summary and Conclusions}

When children have been the victims of maltreatment, their resultant pain and suffering can manifest itself in many ways. Because of this, the wide-ranging effects of that harm are seen by every system that serves children. Past research suggests that, given the convergence of risk factors present in the Medicaid-enrolled population, directing child welfare investigations towards children enrolled on public health insurance programs can be especially fruitful (Putnam-Hornstein, Needell, King, \& Johnson-Motoyama, 2013). When children are safer and healthier, it is often less expensive for state Medicaid programs to insure them; this is turn may free up financial resources that can be used for other programming to benefit children. Ideally, the ability to shift a percentage of state money from acute medical care to services related to early childhood education or the amelioration of poverty would unlock a virtuous cycle, whereby successive generations of children are given better and better opportunities to be safe, healthy, and successful. It is for this reason that researchers performing program evaluations of child maltreatment interventions would be wise to consider creative approaches to measuring the outcomes of those interventions. While the primary aim of these interventions should always be the promotion of children's safety and their family's wellbeing, it can also be valuable to describe ways that beneficial programs produce meaningful cost savings.

Several authorities have called for a more robust effort to study and better understand the financial consequences of providing innovative child welfare interventions to high-need populations (Swenson et al., 2009; Corso \& Lutzker, 2006; Goldhaber-Fiebert, Snowden, Wulczyn, Landsverk, \& Horwitz, 2011; Chamberlain et al., 2011). Such insights provide a number of benefits. First of all, the ability to determine whether providing a program offers 
any ancillary savings to healthcare providers or health insurers provides an extra justification for funding or expanding such programs. While this study did find that comparison group membership was associated with moderately higher Medicaid spending compared to START children, these results alone are unlikely sufficient to support the use of funding mechanisms such as Social Impact Bonds for continued funding for the START program on the basis of prevention of Medicaid spending for children (Trupin, Weiss, \& Kerns, 2014).

These funding mechanisms, which are not bonds in the traditional sense, are often used to help human service organizations access capital in order to scale up programming with demonstrated efficacy. In their most common form, they operate as a partnership between three parties: (1) a human service organization who provides the intervention (2) an investor who provides money to the human service organization to pay for the intervention, and (3) a government agency who repays the investor's principal investment with interest when the predetermined outcomes are achieved by the intervention. The animating principle behind this approach is that it serves each party's interest (including the broader society) and it helps government agencies share the risk of financing large scale interventions. In other words, the human service organization stands to benefit by receiving funds to help them serve their clients, the investor stands to benefit by receiving a return on their investment through a socially advantageous means, and the government agency stands to benefit by reaping a net savings through reducing a costly social problem.

Though these contracts offer a potential for promising results in the future, the literature is mixed on their ultimate success in addressing difficult social problems. The very first social impact bond was conducted in 2010 at Peterborough prison in England in an effort to reduce recidivism. Even though the intervention was ended prematurely, an 
evaluation by the RAND Corporation found a 9\% reduction in recidivism compared to a control group, and investors were paid back with a 3\% compounded annual return on investment. On the other hand, the first social impact bond project in the U.S., which funded an effort by Riker's Island prison in New York City to reduce recidivism, was ended prematurely after it failed to achieve it's outcome goals. Caution is warranted to ensure that policy makers and other stakeholders maintain a humanitarian spirit in these projects, and avoid the appearance of profiteering on the backs of those in need (Fraser, Tan, Lagarde, \& Mays, 2018). In this case, it is unlikely that the modest savings observed by this study would be enough to justify the risks that private investors assume when entering into such contracts. However, that does not preclude future investigations of similar funding mechanisms on the basis of other START outcomes, such as reductions in total out of home care placements, fewer days in out of home care, or improvements in adult health outcomes.

This study further illustrates the well-established reality of the especially high healthcare costs associated with substance use and child maltreatment - especially those related to prenatal substance exposure. If cost containment for Medicaid is a chief policy goal, these results most strongly suggest that prevention and treatment efforts be directed towards SUD-diagnosed pregnant women. When taken as a whole, Medicaid spending on these children was highest at baseline (a period which for the majority of the sample included the costs of their delivery and postnatal care), and tended to decrease within the two years following their family's initial contact with CPS in both study groups. This suggests that the highest "returns" would be yielded from intervention with this vulnerable group.

In conclusion, this study investigated children's rates of utilization of three types of healthcare services covered by Medicaid. A dataset containing information on a large sample 
of START children with matched comparisons collected from five unique regions of Kentucky was analyzed to determine whether participation in the START program was associated with any significant differences between groups. There were predominant findings yielded from this study: START participation is associated with a modest, yet non-significant lower spend for Medicaid. Second, comparison children seemed to use outpatient services at greater rates than START children, START children seemed to use emergency room services at greater rates than comparison children, and there was no distinguishable difference in terms of hospitalization. Third, where a child received START or typical CPS services was significantly associated with their utilization of outpatient services and hospital services, but not emergency room care (with the Martin County cluster appearing to be especially prone to utilizing acute care services). Finally, there appeared to be a strong relationship between oneyear recurrence of child maltreatment and utilization of each of the three service categories. Specifically, families who had new substantiated CPS cases within twelve months of their index case had significantly higher utilization rates of health services than those without new cases. 


\section{REFERENCES}

Adler, L. S. (2001). The meanings of permanence: A critical analysis of the Adoption and Safe Families Act of 1997. Harvard Journal on Legislation, 38, 1.

Afifi, A. A., Kotlerman, J. B., Ettner, S. L., \& Cowan, M. (2007). Methods for improving regression analysis for skewed continuous or counted responses. Annu. Rev. Public Health, 28, 95-111.

Agrawal, A., \& Lynskey, M. T. (2008). Are there genetic influences on addiction: evidence from family, adoption and twin studies. Addiction, 103(7), 1069-1081.

Anda, R. F., Felitti, V. J., Bremner, J. D., Walker, J. D., Whitfield, C. H., Perry, B. D., ... $\&$ Giles, W. H. (2006). The enduring effects of abuse and related adverse experiences in childhood. European Archives of Psychiatry and Clinical Neuroscience, 256(3), 174-186.

Anderson, G. F., Reinhardt, U. E., Hussey, P. S., \& Petrosyan, V. (2003). It's the prices, stupid: why the United States is so different from other countries. Health Affairs, 22(3), 89-105.

Anholt, R. R., \& Mackay, T. F. (2012). Genetics of aggression. Annual Review of Genetics, 46, 145-164.

Antle, B. F., Barbee, A. P., Sullivan, D. J., \& Christensen, D. N. (2009). The effects of training reinforcement on training transfer in child welfare. Child Welfare, 88(3).

Ashford, J. B. (2004). Treating Substance-Abusing Parents: A Study of the Pima County Family Drug Court Approach. Juvenile and Family Court Journal, 55(4), 27-37.

Auerbach, C., McGowan, B. G., \& Laporte, H. H. (2008). How does professional education impact the job outlook of public child welfare workers? Journal of Public Child Welfare, 1(3), 55-76.

Azzi-Lessing, L., \& Olsen, L. J. (1996). Substance abuse-affected families in the child welfare system: New challenges, new alliances. Social Work, 41(1), 15-23.

Barbee, A. P., Antle, B., Sullivan, D. J., Huebner, R., Fox, S., \& Hall, J. C. (2009). Recruiting and retaining child welfare workers: Is preparing social work students enough for sustained commitment to the field? Child Welfare, 88(5), 69-85.

Barnard, M., \& McKeganey, N. (2004). The impact of parental problem drug use on 
children: what is the problem and what can be done to help? Addiction, 99(5), 552-559.

Barry, C. L., \& Huskamp, H. A. (2011). Moving beyond parity-mental health and addiction care under the ACA. New England Journal of Medicine, 365(11), 973975.

Barth, R. P. (1997). Effects of age and race on the odds of adoption versus remaining in long-term out-of-home care. Child Welfare, 76(2), 285.

Barth, R. P., Lee, C. K., Wildfire, J., \& Guo, S. (2006). A comparison of the governmental costs of long-term foster care and adoption. Social Service Review, 80(1), 127-158.

Barth, R. P., Gibbons, C., \& Guo, S. (2006). Substance abuse treatment and the recurrence of maltreatment among caregivers with children living at home: A propensity score analysis. Journal of Substance Abuse Treatment, 30(2), 93-104.

Barth, R. P., Lloyd, E. C., Christ, S. L., Chapman, M. V., \& Dickinson, N. S. (2008). Child welfare worker characteristics and job satisfaction: A national study. Social Work, 53(3), 199-209.

Barth, R. P., Guo, S., \& McCrae, J. S. (2008). Propensity score matching strategies for evaluating the success of child and family service programs. Research on Social Work Practice, 18(3), 212-222.

Barth, R. P., Wulczyn, F., \& Crea, T. (2004). From anticipation to evidence: Research on the Adoption and Safe Families Act. Virginia Journal of Social Policy and the Law, 12, 371.

Bartholet, E. (2009). The racial disproportionality movement in child welfare: False facts and dangerous directions. Arizona Law Review, 51, 871.

Beauman, S. S. (2005). Identification and management of neonatal abstinence syndrome. Journal of Infusion Nursing, 28(3), 159-167.

Belsky, J., Conger, R., \& Capaldi, D. M. (2009). The intergenerational transmission of parenting: Introduction to the special section. Developmental Psychology, 45(5), 1201.

Berger, L. M. (2004). Income, family structure, and child maltreatment risk. Children and Youth Services Review, 26(8), 725-748.

Berger, L. M., \& Waldfogel, J. (2011). Economic determinants and consequences of child maltreatment. OECD Social, Employment, and Migration Working Papers, (111),0_1. 
Berlin, L. J., Appleyard, K., \& Dodge, K. A. (2011). Intergenerational continuity in child maltreatment: Mediating mechanisms and implications for prevention. Child Development, 82(1), 162-176.

Berlyn, C., Wise, S., \& Soriano, G. (2008). Engaging fathers in child and family services: Participation, perceptions and good practice. Family Matters, (80), 37.

Beronio, K., Glied, S., \& Frank, R. (2014). How the Affordable Care Act and Mental Health Parity and Addiction Equity Act greatly expand coverage of behavioral health care. The Journal of Behavioral Health Services \& Research, 41(4), 410428.

Besinger, B. A., Garland, A. F., Litrownik, A. J., \& Landsverk, J. A. (1999). Caregiver substance abuse among maltreated children placed in out-of-home care. Child Welfare, 78(2), 221.

Billings, J., \& Mijanovich, T. (2007). Improving the management of care for high-cost Medicaid patients. Health Affairs, 26(6), 1643-1654.

Birnbaum, H. G., White, A. G., Reynolds, J. L., Greenberg, P. E., Zhang, M., Vallow, S., ... \& Katz, N. P. (2006). Estimated costs of prescription opioid analgesic abuse in the United States in 2001: a societal perspective. The Clinical Journal of Pain, 22(8), 667-676.

Boadway, R., \& Bruce, N. (1984). Welfare Economics. New York, NY. Basil Blackwell.

Boldt, R. C. (1999). Evaluating Histories of Substance Abuse in Cases Involving the Termination of Parental Rights. Journal of Health Care Law \& Policy, 3, 135.

Boles, S. M., Young, N. K., Moore, T., \& DiPirro-Beard, S. (2007). The Sacramento dependency drug court: Development and outcomes. Child Maltreatment, 12(2), 161-171.

Botticelli, M. P., \& Koh, H. K. (2016). Changing the language of addiction. Journal of the American Medical Association, 316(13), 1361-1362.

Bouchery, E. E., Harwood, H. J., Sacks, J. J., Simon, C. J., \& Brewer, R. D. (2011). Economic costs of excessive alcohol consumption in the US, 2006. American Journal of Preventive Medicine, 41(5), 516-524.

Bowlby, J. (2008). A secure base: Parent-child attachment and healthy human development. Basic books.

Boyd, R. (2014). African American disproportionality and disparity in child welfare: Toward a comprehensive conceptual framework. Children and Youth Services Review, 37, 15-27. 
Brady, K. T., Grice, D. E., \& Dustan, L. (1999). Gender differences in substance use disorders. Addictive Disorders, 22(2), 241-252.

Bretherton, I. (1992). The origins of attachment theory: John Bowlby and Mary Ainsworth. Developmental Psychology, 28(5), 759.

Brewster, A. L., Nelson, J. P., Hymel, K. P., Colby, D. R., Lucas, D. R., McCanne, T. R., \& Milner, J. S. (1998). Victim, perpetrator, family, and incident characteristics of 32 infant maltreatment deaths in the United States Air Force. Child Abuse \& Neglect, 22(2), 91-101.

Briere, J., \& Jordan, C. E. (2009). Childhood maltreatment, intervening variables, and adult psychological difficulties in women: An overview. Trauma, Violence, \& Abuse, 10(4), 375-388.

Brook, J., McDonald, T. P., Gregoire, T., Press, A., \& Hindman, B. (2010). Parental substance abuse and family reunification. Journal of Social Work Practice in the Addictions, 10(4), 393-412.

Brook, J., \& McDonald, T. (2009). The impact of parental substance abuse on the stability of family reunifications from foster care. Children and Youth Services Review, 31(2), 193-198.

Brook, J., McDonald, T. P., \& Yan, Y. (2012). An analysis of the impact of the Strengthening Families Program on family reunification in child welfare. Children and Youth Services Review, 34(4), 691-695.

Brown, L., Callahan, M., Strega, S., Walmsley, C., \& Dominelli, L. (2009). Manufacturing ghost fathers: The paradox of father presence and absence in child welfare. Child \& Family Social Work, 14(1), 25-34.

Brown, J., Cohen, P., Johnson, J. G., \& Salzinger, S. (1998). A longitudinal analysis of risk factors for child maltreatment: Findings of a 17-year prospective study of officially recorded and self-reported child abuse and neglect. Child Abuse \& Neglect, 22(11), 1065-1078.

Burrus, S. W., Mackin, J. R., \& Finigan, M. W. (2011). Show me the money: Child welfare cost savings of a family drug court. Juvenile and Family Court Journal, 62(3), 1-14.

Bush-Baskette, S. (2000). The war on drugs and the incarceration of mothers. Journal of Drug Issues, 30(4), 919-928.

California Evidence-Based Clearing House (CEBC). (2008) Reno Family Drug Court - 
Summary. Califorinia Evidence-Based Clearinghouse for Child Welfare. Retrieved from http://www.cachildwelfareclearinghouse.org/program/30\#contact

Cancian, M., Yang, M. Y., \& Slack, K. S. (2013). The effect of additional child support income on the risk of child maltreatment. Social Service Review, 87(3), 417-437.

Carlson, B., Matto, H., Smith, C., \& Eversman, M. (2006). A pilot study of reunification following drug abuse treatment: Recovering the mother role. Journal of Drug Issues, 22, 878-902.

Carter-Black, J. (2002). Transracial adoption and foster care placement: worker perception and attitude. Child Welfare, 81(2).

Center on the Developing Child at Harvard University (2012). The Science of Neglect: The Persistent Absence of Responsive Care Disrupts the Developing Brain: Working Paper No. 12. Retrieved from www.developingchild.harvard.edu

Centers for Disease Control and Prevention (CDC). Adverse Childhood Experiences: Looking at how ACEs affect our lives \& society retrieved from https://vetoviolence.cdc.gov/apps/phl/images/ACE_Accessible.pdf

Chaffin, M., Kelleher, K., \& Hollenberg, J. (1996). Onset of physical abuse and neglect: Psychiatric, substance abuse, and social risk factors from prospective community data. Child Abuse \& Neglect, 20, 191-203.

Chaffin, M., \& Bard, D. (2006). Impact of intervention surveillance bias on analyses of child welfare report outcomes. Child Maltreatment, 11(4), 301-312.

Chamberlain, P., Snowden, L. R., Padgett, C., Saldana, L., Roles, J., Holmes, L., ... \& Landsverk, J. (2011). A strategy for assessing costs of implementing new practices in the child welfare system: Adapting the English cost calculator in the United States. Administration and Policy in Mental Health and Mental Health Services Research, 38(1), 24-31.

Choi, S., \& Ryan, J. P. (2006). Completing substance abuse treatment in child welfare: The role of co-occurring problems and primary drug of choice. Child Maltreatment, 11(4), 313-325.

Chuang, E., Wells, R., Bellettiere, J., \& Cross, T. P. (2013). Identifying the substance abuse treatment needs of caregivers involved with child welfare. Journal of Substance Abuse Treatment, 45(1), 118-125.

Clark, R. E., Samnaliev, M., \& McGovern, M. P. (2009). Impact of substance disorders on medical expenditures for Medicaid beneficiaries with behavioral health disorders. Psychiatric Services, 60(1), 35-42. 
Colman, R. A., \& Widom, C. S. (2004). Childhood abuse and neglect and adult intimate relationships: A prospective study. Child Abuse \& Neglect, 28(11), 1133-1151.

Conway, K. P., Vullo, G. C., Nichter, B., Wang, J., Compton, W. M., Iannotti, R. J., \& Simons-Morton, B. (2013). Prevalence and patterns of polysubstance use in a nationally representative sample of 10th graders in the United States. Journal of Adolescent Health, 52(6), 716-723.

Corso, P. S., \& Lutzker, J. R. (2006). The need for economic analysis in research on child maltreatment. Child Abuse \& Neglect, 30(7), 727-738.

Coulton, C. J., Crampton, D. S., Irwin, M., Spilsbury, J. C., \& Korbin, J. E. (2007). How neighborhoods influence child maltreatment: A review of the literature and alternative pathways. Child Abuse \& Neglect, 31(11), 1117-1142.

Counts, J. M., Buffington, E. S., Chang-Rios, K., Rasmussen, H. N., \& Preacher, K. J. (2010). The development and validation of the protective factors survey: A selfreport measure of protective factors against child maltreatment. Child Abuse \& Neglect, 34(10), 762-772.

Courtwright, D. T. (2009). Forces of habit. Harvard University Press.

Covington, S. (2002). Helping women recover: Creating gender-responsive treatment. In Straussner, S.L.A., \& Brown, S. (Eds.). The handbook of addiction treatment for women: Theory and practice. (52-72). San Francisco: Jossey-Bass.

Cunningham, S., \& Finlay, K. (2013). Parental substance use and foster care: Evidence from two methamphetamine supply shocks. Economic Inquiry, 51(1), 764-782.

Currie, J., \& Gruber, J. (1996). Health insurance eligibility, utilization of medical care, and child health. The Quarterly Journal of Economics, 111(2), 431-466.

Cutts, T., Rafalski, E., Grant, C., \& Marinescu, R. (2014). Utilization of hot spotting to identify community needs and coordinate care for high-cost patients in Memphis, TN. Journal of Geographic Information System, 6(01), 23.

De La Cruz, D. (2018, March 29). Utah Passes 'Free-Range' Parenting Law. The New York Times. Retrieved from https://www.nytimes.com/2018/03/29/well/family/utah-passes-free-rangeparenting-law.html

DeSantis, S. M., Lazaridis, C., Ji, S., \& Spinale, F. G. (2014). Analyzing propensity matched zero-inflated count outcomes in observational studies. Journal of Applied Statistics, 41(1), 127-141.

Desmarais, B. A., \& Harden, J. J. (2013). Testing for zero inflation in count models: Bias correction for the Vuong test. The Stata Journal, 13(4), 810-835. 
Dettlaff, A. J., Rivaux, S. L., Baumann, D. J., Fluke, J. D., Rycraft, J. R., \& James, J. (2011). Disentangling substantiation: The influence of race, income, and risk on the substantiation decision in child welfare. Children and Youth Services Review, 33(9), 1630-1637.

DeVooght, K., Allen, T., \& Geen, R. (2015). Federal, state, and local spending to address child abuse and neglect in SFY 2012. Child Trends.

Dixon, L., Browne, K., \& Hamilton-Giachritsis, C. (2005). Risk factors of parents abused as children: a mediational analysis of the intergenerational continuity of child maltreatment (Part I). Journal of Child Psychology and Psychiatry, 46(1), 47-57.

Dore, M. M., Doris, J. M., \& Wright, P. (1995). Identifying substance abuse in maltreating families: A child welfare challenge. Child Abuse \& Neglect, 19(5), 531-543.

Dozier, M., Stovall-McClough, K. C., \& Albus, K. E. (2008). Attachment and psychopathology in adulthood. In J. Cassidy \& P. R. Shaver (Eds.), Handbook of attachment: Theory, research, and clinical applications (pp. 718-744). New York, NY, US: Guilford Press.

Drabble, L. (2007). Pathways to collaboration: Exploring values and collaborative practice between child welfare and substance abuse treatment fields. Child Maltreatment, 12(1), 31-42.

Drake, B., Jolley, J. M., Lanier, P., Fluke, J., Barth, R. P., \& Jonson-Reid, M. (2011). Racial bias in child protection? A comparison of competing explanations using national data. Pediatrics, 127(3), 471-478.

Drake, B., \& Pandey, S. (1996). Understanding the relationship between neighborhood poverty and specific types of child maltreatment. Child Abuse \& Neglect, 20(11), 1003-1018.

Dube, S. R., Anda, R. F., Felitti, V. J., Croft, J. B., Edwards, V. J., \& Giles, W. H. (2001). Growing up with parental alcohol abuse: exposure to childhood abuse, neglect, and household dysfunction. Child Abuse \& Neglect, 25(12), 1627-1640.

Dube, S. R., Felitti, V. J., Dong, M., Giles, W. H., \& Anda, R. F. (2003). The impact of adverse childhood experiences on health problems: evidence from four birth cohorts dating back to 1900. Preventive Medicine, 37(3), 268-277.

Dubowitz, H., Kim, J., Black, M. M., Weisbart, C., Semiatin, J., \& Magder, L. S. (2011). Identifying children at high risk for a child maltreatment report. Child Abuse \& Neglect, 35(2), 96-104. 
Eluvathingal, T. J., Chugani, H. T., Behen, M. E., Juhasz, C., Muzik, O., Maqbool, M., ... \& Makki, M. (2006). Abnormal brain connectivity in children after early severe socioemotional deprivation: A diffusion tensor imaging study. Pediatrics, 117(6), 2093-2100.

Escohotado, A. (1999). A brief history of drugs: from the Stone Age to the stoned age. Simon and Schuster.

Estee, S., Wickizer, T., He, L., Shah, M. F., \& Mancuso, D. (2010). Evaluation of the Washington state screening, brief intervention, and referral to treatment project: cost outcomes for Medicaid patients screened in hospital emergency departments. Medical Care, 48(1), 18-24.

Fang, X., Brown, D. S., Florence, C. S., \& Mercy, J. A. (2012). The economic burden of child maltreatment in the United States and implications for prevention. Child Abuse \& Neglect, 36(2), 156-165.

Fein, D. J., \& Lee, W. S. (2003). The impacts of welfare reform on child maltreatment in Delaware. Children and Youth Services Review.

Felitti, V. J., Anda, R. F., Nordenberg, D., Williamson, D. F., Spitz, A. M., Edwards, V., ... \& Marks, J. S. (1998). Relationship of childhood abuse and household dysfunction to many of the leading causes of death in adults: The Adverse Childhood Experiences (ACE) Study. American Journal of Preventive Medicine, 14(4), 245-258.

Finkelstein, N. (1994). Treatment issues for alcohol-and drug-dependent pregnant and parenting women. Health \& Social Work, 19(1), 7-15.

Fixsen, D. L., Blase, K. A., Naoom, S. F., \& Wallace, F. (2009). Core implementation components. Research on Social Work Practice, 19(5), 531-540.

Florence, C., Brown, D. S., Fang, X., \& Thompson, H. F. (2013). Health care costs associated with child maltreatment: impact on Medicaid. Pediatrics, 132(2), 1-7.

Ford, J. D., Trestman, R. L., Steinberg, K., Tennen, H., \& Allen, S. (2004). Prospective association of anxiety, depressive, and addictive disorders with high utilization of primary, specialty and emergency medical care. Social Science \& Medicine, 58(11), 2145-2148.

French, M. T., \& Drummond, M. (2005). A research agenda for economic evaluation of substance abuse services. Journal of Substance Abuse Treatment, 29(2), 125-137.

French, M. T., McGeary, K. A., Chitwood, D. D., \& McCoy, C. B. (2000). Chronic illicit 
drug use, health services utilization and the cost of medical care. Social Science \& Medicine, 50(12), 1703-1713.

Frew, E. (2010). Applied methods of cost-benefit analysis in health care (Vol. 4). Oxford University Press.

Friedmann, P. D., Hendrickson, J. C., Gerstein, D. R., Zhang, Z., \& Stein, M. D. (2006). Do mechanisms that link addiction treatment patients to primary care influence subsequent utilization of emergency and hospital care?. Medical Care, 44(1), 815.

Friedmann, P. D., Lemon, S. C., Stein, M. D., \& D'aunno, T. A. (2003). Accessibility of addiction treatment: results from a national survey of outpatient substance abuse treatment organizations. Health Services Research, 38(3), 887-903.

Freisthler, B., Merritt, D. H., \& LaScala, E. A. (2006). Understanding the ecology of child maltreatment: A review of the literature and directions for future research. Child Maltreatment, 11(3), 263-280.

Gadomski, A., Jenkins, P., \& Nichols, M. (1998). Impact of a Medicaid primary care provider and preventive care on pediatric hospitalization. Pediatrics, 101(3), e1.

Gelles, R.J., \& Perlman, S. (2012). Estimated Annual Cost of Child Abuse and Neglect. Chicago IL: Prevent Child Abuse America.

Gifford, E. J., Eldred, L. M., Vernerey, A., \& Sloan, F. A. (2014). How does family drug treatment court participation affect child welfare outcomes? Child Abuse \& Neglect, 38(10), 1659-1670.

Gifford, E. J., Eldred, M. L. M., Sloan, F. A., \& Evans, M. K. E. (2016). Header: Do adult DTC programs prevent child maltreatment? Parental criminal justice involvement and children's involvement with child protective services: Do adult drug treatment courts prevent child maltreatment? Substance use \& Misuse, 51(2), 179 .

Gifford, E. J., Eldred, L. M., McCutchan, S. A., \& Sloan, F. A. (2014). The effects of participation level on recidivism: a study of drug treatment courts using propensity score matching. Substance Abuse Treatment, Prevention, and Policy, 9(1), 40.

Gilbert, R., Widom, C. S., Browne, K., Fergusson, D., Webb, E., \& Janson, S. (2009). Burden and consequences of child maltreatment in high-income countries. The Lancet, 373(9657), 68-81.

Ginexi, E. M., Foss, M. A., \& Scott, C. K. (2003). Transitions from treatment to work: Employment patterns following publicly funded substance abuse treatment. Journal of Drug Issues, 33(2), 497-518. 
Golder, S. (2007). Modeling substance use and related risk behaviors leading to criminal justice involvement among young adult women. Women \& Criminal Justice, 16(4), 43-72.

Goldhaber-Fiebert, J. D., Snowden, L. R., Wulczyn, F., Landsverk, J., \& Horwitz, S. M. (2011). Economic evaluation research in the context of Child Welfare policy: A structured literature review and recommendations. Child Abuse \& Neglect, 35, $722-740$.

Goldstein, R. B., Chou, S. P., Smith, S. M., Jung, J., Zhang, H., Saha, T. D., ... \& Grant, B. F. (2015). Nosologic comparisons of DSM-IV and DSM-5 alcohol and drug use disorders: Results from the National Epidemiologic Survey on Alcohol and Related Conditions-III. Journal of Studies on Alcohol and Drugs, 76(3), 378-388.

Goldstein, R. Z., \& Volkow, N. D. (2011). Dysfunction of the prefrontal cortex in addiction: neuroimaging findings and clinical implications. Nature Reviews Neuroscience, 12(11), 652-669.

Gossop, M., Trakada, K., Stewart, D., \& Witton, J. (2005). Reductions in criminal convictions after addiction treatment: 5-year follow-up. Drug and Alcohol Dependence, 79(3), 295-302.

Granfield, R., \& Cloud, W. (2001). Social context and "natural recovery": The role of social capital in the resolution of drug-associated problems. Substance Use \& Misuse, 36(11), 1543-1570.

Grant, B. F., Stinson, F. S., Dawson, D. A., Chou, S. P., Dufour, M. C., Compton, W., ... \& Kaplan, K. (2004). Prevalence and co-occurrence of substance use disorders and independent mood and anxiety disorders: Results from the national epidemiologic survey on alcohol and related conditions. Archives of General Psychiatry, 61(8), 807-816.

Green, B. L., Furrer, C., Worcel, S., Burrus, S., \& Finigan, M. W. (2007). How effective are family treatment drug courts? Outcomes from a four-site national study. Child Maltreatment, 12(1), 43-59.

Gregoire, T. K. (1994). Assessing the benefits and increasing the utility of addiction training for public child welfare workers: A pilot study. Child Welfare, 73(1), 69.

Gregoire, K. A., \& Schultz, D. J. (2001). Substance-abusing child welfare parents: treatment and child placement outcomes. Child Welfare, 80(4).

Grella, C. E. (2008). From generic to gender-responsive treatment: Changes in social policies, treatment services, and outcomes of women in substance abuse treatment. Journal of Psychoactive Drugs, 40(sup5), 327-343. 
Grella, C. E., Hser, Y. I., \& Huang, Y. C. (2006). Mothers in substance abuse treatment: Differences in characteristics based on involvement with child welfare services. Child Abuse \& Neglect, 30(1), 55-73.

Grossman, L. K., Rich, L. N., \& Johnson, C. (1998). Decreasing nonurgent emergency department utilization by Medicaid children. Pediatrics, 102(1), 20-24.

Guenther, E., Knight, S., Olson, L. M., Dean, J. M., \& Keenan, H. T. (2009). Prediction of child abuse risk from emergency department use. The Journal of Pediatrics, 154(2), 272-277.

Guo, S., Barth, R. P., \& Gibbons, C. (2006). Propensity score matching strategies for evaluating substance abuse services for child welfare clients. Children and Youth Services Review, 28(4), 357-383.

Hacker, K., \& Walker, D. K. (2013). Achieving population health in accountable care organizations. American Journal of Public Health, 103(7), 1163-1167.

Hall, M. T., Wilfong, J., Huebner, R. A., Posze, L., \& Willauer, T. (2016). Medicationassisted treatment improves child permanency outcomes for opioid-using families in the child welfare system. Journal of Substance Abuse Treatment, 71, 63-67.

Hall, M. T., Golder, S., Conley, C. L., \& Sawning, S. (2013). Designing programming and interventions for women in the criminal justice system. American Journal of Criminal Justice, 38(1), 27-50.

Hall, W., Carter, A., \& Forlini, C. (2015). The brain disease model of addiction: is it supported by the evidence and has it delivered on its promises?. The Lancet Psychiatry, 2(1), 105-110.

Hammer, R., Dingel, M., Ostergren, J., Partridge, B., McCormick, J., \& Koenig, B. A. (2013). Addiction: Current criticism of the brain disease paradigm. AJOB Neuroscience, 4(3), 27-32.

Hannett, M. J. (2007). Lessening the sting of ASFA: the rehabilitation-relapse dilemma brought about by drug addiction and termination of parental rights. Family Court Review, 45(3), 524-537.

Hanson, K. E., Saul, D. H., Vanderploeg, J. J., Painter, M., \& Adnopoz, J. (2015). Family-Based Recovery: An Innovative In-Home Substance Abuse Treatment Model for Families with Young Children. Child Welfare, 94(4), 161-183.

Hashima, P. Y., \& Amato, P. R. (1994). Poverty, social support, and parental behavior. Child Development, 65(2), 394-403. 
Hasin, D. S., O’Brien, C. P., Auriacombe, M., Borges, G., Bucholz, K., Budney, A., ... \& Schuckit, M. (2013). DSM-5 criteria for substance use disorders: recommendations and rationale. American Journal of Psychiatry, 170(8), 834851.

Hazan, C., \& Shaver, P. R. (1994). Deeper into attachment theory. Psychological Inquiry, 5(1), 68-79.

Heckman, J. J., Ichimura, H., \& Todd, P. E. (1997). Matching as an econometric evaluation estimator: Evidence from evaluating a job training programme. The Review of Economic Studies, 64(4), 605-654.

Herndon, J. B., Chaney, M., \& Carden, D. (2011). Health literacy and emergency department outcomes: a systematic review. Annals of Emergency Medicine, 57(4), 334-345.

Hines, A. M., Lemon, K., Wyatt, P., \& Merdinger, J. (2004). Factors related to the disproportionate involvement of children of color in the child welfare system: A review and emerging themes. Children and Youth Services Review, 26(6), 507527.

Holt, S., Buckley, H., \& Whelan, S. (2008). The impact of exposure to domestic violence on children and young people: A review of the literature. Child Abuse \& Neglect, 32(8), 797-810.

Howell, M. L. (2008). Decisions with good intentions: Substance use allegations and child protective services screening decisions. Journal of Public Child Welfare, 2(3), 293-316.

Huebner, R. A., Robertson, L., Roberts, C., Brock, A., \& Geremia, V. (2012). Family preservation: cost avoidance and child and family service review outcomes. Journal of Public Child Welfare, 6(2), 206-224.

Huebner, R., Willauer, T., \& Posze, L. (2012). The impact of Sobriety Treatment and Recovery Teams (START) on family outcomes. Families in Society: The Journal of Contemporary Social Services, 93(3), 196-203.

Huebner, R. A., Posze, L., Willauer, T. M., \& Hall, M. T. (2015). Sobriety treatment and recovery teams: implementation fidelity and related outcomes. Substance Use \& Misuse, 50(10), 1341-1350.

Huebner, R. A., Young, N. K., Hall, M. T., Posze, L., \& Willauer, T. (2017). Serving families with child maltreatment and substance use disorders: A decade of learning. Journal of Family Social Work, 20(4), 288-305.

Hunter, R. S., Kilstrom, N., Kraybill, E. N., \& Loda, F. (1978). Antecedents of child 
abuse and neglect in premature infants: A prospective study in a newborn intensive care unit. Pediatrics, 61(4), 629-635.

Hussey, J. M., Chang, J. J., \& Kotch, J. B. (2006). Child maltreatment in the United States: prevalence, risk factors, and adolescent health consequences. Pediatrics, 118(3), 933-942.

Johnson, J. L., \& Leff, M. (1999). Children of substance abusers: Overview of research findings. Pediatrics, 103(Supplement 2), 1085-1099.

Johnson, T. P. (2014). Sources of error in substance use prevalence surveys. International Scholarly Research Notices, 2014.

Johnson-Motoyama, M., Brook, J., Yan, Y., \& McDonald, T. P. (2013). Cost analysis of the strengthening families program in reducing time to family reunification among substance-affected families. Children and Youth Services Review, 35(2), 244-252.

Jones, L. (2004). The prevalence and characteristics of substance abusers in a child protective service sample. Journal of Social Work Practice in the Addictions, $4(2), 33-50$.

Kaufman, J., \& Zigler, E. (1987). Do abused children become abusive parents? American Journal of Orthopsychiatry, 57(2), 186.

Kelleher, K., Chaffin, M., Hollenberg, J., \& Fischer, E. (1994). Alcohol and drug disorders among physically abusive and neglectful parents in a community-based sample. American Journal of Public Health, 84(10), 1586-1590.

Kelly, J. F., Saitz, R., \& Wakeman, S. (2016). Language, substance use disorders, and policy: The need to reach consensus on an "addiction-ary". Alcoholism Treatment Quarterly, 34(1), 116-123.

Kemper, K. J. (1988). Medically inappropriate hospital use in a pediatric population. New England Journal of Medicine, 318(16), 1033-1037.

Kentucky Revised Statutes. (2014). § 600.020.

Keshavarz, R., Kawashima, R., \& Low, C. (2002). Child abuse and neglect presentations to a pediatric emergency department. Journal of Emergency Medicine, 23(4), 341345.

Kessler, R. C. (2004). The epidemiology of dual diagnosis. Biological Psychiatry, 56(10), 730-737.

King, W. K., Kiesel, E. L., \& Simon, H. K. (2006). Child abuse fatalities: are we missing 
opportunities for intervention?. Pediatric Emergency Care, 22(4), 211-214.

Kochanek, KD, Murphy, SL, Xu, JQ, Arias, E. (2017). Mortality in the United States, 2016. NCHS Data Brief, no 293. Hyattsville, MD: National Center for Health Statistics.

Kohomban, J., Rodriguez, J., \& Haskins, R. (2018, January 31). The foster care system was unprepared for the last drug epidemic - let's not repeat history. The Brookings Institute.

Kolodny, A., Courtwright, D. T., Hwang, C. S., Kreiner, P., Eadie, J. L., Clark, T. W., \& Alexander, G. C. (2015). The prescription opioid and heroin crisis: a public health approach to an epidemic of addiction. Annual Review of Public Health, 36, 559574.

Kumpfer, K. L., Whiteside, H. O., Greene, J. A., \& Allen, K. C. (2010). Effectiveness outcomes of four age versions of the Strengthening Families Program in statewide field sites. Group Dynamics: Theory, Research, and Practice, 14(3), 211.

Kurtz, E. (2010). Not God: A History of Alcoholics Anonymous. Simon and Schuster.

Lander, L., Howsare, J., \& Byrne, M. (2013). The impact of substance use disorders on families and children: from theory to practice. Social Work in Public Health, 28(3-4), 194-205.

Långström, N., Babchishin, K. M., Fazel, S., Lichtenstein, P., \& Frisell, T. (2015). Sexual offending runs in families: A 37-year nationwide study. International Journal of Epidemiology, 44(2), 713-720.

Lantz, P. M., Rosenbaum, S., Ku, L., \& Iovan, S. (2016). Pay For Success And Population Health: Early Results From Eleven Projects Reveal Challenges And Promise. Health Affairs, 35(11), 2053-2061.

Lassman, D., Hartman, M., Washington, B., Andrews, K., \& Catlin, A. (2014). US health spending trends by age and gender: selected years 2002-10. Health affairs, 33(5), 815-822.

Laudet, A. B., \& White, W. (2010). What are your priorities right now? Identifying service needs across recovery stages to inform service development. Journal of Substance Abuse Treatment, 38(1), 51-59.

Leonard, K. E., Smith, P. H., \& Homish, G. G. (2014). Concordant and discordant alcohol, tobacco, and marijuana use as predictors of marital dissolution. Psychology of Addictive Behaviors, 28(3), 780-789.

Leshner, A. I. (1997). Addiction is a brain disease, and it matters. Science, 278(5335), 45- 
47.

Leslie, L. K., Gordon, J. N., Meneken, L. E. E., Premji, K., Michelmore, K. L., \& Ganger, W. (2005). The physical, developmental, and mental health needs of young children in child welfare by initial placement type. Journal of Developmental and Behavioral Pediatrics: JDBP, 26(3), 177.

Leventhal, J. M., Martin, K. D., \& Gaither, J. R. (2012). Using US data to estimate the incidence of serious physical abuse in children. Pediatrics, 129(3), 458-464.

Levine, R. S. (1973). Caveat parens: A demystification of the child protection system. University of Pittsburgh. Law Review, 35(1), 1-52.

Levy, N. (2013). Addiction is not a brain disease (and it matters). Frontiers in Psychiatry, 4, 1-7.

Li, F., Godinet, M. T., \& Arnsberger, P. (2011). Protective factors among families with children at risk of maltreatment: Follow up to early school years. Children and Youth Services Review, 33(1), 139-148.

Loizaga-Velder, A., \& Verres, R. (2014). Therapeutic effects of ritual ayahuasca use in the treatment of substance dependence - qualitative results. Journal of Psychoactive Drugs, 46(1), 63-72.

Lloyd, M. (2015). Family drug courts: Conceptual frameworks, empirical evidence, and implications for social work. Families in Society: The Journal of Contemporary Social Services, 96(1), 49-57.

Lynch, M. (2012). Theorizing the role of the 'war on drugs' in US punishment. Theoretical Criminology, 16(2), 175-199.

Marcellus, L. (2010). Supporting resilience in foster families: A model for program design that supports recruitment, retention, and satisfaction of foster families who care for infants with prenatal substance exposure. Child Welfare, 89(1), 7.

Magura, S., \& Laudet, A. B. (1996). Parental substance abuse and child maltreatment: Review and implications for intervention. Children and Youth Services Review, 18(3), 193-220.

Mark, T. L., Levit, K. R., Vandivort-Warren, R., Buck, J. A., \& Coffey, R. M. (2011). Changes in US spending on mental health and substance abuse treatment, 19862005, and implications for policy. Health Affairs, 30(2), 284-292.

Mark, T. L., Levit, K. R., Vandivort-Warren, R., Coffey, R. M., \& Buck, J. A. (2007). Trends in spending for substance abuse treatment, 1986-2003. Health Affairs, 26(4), 1118-1128. 
Mark, T. L., Woody, G. E., Juday, T., \& Kleber, H. D. (2001). The economic costs of heroin addiction in the United States. Drug \& Alcohol Dependence, 61(2), 195206.

Marmot, M., Friel, S., Bell, R., Houweling, T. A., Taylor, S., \& Commission on Social Determinants of Health. (2008). Closing the gap in a generation: health equity through action on the social determinants of health. The Lancet, 372(9650), 16611669 .

Marmot, M. (2005). Social determinants of health inequalities. The lancet, 365(9464), 1099-1104.

Marsh, J. C., Smith, B. D., \& Bruni, M. (2011). Integrated substance abuse and child welfare services for women: A progress review. Children and Youth Services Review, 33(3), 466-472.

Martin, P. (2018, January 30). Healthcare consumerism: Taming the hungry tapeworm. Forbes, Retrieved from https://www.forbes.com/sites/paulmartyn/2018/01/30/healthcare-consumerismtaming-the-hungry-tapeworm/\#268bd3ce6a0f

Martin, A., Gardner, M., \& Brooks-Gunn, J. (2012). The mediated and moderated effects of family support on child maltreatment. Journal of Family Issues, 33(7), 920941.

Maze, I., \& Nestler, E. J. (2011). The epigenetic landscape of addiction. Annals of the New York Academy of Sciences, 1216(1), 99-113.

McCollister, K. E., \& French, M. T. (2003). The relative contribution of outcome domains in the total economic benefit of addiction interventions: A review of first findings. Addiction, 98, 1647 - 1659.

McCrory, E., De Brito, S. A., \& Viding, E. (2012). The link between child abuse and psychopathology: a review of neurobiological and genetic research. Journal of the Royal Society of Medicine, 105(4), 151-156.

McGeary, K. A., \& French, M. T. (2000). Illicit drug use and emergency room utilization. Health Services Research, 35(1 Pt 1), 153.

McLaughlin, M. (2018). The relationship between cigarette taxes and child maltreatment. Child Abuse \& Neglect, 79, 339-349.

McLaughlin, M. (2017). Less money, more problems: how changes in disposable income affect child maltreatment. Child Abuse \& Neglect, 67, 315-321.

Merikangas, K. R., \& McClair, V. L. (2012). Epidemiology of substance use 
disorders. Human Genetics, 131(6), 779-789.

Michalopoulos, C., Bloom, H. S., \& Hill, C. J. (2004). Can propensity score methods match the findings from a random assignment evaluation of mandatory welfareto-work programs? Review of Economics and Statistics, 86, 156-179.

Miller, S. E. (2011). Fostering attachment in the face of systemic disruption: Clinical treatment with children in foster care and the Adoption and Safe Families Act. Smith College Studies in Social Work, 81(1), 62-80.

Mirick, R. (2014). Engagement in child protective services: The role of substance abuse, intimate partner violence and race. Child and Adolescent Social Work Journal, 31(3), 267-279.

Moineddin, R., Meaney, C., Agha, M., Zagorski, B., \& Glazier, R. H. (2011). Modeling factors influencing the demand for emergency department services in Ontario: a comparison of methods. BMC Emergency Medicine, 11(1), 13.

Moore, L. D., \& Elkavich, A. (2008). Who's using and who's doing time: incarceration, the war on drugs, and public health. American Journal of Public Health, 98(5), 782-786.

Mowbray, O., Victor, B. G., Ryan, J. P., Moore, A., \& Perron, B. E. (2017). Parental Substance Use and Foster Care Reentry. Journal of Social Work Practice in the Addictions, 17(4), 352-373.

Moye, J., \& Rinker, R. (2002). It's a Hard Knock Life: Does the Adoption and Safe Families Act of 1997 Adequately Address Problems in the Child Welfare System?. Harvard Journal on Legislation, 39, 375-521.

National Center on Addiction and Substance Abuse (CASA), at Columbia University, \& Califano, J. A. (2007). Wasting the Best and the Brightest: Substance Abuse at America's Colleges and Universities. CASA.

Negriff, S., Schneiderman, J. U., \& Trickett, P. K. (2017). Concordance Between SelfReported Childhood Maltreatment Versus Case Record Reviews for Child Welfare-Affiliated Adolescents: Prevalence Rates and Associations With Outcomes. Child Maltreatment, 22(1), 34-44.

Nelson, P. K., Mathers, B. M., Cowie, B., Hagan, H., Des Jarlais, D., Horyniak, D., \& Degenhardt, L. (2011). Global epidemiology of hepatitis B and hepatitis C in people who inject drugs: results of systematic reviews. The Lancet, 378(9791), 571-583.

Nonprofit Finance Fund (2017). Connecticut Family Stability Project. Retrieved from: http://www.payforsuccess.org/project/connecticut-family-stability-project\# 
O'Flynn, M. (1999). The Adoption and Safe Families Act of 1997: Changing child welfare policy without addressing parental substance abuse. J. Contemp. Health L. \& Pol'y, 16, 243.

Ogbu, U. C., Lotfipour, S., \& Chakravarthy, B. (2015). Polysubstance abuse: alcohol, opioids and benzodiazepines require coordinated engagement by society, patients, and physicians. Western Journal of Emergency Medicine, 16(1), 76.

Olds, D., Chamberlain, R., \& Henderson, C. (1986). The prevention of child abuse and neglect: A randomized trial of nurse home visitation. Pediatrics, 76. 65-78.

Oliveros, A., \& Kaufman, J. (2011). Addressing substance abuse treatment needs of parents involved with the child welfare system. Child Welfare, 90(1), 25-41.

Osterling, K. L., \& Austin, M. J. (2008). Substance abuse interventions for parents involved in the child welfare system: Evidence and implications. Journal of Evidence-Based Social Work, 5(1-2), 157-189.

Palmiste, C. (2011). From the Indian Adoption Project to the Indian Child Welfare Act: the resistance of Native American communities. Indigenous Policy Journal, 22(1).

Panksepp, J., Knutson, B., \& Burgdorf, J. (2002). The role of brain emotional systems in addictions: a neuro-evolutionary perspective and new 'self-report' animal model. Addiction, 97(4), 459-469.

Park, J. M., Solomon, P., \& Mandell, D. S. (2006). Involvement in the child welfare system among mothers with serious mental illness. Psychiatric Services, 57(4), 493-497.

Parthasaruthy, S., \& Weisner, C. M. (2005). Five-year trajectories of health care utilization and cost in a drug and alcohol treatment sample. Drug and Alcohol Dependence, 80, $231-240$.

Pears, K. C., \& Capaldi, D. M. (2001). Intergenerational transmission of abuse: a twogenerational prospective study of an at-risk sample. Child Abuse \& Neglect, 25(11), 1439-1461.

Peirce, R. S., Frone, M. R., Russell, M., \& Cooper, M. L. (1994). Relationship of financial

strain and psychosocial resources to alcohol use and abuse: The mediating role of negative affect and drinking motives. Journal of Health and Social Behavior, 291-308.

Pelton, L. H. (1997). Child welfare policy and practice: The myth of family 
preservation. American Journal of Orthopsychiatry, 67(4), 545.

Perry, A. R., Rollins, A., Sabree, R., \& Grooms, W. (2016). Promoting Paternal Participation in Maternal and Child Health Services. Human Service Organizations: Management, Leadership \& Governance, 40(2), 170-186.

Petry, N. M. (2003). A comparison of African American and non-Hispanic Caucasian cocaine-abusing outpatients. Drug and Alcohol Dependence, 69(1), 43-49.

Platt, D., \& Riches, K. (2016). Assessing parental capacity to change: The missing jigsaw piece in the assessment of a child's welfare?. Children and Youth Services Review, 61, 141-148.

Ponizovsky, A. M., Nechamkin, Y., \& Rosca, P. (2007). Attachment patterns are associated with symptomatology and course of schizophrenia in male inpatients. American Journal of Orthopsychiatry, 77(2), 324-331.

Prevent Child Abuse Kentucky. (2016). Data Facts - CY 2016: Child Protective Services (CPS) Reports to the Department for Community Based Services. Accessed http://www.pcaky.org/images/files/Data\%20Facts\%20CPS\%20Calendar\%20Year \%202016.pdf

Raghavan, R., Brown, D. S., Allaire, B. T., Garfield, L. D., \& Ross, R. E. (2014). Medicaid expenditures on psychotropic medications for maltreated children: a study of 36 states. Psychiatric Services, 65(12), 1445-1451.

Raissian, K. M., \& Bullinger, L. R. (2017). Money matters: Does the minimum wage affect child maltreatment rates?. Children and Youth Services Review, 72, 60-70.

Raney, L. (2013). Integrated care: the evolving role of psychiatry in the era of health care reform. Psychiatric Services, 64(11), 1076-1078.

Ravitz, P., Maunder, R., Hunter, J., Sthankiya, B., \& Lancee, W. (2010). Adult attachment measures: A 25-year review. Journal of Psychosomatic Research, 69(4), 419-432.

Ray, G. T., Mertens, J. R., \& Weisner, C. (2007). The excess medical cost and health problems of family members of persons diagnosed with alcohol or drug problems. Medical Care, 45(2), 116-122.

Restrepo, C. S., Carrillo, J. A., Martínez, S., Ojeda, P., Rivera, A. L., \& Hatta, A. (2007). Pulmonary complications from cocaine and cocaine-based substances: imaging manifestations. Radiographics, 27(4), 941-956.

Ridout, M., Hinde, J., \& DeméAtrio, C. G. (2001). A score test for testing a zero-inflated Poisson regression model against zero-inflated negative binomial alternatives. Biometrics, 57(1), 219-223. 
Robins, L. N. (1993). Vietnam veterans' rapid recovery from heroin addiction: A fluke or normal expectation?. Addiction, 88(8), 1041-1054.

Rockett, I. R., Putnam, S. L., Jia, H., Chang, C. F., \& Smith, G. S. (2005). Unmet substance abuse treatment need, health services utilization, and cost: a populationbased emergency department study. Annals of emergency medicine, 45(2), 118127.

Rockhill, A., Green, B. L., \& Furrer, C. (2007). Is the adoption and safe families act influencing child welfare outcomes for families with substance abuse issues?. Child Maltreatment, 12(1), 7-19.

Room, R., Janca, A., Bennett, L. A., Schmidt, L., \& Sartorius, N. (1996). WHO crosscultural applicability research on diagnosis and assessment of substance use disorders: an overview of methods and selected results. Addiction, 91(2), 199-220.

Rosenbaum, P. R., \& Rubin, D. B. (1983). The central role of the propensity score in observational studies for causal effects. Biometrika, 70(1), 41-55.

Rote, S. M., \& Taylor, J. (2014). Black/White differences in adolescent drug use: A test of six hypotheses. Journal of Child \& Adolescent Substance Abuse, 23(5), 282290.

Rovi, S., Chen, P. H., \& Johnson, M. S. (2004). The economic burden of hospitalizations associated with child abuse and neglect. American Journal of Public Health, 94(4), 586-590.

Rubin, D. B. (1997). Estimating causal effects from large data sets using propensity scores. Annals of internal medicine, 127(8_Part_2), 757-763.

Rubin, D. B., \& Thomas, N. (1996). Matching using estimated propensity scores: relating theory to practice. Biometrics, 249-264.

Rudd, R. A., Aleshire, N., Zibbell, J. E., \& Gladden, M. R. (2016). Increases in drug and opioid overdose deaths-United States, 2000-2014. American Journal of Transplantation, 16(4), 1323-1327.

Ryan, J. P., Marsh, J. C., Testa, M. F., \& Louderman, R. (2006). Integrating substance abuse treatment and child welfare services: Findings from the Illinois alcohol and other drug abuse waiver demonstration. Social Work Research, 30(2), 95-107.

Saloner, B., \& Karthikeyan, S. (2015). Changes in substance abuse treatment use among individuals with opioid use disorders in the United States, 20042013. Jama, 314(14), 1515-1517. 
Salzinger, S., Feldman, R. S., Hammer, M., \& Rosario, M. (1993). The effects of physical abuse on children's social relationships. Child Development, 64(1), 169187.

Samuel, L. J., Szanton, S. L., Cahill, R., Wolff, J. L., Ong, P., Zielinskie, G., \& Betley, C. (2018). Does the Supplemental Nutrition Assistance Program Affect Hospital Utilization Among Older Adults? The Case of Maryland. Population Health Management, 21(2), 88-95.

Sarkadi, A., Kristiansson, R., Oberklaid, F., \& Bremberg, S. (2008). Fathers' involvement and children's developmental outcomes: a systematic review of longitudinal studies. Acta Paediatrica, 97(2), 153-158.

Sedlak, A. J., Mettenburg, J., Basena, M., Peta, I., McPherson, K., \& Greene, A. (2010). Fourth national incidence study of child abuse and neglect (NIS-4). Washington, DC: US Department of Health and Human Services. Retrieved on July, 9, 2010.

Schneider, W., Waldfogel, J., \& Brooks-Gunn, J. (2017). The Great Recession and risk for child abuse and neglect. Children and Youth Services Review, 72, 71-81.

Schroeder, J., Lemieux, C., \& Pogue, R. (2008). The collision of the Adoption and Safe Families Act and substance abuse: Research-based education and training priorities for child welfare professionals. Journal of Teaching in Social Work, 28, 227-246.

Semidei, J., Radel, L. F., \& Nolan, C. (2001). Substance abuse and child welfare: Clear linkages and promising responses. Child Welfare, 80(2), 109.

Shaw, T. V., Putnam-Hornstein, E., Magruder, J., \& Needell, B. (2008). Measuring racial disparity in child welfare. Child Welfare, 87(2), 23.

Shlonsky, A., \& Wagner, D. (2005). The next step: Integrating actuarial risk assessment and clinical judgment into an evidence-based practice framework in CPS case management. Children and Youth Services Review, 27(4), 409-427.

Simoneaux, M. (2017, January 20). Opiod epidemic leading to broken families: more than 8,000 Kentucky children in foster care. The Richmond Register. Retrieved from http://www.richmondregister.com/news/opioid-epidemic-leading-to-brokenfamilies/article_bee11ed0-df62-11e6-9e24-8f09d5b08e68.html

Slack, K. S., Holl, J. L., McDaniel, M., Yoo, J., \& Bolger, K. (2004). Understanding the risks of child neglect: An exploration of poverty and parenting characteristics. Child Maltreatment, 9(4), 395-408.

Slack, K. S., Lee, B. J., \& Berger, L. M. (2007). Do welfare sanctions increase child 
protection system involvement? A cautious answer. Social Service Review, 81(2), 207-228.

Sobell, L. C., Ellingstad, T. P., \& Sobell, M. B. (2000). Natural recovery from alcohol and drug problems: Methodological review of the research with suggestions for future directions. Addiction, 95(5), 749-764.

Soderstrom, C. A., Smith, G. S., Dischinger, P. C., McDuff, D. R., Hebel, J. R., Gorelick, D. A., ... \& Read, K. M. (1997). Psychoactive substance use disorders among seriously injured trauma center patients. Jama, 277(22), 1769-1774.

Smith, D. K., Johnson, A. B., Pears, K. C., Fisher, P. A., \& DeGarmo, D. S. (2007). Child maltreatment and foster care: Unpacking the effects of prenatal and postnatal parental substance use. Child Maltreatment, 12, 150-160.

Stange, K. C. (2009). The problem of fragmentation and the need for integrative solutions. The Annals of Family Medicine, 7(2), 100-103.

Stuart, G. L., Temple, J. R., Follansbee, K. W., Bucossi, M. M., Hellmuth, J. C., \& Moore, T. M. (2008). The role of drug use in a conceptual model of intimate partner violence in men and women arrested for domestic violence. Psychology of Addictive Behaviors, 22(1), 12.

Substance Abuse and Mental Health Services Administration. (2017). Key substance use and mental health indicators in the United States: Results from the 2016 National Survey on Drug Use and Health (HHS Publication No. SMA 17-5044, NSDUH Series H-52). Rockville, MD: Center for Behavioral Health Statistics and Quality, Substance Abuse and Mental Health Services Administration. Retrieved from https://www. samhsa.gov/data/

Sullivan, P. M., \& Knutson, J. F. (2000). Maltreatment and disabilities: A populationbased epidemiological study. Child Abuse \& Neglect, 24(10), 1257-1273.

Svenson, L. W., Forster, D. I., Woodhead, S. E., \& Platt, G. H. (1995). Individuals with a chemical-dependent family member. Does their health care use increase? Canadian Family Physician, 41, 1488.

Swenson, C. C., Schaeffer, C. M., Tuerk, E., Henggeler, S. W., Tuten, M., Panzarella, P., ... \& Guillorn, A. (2009). Adapting multisystemic therapy for co-occurring child maltreatment and parental substance abuse: The Building Stronger Families project. Emotional and Behavioral Disorders in Youth, 9(1), 3-8.

Tang, N., Stein, J., Hsia, R. Y., Maselli, J. H., \& Gonzales, R. (2010). Trends and characteristics of US emergency department visits, 1997-2007. Jama, 304(6), 664-670. 
Thomas Jr, M. P. (1971). Child Abuse and Neglect Part I--Historical Overview, Legal Matrix, and Social Perspectives. North Carolina Law Review, 50, 293-349.

Trupin, E., Weiss, N., \& Kerns, S. E. (2014). Social impact bonds: behavioral health opportunities. JAMA Pediatrics, 168(11), 985-986.

United States Government Accountability Office. (2015). Medicaid: A Small Share of Enrollees Consistently Accounted for a Large Share of Expenditures.

Vaillant, G. E. (1982) Natural history of male alcoholism IV: paths to recovery. Archives of General Psychiatry, 39, 127- 133.

Valentine, D. (2004). The Strength of the Wolf: The Secret History of America's War on Drugs. Verso.

Volkow, N. D., Fowler, J. S., \& Wang, G. J. (2003). The addicted human brain: insights from imaging studies. The Journal of Clinical Investigation, 111(10), 1444-1451.

Wakeman, S. E. (2013). Language and addiction: choosing words wisely. American Journal of Public Health, 103(4), e1.

Walsh, C., MacMillan, H. L., \& Jamieson, E. (2003). The relationship between parental substance abuse and child maltreatment: findings from the Ontario Health Supplement. Child Abuse \& Neglect, 27(12), 1409-1425.

Walton, M. T., \& Hall, M. T. (2016). The effects of employment interventions on addiction treatment outcomes: a review of the literature. Journal of Social Work Practice in the Addictions, 16(4), 358-384.

Weisner, C., Parthasarathy, S., Moore, C., \& Mertens, J. R. (2010). Individuals receiving addiction treatment: are medical costs of their family members reduced?. Addiction, 105(7), 1226-1234.

Westover, A. N., McBride, S., \& Haley, R. W. (2007). Stroke in young adults who abuse amphetamines or cocaine: a population-based study of hospitalized patients. Archives of General Psychiatry, 64(4), 495-502.

White, G. C., \& Bennetts, R. E. (1996). Analysis of frequency count data using the negative binomial distribution. Ecology, 77(8), 2549-2557.

Widom, C. S. (1998). Childhood victimization: Early adversity and subsequent psychopathology. In Dohrenwend, B.P. Adversity, Stress, and Psychopathology, 81-95. Oxford University Press.

Widom, C. S., \& Hiller-Sturmhofel, S. (2001). Alcohol abuse as a risk factor for and consequence of child abuse. Alcohol Research \& Health, 25(1), 52-52. 
Widom, C. S., Czaja, S. J., \& DuMont, K. A. (2015). Intergenerational transmission of child abuse and neglect: Real or detection bias?. Science, 347(6229), 1480-1485.

Williams, C. M., Cprek, S., Asaolu, I., English, B., Jewell, T., Smith, K., \& Robl, J. (2017). Kentucky health access nurturing development services home visiting program improves maternal and child health. Maternal and child health journal, 21(5), 1166-1174.

Wolock, I., \& Magura, S. (1996). Parental substance abuse as a predictor of child maltreatment re-reports. Child Abuse \& Neglect, 20(12), 1183-1193.

Wong, C. C., Mill, J., \& Fernandes, C. (2011). Drugs and addiction: an introduction to epigenetics. Addiction, 106(3), 480-489.

Wooldridge, J. M. (1999). Distribution-free estimation of some nonlinear panel data models. Journal of Econometrics, 90(1), 77-97.

Wright, M. S., \& Litaker, D. (1996). Childhood victims of violence. Hospital utilization by children with intentional injuries. Archives of Pediatrics and Adolescent Medicine, 150, 415-420.

Ye, Y., \& Kaskutas, L. A. (2009). Using propensity scores to adjust for selection bias when assessing the effectiveness of Alcoholics Anonymous in observational studies. Drug and Alcohol Dependence, 104(1-2), 56-64.

Young, N. K., Boles, S. M., \& Otero, C. (2007). Parental substance use disorders and child maltreatment: Overlap, gaps, and opportunities. Child Maltreatment, 12(2), $137-149$.

Zeanah, C. H., Nelson, C. A., Fox, N. A., Smyke, A. T., Marshall, P., Parker, S. W., \& Koga, S. (2003). Designing research to study the effects of institutionalization on brain and behavioral development: The Bucharest Early Intervention Project. Development and Psychopathology, 15(4), 885-907.

Zeller, D., Hornby, H., \& Ferguson, A. (2007). Evaluation of Maine's Family Treatment Drug Courts: A preliminary analysis of short and long-term outcomes. Portland, ME: Hornby Zeller Associates.

Zuravin, S., McMillen, C., DePanfilis, D., \& Risley-Curtiss, C. (1996). The intergenerational cycle of child maltreatment: Continuity versus discontinuity. Journal of Interpersonal Violence, 11(3), 315-334. 


\section{APPENDIX A}

\section{CHFS Institutional Review Board Approval Letter}

MATTHEW G. BEVIN GOVERNOR

December 6, 2018

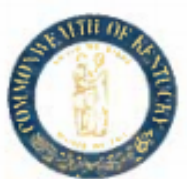

Cabinet For HEalth ANd Family SERVICES

INSTITUTIONAL REVIEW BOARD

275 EASt MAin STREet, 2E-O

FRANKFORT, KENTUCKY 40621

(502) $564-5497$

FAX (502) 564-9523

IRB00005487 FWA00003302

WWW.CHFS.KY.GOV/OS/OMB/RR

CHFS-IRB-DCBS-FY08-55
ADAM M. MEIER SECRETARY

Martin T. Hall, Ph.D.

Assistant Professor

University of Louisville

303 Patterson Hall

Louisville, KY 40292

Dear Dr. Hall:

The continuation and requested modifications of the research project titled "Sobriety and Treatment Recovery Teams (START) Program Evaluation" were approved by the Cabinet for Health and Family Services Institutional Review Board (CHFS IRB) through the expedited review procedure. This approval expires December 5, 2019.

In addition to all other requirements of 45 CFR 46.101-46.409, it is the responsibility of the researcher to:

1. obtain approval by the CHFS IRB for any modification in the research protocol or design that may increase the level of risk to a subject or a subject's confidentiality prior to implementation;

2. advise the CHFS IRB of any unanticipated problem involving a risk to a subject or another individual as a result of the research activity as soon as possible;

3. submit a Continuation Review Form and a progress report to the CHFS IRB on or before November 5, 2019 if the study will extend beyond December 5, 2019; and

4. provide the CHFS IRB, in advance of its presentation or submission for publication, a copy of any presentation, manuscript or other public disclosure document.

If you have any questions about any of the above, or need additional information, please contact the CHFS IRB at (502) 564-5497 x3711.

Respectfully,

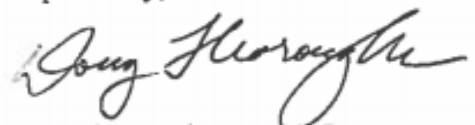

Doug Thoroughman, Ph.D.

Co-Chair 


\section{APPENDIX B}

The Assessment and Documentation Tool (ADT)

\section{ADT CPS Assessment for Abuse/Neglect}

Intake ID: $\quad$ Case: $\quad$ (Case Name) Individual:

Case Number:

Section 1: Allegation/Concern

Summary of current allegations/Type of maltreatment alleged:

Section 2: Referral Members

Section 3: Referral Findings

\begin{tabular}{|l|l|l|l|}
\hline Victim Name & Perp Name & Result & Under Appeal \\
\hline & & & \\
\hline & & & \\
\hline
\end{tabular}

Section 4: Assessment

Child/Youth Assessment

\begin{tabular}{ll}
\hline Interview & \\
Interview & Native American \\
$\square$ Refused to be interviewed & $\square$ No \\
$\square$ Unable to be interviewed & $\square$ Unknown \\
& $\square$ Yes
\end{tabular}


Child Physical/Mental Health (check all that apply)

\section{Risk Factors}

$\square$ Hearing or vision impaired

History of seizures

Medical diagnosis requiring life sustaining measure

$\square$ Medical diagnosis requiring ongoing care

Medical issues (asthma, broken arm, severe allergy)

$\square$ Mental health diagnosis ongoing medications

Physical disability

Requires psychotropic meds to function

No Risk Factors

\section{Protective Factors}

No physical/mental health issues

Received care for identified mental health issues

Receives care for identified medical issues

Up to date on immunizations

Child Development/Education (check all that apply)

\section{Risk Factors}

Developmentally delayed

$\square$ Difficulty communicating needs

Educationally delayed/IEP not utilized

Is not potty trained or unable to use toilet

$\square$ Lack of muscle control, motor skills

Limited verbal ability or non-verbal

Non-mobile or limited mobility

Not attached to adult caregiver

Poor social skills/peer relations

Requires assistance for dressing/bathing

$\square$ No risk factors

\section{Protective Factors}

Able to dress/bath self

Child receiving services for delay

Developmentally on track

Educationally on track

$\square$ Good social skills/peer relations

Secure attachment to adult caregiver 
Child Behaviors (check all that apply)

Risk Factors

$\square$ Alcohol use/abuse

AWOL history/risk

Bullying

Can't focus/hyperactive

Destruction of property

Doesn't follow rules/oppositional

Drug use/abuse

$\square$ Encopresis/enuresis not due to age

$\square$ Escalating negative behaviors

Expulsion/suspensions from school

Fire setting

$\square$ Gang involvement

Has harmed self or others

Past victim of abuse/neglect

$\square$ Previous juvenile court involvement

Rages/tantrums

$\square$ Requires extensive supervision

$\square$ Sexually reactive/Sexually acting out

Sexually active

$\square$ Threatens to harm self or others

Torturing/killing small animals

Truancy/ skipping school

$\square$ No Risk Factors

\section{Protective Factors}

Behavioral issues within normal range for child's age

$\square$ Child is responding to services provided

Receives services for identified behavioral indicators 
Describe child and any factors that need further explanation:

\section{Maltreatment}

Injuries/Conditions

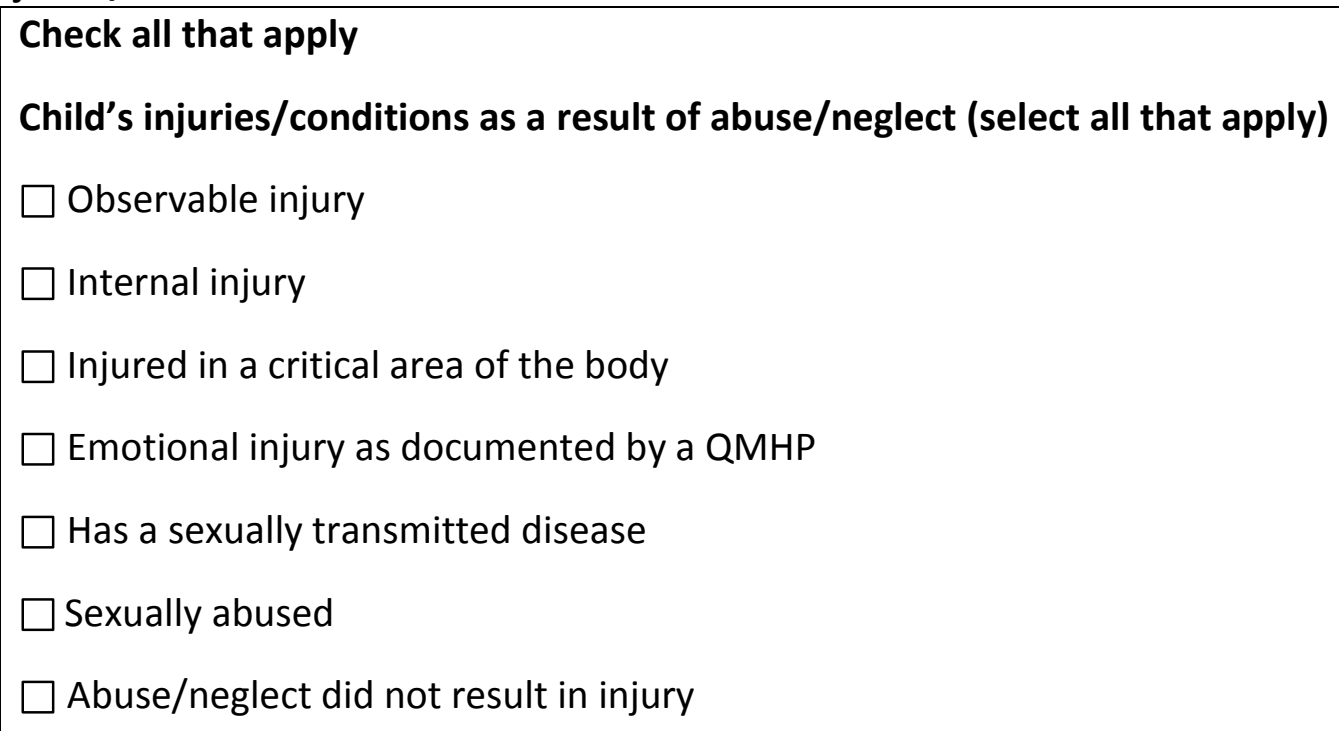


Child had no maltreatment

No issues

Describe injury/condition in specific terms (size, shape, location, color, impact of abuse):

Did the child receive medical treatment or evaluation during this investigation/assessment (select all that apply)

$\square$ EMS

$\square$ General Practitioner

$\square$ Child Advocacy Center

ER/urgent care

Local hospital

Mental health evaluations

No medical evaluation/treatment

Pediatrician 
Neglect (Check all that apply)

\section{Hygiene/clothing}

$\square$ Clothing does not protect from elements

$\square$ Illness or exposure due to clothes

$\square$ Regularly wears soiled clothes

$\square$ Repeated infestations of lice/bedbugs

$\square$ No issues

\section{Food}

$\square$ Dehydration

$\square$ Dietary needs not met

$\square$ Feeding children non-human food items

$\square$ Food poisoning

$\square$ Malnourished

$\square$ Symptoms of failure to thrive

$\square$ No issues

\section{Educational (Check all that apply)}

Numerous unexcused absences

$\square$ No issues

\section{Exploitation}

Engages child in criminal activities

Uses child's financial resources for personal gain

Victim of Human Trafficking

No issues

\section{Medical (Check all that apply)}

Failure to seek medical attention

$\square$ Life threatening unmet health needs

Unmet health needs may have long term effects

No issues

\section{Risk of Harm (Check all that apply)}

\section{Risk of Physical Abuse}

$\square$ Child has fear of caretaker

Caretaker has caused death/serious

injury to a child

Child exposed to bizarre forms of punishment

No issues

\section{Risk of Sexual Abuse}

$\square$ Caretaker has previous sex abuse finding or conviction

$\square$ Child exhibiting physical/ behavioral indicators of sexual abuse

$\square$ Child unsupervised with person listed on the sex offender registry

No issues 


Risk of General Harm (Check all that apply)
$\square$ Caretaker has a prior involuntary TPR on another child
$\square$ Caretaker self-reports inability to cope
$\square$ Caretaker self-reports they may harm child
$\square$ Child allowed to use drugs and/or alcohol
$\square$ Child born exposed to drugs and/or alcohol
$\square$ Child or family member threaten with a weapon
$\square$ DV related incidents are more severe/frequent
$\square$ Parent's cannot meet own needs
$\square$ Per court order, caretaker does not have custody of child
$\square$ Sibling of a child fatality/near fatality victim
$\square$ Violation of EPO/DVO puts child in danger
$\square$ No issues

\section{Maltreatment/neglect description}

\section{Adult Assessment (Complete for each adult)}

Interview

\begin{tabular}{ll}
\hline Interview & Native American \\
$\square$ Refused to be interviewed & $\square$ No \\
$\square$ Unable to be interviewed & $\square$ Unknown \\
& $\square$ Yes \\
& $\square$ Declined to disclose
\end{tabular}




\begin{tabular}{|ll|}
\hline Adult Health and Functioning & \\
Risk Factors & Protective Factors \\
$\square$ Alcohol abuse & $\square$ Accepts assistance that enhances functioning \\
$\square$ Attention seeking & $\square$ Candid and/or cooperative \\
$\square$ Dishonest and/or manipulative & $\square$ Copes or functions despite a disability \\
$\square$ Disregard for others' safety or wellbeing & $\square$ Demonstrates logic/reasoning ability \\
$\square$ Drug abuse & $\square$ No mental health issues \\
$\square$ Hostile to authority figures or service providers & $\square$ No physical health issues \\
$\square$ Impulsive or unpredictable & $\square$ Primary relationships are stable \\
$\square$ Intellectual or cognitive disability & $\square$ Realistic awareness of self and reality \\
$\square$ Irrational or disconnected from reality & $\square$ Respects the rights and feeling or others \\
$\square$ Lacks insight into their own behavior & $\square$ Seeks and give affection to loved ones \\
$\square$ Mental health issue that affects functioning & \\
$\square$ Paranoid & \\
$\square$ Physical disability or debilitating illness & \\
$\square$ Selfish, self-centered decision-making & \\
$\square$ Unable to apply logic to solve problems & \\
$\square$ Unable to assess (due to inability to interview) & \\
$\square$ Victim of domestic violence \\
$\square$ No Risk Factors
\end{tabular}

\begin{tabular}{|ll|}
\hline Ability to Manage Daily Life and Stress (High Risk Behaviors) \\
Risk Factors & Protective Factors \\
$\square$ Abuses substances (drugs/alcohol to escape or & $\square$ College or career training \\
deal with stress & $\square$ Healthy support network \\
$\square$ Blames others for problems & $\square$ High school education or GED \\
$\square$ Displays of frustration/anger cause injury or & $\square$ Realistic coping strategies \\
likelihood of harm & $\square$ Realistic understanding of barriers \\
$\square$ Displays of frustration/anger out of proportion to $\quad \square$ Realistic view of daily needs/obligations \\
$\quad$ situation & $\square$ Self-sufficient, able to meet own needs \\
$\square$ Escalating frustration/anger & \\
$\square$ Lack of realistic long term goals & \\
$\square$ Overwhelmed/discouraged by responsibilities & \\
$\square$ Parasitic lifestyle: relies on others to provide food, & \\
$\quad$ housing, etc. & \\
$\square$ Poor self-control & \\
$\square$ Rapidly changing affect or emotional displays & \\
$\square$ Serial relationships & \\
$\square$ Unable or unwilling to plan ahead & \\
$\square$ Unable to assess (due to inability to interview) & \\
$\square$ Unstable/chaotic relationships \\
$\square$ No Risk Factors
\end{tabular}




\begin{tabular}{|ll|}
\hline Methods of behavior management & \\
Risk Factors & Protective Factors \\
$\square$ Can't articulate discipline strategies & $\square$ Balances teaching and discipline \\
$\square$ Can't articulate how to manage beyond control & $\square$ Discipline techniques corroborated by \\
$\quad$ behaviors & collaterals \\
$\square$ Can't articulate how to manage tantrums, rages & $\square$ Uses age appropriate discipline \\
$\square$ Inconsistant discipline & $\square$ Willingness to learn appropriate discipline \\
$\square$ Methods of discipline result in injury to child & techniques \\
$\square$ Severe or harsh discipline & \\
$\square$ Unable to assess (due to inability to interview) & \\
$\square$ Unable to manage child's behavior & \\
$\square$ Unusual/bizarre discipline & \\
$\square$ Uses no discipline or fails to follow through & \\
$\square$ No Risk Factors &
\end{tabular}

\begin{tabular}{ll|}
\hline Attitude Toward Caretaking & Protective Factors \\
Risk Factors & $\square$ Attached to the child \\
$\square$ Articulates inappropriate expectations for child & $\square$ Demonstrates cooperation with \\
$\square$ Caretaker self-reports may harm child & child's service providers \\
$\square$ Describes child in negative terms & $\square$ Has realistic expectations of \\
$\square$ Doesn't follow through with required medical & child \\
treatment & $\square$ Meets child's needs \\
$\square$ Fails to protect child & $\square$ Parent seeks and follows \\
$\square$ Fails to supervise child & medical advice \\
$\square$ Frustrated by parenting duties & $\square$ Prioritizes the child's safety \\
$\square$ Inability to recognize situational risks to child & $\square$ Receives satisfaction being a \\
$\square$ Not attached to the child & parent \\
$\square$ Puts personal needs before child & $\square$ Recognizes dangerous situations \\
$\square$ Unable to assess (due to inability to interview) & \\
$\square$ Uses poor judgment in choosing caregivers & \\
$\square$ No Risk Factors & \\
\hline
\end{tabular}




\section{CPS/APS/Criminal History}

\section{Risk Factors}

$\square$ Adult is registered sex offender

$\square$ Parental rights on a child involuntarily terminated

$\square$ Prior convictions involving drugs/alcohol

$\square$ Criminal "versatility": variety of types of convictions

$\square$ Prior felony convictions involving weapon/violence

Prior reports of domestic violence

$\square$ Prior revocation of parole/probation

$\square$ Prior substantiated reports

Prior substantiation death/near death of another child

Action or lack of action contributed to death/serious harm of a child

Multiple prior reports not accepted for investigation

$\square$ Prior unsubstantiated reports

$\square$ No Risk Factors

\section{Protective Factors}

$\square$ Acknowledges responsibility for prior charges

$\square$ Acknowledges responsibility for child welfare allegations

$\square$ No criminal charges

No felony convictions

No prior CPS/APS history

Non-violent/traffic offenses

$\square$ Other rehabilitative services

$\square$ Received treatment/rehabilitative services related to prior sexual abuse

\section{Notes}




\section{Family Functioning}

Is the home a health or safety hazard for the individuals living there?

Broken windows

$\square$ Dangerous animals in the home

$\square$ Dangerous chemicals accessible

Exposed wiring

$\square$ Fire safety hazards

Hoarding

Holes in floor or walls $\square$ Human/animal feces

$\square$ Inadequate heat in winter

$\square$ Infestation of rodents/insects

Inoperable sanitation

$\square$ Insufficient shelter

(includes homeless)

Medications not secure
Meth lab

$\square$ Mold infestation $\square$ Spoiled food

$\square$ Unsafe space heaters

$\square$ Unsupervised with loaded guns/weapons

$\square$ No issues

What corrective action has caretaker made for any checked item?

Do you have any current concerns that the child(ren) are not supervised adequately?

$\square$ Caretaker is unqualified or lacks capacity to meet child's needs

$\square$ Child afraid to be alone

$\square$ Child requires more supervision than parents are providing

$\square$ Child unsupervised with individual where there is a no contact order

$\square$ Children do not know what to do in case of emergency

$\square$ Expulsion of child from the home

$\square$ Left alone in a vehicle

$\square$ Medical/QMHP expresses concern that caretaker use of alcohol/drugs/medications impairs their ability

to take care of child

Parent's whereabouts are not known

Unsupervised child 7 y/o or younger(developmental/chronological)

$\square$ Abusing drugs/alcohol or incapacitated while caring for child

No issues found during investigation 
Please explain your current concerns regarding supervision of the child(ren):

\section{Family Structure (check all that apply)}

$\square$ Blended family

$\square$ Married couple

$\square$ Multiple families in home

Multiple generations in the home

$\square$ Single parent

$\square$ Unmarried couple/Domestic partnership

\section{Family Developmental Stage}

$\square$ Infant/preschool children

$\square$ School age children

$\square$ Teenage children

Adult children

\section{Family Functioning /Culture}

Adult was in out of home care as a child

Home setting, urban/suburban

$\square$ Adult was exposed to domestic violence as a child

Caregiver history of childhood abuse/neglect

$\square$ Caregiver, active military

$\square$ Caregiver, inactive military

$\square$ Inconsistent family boundaries

$\square$ Mistrust of medical providers/government

$\square$ Native American heritage/belongs to a tribe

$\square$ Disregard for education

Escalating pattern of child maltreatment

$\square$ Frequent changes in residence

$\square$ Parent/child role confusion

$\square$ Relocated to US during

$\square$ Social or geographic isolation

Strict gender roles 
Family Use of Supports (Check all that apply)

\section{Community}

$\square$ Unwilling to utilize/access

$\square$ Unaware but willing to access

Aware and can access

$\square$ Utilizing available supports

Isolated from supports

No supports identified or available

\section{Family/Friends}

$\square$ Unwilling to utilize/access

$\square$ Unaware but willing to access

Aware and can access

$\square$ Utilizing available supports

$\square$ Isolated from supports

$\square$ No appropriate supports identified or available

\section{Family Functioning Notes}

\section{Chronology Information}

\section{Investigative Related Data}

Report received:

Assigned by Supervisor:

Inv Worker Received Report:

First Attempt to Make Contact:

First Face to Face Contact Made with Victim:

First FSOS Consultation: $\mathrm{mm} / \mathrm{dd} /$ yyyy

$\mathrm{mm} / \mathrm{dd} / \mathrm{yyyy}$

$\mathrm{mm} / \mathrm{dd} /$ yyyy

$\mathrm{mm} / \mathrm{dd} /$ yyyy

$\mathrm{mm} / \mathrm{dd} / \mathrm{yyyy}$

$\mathrm{mm} / \mathrm{dd} /$ yyyy 


\begin{tabular}{lll}
\hline Roles of Individuals Interviewed & & \\
$\square$ Alleged Perpetrator & $\square$ Family Friend & $\square$ Mental Health Provider \\
$\square$ Alleged Victim & $\square$ Family Support/Kames & $\square$ Neighbor \\
$\square$ Attorney & $\square$ Forensic Consultation & $\square$ Non-Custodial Parent \\
$\square$ Clergy & $\square$ Household Member-Related & $\square$ Paramour/Partner \\
$\square$ Custodial Parent & $\square$ Household Member Non-Related & $\square$ Relative \\
$\square$ Day Care Provider & $\square$ Landlord & $\square$ School Personnel \\
$\square$ Employer & $\square$ Law Enforcement & $\square$ No collateral contact \\
$\square$ EMS/Fire Department & $\square$ Medical Provider & $\square$ Spouse \\
$\square$ Former Spouse & &
\end{tabular}

\section{Evidence Collected}

Child Care Provider records

$\square$ Medical records

$\square$ Court records

$\square$ Mental Health records

$\square$ Law Enforcement records

$\square$ Other CPS agency records

$\square$ Photographs

$\square$ School records

Drug Screen

\section{Investigation narrative:}

\section{Incident results}

\section{Maltreatment Factors}

Mental Health

Family Violence

Substance Abuse
Directly Contributed $\square$ Directly Contributed $\square$ Directly Contributed $\square$ Indirectly Contributed

$\square$ Indirectly Contributed

$\square$ Indirectly Contributed
Was a Risk Factor Was a Risk Factor Was a Risk Factor
Not Applicable Not Applicable Not Applicable 


\section{Physical Abuse (Check all that apply)}

\section{Severity 4}

$\square$ Inflicted injury to a child 4 years or younger

$\square$ Assault of a child 4 years or younger (including a child injured in a DV incident)

$\square$ Inflicted injury to a non-mobile child of any age

$\square$ Bizarre or cruel discipline including restraints, i.e. binding child to chair or locking in a closet

\section{Severity 3}

$\square$ Inflicted injury to a critical area of the body in a child 5 years or younger

$\square$ Assault of any child 12 years or younger (including physical altercation between a child and caregiver)

$\square$ Method of discipline is excessive or includes threats of harm

\section{Severity 2}

$\square$ Physical altercation between parent/caretaker and child 13 years or younger

\section{Severity 0}

$\square$ None

\section{Sexual Abuse (Check all that apply)}

\section{Severity 4}

$\square$ Sexual abuse or sexual exploitation of a child

$\square$ Child with a sexually transmitted disease

\section{Severity 3}

$\square$ Adults exposing child to sexual activity or pornography

$\square$ Adults exposing their private parts to a child

\section{Severity 0}

\section{$\square$ None}




\section{Medical (Check all that apply)}

\section{Severity 4}

$\square$ Child with life threatening unmet health needs

\section{Severity 3}

$\square$ Unmet health needs may result in future health problems or have cause long term effects

\section{Severity 2}

$\square$ Failure to seek medical attention or lack of follow up for non-life threatening situations

\section{Severity 0}

None

\section{Supervision (Check all that apply)}

\section{Severity 4}

$\square$ Abandonment of any child (including parent incapacitated due to drugs or alcohol)

$\square$ Unsupervised child 7 and under (chronological or developmental)

\section{Severity 3}

$\square$ Child ages 8-12 unsupervised for extended periods of time

$\square$ Parent's chronic use of drug/alcohol renders them incapable of caring for child

\section{Severity 2}

$\square$ Child age 13-15 unsupervised for extended periods of time (consider developmental age of child)

$\square$ Child allowed to have inappropriate sexual relationships

\section{Severity 1}

$\square$ Child left with family/caretaker with no provisions for making educational or medical decisions and no way to contact parent

$\square$ Caretaker fails to make reasonable efforts to get child to school

\section{Severity 0}




\section{Neglect (Check all that apply)}

\section{Severity 4}

$\square$ Extreme hazardous environment

$\square$ Malnutrition and dehydration due to neglect

\section{Severity 3}

$\square$ Insufficient shelter (living in care, under a bridge, in a barn, tent, etc.)

$\square$ Child's special dietary needs are not being met resulting in health issues

\section{Severity 2}

$\square$ Home has trash or clutter creating fire hazard, unsecured/exposed chemicals, medications or other hazards

$\square$ Child age 0-7 dressed inappropriately for weather conditions resulting in health issues for child $\square$ Financial exploitation to provide financial or material gain for the adult

Poor hygiene in children 0-7 that has negative impact on the child's health or emotional well-being

\section{Severity 1}

Home with inadequate heat, food, home cluttered, dirty dishes, etc.

$\square$ Parent has failed to follow through with getting rid of head lice

$\square$ Poor hygiene for children age 8 and older that has negative impact on the child's health or emotional well-being

\section{Severity 0}

None

\section{Risk of harm (Check all that apply)}

\section{Severity 4}

$\square$ Previous child death/near death (due to abuse/neglect or unexplained/undetermined causes)

$\square$ Child involved in a DV incident

\section{Severity 3}

$\square$ Child forced/allowed to engage in a criminal activity, exposed to the distribution of drugs or criminal activity by the parent

$\square$ Child ages 12 and younger allowed to use drugs/alcohol

\section{Severity 2}

$\square$ Child $13 \mathrm{y} / \mathrm{p}$ and older allowed to engage in criminal activity including drugs/alcohol

\section{Severity 0}




\section{Emotional (Check all that apply)}

\section{Severity 3}

$\square$ Qualified mental health professional has found emotional injury

\section{Severity 0}

None

What broke down in the family that led to the abuse/neglect?

\section{Assessment Results}

\section{Risk Factors}

Based on your observations, interviews and information collected during this assessment, please rate the following:

The most vulnerable child in the family (considering age, development and behavioral needs) (select only one):

$\square$ Not vulnerable-behaviors within normal range, child attached to caregiver, developmentally on track, able to complete tasks of daily living (bathing, feeding, dressing)

$\square$ Mild-has behaviors that are controlled by medication or therapy, struggles with some subjects in school, can usually complete tasks of daily living without assistance

$\square$ Moderate-often has problematic behaviors that interfere with functioning, can generally communicate needs, mild developmental delays, requires assistance with tasks of daily living

$\square$ Severe-physical or mental illness that requires intensive treatment, behaviors are out of control, difficulty in communication needs

$\square$ Extremely vulnerable-physical disability requiring life sustaining care, not attached to caregiver, nonmobile or very limited mobility, nonverbal, unable to complete tasks of daily living

The primary caregiver's ability to manage daily life/stress and attitude toward caregiving (select only one):

$\square$ No concerns-Satisfied being a parent, balances teaching with discipline, realistic coping strategies, and healthy support system 
Mild-Mostly satisfied with parent/caretaker role, has some community/family supports

Moderate-Sometimes uses positive methods to deal with conflict, Physical or mental impairment limits ability but accepts assistance, Inconsistent in providing basic care, nurturing and/or support

$\square$ Severe-Non-offending parent does not believe maltreatment occurred, has unstable relationships, relies on others to meet children's needs, overwhelmed by responsibilities, unable/unwilling to plan ahead, unsatisfied with parent/caretaker role

$\square$ Extreme concerns-Puts perpetrator needs before family's needs, fails to supervise the child, not attached or describes the child in negative terms, inability to recognize risks to the child, very dissatisfied with parent/caretaker role

The perpetrator's access to the child and high risk patterns/behaviors (select only one):

$\square$ No concerns-Verified no perpetrator access, No threats/use of violence, recognizes/manage threats/dangers to child, identifies high risk times and appropriate responses

$\square$ Mild-Limited perpetrator access, situational stress-linked to services to manage, usually can verbalize high-risk times/trigger-respond appropriately, problem-solving skills can be increased with supports; First occurrence-parent is remorseful

$\square$ Moderate-Limited self-control in caretaking or disciplining-no injury, Alcohol/Drug abuse (including prescription drug) impacts caretaking, Unrealistic expectations based on the child's strengths/limitations, history of violence

$\square$ Severe-Uses threats to manage conflict, Incapacitated from drugs/alcohol, unable to verbalize high-risk times/triggers, History of intergenerational family violence, criminal charges

$\square$ Extreme concerns-Child resides with perpetrator, Actions resulted in serious physical injury, Expresses fear they will harm child, Parent justify maltreatment as cultural/religious practice, Previous involuntary TPR, Perpetrator unknown

\section{Outcome}

Close Referral

In home ongoing case

Out of home ongoing case
Plan

$\square$ Prevention Plan

$\square$ Aftercare Plan

\section{Assessment Conclusion}




\section{CURRICULUM VITAE}

Matthew Walton

1608 Roosevelt Avenue

Louisville, KY 40242

matthew.walton0@gmail.com

(502) 387-3293

\section{EDUCATION}

Doctor of Philosophy - PhD.

$2015-2019)$

Social Work

University of Louisville - Kent School of Social Work

Louisville, $K Y$

Committee Members:

Chair - Dr. Martin Hall, PhD, MSSW

Members - Dr. Anita Barbee, PhD, MSSW; Dr. Seana

Golder, PhD, MSW; Dr. Jose Fernandez, PhD; Dr. Glen

Mays, $P h D, M P H$

Dissertation: Comparative Spending of Medicaid

Dollars on Child Participants of Kentucky's Sobriety

Treatment and Recovery Teams Program Versus a

Matched Comparison Group

Master of Science in Social Work - M.S.S.W.

$2010-2012$

Alcohol and Drug Abuse Counselor Specialization

University of Louisville - Kent School of Social Work

Louisville, $K Y$

Spanish Language and Culture Study Abroad

Summer Term 2009

\section{Program}

Kentucky Institute for International Study

Segovia, Spain 
Bachelor of Science - B.S.

Psychology - Magna Cum Laude $\quad$ 2005-2009

University of Kentucky

Lexington, $K Y$

\section{PROFESSIONAL CERTIFICATION/LICENSURE}

Certified Social Worker (CSW) - Commonwealth of

Certification \#6411

Kentucky

Awarded 6-11-2012

Kentucky Board of Social Work

\section{SCHOLARSHIPS AND AWARDS}

University of Louisville School of Interdisciplinary and

Fall $2015-$

Graduate Studies University Fellowship -

Spring 2017

1 year award (+1 additional renewable year) for doctoral students. Included tuition remission, \$1,500 monthly stipend, and student health insurance.

University of Louisville - Kent School of Social Work

Fall 2011 Maude Ainslie MSSW Merit Scholarship Spring 2012

1 time $\$ 1,500$ award

University of Kentucky Academic Excellence Scholarships -

Fall 2007;

1 time $\$ 1,500$ awards

Spring 2009

University of Kentucky Flagship Scholarships -

Fall $2005-$

1 time $\$ 1,500$ awards

Spring 2006

\section{EMPLOYMENT/PROFESSIONAL EXPERIENCE}

Instructor -

August 2017 - Present

University of Louisville - Kent School of Social

Work

Louisville, KY 
Independently teaching courses at the baccalaureate and master's level, with a combination of online, field education, and traditional on-campus formats.

Research Assistant -

April 2014 - Present

University of Louisville - Kent School of Social

Work

Louisville, $K Y$

Participating in program evaluation projects of child welfare interventions to address parental substance use and addiction child maltreatment. Funders include SAMHSA and the U.S. Children's Bureau.

Hospital Social Worker -

June 2011 - July 2015

University of Louisville Hospital

Louisville, $K Y$

Oversaw and coordinated the discharge planning process for a 25 bed acute care medical/surgical unit at an academic hospital with Level I trauma center designation. Primary patient population included trauma surgery, orthopedic surgery, internal medicine, and neurosurgery patients.

\section{Rehabilitation Counselor -}

Wellspring House Psychiatric Services

September 2009 - June

2011

Louisville, $K Y$

Served in a crisis stabilization residential treatment house in downtown Louisville, KY for adults with psychiatric diagnoses. Conducted 1:1 psychotherapy sessions with clients and assisted clients with carrying out necessary treatmentrelated tasks.

Research Assistant -

University of Kentucky Biomedical and Biological August 2008 - May 2009

Sciences Research Building

Lexington, $K Y$ 
Worked as an undergraduate research assistant in the lab of Dr. Michael Bardo, PhD. Participated in several research projects investigating the physiologic and behavioral effects of stimulant drugs of abuse on Sprague-Dawley rats.

Mental Health Technician -

May 2006 - May 2011

Baptist Hospital East

Louisville, $K Y$

Conducted community groups for adult psychiatric patients in an inpatient hospital setting. Obtained and charted vital signs, monitored patients in seclusion, and communicated with interdisciplinary team of doctors, nurses, and psychologists regarding progress of patients.

\section{SOCIAL WORK CLINICAL PRACTICUM EXPERIENCE}

\section{Advanced Standing Practicum}

August 2011 - May 2012

The Morton Center

Louisville, KY

Assisted with group therapy sessions with adults and adolescents in an intensive outpatient addiction treatment program. Performed substance use disorder assessments and conducted psychoeducational courses with clients and families.

\section{Foundation Practicum}

The Healing Place - Men's Campus

Louisville, KY

Supervised a small caseload of male clients at a residential addiction treatment facility to monitor progress towards long-term recovery.

\section{COURSES INDEPENDENTLY TAUGHT (EACH AT THE UNIVERSITY OF LOUISVILLE - KENT SCHOOL)}


SW 471 - Social Work Foundation Practicum II (BSW Program)

SW 641 - Advanced Social Work Practice I (MSSW Program)

SW 677 - Advanced Social Work Practice III (MSSW Program)
Spring 2018

Fall 2017, Fall 2018

Spring 2018, Spring 2019

\section{PEER-REVIEWED PUBLICATIONS}

Walton, M.T. (2017). Administrative Discharges in Addiction Treatment: Bringing Practice in Line with Ethics and Evidence. Social Work, 63(1), 85-90.

Walton, M.T., \& Hall, M.T. (2017). Involuntary Civil Commitment for Substance Use Disorder: Legal Precedents and Ethical Considerations for Social Workers. Social Work in Public Health, 32(6), 382-393.

Walton, M.T. \& Hall, M.T. (2016). The Effects of Employment Interventions on Addiction Treatment Outcomes: A Review of the Literature. Journal of Social Work Practice in the Addictions, 16(4), 358-384.

Wooters, TE., Walton, MT., Bardo, MT. (2010). Oral Methylphenidate Establishes a Conditioned Place Preference in Rats. Neuroscience Letters. 487(3), 293-296.

\section{MANUSCRIPTS IN PREPARATION}

Hall, M.T, Sears, J., \& Walton, M.T. (in preparation). Motivational Interviewing in Child Welfare: A Systematic Review.

\section{TECHNICAL REPORTS}

Hall, MT, \& Walton, M.T. (2018). Team Cohesion, Job Satisfaction, and Predictors of Turnover and Retention in the Sobriety Treatment and Recovery Teams Workforce. Prepared for the U.S. Children's Bureau (Title IV-E). 
Hall, MT, \& Walton, M.T. (2018). Program Evaluation of the Enhanced Families Moving Beyond Abuse Program: Final Report. Prepared for the U.S. Substance Abuse and Mental Health Services Administration (SAMHSA).

\section{ACADEMIC PRESENTATIONS}

Walton, M.T. - Experiences of a Hospital Social Worker:

June 11, 2016

The Role of Social Work in the Care of Geriatric Patients.

Institute for Sustainable Health and Optimal Aging

Optimal Aging Conference, Louisville, $K Y$

Walton, M.T. - Instructional Presentation on Patient

June 30, 2015

Placement in Acute Hospital Settings to $4^{\text {th }}$ year medical

students

University of Louisville School of Medicine "Topics in

Clinical Medicine"

Louisville, $K Y$

Walton, M.T. - Comparison of oral vs. intraperitoneal

March 30, 2009

methylphenidate on locomotor activity

Midwestern Psychological Association Poster

Presentation, Chicago, IL

Walton, M.T. - The nicotinic receptor antagonist

November 1, 2008

mecamylamine attenuates the induction, but not

expression, of behavioral sensitization to repeated

methylphenidate in rats.

Kentucky Academy of Science Poster Presentation,

Lexington, $K Y$

\section{SERVICE}

Reviewer, Journal of Social Work Practice in

January 2019 - Present

the Addictions

City of Louisville Metro Public Health and

October 2017 - Present

Wellness Opioid Taskforce - Expanding

Treatment and Recovery Metrics workgroups 
UofL Today Radio Show appearance with

August 9, 2017

Mark Hebert: "Involuntary Civil Commitment

for Substance Use Disorder"

Kent School of Social Work 2017 Strategic

April 2017

Planning Committee - subcommittee on

research

Mayor's Office Dual Diagnosis Cross

July 2015-Present

Functional Team -

Board Member - Greater Louisville Reentry

June 14, 2015 - June 2017

Coalition

Student Practicum Supervision:

D'Andrea Halcomb (BSW student on-site

August 2013 - May 2014

supervisor)

University of Louisville Hospital Emergency

Room

Tasha Corbett (MSW student on-site

December 2014 - July 2015

supervisor)

University of Louisville Hospital Unit 9 East

\section{OTHER SKILLS}

Intermediate level Spanish language proficiency

Experienced with a variety of healthcare information technology systems used in hospital applications (McKesson, Allscripts, etc.)

Experienced with SPSS, $\mathrm{R}$, and LISREL statistical software packages 